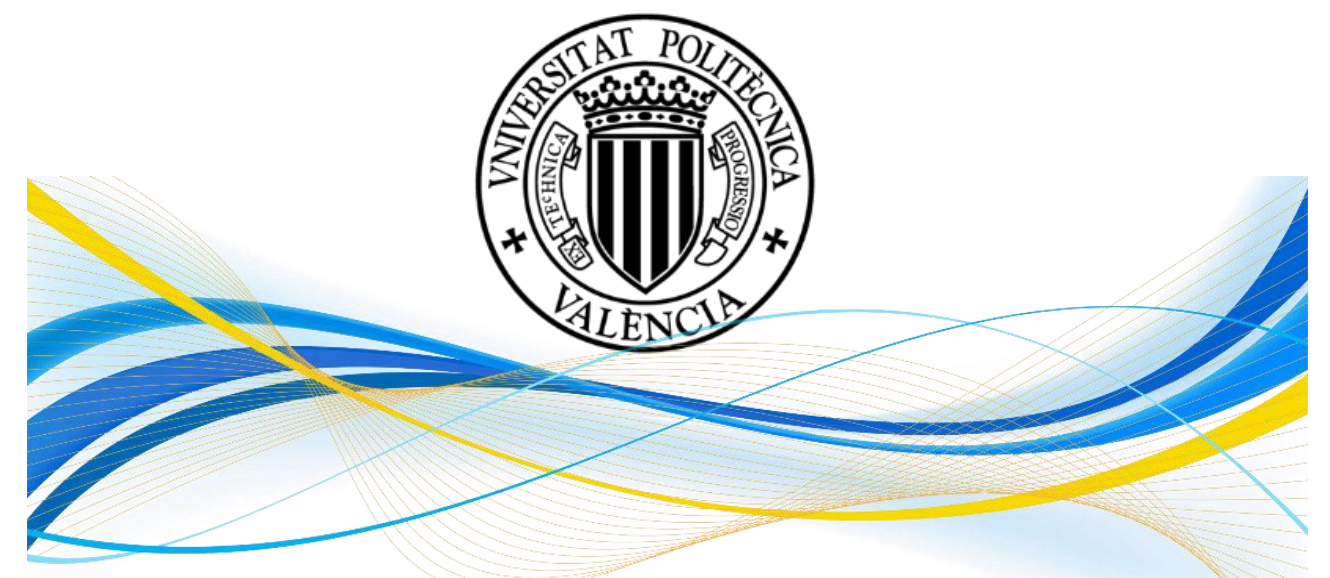

\title{
Development and Validation of a Minichannel Evaporator Model under Dehumidification
}

\author{
Ph.D. Thesis \\ By \\ Abdelrahman Hussein Abdelhalim Hassan \\ Under supervision of \\ Prof. Dr. José Gonzálvez Maciá \\ Dr. Santiago Martínez Ballester





\title{
Development and Validation of a Minichannel Evaporator Model under Dehumidification
}

\author{
By \\ Abdelrahman Hussein Abdelhalim Hassan \\ A Thesis Submitted for Obtaining the Degree of \\ DOCTOR OF PHILOSOPHY IN MECHANICAL ENGINEERING \\ In \\ Instituto Ingeniería Energética \\ Departamento de Ingeniería Mecánica y de Materiales \\ UNIVERSITAT POLITÈCNICA DE VALÈNCIA \\ Under supervision of \\ Prof. Dr. José Gonzálvez Maciá \\ Dr. Santiago Martínez Ballester
}

Doctoral Committee:

Prof. Dr. Davide Del Col

Department of Industrial Engineering

University of Padova, Italy

Prof. Dr. José Miguel Corberán Salvador

Department of Applied Thermodynamics

Technical University of Valencia, Spain

Prof. Dr. José Fernández Seara

Department of Mechanical Engineering, Heat Engines, and

Fluid Mechanics

University of Vigo, Spain

June 2016 



\section{Acknowledgements}

efore anything, all the thanks go to Allah (God) the Compassionate, the
Merciful for his unconditional love, support, and infinite graces which en-
circle me since birth.

Pursuing a $\mathrm{PhD}$ project is a both painful and enjoyable experience. It is just like climbing a high peak, step-by-step, accompanied by bitterness, hardships, frustration, encouragement, and with so many people's kind help. When I found myself at the top enjoying the beautiful scenery, I realize that it was, in fact, teamwork that got me there. Though it will not be enough to express my gratitude in words to all those people who helped me. However, I would still like to give my many, many thanks to some special persons who have the greatest influence on this marvelous achievement.

First of all, I would like to express my sincere gratitude to my advisors Prof. Dr. José Gonzálvez Maciá and Dr. Santiago Martínez Ballester. They have been of great help, patience, understanding, and of indefinite support. They have offered me so much advice and guidance in the right direction.

Also, I would like to thank Prof. Dr. José Miguel Corberán Salvador, the director of the Institute for Energy Engineering (IIE), for his tremendous support through my research stay in Spain. Also, I would like to mention the great help and support from the administrative staff of the IIE, Marián and Enrique.

My deep appreciation goes out to all my friends and colleagues at the Institute for Energy Engineering; especially Alessandro, Albert, Alejandro, Antonio, Bárbara, Fernando, Fran, Miguel, and Rafa. They all are like my second family in Spain. I have really spent with them one of the best time periods in my life. Despite the different culture and language, we have found many, many common interests to share, discuss, and enjoy.

I am indebted to all my Egyptian and Arab friends in Spain, with you guys I have not felt the bitterness of alienation. However, I would like to express my heartfelt appreciation and gratitude to four special friends. Firstly, Ramy Shaltout, my precious friend and brother who always shares my burdens as well as my joys. He gave me a full support during my first steps in Spain, in addition to his tremendous effort 
in proofreading this thesis. Secondly, Mohamed Maher, my dear friend who has stood beside me in many crucial situations and has helped me a lot without any hesitation. Thirdly, Mohamad Al-Hassan, my Lebanese intellectual friend with whom I always enjoy discussing all the aspects of life. Finally, Mohamed ElFakharany, who simplified and clarified to me many, many mathematical issues.

In Zagazig University, I would like to express my thanks to my MSc supervisor, Prof. Dr. Sayed-Ahmed El-Sayed, who implanted the basis of scientific research in me. I cannot also forget my dear friend Mohamed Attia, who carried on his shoulders a tremendous pile of tedious routine papers and certificates which I had to finish in Egypt during my stay in Spain.

Of course, no acknowledgments would be completed without giving sincerest thanks to my Parents. Both have instilled many admirable qualities in me and have given me a good foundation with which I can meet the life. They have taught me about hard work \& self-respect, about persistence, and about how to be independent. Both have always expressed how proud they are of me and how much they love me. In turn, I am also so proud of them and I love them very much. Furthermore, I would like to extend my deep appreciation to my brothers, Eslam and Omar, for their emotional support and unconditional love.

I must acknowledge with tremendous and deep thanks my beloved wife, Shaimaa (Shosho). We have married five years ago and since then I have been happier, calmer, and more content. Through her love, patience, support and unwavering belief in me, I have been able to complete this long dissertation journey. She has taken care of whatever needed tending to without complaining, so that I could focus on completing my dissertation. There are no words that can express my gratitude and appreciation for all she has done and been for me. As I ramble, I still have not found the words that describe or express how I feel for this woman and what her presence in my life has meant. I love you Shaimaa and am forever indebted to you for giving me the life, love, and your affectionate heart.

Last, but certainly not least, I devote this entire work to my gorgeous kids, prince Marwan and princess Fairouz. They are sparkling stars in the sky of my life, which always give me much happiness and keep me dreaming and hoping.

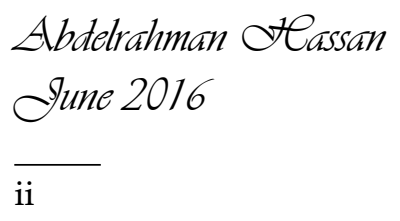




\section{Abstract}

In the first part of the current thesis, two fundamental numerical models (Fin2D-W and Fin1D-MB) for analyzing the air-side performance of minichannel evaporators were developed and verified. The Fin2D-W model applies a comprehensive two-dimensional scheme to discretize the evaporator. On the other hand, the Fin1D-MB model is based on the one-dimensional fin theory in conjunction with the moving boundaries technique along the fin height. The first objective of the two presented models is to identify and quantify the most influential phenomena encountered in the process of cooling and dehumidification. The second objective is to study the impact of the classical modeling assumptions on the air-side performance of minichannel evaporators. Different comparative studies between the traditional $\varepsilon$-NTU approach and the proposed numerical models were implemented to achieve the mentioned goals. The results revealed that the modeling assumptions which have the most significant impacts on the heat and mass transfer rates are: the uniform air properties along the fin height, adiabatic-fin-tip at half the height, and negligence of partial dehumidification scenarios. These widely used assumptions resulted in substantial deviations in total heat transfer rate, up to $52 \%$, between the $\varepsilon$-NTU approach and Fin2D-W model.

In the second part of the thesis, the Fin1D-MB model was integrated into the IMST$\mathrm{ART}^{\circledR}$ simulation tool to evaluate the global performance of minichannel evaporators (air- and refrigerant-side). The Fin1D-MB model was selected because of its simplicity, calculation speed, and reasonable solution accuracy relative to the Fin2D-W model. The validation of the complete Fin1D-MB model was conducted against many experimental data and numerical models available in the literature. The validation process was achieved for different heat exchanger geometries, refrigerants, and operating conditions. The results showed that for the R134a minichannel evaporators studied, the Fin1D-MB model successfully predicted the Inlet refrigerant and outlet air temperatures, cooling capacity, and refrigerant-side pressure drop within error bands of $\pm 0.5{ }^{\circ} \mathrm{C}, \pm 5 \%$, and $\pm 20 \%$, respectively. For the $\mathrm{CO}_{2}$ (R744) minichannel evaporator studied, the presented model estimated the cooling capacity and outlet air temperature within error bands of $\pm 10 \%$ and $\pm 1.0^{\circ} \mathrm{C}$, respectively. Regarding the $\mathrm{CO}_{2}$ pressure drop, the Fin $1 \mathrm{D}-\mathrm{MB}$ model generally underpredicted the pressure drop values compared to the experimental data, with a maximum deviation of $11 \mathrm{kPa}$. 



\section{ResUmen}

En la primera parte de la tesis actual, dos modelos numéricos fundamentales (Fin2D-W

y Fin1D-MB) para analizar el lado del aire de los evaporadores de minicanales se han desarrollado y verificado. El modelo Fin2D-W aplica un esquema detallado de dos dimensiones para discretizar el evaporador mientras que el modelo Fin1D-MB se basa en la teoría de la aleta unidimensional junto con la técnica de fronteras móviles para el lado del aire. El primer objetivo de los dos modelos presentados es identificar y cuantificar los fenómenos más influyentes encontrados en el proceso de enfriamiento y deshumidificación. El segundo objetivo es estudiar el impacto de las hipótesis comúnmente usadas en el modelado de la transmisión de calor del aire de los evaporadores de minicanales. Se implementaron diferentes estudios comparativos entre el enfoque tradicional $\varepsilon$-NTU y los modelos numéricos propuestos para alcanzar los objetivos mencionados. Los resultados muestran que las hipótesis que provocan una mayor desviación con respecto a la solución detallada en la transferencia de calor y masa son: propiedades de aire uniforme a lo largo de la altura de la aleta, extremo adiabático de aleta a mitad de su longitud, y no contemplar el supuesto de deshumidificación parcial en la aleta. Estas hipótesis ampliamente utilizadas han resultado en errores importantes en la transferencia de calor total, hasta un 52\%, entre el enfoque $\varepsilon$-NTU y el modelo Fin2D-W.

En la segunda parte de la tesis, el modelo Fin1D-MB se integró en la herramienta de simulación IMST-ART ${ }^{\circledR}$ para evaluar el rendimiento global de los evaporadores de minicanales (en el lado del aire y del refrigerante). El modelo Fin1D-MB se seleccionó gracias a su simplicidad, velocidad de cálculo, y solución de una precisión razonable relativa al modelo Fin2D-W. Se realizó una validación del modelo completo Fin1D-MB con la ayuda de datos experimentales y modelos numéricos ya disponibles en la literatura. El modelo se ha validado para diferentes geometrías de intercambiadores de calor, refrigerantes y condiciones de funcionamiento. Los resultados han mostrado que para los evaporadores de minicanales funcionando con el refrigerante R134a, el modelo Fin1DMB predice de manera correcta las temperaturas de entrada del refrigerante y de salida del aire, la capacidad de enfriamiento, y la caída de presión del lado de refrigerante dentro de las bandas de error de $\pm 0.5^{\circ} \mathrm{C}, \pm 5 \%, \mathrm{y} \pm 20 \%$, respectivamente. Para el evaporador de minicanales con $\mathrm{CO}_{2}$ (R744) estudiado, el modelo estima la capacidad de refrigeración y la temperatura de salida del aire dentro de las bandas de error de $\pm 10 \%$ y $\pm 1.0{ }^{\circ} \mathrm{C}$, respectivamente. En cuanto a la caída de presión de $\mathrm{CO}_{2}$, el modelo Fin1D-MB generalmente predice a la baja los valores de la caída de presión en comparación con los datos experimentales, con una desviación máxima de $11 \mathrm{kPa}$. 



\section{Resum}

A la primera part de la tesi actual, dos models numèrics fonamentals (Fin2D-W i Fin1DMB) per analitzar el costat de l'aire dels evaporadors de minicanals s'han desenvolupat i verificat. Al model Fin2D-W s'aplica un esquema detallat de dues dimensions per discretitzar l'evaporador mentre que al model Fin1D-MB es basa en la teoria d'aleta unidimensional juntament amb la tècnica de frontera mòbil per al costat de l'aire. El primer objectiu dels dos models presentats és identificar i quantificar els fenòmens més influents trobats en el procés de refredament i deshumidificació. El segon objectiu és estudiar l'impacte de les hipòtesis comunament utilitzades en el modelatge de la transmissió de calor de l'aire dels evaporadors de minicanals. Es van implementar diferents estudis comparatius entre l'enfocament tradicional $\varepsilon$-NTU i els models numèrics proposats per assolir els objectius esmentats. Els resultats mostren que les hipòtesis que provoquen una major desviació respecte a la solució detallada a la transferència de calor i massa són: propietats d'aire uniforme al llarg de l'altura de l'aleta, extrem adiabàtic d'aleta a la meitat de la seua longitud, i no contemplar el supòsit de deshumidificació parcial en l'aleta. Aquestes hipòtesis àmpliament utilitzades donen errors importants en la transferència de calor total, fins a un 52\%, entre l'enfocament $\varepsilon$ NTU i el model Fin2D-W.

A la segona part de la tesi, el model Fin1D-MB es va integrar en l'eina de simulació IMST-ART ${ }^{\circledR}$ per avaluar el rendiment global dels evaporadors de minicanals (al costat de l'aire i del refrigerant). El model Fin1D-MB es va seleccionar gràcies a la seva simplicitat, velocitat de càlcul, i solució d'una precisió raonable relativa al model Fin2DW. Es va realitzar una validació del model complet Fin1D-MB amb l'ajuda de dades experimentals i models numèrics ja disponibles a la literatura. El model s'ha validat per a diferents geometries d'intercanviadors de calor, refrigerants i condicions de funcionament. Els resultats mostren que per als evaporadors de minicanals funcionant amb el refrigerant R134a, el model Fin1D-MB prediu de manera correcta les temperatures d'entrada del refrigerant i de sortida de l'aire, la capacitat de refreda-ment, i la caiguda de pressió del costat de refrigerant dins de les bandes d'error de $\pm 0.5{ }^{\circ} \mathrm{C}$, $\pm 5 \%$, i $\pm 20 \%$, respectivament. Per a l'evaporador de minicanals amb $\mathrm{CO}_{2}(\mathrm{R} 744)$ estudiat, el model estima la capacitat de refrigeració i la temperatura de sortida de l'aire dins de les bandes d'error de $\pm 10 \% \mathrm{i} \pm 1.0^{\circ} \mathrm{C}$, respectivament. Pel que fa a la caiguda de pressió de $\mathrm{CO}_{2}$, el model Fin1D-MB generalment prediu a la baixa els valors de la caiguda de pressió en comparació amb les dades experimentals, amb una desviació màxima d'11 $\mathrm{kPa}$. 



\section{T $_{\text {ABLe OF CONTENTES }}$}

ACKNOWLEDGEMENTS ....................................................................................... i

ABSTRACT..................................................................................................................iii

RESUMEN ........................................................................................................................... v

RESUM ................................................................................................................ vii

TABLE OF CONTENTES..................................................................................... ix

LIST OF FIGURES ....................................................................................................... xiii

LIST OF TABLES ......................................................................................................

NOMENCLATURE............................................................................................... $\mathrm{xix}$

Chapter 1: Introduction and Mathematical Background................................. 25

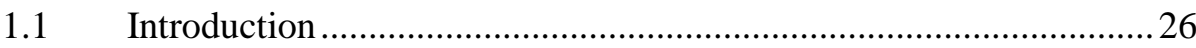

1.2 Channel Size Classification of a Heat Exchanger .............................2 27

$1.3 \quad$ Minichannel Heat Exchangers (MCHXs) …..................................... 28

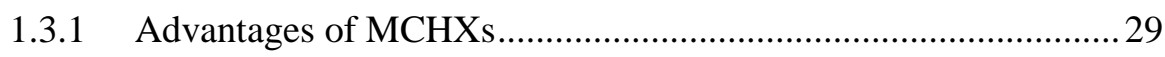

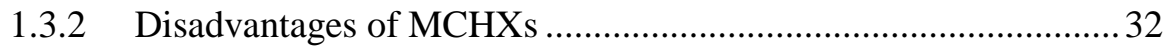

1.4 Mathematical Background: Simultaneous Heat and Mass Transfer .33

1.4.1 The single potential model vs. the dual potential model................ 33

1.4.2 Fin performance under wet conditions ......................................... 36

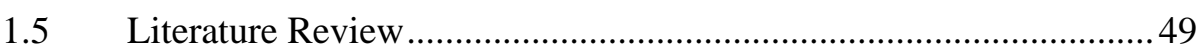

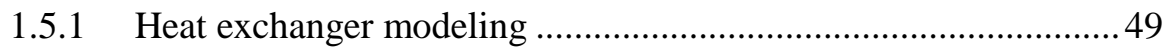

1.5.2 Impacts of the classical modeling assumptions on the performance of heat exchangers ............................................................................ 50 


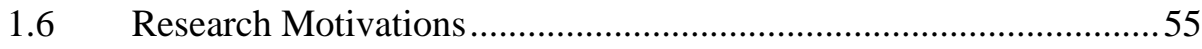

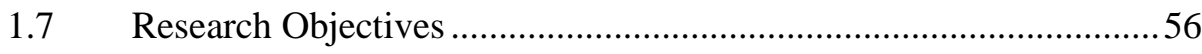

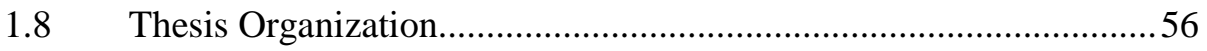

Chapter 2: Fin2D-W Model..............................................................................59

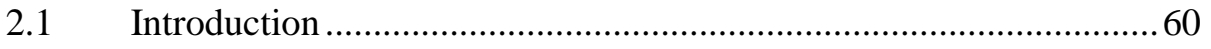

2.2 Development of the Fin2D-W Model …............................................61

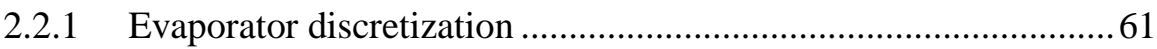

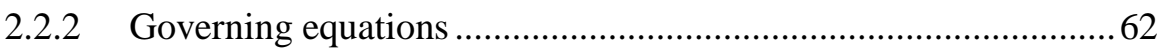

2.3 General Description of the Numerical Solution ..................................71

2.4 Case Study and Evaporator Dimensions …………............................ 74

2.5 Numerical Verification of the Fin2D-W Model..................................77

2.6 A Comparative Study between the Classical $\varepsilon$-NTU Approach and the

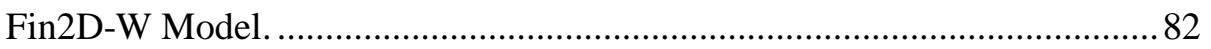

2.6.1 Equal temperature for the upper and lower tubes (no superheat) .86

2.6.2 Presence of a temperature difference between the upper and lower

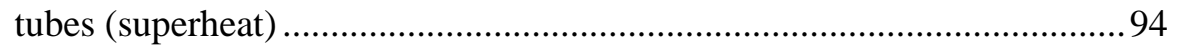

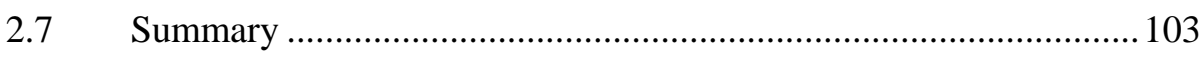

Chapter 3: Fin1D-MB Model ........................................................................................105

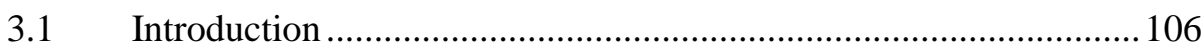

3.2 Description of the Fin1D-MB Model................................................106

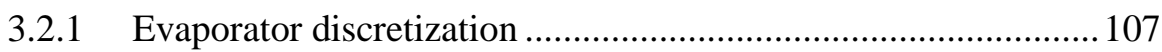

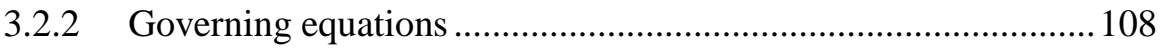

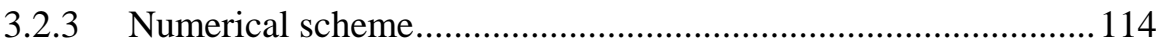

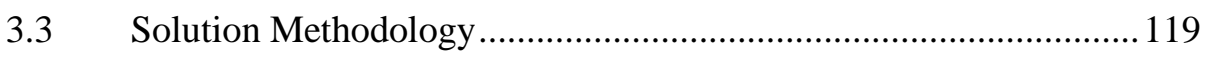

3.4 Numerical Verification of the Fin1D-MB Model ............................ 122 
3.5 Comparison of the Heat Transfer Results between the Fin1D-MB and

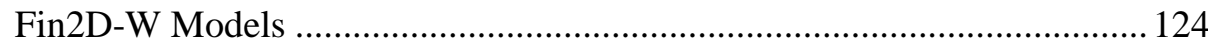

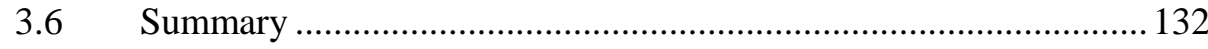

Chapter 4: Experimental Validation of the Fin1D-MB Model....................133

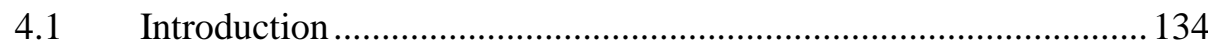

4.2 Discretization of MCHXs in the IMST-ART ${ }^{\circledR}$ Program .................. 134

4.3 Refrigerant-side Heat Transfer Coefficient and Pressure Drop ...... 136

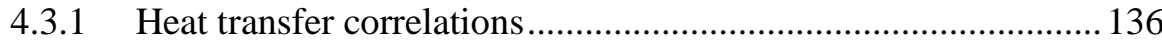

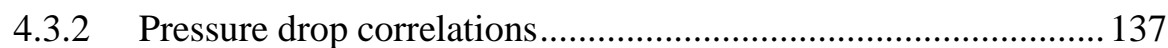

4.4 Air-side Heat Transfer Coefficient and Pressure Drop .................... 143

4.5 Validation of the Complete Fin1D-MB Model ................................ 144

4.5.1 Validation of minichannel evaporators operating with R134a ... 144

4.5.2 Validation of a minichannel evaporator operating with $\mathrm{CO}_{2} \ldots \ldots .152$

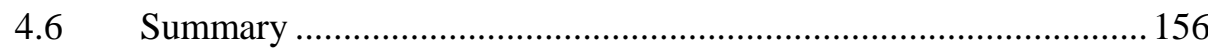

Chapter 5: Conclusions and Future Work ......................................................... 157

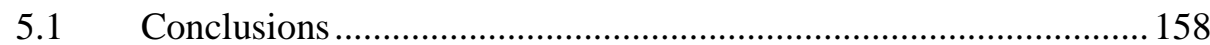

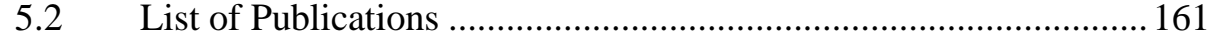

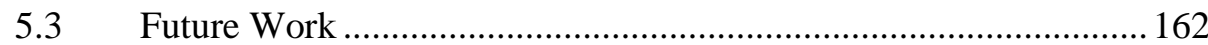

Chapter 6: Appendices............................................................................................ 163

6.1 Appendix A: Psychrometric Relationships and Charts .................... 164

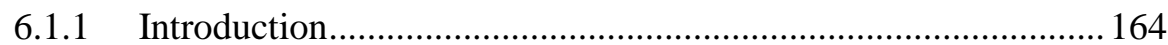

6.1.2 Thermodynamic properties of water at saturation ....................... 164

6.1.3 Perfect gas relationships for dry and moist air.......................... 165

6.1.4 Humidity parameters involving saturation.................................. 167 
6.1.5 Thermodynamic wet-bulb and dew point temperature

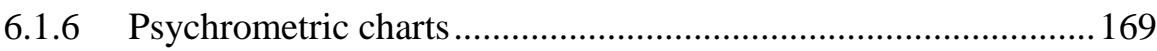

6.2 Appendix B: C++ Modeling Structure .......................................... 171

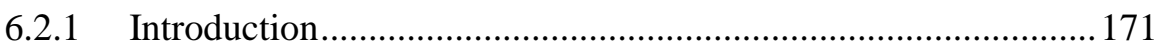

6.2.2 Classes of the evaporator models (Fin2D-W and Fin1D-MB) ...173

6.3 Appendix C: Matrix [B] Coefficients............................................... 178

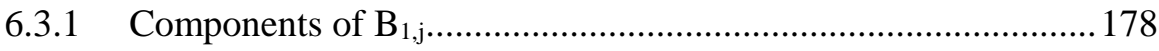

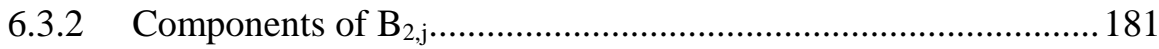

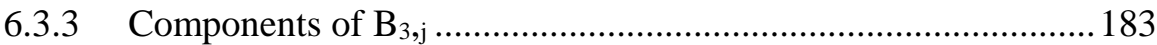

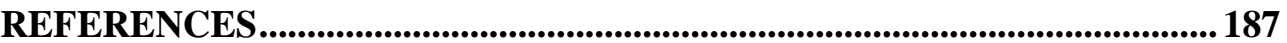

Note: the current thesis contains interactive-links and cross-references for the figures, tables, equations, sections, and headers. This allows a convenient browsing for the reader. 


\section{LIST OF FIGURES}

Figure 1.1. Common types of air-to-refrigerant heat exchangers used in HVAC\&R.

Figure 1.2. Schematic of a compact minichannel condenser (Shah, 1983), ...........29

Figure 1.3. Schematic of cooling and dehumidifying of moist air.......................... 34

Figure 1.4. Schematic of a fully wet rectangular fin................................................ 39

Figure 1.5. Linear approximation of saturated enthalpy curve. ............................. 41

Figure 1.6. Linear approximation of saturated humidity ratio curve, as it was proposed by Sharqawy and Zubair (2008)......................................................... 43

Figure 1.7. Comparison of the fin efficiency for a fully wet rectangular fin (Sharqawy

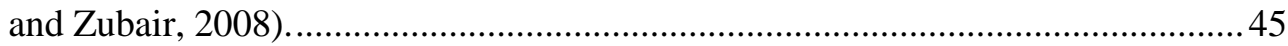

Figure 1.8. Schematic of a partially wet rectangular fin. ........................................ 46

Figure 2.1. (a) Main discretization of tubes in minichannel evaporator. (b) General concept of discretization in one evaporator segment............................................ 61

Figure 2.2. Energy balance of a differential control volume of the fin wall........... 63

Figure 2.3. Equivalent thermal resistance between the moist air and the wall element. 64

Figure 2.4. Cells schematic and definition of the cell nodes. .................................. 68

Figure 2.5. Direction references. (a) For fin wall cells. (b) For tube wall cells...... 70

Figure 2.6. Flowchart of the numerical solution for the Fin2D-W model.............. 73

Figure 2.7. Correction procedure for the exceeding outlet air points..................... 74

Figure 2.8. Minichannel tube used by Zhao et al. (2001)..................................... 75

Figure 2.9. Schematic of a minichannel unit slab (Zhao et al., 2001)................... 75

Figure 2.10. Picture of a unit slab (Zhao et al., 2001)......................................... 75

Figure 2.11. Picture of fins and tubes (Zhao et al., 2001)..................................... 76

Figure 2.12. Schematic of the evaporator portion under study............................. 76

Figure 2.13. V1 results of the Fin2D-W model. (a) For totally wet fin condition. (b)

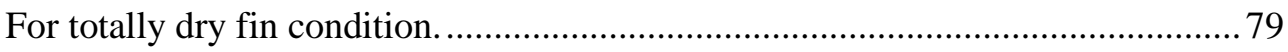


Figure 2.14. V2 results of the Fin2D-W model for a totally wet fin. (a) No temperature difference between tubes. (b) Temperature difference of $5 \mathrm{~K}$ between tubes.

Figure 2.15. V2 results of the Fin2D-W model for a totally dry fin. (a) No temperature difference between tubes. (b) Temperature difference of $5 \mathrm{~K}$ between tubes.

Figure 2.16. Schematic of the equivalent evaporator portion used in the $\varepsilon$-NTU modeling.

Figure 2.17. Relative deviations in $(a)$ sensible, $(b)$ latent, and $(c)$ total heat transfer rates between the $\varepsilon$-NTU and Fin2D-W models, for Case I (without superheat). .. 87

Figure 2.18. Relative deviations in $(a)$ sensible, $(b)$ latent, and $(c)$ total heat transfer rates between the $\varepsilon$-NTU and Fin2D-W models, for Case II (without superheat).. 88

Figure 2.19. Relative deviations in $(a)$ sensible, $(b)$ latent, and $(c)$ total heat transfer rates between the $\varepsilon$-NTU and Fin2D-W models, for Case III (without superheat). 89 Figure 2.20. (a) Fin temperature profile. (b) Mass flow rate of condensed water. (c) Air temperature profile. (d) Air humidity ratio profile for Case III at $\mathrm{T}_{\mathrm{t}}=32.60{ }^{\circ} \mathrm{C}$.

Figure 2.21. (a) Fin temperature profile. (b) Mass flow rate of condensed water. (c) Air temperature profile. $(d)$ Air humidity ratio profile for Case II at $\mathrm{T}_{\mathrm{t}}=17.0^{\circ} \mathrm{C} .92$ Figure 2.22. (a) Fin temperature profile. (b) Mass flow rate of condensed water. (c) Air temperature profile. $(d)$ Air humidity ratio profile for Case III at $\mathrm{T}_{\mathrm{t}}=10.0^{\circ} \mathrm{C} .93$ Figure 2.23. Relative deviations in $(a)$ sensible and $(b)$ latent heat transfer rates between the $\varepsilon$-NTU and Fin2D-W models, for Case I (with superheat) 95

Figure 2.24. Relative deviations in $(a)$ sensible and $(b)$ latent heat transfer rates between the $\varepsilon$-NTU and Fin2D-W models, for Case II (with superheat) 96

Figure 2.25. Relative deviations in $(a)$ sensible and $(b)$ latent heat transfer rates between the $\varepsilon$-NTU and Fin2D-W models, for Case III (with superheat). .97

Figure 2.26. (a) Fin temperature profile and $(b)$ mass flux of condensed water, at half the fin depth, for a point in R2. This represents Case II, when $\mathrm{T}_{\mathrm{lt}}=2.0{ }^{\circ} \mathrm{C}$ and $\mathrm{SH}=15.15 \mathrm{~K}$. .99

Figure 2.27. (a) Fin temperature profile and $(b)$ mass flux of condensed water, at half the fin depth, for a point in R3. This represents Case II, when $\mathrm{T}_{1 \mathrm{t}}=12.0^{\circ} \mathrm{C}$ and $\mathrm{SH}=15.0 \mathrm{~K}$ 100

xiv 
Figure 2.28. Relative deviations in total heat transfer rate between the $\varepsilon$-NTU and Fin2D-W models, for ( $a$ ) Case I, $(b)$ Case II, and (c) Case III. ........................... 102

Figure 3.1. (a) Discretization of evaporator tubes into segments. (b) Schematic representation of a segment discretization into cells. 108

Figure 3.2. (a) $y-z$ plane, which shows the virtual discretization of the fin in $y$ direction and boundaries between wet and dry portions, $\zeta_{1}$ and $\zeta_{2}$. (b) $y-x$ plane, which shows the locations of $T_{f B}$ and $T_{f T}$.

Figure 3.3. A numerical example of the estimated fin temperature profile in the Fin1D-MB model

Figure 3.4. Linearization scheme of saturated humidity ratio curve used in the Fin1D-MB model for wet fin analysis. 116

Figure 3.5. Flowchart of the numerical solution for the Fin1D-MB model 120

Figure 3.6. V1 results of the Fin1D-MB model. (a) For a totally wet fin. (b) For a totally dry fin. 123

Figure 3.7. V2 results of the Fin1D-MB model. (a) For a totally wet fin. (b) For a totally dry fin. 124

Figure 3.8. Relative deviations in $(a)$ sensible and $(b)$ latent heat transfer rates between the Fin1D-MB and Fin2D-W models, for Case I.

Figure 3.9. Relative deviations in $(a)$ sensible and $(b)$ latent heat transfer rates between the Fin1D-MB and Fin2D-W models, for Case II.

Figure 3.10. Relative deviations in $(a)$ sensible and $(b)$ latent heat transfer rates between the Fin1D-MB and Fin2D-W models, for Case III. 128

Figure 3.11. (a) Fin temperature profile and $(b)$ mass flux of condensed water, at half the fin depth, for a point in R3. This represents Case II, when $\mathrm{T}_{\mathrm{lt}}=12{ }^{\circ} \mathrm{C}$ and $\mathrm{SH}=15$ $\mathrm{K}$.. 129

Figure 3.12. Relative deviations in total heat transfer rate between the Fin1D-MB and Fin2D-W models, for ( $a$ ) Case I, (b) Case II, and (c) Case III. 131

Figure 4.1. Example of a MCHX that can be simulated by the IMST-ART ${ }^{\circledR}$ program. 134

Figure 4.2. (a) Discretization of a MCHX to segments. (b) Schematic of a segment discretization into cells. 135

Figure 4.3. Schematic diagram of the test facility for the R134a air-to-refrigerant heat pump 
Figure 4.4. Comparison of the inlet refrigerant temperature $T_{r, \text { in }}$ between the calculated and measured values of the UPCT's R134a evaporator.

Figure 4.5. Comparison of the refrigerant-side pressure drop $\Delta \mathrm{p}_{\mathrm{r}}$ between the calculated and measured values of the UPCT's R134a evaporator.

Figure 4.6. Comparison of the outlet air temperature $\mathrm{T}_{\mathrm{a}, \text { out }}$ between the calculated and measured values of the UPCT's R134a evaporator.

150

Figure 4.7. Comparison of the refrigerant-side cooling capacity $\mathrm{Q}_{\mathrm{r}}$ between the calculated and measured values of the UPCT's R134a evaporator 150

Figure 4.8. Total and latent heat transfer rates vs. inlet air flow rate, for the Fin1DMB model and the model of Yun et al. (2007)

Figure 4.9. Cross-section of minichannel tube used in the R744 evaporator (Beaver et al., 1999). 152

Figure 4.10. Predicted vs. measured air-side cooling capacity, $\mathrm{Q}_{\mathrm{a}}$, of Beaver et al. (1999) 154

Figure 4.11. Ratio of predicted to measured refrigerant-side pressure drop vs. refrigerant mass flow rate for the R744 evaporator.

Figure 4.12. Predicted vs. measured outlet air temperature, $\mathrm{T}_{\mathrm{a}, \mathrm{out}}$, of Beaver et al. (1999)

Figure 6.1. ASHRAE psychrometric chart for sea-level pressure (101.325 kPa). 170

Figure 6.2. General discretization scheme for a heat exchanger 171

Figure 6.3. $\mathrm{C}++$ Objects used in the current models. 172

Figure 6.4. $\mathrm{C}++$ Classes adopted in the present models. 173

Figure 6.5. General discretization scheme for fluid flow.... 175 


\section{List OF TABLES}

Table 1.1. Channel dimensions for different types of flow for gases at one atmospheric pressure (Kandlikar and Grande, 2003)........................................... 28

Table 1.2. Channel size classification (Kandlikar and King, 2006)....................... 28

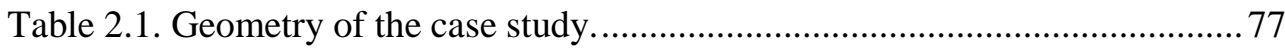

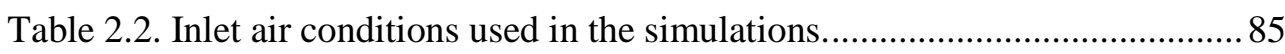

Table 2.3. Average relative deviation (ARD) in heat transfer rates under totally wet condition (without superheat) [\%] .................................................................. 94

Table 2.4. Average relative deviation (ARD) in latent and total heat transfer rates between the $\varepsilon$-NTU and Fin2D-W models (with superheat) [\%].......................... 101

Table 4.1. Two-phase heat transfer coefficient correlations ................................. 138

Table 4.2. Two-phase frictional pressure drop correlations.................................... 141

Table 4.3. Operating conditions for the UPCT's R134a evaporator..................... 146

Table 4.4. Abbreviations of the refrigerant-side FPD and HTC correlations used in

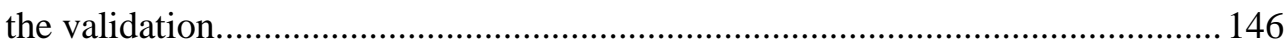

Table 4.5. MAE and SD values of the calculated $\mathrm{T}_{\mathrm{r}, \mathrm{in}}$ (UPCT's R134a evaporator). 148

Table 4.6. MAE and SD values for the calculated $\Delta \mathrm{p}_{\mathrm{r}}$ (UPCT's R134a evaporator). 148

Table 4.7. Specifications of the R134a minichannel evaporator (Yun et al., 2007). 151

Table 4.8. Specifications of the R744 minichannel evaporator (Beaver et al., 1999) 



\section{Nomenclature}

\begin{tabular}{ll} 
Uppercase & \\
\cline { 1 - 2 }$A$ & heat transfer area $\left[\mathrm{m}^{2}\right]$ \\
$A_{c}$ & cross-section area $\left[\mathrm{m}^{2}\right]$ \\
$C$ & McQuiston's constant $[1 / \mathrm{K}]$, defined in Eq. $(1.19)$ \\
$C_{0}$ & parameter defined in Eq. $(1.25)\left[\mathrm{kg}_{\mathrm{wv}} / \mathrm{kg}_{\mathrm{da}}\right]$ \\
$C_{p}$ & specific heat $[\mathrm{J} / \mathrm{kg} \cdot \mathrm{K}]$ \\
$D$ & diameter $[\mathrm{m}]$ \\
$D_{h}$ & hydraulic diameter $[\mathrm{m}]$ \\
$D_{f}$ & fin depth $[\mathrm{m}]$ \\
$D_{t}$ & tube depth $[\mathrm{m}]$ \\
$\mathrm{G}$ & mass flux $\left[\mathrm{kg} / \mathrm{m}^{2} \cdot \mathrm{s}\right]$ \\
$h$ & specific enthalpy $[\mathrm{J} / \mathrm{kg}]$ \\
$H_{f}$ & fin height $[\mathrm{m}]$ \\
$L e$ & Lewis number $[-]$ \\
$M$ & wet fin parameter $[1 / \mathrm{m}]$, defined in Eq. $(1.25)$ \\
$m$ & dry fin parameter $[1 / \mathrm{m}]$, defined in Eq. $(1.16)$ \\
$\dot{m}$ & mass flow rate $[\mathrm{kg} / \mathrm{s}]$ \\
$M_{h}$ & parameter defined in Eq. $(1.16)[1 / \mathrm{m}]$ \\
$\mathrm{M}_{\mathrm{mol}}$ & molecular weight $[\mathrm{kg} / \mathrm{mol}]$ \\
$\mathrm{NMTU}$ & number of mass transfer units $[-]$ \\
$\mathrm{NTU}$ & number of transfer units $[-]$ \\
$\mathrm{Nu}$ & Nusselt number $[-]$ \\
$P$ & perimeter $[\mathrm{m}]$ \\
$Q$ & heat transfer rate $[\mathrm{W}]$ \\
$\mathrm{R}$ & thermal resistance $\left[\mathrm{m}^{2} \cdot \mathrm{K} / \mathrm{W}\right]$ \\
$\mathrm{Re}$ & Reynolds number $[-]$ \\
$\mathrm{RH}$ & relative humidity $[\%]$ \\
$R_{\mathrm{unv}}$ & universal gas constant $[\mathrm{J} / \mathrm{kmol} \cdot \mathrm{K}]$ \\
$\mathrm{SH}$ & superheat $[\mathrm{K}]$ \\
&
\end{tabular}




$\begin{array}{ll}T & \text { temperature }\left[{ }^{\circ} \mathrm{C}\right] \\ T^{*} & \text { modified temperature for moist air }\left[{ }^{\circ} \mathrm{C}\right] \\ T_{d p} & \text { dew point of air }\left[{ }^{\circ} \mathrm{C}\right] \\ U & \text { overall heat transfer coefficient }\left[\mathrm{W} / \mathrm{m}^{2} \cdot \mathrm{K}\right] \\ U_{\text {wet }} & \text { overall heat transfer coefficient under wet conditions }\left[\mathrm{W} / \mathrm{m}^{2} \cdot \mathrm{K}\right] \\ V & \text { volume }\left[\mathrm{m}^{3}\right] \\ W & \text { humidity ratio, or specific humidity }\left[\mathrm{kg}_{\mathrm{wv}} / \mathrm{kg}_{\mathrm{da}}\right] \\ X_{t t} & \text { Martinelli parameter }[-]\end{array}$

\section{Lowercase}

$\begin{array}{ll}\{\mathrm{a}, \mathrm{b}, \mathrm{c}, \mathrm{d}, \mathrm{e}\} & \text { grid dimensions [-] } \\ a_{h}^{\prime} & \text { parameter defined in Eq. }(1.13)[\mathrm{J} / \mathrm{kg} \cdot \mathrm{K}] \\ a_{h} & \text { parameter defined in Eq. }(1.15)[\mathrm{J} / \mathrm{kg} \cdot \mathrm{K}] \\ a_{f}^{\prime} & \text { parameter defined in Eq. }(1.20)\left[\mathrm{kg}_{\mathrm{wv}} / \mathrm{kg}_{\mathrm{da}}\right] \\ a_{f} & \text { parameter defined in Eq. }(1.22)\left[\mathrm{kg}_{\mathrm{wv}} / \mathrm{kg}_{\mathrm{da}}\right] \\ b_{h}^{\prime} & \text { parameter defined in Eq. }(1.13)[\mathrm{J} / \mathrm{kg}] \\ b_{h} & \text { parameter defined in Eq. }(1.15)[\mathrm{J} / \mathrm{kg}] \\ b_{f}^{\prime} & \text { parameter defined in Eq. }(1.20)[1 / \mathrm{K}] \\ b_{f} & \text { parameter defined in Eq. }(1.22)[1 / \mathrm{K}] \\ f & \text { friction coefficient }[-] \\ g & \text { gravitational acceleration }\left[\mathrm{m} / \mathrm{s}^{2}\right] \\ h & \text { enthalpy [J/kg] } \\ h_{f g} & \text { latent heat of water vapor condensation }[\mathrm{J} / \mathrm{kg}] \\ j & \text { Chilton and Colburn factor }[-] \\ k & \text { thermal conductivity [W/m. } \mathrm{K}] \\ n & \text { number of moles [kmol] } \\ p & \text { pressure [Pa] } \\ q & \left.\text { heat flux [W/m }{ }^{2}\right] \\ s & \text { length in the forward direction of a fluid }[\mathrm{m}] \\ t & \text { thickness [m] } \\ x, y, z & \text { spatial coordinates [m] } \\ \dot{x} & \text { vapor quality [-] }\end{array}$




\section{Greek symbols}

$\begin{array}{ll}\mu & \text { dynamic viscosity [Pa.s] } \\ \alpha & \text { sensible heat transfer coefficient }\left[\mathrm{W} / \mathrm{m}^{2} \cdot \mathrm{K}\right] \\ \alpha_{D} & \text { mass transfer coefficient }\left[\mathrm{kg} / \mathrm{m}^{2} \cdot \mathrm{s}\right] \\ \alpha_{\text {wet }} & \text { total heat transfer coefficient under wet conditions }\left[\mathrm{W} / \mathrm{m}^{2} \cdot \mathrm{K}\right] \\ \beta & \text { parameter defined in Eq. }(1.25)[\mathrm{K}] \\ \varepsilon & \text { thermal effectiveness [-] } \\ \zeta & \text { boundary between wet and dry portions of the fin }[\mathrm{m}] \\ \zeta_{1} & \text { parameter defined in Eq. }(3.22)[\mathrm{m}] \\ \zeta_{2} & \text { parameter defined in Eq. }(3.23)[\mathrm{m}] \\ \eta & \text { thermal efficiency [-] } \\ \theta & \text { temperature difference }[\mathrm{K}] \\ \lambda & \text { thermal conductance }[\mathrm{W} / \mathrm{K}] \\ \xi & \text { enthalpy difference }[\mathrm{J} / \mathrm{kg}] \\ \sigma & \text { surface tension [N/m] } \\ \varphi & \text { vapor void fraction }[-] \\ \Phi^{2} & \text { pressure multiplier [-] } \\ \psi & \text { parameter defined in Eq. }(1.25)[\mathrm{K}] \\ \omega & \text { humidity ratio difference }\left[\mathrm{kg} \text { wv } / \mathrm{kg}_{\mathrm{da}}\right] \\ \Omega & \text { ratio between wet and dry fin parameters }=M / m[-]\end{array}$

\section{Subscript/ Superscript}

$\begin{array}{ll}a & \text { air, or air cell index in Ch. 3 } \\ \text { atm } & \text { atmospheric } \\ c & \text { centroid of the cell } \\ c b & \text { convective boiling } \\ \text { cond } & \text { conduction } \\ \text { conv } & \text { convection } \\ \text { crit } & \text { critical } \\ d a & \text { dry air } \\ d b & \text { dry-bulb } \\ \text { dry_fp } & \text { dry fin portion }\end{array}$




\begin{tabular}{ll}
$f$ & fin, or fin cell index in Ch. 3 \\
$f B$ & fin base \\
fp1,fp2, fp3 & first, second, and third fin portions, in Ch. 3 \\
$f T$ & fin tip \\
$G$ & gas \\
$G O$ & gas-only \\
$i$ & fluid cell index \\
in & inlet \\
$j$ & wall cell index \\
$k$ & direction index \\
$L$ & liquid \\
lat & latent \\
$L O$ & liquid-only \\
$m a$ & moist air \\
max & maximum \\
min & minimum \\
$\mathrm{N}, \mathrm{S}, \mathrm{W}, \mathrm{E}$ & directions of neighbor wall cell \\
$n b$ & nucleate boiling \\
out & outlet \\
part-wet & partially wet \\
$r$ & refrigerant, or refrigerant cell index in Ch. 3 \\
$s$ & surface \\
sat & saturated \\
sens & sensible \\
$s p$ & single-phase \\
$t$ & tube, or tube cell index in Ch. 3 \\
$t p$ & two-phase \\
tot & total \\
$w$ & wall \\
$w b$ & wet-bulb \\
wet_fp & wet fin portion \\
$w f$ & water film \\
\hline xxii & \\
\hline &
\end{tabular}




\section{Abbreviations}

1D one-dimensional

2D two-dimensional

ADM Adomian decomposition method

ARD average relative deviation

ARI Air-conditioning and Refrigeration Institute

ASHRAE American Society of Heating, Refrigerating and Air-Condi-

tioning Engineers

COP coefficient of performance

FEM finite element method

FPD frictional pressure drop

FVM finite volume method

HTC heat transfer coefficient

HVAC\&R heating, ventilation, air-conditioning, and refrigeration

LFTV linear fluid temperature variation

LHC longitudinal heat conduction

LMHD logarithmic mean enthalpy difference

LMTD logarithmic mean temperature difference

MAE mean absolute error

MCHX mini/microchannel heat exchanger

OOP object-oriented programming

RMS root-mean-square

RTPFHX round-tube and plate-fin heat exchanger

SD standard deviation

SEWTLE semi-explicit method for wall temperature linked equation

UPCT Technical University of Cartagena

UPV Technical University of Valencia 



\section{Chapter 1.}

\section{Introduction and}

Mathematical Background

"The great Pleasure in life is doing what people say you cannot do"

-Walter Bagehot 
Chapter 1.

\subsection{Introduction}

A heat exchanger is a device that is used to transfer thermal energy (enthalpy) between two or more fluids, between a solid surface and a fluid, or between solid particulates and a fluid, at different temperatures and in thermal contact. In heat exchangers, there are usually no external heat and work interactions.

Typical applications involve heating or cooling of a fluid stream and evaporation or condensation of single- or multi-component fluid streams of concern. In other applications, the objective may be to recover or reject heat, or sterilize, pasteurize, fractionate, distil, concentrate, crystallize, or control a process fluid.

The present work is focusing on specific applications of heat exchangers that include heating, ventilation, air-conditioning and refrigeration (HVAC\&R) by using air as a secondary fluid. Figure 1.1 shows some of the heat exchangers used in these applications.

Refrigeration and air conditioning systems have become an integral part in the design of spaces occupied by people and intended to provide controlled thermal, humidity, cleanliness, and/or other process requirements. As we strive to design these systems, the constraints imposed on the size and specific dimensions of the system components are becoming increasingly important, while the operating cost remains a critical factor with high energy prices. The impetus for improving the energy efficiency of refrigeration and air-conditioning equipment becomes clear when we recognize that this sector accounts for 15 percent of total energy consumption worldwide (Kandlikar, 2007). Another issue of great environmental concern is the release of large quantities of refrigerants. The necessity to design a low refrigerant system inventories become more important to reduce the risk of accidental leakage with harmful effects on the environment. According to what discussed before, we can summarize the major challenges facing the refrigeration and air conditioning industry as follows:

i) improving the system coefficient of performance (COP),

ii) reducing the total refrigerant charge in the system,

iii) reducing the footprint and size of the equipment, and

iv) meeting these challenges in a cost-effective manner.

In a conventional refrigeration/air conditioning unit, the heat exchangers offer significant potential for addressing the above challenges, which are somehow similar 
to those faced in other applications, including absorption refrigeration, air liquefaction, automotive air conditioning, and high flux chip cooling.

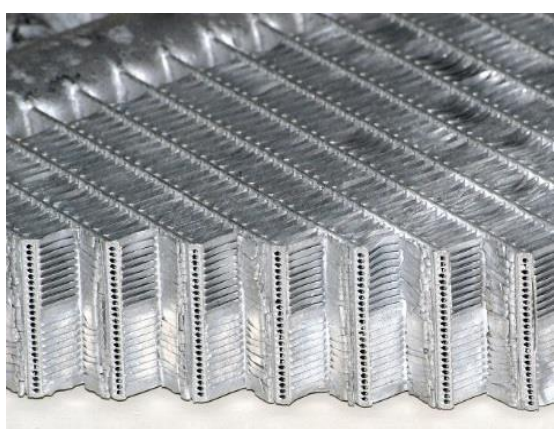

(a) Mini/Microchannel heat exchanger (MCHX).

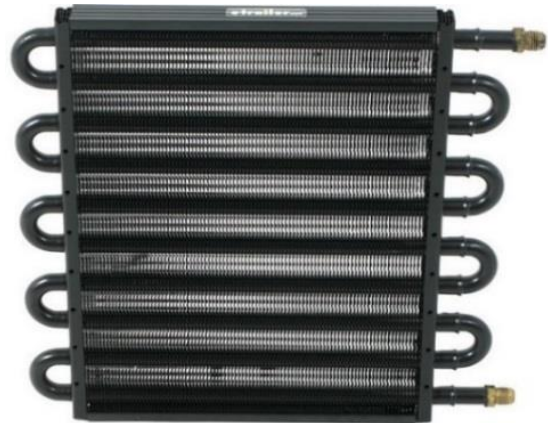

(b) Round-tube and plate-fin heat exchanger (RTPFHX).

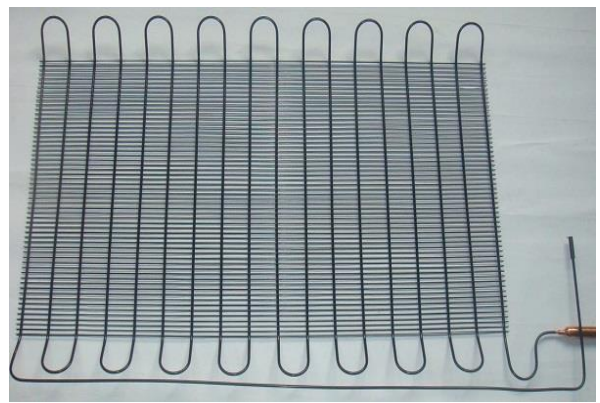

(c) Tube and wire heat exchanger.

Figure 1.1. Common types of air-to-refrigerant heat exchangers used in HVAC\&R.

\subsection{Channel Size Classification of a Heat Exchanger}

Channel classification based on hydraulic diameter is intended to serve as a simple guide for conveying the dimensional range under consideration. Channel size reduction has different effects on different processes. Deriving specific criteria based on the process parameters may seem to be an attractive option, but considering the number of processes and parameters that govern transitions from regular to microscale phenomena (if present), a simple dimensional classification is generally adopted in literature (Kandlikar and King, 2006). The classification proposed by Mehendale et al. (2000) divided the channels size range as follows:

- Microchannels: 1 to $100 \mu \mathrm{m}$. 
Chapter 1.

- Meso-channels: $100 \mu \mathrm{m}$ to $1 \mathrm{~mm}$.

- Compact passages: 1 to $6 \mathrm{~mm}$.

- Conventional passages: $>6 \mathrm{~mm}$.

Kandlikar and Grande (2003) considered the rarefaction effect of common gases at atmospheric pressure. Table 1.1 shows the ranges of channel dimensions that would fall under different flow types.

Table 1.1. Channel dimensions for different types of flow for gases at one atmospheric pressure (Kandlikar and Grande, 2003).

\begin{tabular}{|c|c|c|c|c|}
\hline \multirow[b]{2}{*}{ Gas } & \multicolumn{4}{|c|}{ Channel dimensions $(\mu \mathrm{m})$} \\
\hline & $\begin{array}{l}\text { Continuum } \\
\text { flow }\end{array}$ & Slip flow & $\begin{array}{l}\text { Transition } \\
\text { flow }\end{array}$ & $\begin{array}{l}\text { Free molecular } \\
\text { flow }\end{array}$ \\
\hline Air & $>67$ & $0.67-67$ & $0.0067-0.67$ & $<0.0067$ \\
\hline Helium & $>194$ & $1.94-194$ & $0.0194-1.94$ & $<0.0194$ \\
\hline Hydrogen & $>123$ & $1.23-123$ & $0.0123-1.23$ & $<0.0123$ \\
\hline
\end{tabular}

However, Kandlikar and King (2006) presented later a more general and simple scheme based on the smallest channel dimension, as shown in Table 1.2.

Table 1.2. Channel size classification (Kandlikar and King, 2006).

\begin{tabular}{ll}
\hline Conventional-channels & ${ }^{*} \mathrm{D}>3 \mathrm{~mm}$ \\
Minichannels & $3 \mathrm{~mm} \geq \mathrm{D}>200 \mu \mathrm{m}$ \\
Microchannels & $200 \mu \mathrm{m} \geq \mathrm{D}>10 \mu \mathrm{m}$ \\
Transitional channels: & $10 \mu \mathrm{m} \geq \mathrm{D}>0.1 \mu \mathrm{m}$ \\
$\quad$ - Transitional microchannels & $10 \mu \mathrm{m} \geq \mathrm{D}>1 \mu \mathrm{m}$ \\
- Transitional nanochannels & $1 \mu \mathrm{m} \geq \mathrm{D}>0.1 \mu \mathrm{m}$ \\
Molecular nanochannels & $0.1 \mu \mathrm{m}>\mathrm{D}$ \\
\hline
\end{tabular}

*D is the minimum channel dimension.

The classification scheme in Table 1.2 is essentially employed in literature, besides the current work, for ease in terminology.

\subsection{Minichannel Heat Exchangers (MCHXs)}

Extruded aluminum multi-port minichannels is a technology that has increased the heat transfer and performance of condensers and evaporators for air-conditioning 
Introduction and Mathematical Background

systems especially in vehicles. Industries are actively investigating the use of minichannel tubes for many other heat transfer applications in refrigerators, and household air conditioning.

A typical MCHX employs a flat tube with circular, or non-circular passages of 0.5$2.5 \mathrm{~mm}$ hydraulic diameter, with an average width of $25 \mathrm{~mm}$, and length dependent on the refrigerant and operating conditions. These heat exchangers are generally employed in refrigerant-to-air heat exchangers, with folded louvered fins employed on the air-side. Figure 1.2 shows a schematic of a MCHX condenser.

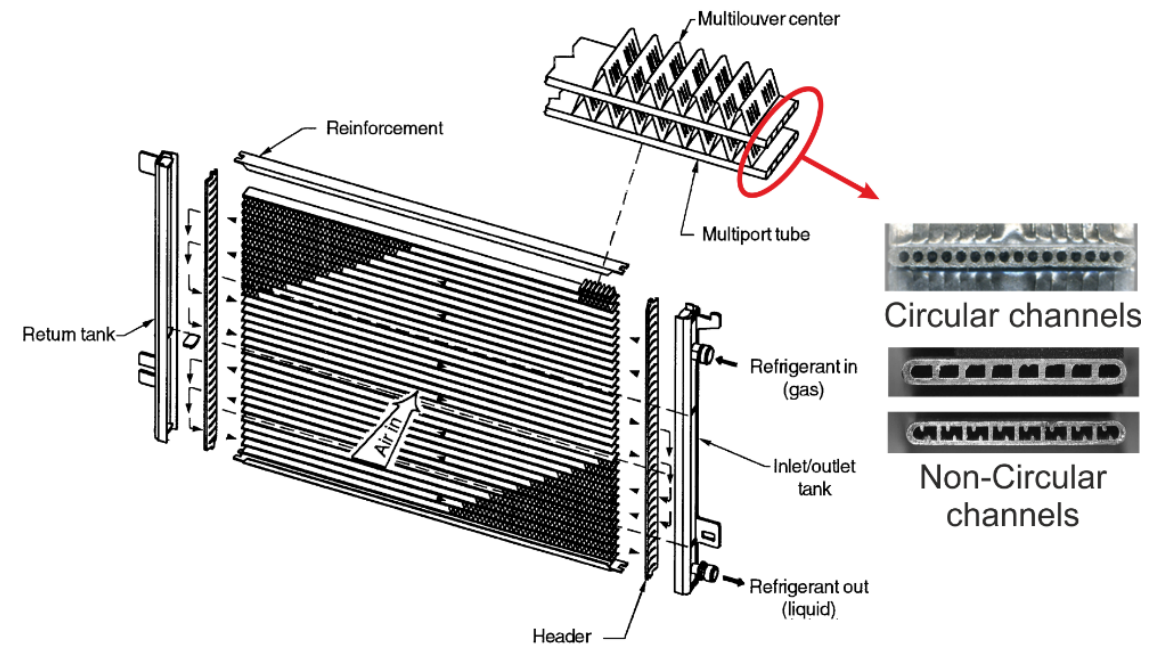

Figure 1.2. Schematic of a compact minichannel condenser (Shah, 1983).

\subsubsection{Advantages of MCHXs}

\subsubsection{Heat exchanger size reduction}

The reduction in the internal volume and the overall size of the heat exchanger (compactness) is one of the great advantages offered by minichannels. The fundamental parameter describing compactness is the hydraulic diameter $D_{h}$ which can be defined as:

$$
D_{h}=\frac{4 V_{s}}{A_{s}}
$$

where $V_{s}$ and $A_{s}$ are the enclosed wetted volume, and surface area, respectively. 
Chapter 1.

The surface area density $\varphi\left[\mathrm{m}^{2} / \mathrm{m}^{3}\right]$, which relates $A_{s}$ to the overall surface volume $V$, also often used as a measure of compactness (Hesselgreaves, 2001).

$$
\varphi=\frac{A_{s}}{V}=\frac{4 \sigma}{D_{h}}
$$

where $\sigma=V_{s} / V$ is the surface porosity.

For the same value of porosity, for example $\sigma=0.75$, a minichannel heat exchanger of $1 \mathrm{~mm}$ hydraulic diameter gives surface area density of $3000 \mathrm{~m}^{2} / \mathrm{m}^{3}$, compared to $300 \mathrm{~m}^{2} / \mathrm{m}^{3}$ for a macrochannel (conventional-tube) heat exchanger of $10 \mathrm{~mm}$ hydraulic diameter. This simple example markedly demonstrates that for the same internal volume, MCHXs provide ten times larger surface area as compared to conventionalchannel heat exchangers.

\subsubsection{Heat transfer enhancement}

For a single side, a specific heat load, $Q$, is expressed through the following basic heat transfer equation

$$
Q=\alpha \cdot A_{s} \cdot \Delta T
$$

where $\alpha$ and $\Delta T$ are the heat transfer coefficient and temperature difference, respectively. For convenience, the influence of wall resistance and surface efficiency on $\alpha$ is neglected.

By employing Equation (1.2) into Equation (1.3), the specific heat load $Q$ can further be written in the following expression:

$$
Q=\alpha \frac{4 \sigma V}{D_{h}} \Delta T
$$

Under the assumption of fully developed laminar flow the Nusselt number $N u$ is constant, does not depend on Reynolds number $R e$, and the heat transfer coefficient varies inversely with channel hydraulic diameter as given by the following equation:

$$
\alpha=N u \frac{k}{D_{h}}
$$

where $k$ is the thermal conductivity of the fluid. 
Introduction and Mathematical Background

Substituting the value of $\alpha$ in Equation (1.4), and dividing by $V$, gives

$$
\frac{Q}{V}=\frac{4 \sigma \cdot N u \cdot k \cdot \Delta T}{D_{h}^{2}}
$$

Hence, in cases of laminar flow and for given values of $\sigma$ and $\Delta T$, the heat transfer rate per unit volume is proportional to the inverse square of the hydraulic diameter of the heat exchanger tube.

\subsubsection{Reduction in refrigerant charge}

The refrigerant charge is another major consideration from the overall cost and environmental viewpoints. The amount of refrigerant in large industrial refrigeration equipment can be in the range of several hundred kilograms. Using minichannels reduces the internal volume of the heat exchangers with a significant reduction in the refrigerant charge. Hrnjak (2005) presented a study focusing on charge reduction strategies in ammonia refrigeration systems. He recommended using smaller diameter channels and plate heat exchangers with small gaps. A higher void fraction in the heat exchanger is desirable from this standpoint. Hrnjak reported the following specific refrigerant charge per $\mathrm{kW}$ of heat removal rate in ammonia systems:

- Air-cooled condensers: $18-159 \mathrm{~g} / \mathrm{kW}$.

- Water-cooled condensers: 23-228 g/kW.

- Condensers with minichannels: 5-10 g/kW.

In ammonia evaporators, Pearson (2003) and Ayub (2004) provided the following values for typical specific charge in different heat exchanger types:

- Shell-and-tube: $1000 \mathrm{~g} / \mathrm{kW}$.

- Plate: $500 \mathrm{~g} / \mathrm{kW}$.

- Gravity-fed plate: $250 \mathrm{~g} / \mathrm{kW}$.

- Spray-type: 54-113 g/kW.

Ayub (2005) reported that the values of the refrigerant charge in a direct expansion evaporator employing $15 \mathrm{~mm}$ enhanced tubes of around $75 \mathrm{~g} / \mathrm{kW}$ for a 100-ton evaporator under Air-conditioning and Refrigeration Institute (ARI) conditions. Significant refrigerant charge reductions can be obtained by employing minichannel heat exchangers in these systems. Considering the surface area and performance enhancements presented earlier with minichannels, a design goal of $10-20 \mathrm{~g} / \mathrm{kW}$ for refrigerant charge seems feasible in evaporators. 
Chapter 1.

Hrnjak (2005) also suggested increasing the void fraction in condensers and evaporators in order to reduce the refrigerant charge in a system.

\subsubsection{Disadvantages of MCHXs}

The reduction of channel size is desirable to enhance the heat transfer rate as discussed before; however, it has an adverse effect on the pressure drop. The pressure gradient (pressure drop per unit length) drastically increases with channel size reduction, but it was also noted that minichannel heat exchangers need to be suitably designed to provide short flow lengths and enough face area to limit the overall pressure drop (Kandlikar and Grande, 2003).

The other common disadvantages which reported in the literature include: high cost of manufacture, and in case of evaporators problems to drain the condensate water (Pettersen et al., 1998; Qi et al., 2009; Zhang and Hrnjak, 2010; Moallem et al., 2012); and refrigerant flow maldistribution (Kulkarni et al., 2004; Brix et al., 2010; Nielsen et al., 2012).

Additionally, the macroscale ( $>3 \mathrm{~mm}$ ) two-phase flow methods do not usually work very well when compared with data for channels below about $3 \mathrm{~mm}$ diameter (microscale). Thus, it is very risky to extrapolate macroscale two-phase flow pattern maps, flow boiling heat transfer methods and two-phase pressure drop models to micro/minichannels, except for specific documented cases. Furthermore, many of the controlling phenomena and mechanisms change when passing from macrochannel two-phase flow and heat transfer to micro/minichannels. For example, surface tension (capillary) forces become much stronger as the channel size diminishes while gravitational forces are weakened. In the literature, existing many efforts related to this topic, among these: Kandlikar (2002), Thome (2004), Garimella et al. (2005), Cavallini et al. (2005), Kandlikar et al. (2006), Revellin and Thome (2007), Bertsch et al. (2008), Cavallini et al. (2009), Revellin et al. (2009), Agarwal et al. (2010), and Thome (2010). These problems are the goal of much of the research involving micro/minichannels right now. 
Introduction and Mathematical Background

\subsection{Mathematical Background: Simultaneous Heat and Mass Transfer}

When the heat exchanger is used as an evaporator, its wall surface temperature is usually below the average dew point of the surrounding moist air $T_{d p}$. Under this situation, it is more common that dehumidification of air occurs simultaneously with the sensible cooling process. With dehumidification, the air-side surface is wetted (liquid water or frost). In addition to sensible heat transfer, there is a transfer of latent heat because of condensation.

Analyzing the air-side performance of evaporators under wet conditions is complicated. Accordingly, several simplifications of the original differential equations have been proposed, based on different assumptions, resulting in a variety of alternative heat and mass transfer models. The two most well-known models are the single potential model proposed by Threlkeld (1970), and the dual potential model proposed by McQuiston (1975). The main differences between the two models are explained next; firstly for a differential wall element, then for a straight fin under different dehumidifying conditions.

\subsubsection{The single potential model vs. the dual potential model}

Figure 1.3 shows schematically a cold surface in contact with a moving stream of moist air. A moving film of water is formed on the surface by condensation of moisture from the air stream.

There is a boundary layer of air next to the water surface. In this layer, we assume that the air temperature, air humidity ratio, and air velocity vary in a plane perpendicular to the bulk motion of air. Immediately next to the water film, we assume that the air is saturated at the condensed water film temperature $T_{w f}$. The thermal heat resistance associated with a presence of the thin water film due to condensation is very small and may be neglected which results to a water film temperature equal to the wall surface temperature $T_{s}$.

For the differential surface area $d A$ in Figure 1.3, the general differential equation of total heat transfer rate is expressed as following:

$$
d Q_{\mathrm{tot}}=d A\left[d q_{\mathrm{sens}}+d q_{\mathrm{lat}}\right]=d A\left[\alpha_{a}\left(T_{a}-T_{s}\right)+\alpha_{D} \cdot h_{f g}\left(W_{a}-W_{\mathrm{sat}, s}\right)\right]
$$




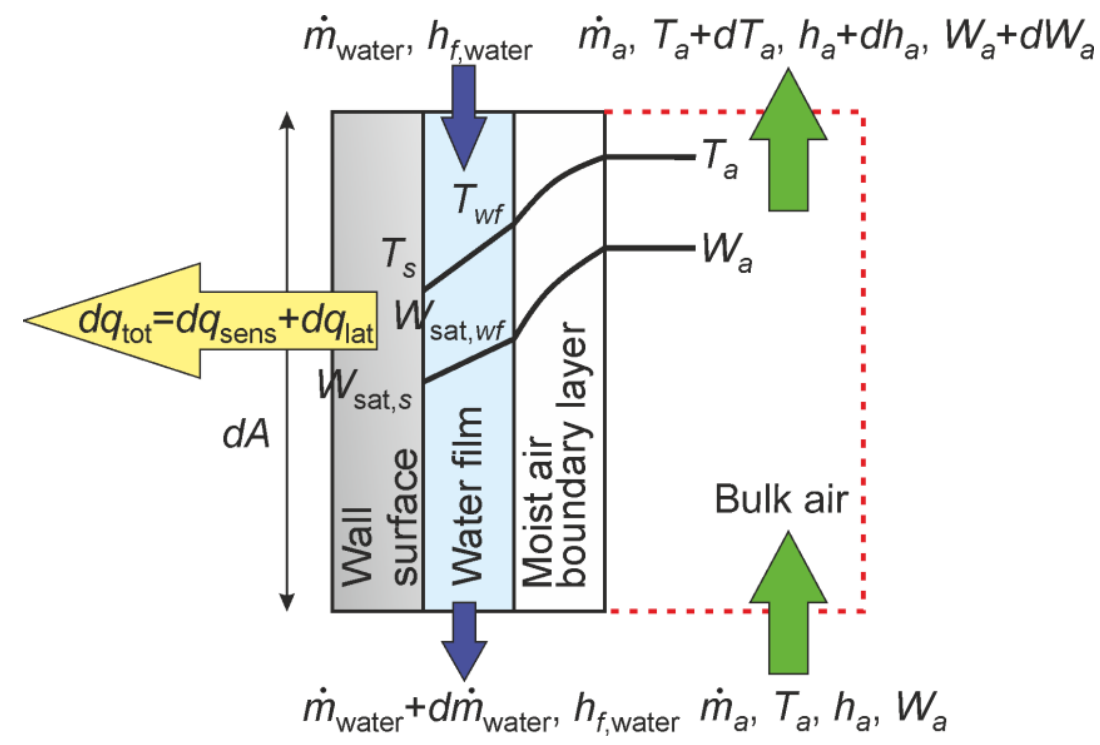

Figure 1.3. Schematic of cooling and dehumidifying of moist air.

where $W_{\text {sat, } s}$ is the saturated air humidity ratio evaluated at $T_{s}$, and $h_{f g}$ is the latent heat of water condensation. $\alpha_{D}$ in Equation (1.7) represents the mass transfer coefficient which could be related to the air-side sensible heat transfer coefficient, $\alpha_{a}$, by using Chilton-Colburn analogy (Chilton and Colburn, 1934):

$$
\alpha_{D}=\frac{\alpha_{a}}{L e^{2 / 3} \cdot C_{p, m a}}
$$

where $L e$ and $C_{p, m a}$ are Lewis number and moist air specific heat, respectively. For humid air, Lewis number is usually close to unity (ranged from 0.8 to 0.9 ). Also, it is relatively insensitive to variations in temperature (Coney et al., 1989c; Cengel, 2002).

Equations (1.7) and (1.8) could be combined and rearranged to give the total heat transfer rate in an element under wet condition as:

$$
d Q_{\mathrm{tot}}=\alpha_{a} \cdot d A\left[\left(T_{a}-T_{s}\right)+\frac{1}{L e^{2 / 3} \cdot C_{p, m a}} \cdot h_{f g}\left(W_{a}-W_{\mathrm{sat}, s}\right)\right]
$$

Equation (1.9) is the main equation used by McQuiston (1975) to develop the dual potential method for modeling the simultaneous heat and mass transfer. 
Introduction and Mathematical Background

The term in the square brackets in Equation (1.9), may be approximated by the difference between the enthalpy of moist air and the enthalpy of saturated air at the wall surface temperature. Thus,

$$
d Q_{\mathrm{tot}}=\frac{\alpha_{a}}{C_{p, m a}} \cdot d A\left[h_{a}-h_{\mathrm{sat}, s}\right]
$$

where $h_{\text {sat }, s}$ is the saturated air enthalpy evaluated at $T_{s}$. Equation (1.10) represents the single potential or enthalpy potential model proposed by McElgin and Wiley (1940), and Threlkeld (1970). It is worth mentioning that the single potential model implicitly assumes, in its derivation, that Lewis number is equal to unity.

Mirth and Ramadhyani (1993) applied both methods (the dual potential method which is based on Equation (1.9) and the single potential method which is based on Equation (1.10), in addition to his own, to a discretized cooling coil using water as a refrigerant. The capacity predictions obtained with the single potential and dual potential method were within $1 \%$ of those obtained with his more fundamentally sound approach.

However, the main advantages of the dual potential method that it allows for:

- the independent evaluation of each contribution (sensible and latent heat);

- employing different values of Lewis number which makes it more accurate, compared to the single potential method, (Kandlikar, 1990); and

- continuous evaluation of total heat in the transitions from humid to dry condition.

On the other hand, the single potential method is more simple and recommended by the industry standard (ARI Standard 410-87, 1987); however, in this approach the total heat transfer rate is based on the log-mean enthalpy potential of the heat exchanger, making it difficult to separate its sensible and latent heat contributions. In addition, the integrated enthalpy potential equation only gives the exit air enthalpy. But in order to locate the exit air state, one more air property such as temperature or humidity ratio needs to be calculated independently. In Threlkeld's method, the condition of air in the evaporator is traced by integrating the following equation in a step-wise fashion:

$$
d h_{a} / d W_{a}=L e^{2 / 3}\left(h_{a}-h_{\mathrm{sat}, w f}\right) /\left(W_{a}-W_{\mathrm{sat}, w f}\right)+\left(h_{g}-2467.0 L e^{2 / 3}\right)
$$


Chapter 1.

where $h_{\text {sat, } w f}$ and $W_{\text {sat, wf }}$ are the saturated air enthalpy and humidity ratio evaluated at the water film temperature, respectively. The status of the outlet air can be determined by the intersection of the condition line obtained from Equation (1.11) with the outlet air enthalpy value determined from the log-mean enthalpy potential equation.

\subsubsection{Fin performance under wet conditions}

The fins and tubes of the evaporator become partially or totally wet depending on the surface temperature and inlet air properties (temperature and humidity ratio). The fin performance is dramatically influenced by the combined heat and mass transfer associated with the cooling and dehumidification of air. The condensation of moist air over the fin surface attributes to the decrease of fin efficiency. An example of calculations done by Hong and Webb (1996), showed that the wet fin efficiency (Equation 1.18) can be as much as $35 \%$ below the dry surface fin efficiency. Since the fin performance under wet conditions may be very different from the dry conditions, special attention is needed for the wet fin performance analysis.

Many Analytical, numerical, and experimental studies were conducted by many authors to analyze and study the performance and efficiency of the fin under dehumidification. Analytically, Threlkeld (1970) obtained an analytical expression for the overall fin efficiency by using the enthalpy difference as the driving force for the combined heat and mass transfer process. The overall efficiency of a wet fin, calculated with his method, does not depend much on the relative humidity of the air. McQuiston (1975) studied the overall efficiency of a wet straight fin, he adopted the dual potential approach. His result showed that the overall fin efficiency strongly depends on the relative humidity. An analysis was done by Wu and Bong (1994) on the overall efficiency of a straight wet fin by using a dual potential approach. Analytical solutions were obtained for the overall fin efficiency in full and partial wet conditions. Contrary to some numerical and analytical results found in literature, their work showed that the overall efficiency of a fully wet fin is nearly independent of relative humidity of the air. It was also shown that only the overall fin efficiency significantly depends on the relative humidity when the fin is partially wet.

There are intensive numerical studies on the wet fin efficiency. For example Elmahdy and Biggs (1983) obtained the overall fin efficiency of a circular fin by taking into consideration the temperature distribution over the fin surface. They treated heat and mass transfer separately by considering their respective driving 
Introduction and Mathematical Background

force. Their numerical result indicated that the fin efficiency strongly depends on the relative humidity. In the same way, Coney et al. (1989c) used a one-dimensional (1D) numerical model to calculate wet fin efficiency for a vertical rectangular fin laterally attached to a tube. In their model, they computed the fin temperature distribution, the condensate film thickness, and fin efficiency as a function of relative humidity of inlet air. But, the variation of the moist-air parameters in the air flow direction was not considered. They concluded that for a fin in laminar humid air cross flow the condensation has a substantial influence on fin performance, the reduction in fin effectiveness being a function of additional heat associated with latent heat when condensation occurs. Chen (1991) presented a two-dimensional (2D) numerical model to calculate the wet fin efficiency for a rectangular fin. In contrast to the numerical model of Coney et al. (1989c), in Chen's model the variations of air temperature and specific humidity along the air flow were considered, but the resistance of film thickness was neglected. Chen's study showed that streamwise variations in moist air properties have a substantial effect on the fin efficiency, especially at low values of relative humidity.

Liang et al. (2000) implemented a comparative study between a 1D analytical model, a 1D numerical model, and a 2D numerical model. Moreover, a quantitative comparison of these models together with a widely used method by McQuiston (dual potential model) was presented. Their results showed in general that the 1D numerical model compared very well with the 2D model. The errors associated with neglecting the variation of the air properties along the air flow direction (type I error) and that associated with the shape transformation from a rectangular fin to an equivalent circular fin (type II error) are influenced by the air flow conditions and fin geometric parameters. The type I error increases significantly with the decrease in air velocity; while, the type II error increases significantly with the increase in fin width. These two errors are partially counterbalanced by each other. Liang's model can be used for the design and modeling of a wet-surface plate-fin-tube heat exchanger based on an arbitrarily small control volume. At a very low air velocity, the deviation between the 1D and 2D numerical models should not be ignored.

Chen and Wang (2008) proposed 1D and 2D inverse heat conduction models involving the finite difference method in conjunction with the least-squares method and measured fin temperatures at various measurement locations to estimate the unknown average overall heat transfer coefficient on the fin, total heat transfer rate, and wet fin efficiency for different values of inlet air velocity and relative humidity. Their results showed that the estimated fin efficiency under partially and fully wet 
Chapter 1.

conditions is sensitive to the relative humidity. They also concluded that the latent heat transfer under wet conditions is a very significant portion of the total heat transfer and should not be negligent in any aspect of the dehumidification design.

An extensive 2D numerical study was conducted by Riad and Junhua (2011), to estimate the overall heat transfer coefficient and the fin efficiency; as well as, the total heat rate exchanged under partially and fully wet conditions in a plate fin-and-tube heat exchanger. They concluded that the overall heat transfer coefficient and the condensation factor increase with the inlet air temperature, relative humidity, and velocity. The results reveled that in the partially wet conditions, the wet fin efficiency is dramatically affected by the change in the relative humidity and the fin base temperature. While in the fully wet cases the decrease in efficiency is very weak, especially for higher values of relative humidity and the fin base temperature.

Experimentally, there is limited information of extended fin surfaces under dehumidifying conditions. Lin et al. (2001) performed a detailed study concerning the performance of a rectangular fin in both dry and wet conditions. The visual observation of the dehumidifying phenomenon identified four regions including the fully dry, very fine droplet, larger droplet, and film-like region. Their results showed that the effect of dry bulb temperature on the wet fin efficiency is very small. The dry fin efficiency is about $15-25 \%$ higher than that of the corresponding wet fin efficiency. For the fully wet conditions, the effect of relative humidity on the fully wet fin efficiency is also small. For the partially wet surface, a considerable influence of the relative humidity on the fin efficiency is encountered. They also stated that the main cause of this controversy may be attributed to the formulation of the relation between the humidity ratio and the fin temperature.

From the previous discussion, we can conclude that the dehumidifying condition of the fin has a substantial impact on its efficiency, especially under partially wet scenarios. It is quite important to capture the actual fin condition and latent heat transfer rate in order to evaluate correctly the air-side performance of the heat exchangers which operate under different wet conditions. These conclusions motivated the author to present next a fundamental analytical analysis for the fin performance under wet conditions. This analysis has been conducted using the single and dual potential models in order to understand the main differences between them for modeling the heat and mass transfer between the moist air and fin. 
Introduction and Mathematical Background

\subsubsection{Mathematical analysis of a totally wet fin}

A steady state analysis is carried out on a straight fin when exposed to moving moist air stream, as shown in Figure 1.4. In this regard, the following assumptions are made to simplify the analysis:

- Temperature variation across both the fin thickness and its width are small and may be neglected.

- The thermal conductivity of the fin material is constant.

- The heat transfer from the edges and fin tip may be neglected.

- The temperature at each point on the fin surface is below the dew point temperature of the bulk air.

- The humid air flow is steady and one-dimensional.

- The local air-side heat transfer and mass transfer coefficients are constant.

- The thermal heat resistance associated with the presence of thin water film due to condensation is very small and may be neglected.

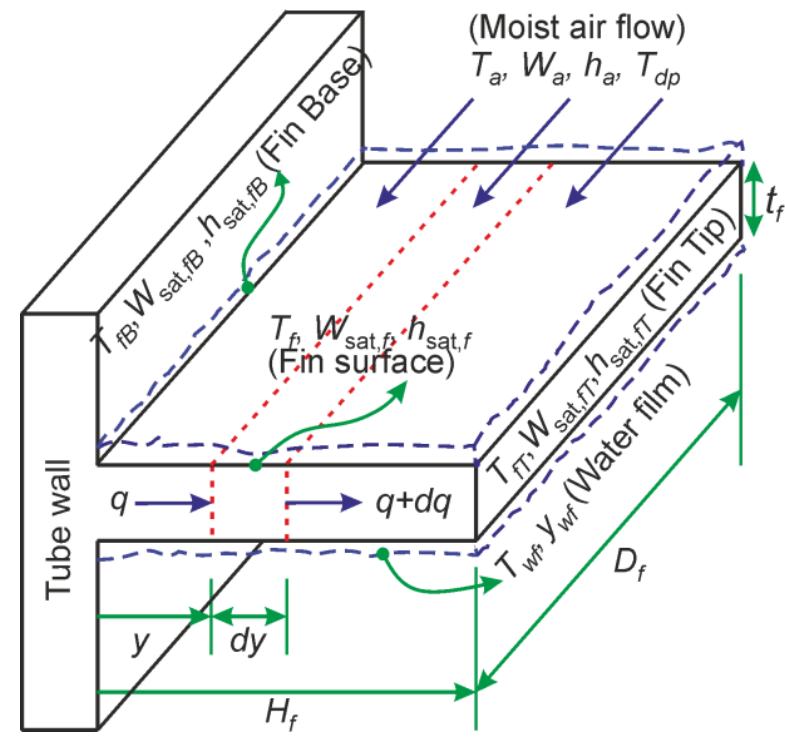

Figure 1.4. Schematic of a fully wet rectangular fin.

These are essentially the classical assumptions that are typically used for the analysis of conducting-convecting finned surfaces. It may be noted that the assumption of negligible thermal resistance in the condensate film is applicable for relative humidity and dry bulb temperature up to $90 \%$ and $35^{\circ} \mathrm{C}$, respectively (Coney et al., 1989a 
Chapter 1.

and 1989b). For example, during the humidification process, the thickness of condensate film is much smaller compared to the boundary layer thickness for forced convection. It is expected that the rate of condensation increases with the increase of both dry bulb temperature and relative humidity of the incoming air. However, the condensate film drains off the fin surface due to gravity as well as by forced air flow (Sharqawy and Zubair, 2008).

The general differential equation which is resulted from an energy balance on element of the fin normal to direction of heat flow, as shown in Figure 1.4, can be expressed as follows.

$$
\frac{d}{d y}\left(k_{f} \cdot A_{c, f} \cdot \frac{d T_{f}}{d y}\right) d y+d q_{\mathrm{tot}} \cdot P_{f} \cdot d y=0
$$

where $k_{f}, A_{c, f}$, and $P_{f}$ are the fin thermal conductivity, cross-section area, and perimeter respectively. Proper heat and mass transfer model is required to solve and evaluate the total heat flux $d q_{\text {tot }}$ in Equation (1.12), to obtain expressions for wet fin temperature profile and efficiency.

As discussed in Sub-section 1.4.1, there are two common models to simulate the process of heat and mass transfer, the single potential and dual potential models. The next sections illustrate the different solutions of the differential equation for wet fin based on the two models of heat and mass transfer.

a) Totally wet fin analysis: single potential model

In this approach, the enthalpy potential which proposed by Threlkeld (1970) (Equation 1.10) is used to represent the process of cooling and dehumidification of moist air over the fin surface. But to solve Equation (1.12) another relation between the saturated air enthalpy and corresponding surface temperature is required, so Threlkeld (1970) introduced a fictitious linear relation for saturated air enthalpy as follows:

$$
h_{\text {sat }, f}=a_{h}^{\prime}+b_{h}^{\prime} \cdot T_{f}
$$

$b_{h}^{\prime}$ is the saturated enthalpy line slope evaluated at fin base temperature $T_{f B}$

$$
b_{h}^{\prime}=\frac{h_{a}-h_{\mathrm{sat}, f B}}{T_{w b}-T_{f B}}
$$

where $T_{w b}$ represents the wet-bulb temperature of the air at the freestream conditions. 
Ware and Hacha (1960) proposed approximating $b_{h}^{\prime}$ by $b_{h}$, which is evaluated at the mean surface temperature as follows:

$$
h_{\text {sat }, f}=a_{h}+b_{h} \cdot T_{f} \text {, where }\left.b_{h} \approx b_{h}^{\prime} \cong \frac{d h_{\mathrm{sat}}}{d T}\right|_{T=\bar{T}_{f}}
$$

Figure 1.5 shows an exaggerated schematic of $b_{h}$ and $b_{h}^{\prime}$. The advantage of using $b_{h}$ is that it eliminates the need to reference the freestream conditions.

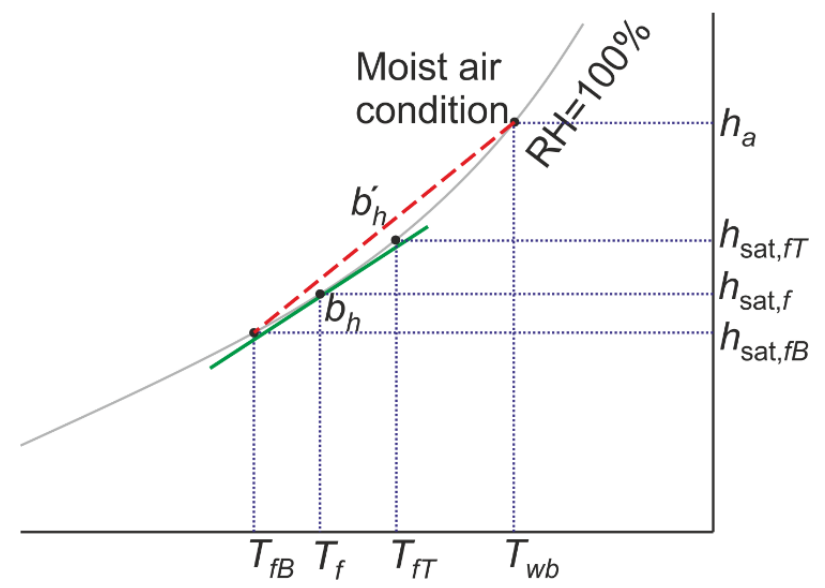

Figure 1.5. Linear approximation of saturated enthalpy curve.

By substituting Equations (1.10), (1.13), and (1.15) into Equation (1.12), the final differential equation for wet fin based on single potential model is expressed as:

$$
\frac{d^{2} \xi_{a, f}}{d x^{2}}=M_{h}^{2} \cdot \xi_{a, f}
$$

where

$$
\begin{array}{ll}
\xi_{a, f}=h_{a}-h_{\mathrm{sat}, f}(y) & \begin{array}{l}
\text { is the enthalpy difference between the surrounding air } \\
\text { and saturated air at the fin surface; }
\end{array} \\
M_{h}=m \cdot\left(b_{h} / C_{p, m a}\right)^{1 / 2} & \begin{array}{l}
\text { is the wet fin parameter based on single potential ap- } \\
\text { proach; and }
\end{array} \\
m=\sqrt{\frac{P_{f} \cdot \alpha_{a}}{k_{f} \cdot A_{c, f}}} & \text { is the dry fin parameter. }
\end{array}
$$


Chapter 1.

The boundary conditions for Equation (1.16) are $\xi_{a, f}(\mathrm{y}=0)=\xi_{a, f B}=h_{a}-h_{\mathrm{sat}, f B}$, and $d \xi_{a, f}$ $I d y=0$ at $y=H_{f}$. Equation (1.16) and its boundary conditions are completely analogous to dry fin equation and its boundary conditions. Thus, the wet fin temperature profile is defined as:

$$
\frac{\xi_{a, f}}{\xi_{a, f B}}=\frac{\cosh \left[M_{h}\left(H_{f}-y\right)\right]}{\cosh \left(M_{h} \cdot H_{f}\right)}
$$

and the efficiency of wet fin

$$
\eta_{f, \text { wet }}=\frac{\tanh \left(M_{h} \cdot H_{f}\right)}{M_{h} \cdot H_{f}}
$$

It can be noticed that the solution for efficiency of the wet fin is of identical form to that of the dry fin. However in a case of the dry fin, the wet fin parameter $M_{h}$ is reduced to dry fin parameter $m$.

\section{b) Totally wet fin analysis: dual potential model}

The dual potential model considers independently the sensible heat transfer due to the temperature difference between the moist air and the cooling surface; and the latent heat transfer due to the specific humidity difference between the flowing air stream and the saturated air near the cooling surface. In the current approach, Equation (1.9) is used to evaluate the total heat term in Equation (1.12). However, an additional equation for saturated humidity ratio is needed to solve the differential equation of wet fin. McQuiston (1975), considered the assumption that

$$
W_{a}-W_{\mathrm{sat}, f}=C\left(T_{a}-T_{f}\right)
$$

where $C$ is a constant. Thus, Equation (1.12) becomes a homogeneous differential equation, which is easy to solve. Although this assumption simplifies the solution of the differential equation, however, it is not a general physical relationship.

Actually, Equation (1.12) still can be solved by making use of the fact that the air near the fin surface is saturated, similar to the work of Elmahdy and Biggs (1983). However, Wu and Bong (1994) used a linear relationship between $W_{\text {sat } f}$ and $T_{f}$ over the temperature range $\left(T_{f B}<T_{f}<T_{f T}\right)$, given by:

$$
W_{\text {sat }, f}=a_{f}^{\prime}+b_{f}^{\prime} \cdot T_{f}
$$

where 


$$
b_{f}^{\prime}=\left.\frac{W_{\mathrm{sat}, f T}-W_{\mathrm{sat}, f B}}{T_{f T}-T_{f B}} \approx \frac{d W_{\mathrm{sat}}}{d T}\right|_{T=\bar{T}_{f}}
$$

While this assumption looks physically acceptable, we still do not know the temperature at the fin tip. Hence, we cannot calculate the constants $a_{f}^{\prime}$ and $b_{f}^{\prime}$ before solving the temperature distribution over the fin surface. Another linear relationship (Figure 1.6) was suggested by Sharqawy and Zubair (2008) between $W_{\text {sat } f}$ and $T_{f}$ over the temperature range $\left(T_{f B}<T_{f}<T_{d p}\right)$ can be written as:

$$
W_{\text {sat }, f}=a_{f}+b_{f} \cdot T_{f}
$$

where

$$
\begin{gathered}
b_{f}=\frac{W_{a}-W_{\mathrm{sat}, f B}}{T_{d p}-T_{f B}} \\
a_{f}=W_{\mathrm{sat}, f B}-\left(\frac{W_{a}-W_{\mathrm{sat}, f B}}{T_{d p}-T_{f B}}\right) T_{f B}
\end{gathered}
$$

Now, the constants $a_{f}$ and $b_{f}$ can be calculated easily from the ambient air conditions and the fin base temperature. Actually, the maximum temperature at fin tip for the wet condition is the dew point temperature, $T_{d p}$ of the air stream.

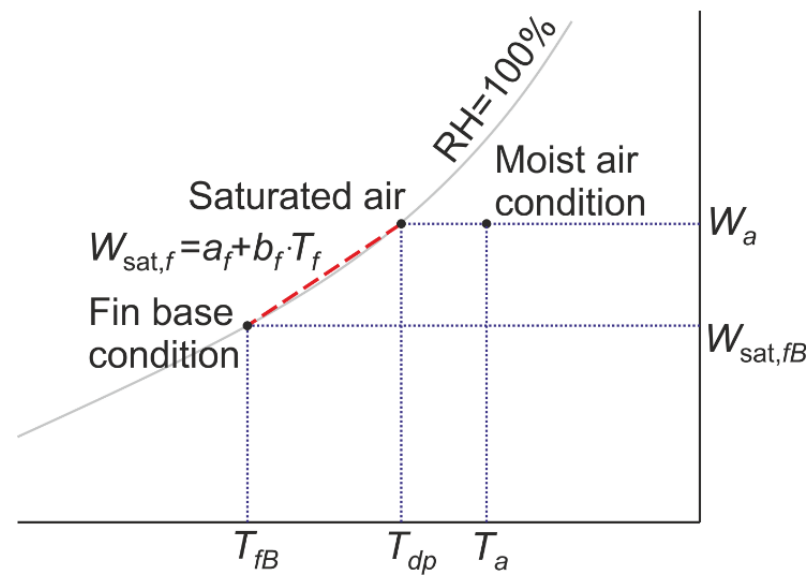

Figure 1.6. Linear approximation of saturated humidity ratio curve, as it was proposed by Sharqawy and Zubair (2008).

Substituting Equations (1.9), (1.22), (1.23), and (1.24) into Equation (1.12) we get 
Chapter 1.

$$
\frac{d^{2} \theta_{a, f}}{d y^{2}}-M^{2} \cdot \theta_{a, f}=M^{2} \cdot \psi
$$

where

$\theta_{a, f}=T_{a}-T_{f}(y) \quad \begin{aligned} & \text { is the difference between the surrounding air temperature } \\ & \text { and fin temperature; }\end{aligned}$ $M=m\left(1+\beta \cdot b_{f}\right)^{1 / 2}$ is the wet fin parameter based on dual potential approach;

$\psi=\frac{\beta \cdot C_{0}}{1+\beta \cdot b_{f}} \quad$ this parameter includes the effect of moist air humidity ratio on the temperature distribution of wet fin;

$\beta=\frac{h_{f g}}{L e^{2 / 3} \cdot C_{p, m a}} \quad \begin{aligned} & \text { this parameter is resulted from using Chilton-Colburn } \\ & \text { analogy; and }\end{aligned}$ $\begin{array}{ll}C_{0}=W_{a}-a_{f}-b_{f} \cdot T_{a} & \begin{array}{l}\text { this parameter represents the residual part of the driving } \\ \text { force }\left(W_{a}-W_{\text {sat } f f}\right) \text { for the mass transfer. }\end{array}\end{array}$

Equation (1.25) is a linear non-homogeneous second order differential equation which can be solved in the following general form:

$$
\theta_{a, f}(y)=C_{1} \cdot e^{M y}+\left.C_{2} \cdot e^{-M y}\right|_{\text {Complementary solution }}-\left.\psi\right|_{\text {Particular solution }}
$$

The boundary conditions for a fully wet fin with an adiabatic tip are: at the fin base $\theta_{a, f}=\theta_{a, f B}=T_{a}-T_{f B}$; while at the tip $d \theta_{a, f} / d y=0$.

The final solution of Equation (1.26) subjected to the previous boundary conditions gives us the temperature distribution along the fin surface, which can be written in the form

$$
\frac{\theta_{a, f}+\psi}{\theta_{a, f B}+\psi}=\frac{\cosh \left[M\left(H_{f}-y\right)\right]}{\cosh \left(M \cdot H_{f}\right)}
$$

This equation is very similar to Equation (1.17) which based on the single potential model, however, the parameter $\psi$ resulted from the non-homogeneity of Equation (1.25). The fin efficiency is calculated from Equation (1.18), but with wet fin parameter based on dual potential model $M$ instead of single potential one $M_{h}$.

To evaluate the effect of air relative humidity $\mathrm{RH}_{\mathrm{a}}$ on the straight rectangular fin efficiency, Sharqawy and Zubair (2008) compared between their saturation line 
Introduction and Mathematical Background

slope approximation (Equations 1.22-1.24) with the approximations of $\mathrm{Wu}$ and Bong (1994) (Equations 1.20 and 1.21), McQuiston (1975) (Equation 1.19), and Threlkeld (1970) (Equations 1.13 and 1.14). For comparison purposes, the fin base temperature $\mathrm{T}_{\mathrm{fB}}$ was set at $7{ }^{\circ} \mathrm{C}$; whereas the value of fin parameter $\left(m \cdot H_{f}\right)$ was chosen to be equal to 0.8 . The bulk air temperature $\mathrm{T}_{\mathrm{a}}$ was kept at $27{ }^{\circ} \mathrm{C}$, while the $\mathrm{RH}_{\mathrm{a}}$ ranged from $40 \%$ to $100 \%$, within this range the fin was fully wet. Figure 1.7 summarizes the results of their comparative study.

It is important to note that in using McQuiston's method, the fin efficiency depends strongly on the relative humidity. The approaches of $\mathrm{Wu}$ and Bong, and Threlkeld agree well with the results of Sharqawy and Zubair (2008). However, as discussed earlier it is difficult to calculate the wet fin parameter $M$ in Wu and Bong's model without knowing the fin tip condition. For the entire range of $\mathrm{RH}_{\mathrm{a}}$ studied they found that the efficiency value was $2 \%$ lower than $\mathrm{Wu}$ and Bong (1994). This difference increased to $4.5 \%$ at $m \cdot H_{f}=1.2$. It can be concluded from these results that the best linear approximation of the saturation curve is the one which was proposed by Sharqawy and Zubair (2008). The main advantages of this linear approximation are the simplicity and the proper physical representation of the saturated humidity ratio curve on the psychrometric chart.

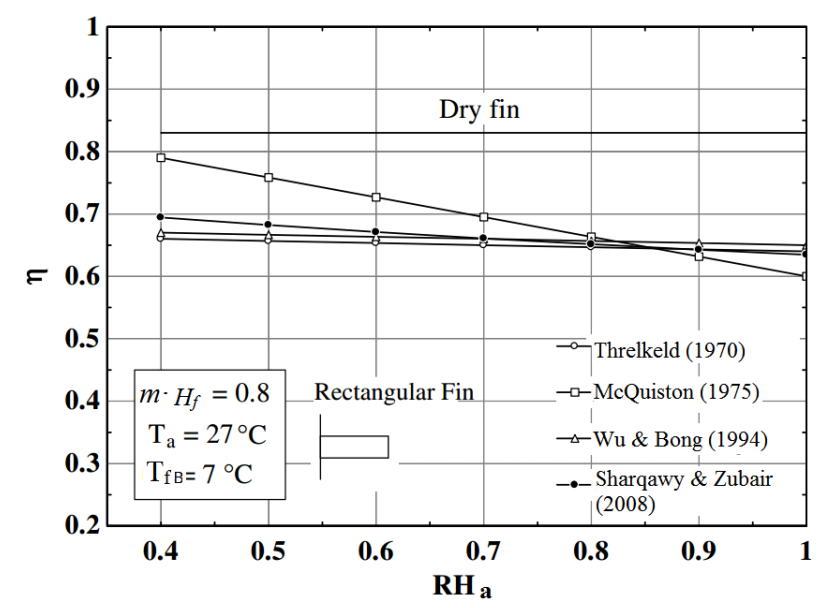

Figure 1.7. Comparison of the fin efficiency for a fully wet rectangular fin (Sharqawy and Zubair, 2008). 
Chapter 1.

\subsubsection{Mathematical analysis of a partially wet fin}

A partially wet fin is encountered when the fin base temperature is lower, but the fin tip temperature is higher than the dew point of the air. On the fin surface there is a place, say $y=\zeta$, where the surface temperature equals the dew point of the air. The fin is then separated into two regions: a wet region $(0 \leq y \leq \zeta)$, with the surface temperature lower than $T_{d p}$; and a dry region $\left(\zeta \leq y \leq H_{f}\right)$, with the surface temperature higher than $T_{d p}$. Figure 1.8 shows a schematic of a partially wet fin.

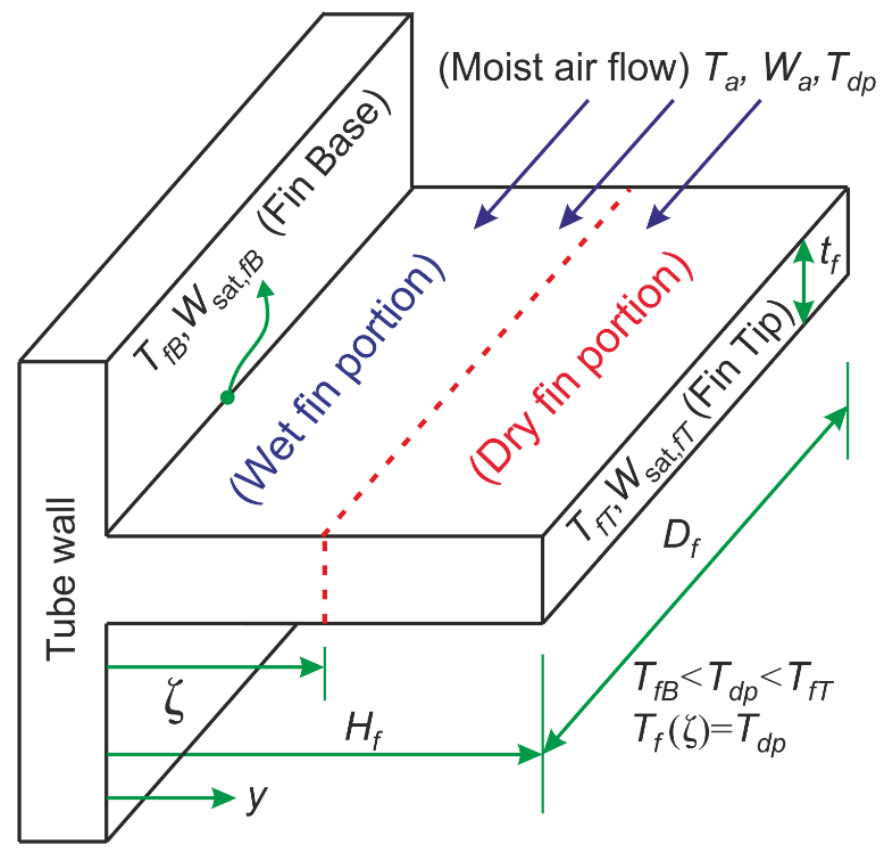

Figure 1.8. Schematic of a partially wet rectangular fin.

a) Dry fin portion analysis $\left(\zeta \leq y \leq H_{f}\right)$

The dry fin general differential equation (Bergman et al., 2011)

$$
\frac{d^{2} \theta_{a, \text { dry_fp }}}{d x^{2}}=m^{2} \cdot \theta_{a, \text { dry_fp }}
$$

where $\theta_{a, \text { dry_f }}$ is the temperature difference between the air and dry fin portion.

The general solution of Equation (1.28) is 


$$
\theta_{a, \text { dry_fp }_{\mathrm{fp}}}(y)=C_{3} \cdot e^{m y}+C_{4} \cdot e^{-m y}
$$

The boundary conditions subjected to Equation (1.29) are as follows:

$$
\begin{aligned}
& \theta_{a, \text { dry_fp }}=\theta_{a, d p}=T_{a}-T_{d p} \text { at } y=\zeta \\
& \frac{d \theta_{a, \text { dry_fp }}}{d y}=0 \text { at } y=H_{f}
\end{aligned}
$$

Solving Equation (1.29) with corresponding boundary conditions, the temperature distribution of dry fin portion is obtained

$$
\theta_{a, \text { dry_fp }}=\theta_{a, d p} \cdot \frac{\cosh \left[m\left(H_{f}-y\right)\right]}{\cosh \left[m\left(H_{f}-\zeta\right)\right]}
$$

The heat transfer by convection to the dry fin surface is given by

$$
Q_{\text {dry_fp }}=-k_{f} \cdot A c_{f}\left(\frac{d \theta_{a, \text { dry_fp }}}{d y}\right)_{y=\zeta}=k_{f} \cdot A_{c, f} \cdot m \cdot \theta_{a, d p} \cdot \tanh \left[m\left(H_{f}-\zeta\right)\right]
$$

and the maximum heat transfer rate is

$$
\begin{gathered}
Q_{\text {dry_fp,max }}=\alpha_{a} \cdot P_{f}\left(H_{f}-\zeta\right) \theta_{a, f B}+\alpha_{D} \cdot P_{f}\left(H_{f}-\zeta\right)\left(W_{a}-W_{\text {sat }, f B}\right) h_{f g} \\
=\alpha_{a} \cdot P_{f}\left(H_{f}-\zeta\right)\left(1+\beta \cdot b_{f}\right)\left(\theta_{a, f B}+\psi\right)
\end{gathered}
$$

This maximum heat transfer rate includes both the sensible and latent heat transfer components, since it is defined as the heat transfer rate that would exist if the dry region of the fin were at the fin base temperature, and the fin base temperature is below the dew point of the air for the partially wet fin. Thus, the dry fin portion efficiency becomes:

$$
\eta_{\text {dry_fp }}=\frac{Q_{\text {dry_fp }}}{Q_{\text {dry_fp,max }}}
$$


Chapter 1.

b) Wet fin portion analysis $(0 \leq y \leq \zeta)$

The dual potential model is used as discussed before to analyze the simultaneous heat and mass transfer for wet fin portion. The boundary conditions for wet portion are:

$\theta_{a, \text { wet_fp }}=\theta_{a, f B}=T_{a}-T_{f B}$ at $y=0$

$\left.\frac{d \theta_{a, \text { dry_fp }}}{d y}\right|_{y=\zeta^{+}}=\left.\frac{d \theta_{a, \text { wet_fp }}}{d y}\right|_{y=\zeta^{-}}$

After substituting the previous boundary conditions into the general solution of wet fin (Equation 1.26) the temperature distribution of wet portion could now be illustrated as:

$$
\begin{gathered}
\theta_{a, \text { wet_fp }}(y)=\left(\theta_{a, f B}+\psi\right) e^{M y}- \\
{\left[\frac{\left(\frac{m}{M}\right) \theta_{a, d p} \cdot \tanh \left[m\left(H_{f}-\zeta\right)\right]+\left(\theta_{a, f B}+\psi\right) e^{M \zeta}}{\cosh (M \zeta)}\right] \sinh (M y)-\psi}
\end{gathered}
$$

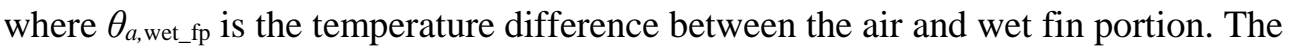
quantity $\zeta$ is unknown; then it is assumed at the beginning of solution and accordingly the temperature of the fin surface could be calculated from Equation (1.38). If the obtained fin surface temperature is not equal to the dew point of air, an iterative procedure is used till obtaining a proper value of $\zeta$ which satisfies the condition of continuity of heat flow at the point separating the dry and wet portions.

The total heat transfer from the wet portion of the fin surface can be calculated from

$$
\begin{aligned}
Q_{\text {wet_fp }}= & \left.\int_{0}^{\zeta} \alpha_{a} \cdot P_{f} \cdot \theta_{a, \text { wet_fp }}(y) \cdot d y\right|_{\text {sensible heat }}+ \\
& \left.\int_{0}^{\zeta} \alpha_{D} \cdot P_{f}\left[W_{a}-W_{\text {sat,wet_fp }}(y)\right] h_{f g} \cdot d y\right|_{\text {latent heat }}
\end{aligned}
$$

By applying Chilton-Colburn analogy (Equation 1.8) and dual potential model assumptions, Equation (1.39) can now be reduced to the following expression: 


$$
Q_{\text {wet_fp }}=\alpha_{a} \cdot P_{f}\left(1+\beta \cdot b_{f}\right) \int_{0}^{\zeta}\left(\theta_{a, \text { wet_fp }}+\psi\right) \cdot d y
$$

The maximum total heat transfer rate that would exist if the wet region were at the fin base temperature may be expressed as:

$$
\begin{aligned}
Q_{\text {wet_fp,max }} & =\alpha_{a} \cdot P_{f} \cdot \zeta \cdot \theta_{a, f B}+\alpha_{D} \cdot P_{f} \cdot \zeta\left(W-W_{\text {sat }, f B}\right) h_{f g} \\
& =\alpha_{a} \cdot P_{f} \cdot \zeta\left(1+\beta \cdot b_{f}\right)\left(\theta_{a, f B}+\psi\right)
\end{aligned}
$$

The efficiency of wet fin portion becomes

$$
\eta_{\text {wet_fp }}=\frac{Q_{\text {wet_fp }}}{Q_{\text {wet_fp,max }}}
$$

Finally, the partially wet fin efficiency can be calculated as:

$$
\eta_{f, \text { part_wet }}=\frac{\zeta}{H_{f}} \eta_{\text {wet_fp }}+\frac{H_{f}-\zeta}{H_{f}} \eta_{\text {dry_fp }}
$$

\subsection{Literature Review}

\subsubsection{Heat exchanger modeling}

Computer models and simulation tools have been developed for heat exchanger design and optimization since the 1980s, with increasing the complexity of calculation procedure and coil details, and range of working fluids. These tools aim to save much the cost and time in the laboratory working with expensive test benches.

To allow for good and accurate modeling of the heat exchangers, a discretization process is required. The tubes of the heat exchanger are divided into a number of segments, usually along the refrigerant flow direction, with its corresponding fins. Each segment represents an individual heat exchanger which could be evaluated by classical global methods; i.e., the logarithmic mean temperature difference (LMTD) method, logarithmic mean enthalpy difference (LMHD) method, effectiveness-number of transfer units ( $\varepsilon-\mathrm{NTU}$ ) method, and so on. But, on the other hand, those segments could be additionally discretized into a number of cells using finite volume method (FVM) or finite element method (FEM). For each cell heat and mass balances are implemented. 
Chapter 1.

Currently, several models or simulation tools for heat exchangers are available in the literature: for finned conventional-tubes (Domanski, 1991; Ragazzi, 1995; Lee and Domanski, 1997; Corberán et al., 2002; Jiang et al., 2006; Singh et al., 2008; CoilDesigner, 2010; EVAP-COND, 2010; IMST-ART, 2010) and for micro/minichannel heat exchangers (Kim and Bullard, 2001; Yin et al., 2001; Wu and Webb, 2002; Asinari et al., 2004; Fernando et al., 2008; Brix et al., 2009; García-Cascales et al., 2010; Jin et al., 2011; Martínez-Ballester, 2012; Zhao et al., 2012; Gossard et al., 2013; Ren et al., 2013; Huang et al., 2014; Huang et al., 2015; Yin et al., 2015).

Some of the above mentioned models (Kim and Bullard, 2001; Yin et al., 2001; Corberán et al., 2002; Asinari et al., 2004; Fernando et al., 2008; Singh et al., 2008; Brix et al., 2009; CoilDesigner, 2010; IMST-ART, 2010; Jin et al., 2011; MartínezBallester, 2012; Ren et al., 2013; Huang et al., 2014; Huang et al., 2015) apply the energy conservation equations to each control volume or finite element, while others (Domanski, 1991; Ragazzi, 1995; Lee and Domanski, 1997; Wu and Webb, 2002; Jiang et al., 2006; EVAP-COND, 2010; García-Cascales et al., 2010; Zhao et al., 2012; Gossard et al., 2013; Yin et al., 2015) apply the classical $\varepsilon$-NTU method. The main difference between both methodologies is that the $\varepsilon$-NTU method uses several implicit assumptions resulting in less freedom to describe the actual phenomena, especially at a presence of the dehumidification process on the air-side of the evaporator.

The commonly used assumptions and their impacts on the air-side performance of heat exchangers are discussed next.

\subsubsection{Impacts of the classical modeling assumptions on the performance of heat exchangers}

As mentioned before that the $\varepsilon$-NTU approach and fin theory are based on many assumptions which are usually adopted to reduce the complexity of the solution. But, these assumptions neglect, or simplify, many of important phenomena encountered in the process of heat and mass transfer. Those classical assumptions are not only adopted by heat exchanger models which are based on the $\varepsilon$-NTU approach, but they are also employed by many other models which do not use the $\varepsilon$-NTU methodology.

The most important assumptions, which are in the scope of the current work, are the following: 
Introduction and Mathematical Background

\section{- Uniform properties along air flow direction}

In most models in the literature, the heat exchanger tubes are discretized only in the refrigerant direction. This methodology only improves the representation of the refrigerant properties. However, the lack of discretization in the air flow direction results to approximated air properties for the heat exchanger depth based on the average of the inlet and outlet temperatures.

- Adiabatic-fin-tip assumption at half the height: no heat conduction between tubes through the fin

This assumption is usually adopted by the classical modeling methods in order to use the corresponding relationship for the fin efficiency. It is a quite simple expression, but this efficiency does not fundamentally account for the heat transfer via fins between the tubes of different temperatures. Many authors developed detailed numerical models to study the effect of this assumption on the performance of gas coolers and condensers. For example, Asinari et al. (2004) implemented a three-dimensional (3D) numerical model to simulate the crossflow in compact heat exchangers using finned flat tubes with internal microchannels. Their model discretizes the governing equations using a finite-volume and finite-element hybrid technique taking into account the heat conduction in all directions for all elements (fins and tubes), thus it does not employ the adiabatic-fin-tip assumption.

Asinari et al. (2004) concluded that the models using the half-fin length idealization, although do not accurately represent the real distribution of heat flow between the fin roots when the temperatures at the fin bases are different, give a reasonably accurate prediction of the total heat flow exchanged. Another study was implemented by Yin et al. (2015), in which a finite-volume-based numerical condenser model was presented. This model accounts for many important factors which affect the predicted capacity of heat exchangers, where the heat conduction through the fin is one of them. Their final conclusion is similar to Asinari et al. (2004), they found that the transverse fin conduction slightly influences the overall capacity by $\approx 0.06 \%$, and pressure drop by $\approx 0.16 \%$.

However, the previous authors did not report the effects of this assumption in the predicted capacity for the individual tubes of the heat exchanger. It is important to note that a consequence of a wrong prediction of the individual tube capacity introduces a wrong evaluation of the fluid temperature and pressure at the tube outlet section. So to study the impact of adiabatic-fin-tip assumption, besides some other 
Chapter 1.

classical assumptions, on the capacity of the individual tubes of a minichannel $\mathrm{CO}_{2}$ gas cooler, Martínez-Ballester et al. (2011) developed a segment-by-segment 2D model. The model discretized the heat exchanger into segments and cells, to which a system of energy conservation equations was applied without traditional heat exchanger modeling assumptions. Their model is not only capable of evaluating the heat conduction in all wall elements as the model of Asinari et al. (2004), but it also accounts for the change in air temperature along the fin height. This makes it capable of capturing a detailed representation of the air flow. They concluded that using the adiabatic-fin-tip efficiency leads to large errors in heat distribution per tube when a temperature difference between the tubes exists. Also, this assumption affects the global capacity prediction of gas coolers with a large number of refrigerant passes.

Some authors have implemented the heat conduction through the fin in their models for finned-tube heat exchangers. Lee and Domanski (1997) presented a tube-by-tube heat exchanger model. They accounted for this phenomenon by adding an additional conduction term in the $\varepsilon$-NTU relation. By using wall temperatures of the neighboring tubes and applying Fourier's law of conduction for a rectangular slab, they obtained the heat conducted into or out of given control volume. However Singh et al. (2008) stated that the $\varepsilon$-NTU approach, in its development, ignores any heat flux coming in or leaving the control volume besides the two fluid streams. Consequently, they developed a thermal resistance model which combines the fin temperature with wall temperature through the use of fin efficiency. This ensures that the numerical model represents the physics more accurately than the $\varepsilon$-NTU model. Afterward, they added a heat conduction term to the energy conservation equation in the tube wall. To get accurate results, they also applied to this term a multiplier which has to be adjusted either numerically or experimentally.

It is quite interesting to mention that cutting the fins between tubes for air-to-refrigerant heat exchangers is considered to be an improvement in heat exchanger performance. The heat conduction along the fin height significantly degrades the effectiveness of heat exchanger. Domanski et al. (2007) implemented a comparative experimental study between a finned conventional-tube evaporator with and without cut fins. They reported that the evaporator with cut fins had a significantly higher capacity, as much as $23 \%$, compared to the same evaporator without cut fins, especially for high exit superheats. For $\mathrm{CO}_{2}$ gas coolers Singh et al. (2010) reported a heat load gain of up to $12 \%$ with cut fins; and, for a target heat load, savings in fin material of up to $40 \%$. 
Introduction and Mathematical Background

However, this improvement does not have a such significant effect on the performance of MCHXs. As mentioned before Asinari et al. (2004) concluded that the impact of cut fins could be assumed to be negligible for a wide range of MCHXs applications. Experimentally, Park and Hrnjak (2007) found that the capacity of a microchannel $\mathrm{CO}_{2}$ gas cooler was improved up to $3.9 \%$ by cutting the fins, and the temperature difference between refrigerant exit and air inlet for the gas cooler was reduced by $0.9-1.5^{\circ} \mathrm{C}$.

\section{- One-dimensional heat conduction in tubes and fins}

The one-dimensional heat conduction assumption only accounts for transverse heat flux through the wall between two fluids. It does not account for two-dimensional longitudinal heat conduction (2D LHC) in the tube and fin.

Asinari et al. (2004) and Martínez-Ballester et al. (2011) studied the effects of this assumption in their previously mentioned models. The authors reported that the longitudinal conduction in fins had a negligible effect on the heat exchanger capacity. Also, several current fin surfaces (e.g. louvered, slit, etc.) have cuts along the air flow direction which cancel the LHC in that direction. Contrary to Asinari et al. (2004) who concluded that the effects of the transverse and longitudinal heat conductions in the tubes could also be neglected; Martínez-Ballester et al. (2011) reported that these effects result to a small error in heat capacity with an order of $2.5 \%$, when they are combined with the longitudinal conduction in the fin. Martínez-Ballester et al. (2011) also concluded that the impact of LHC strongly depends on the air-side heat transfer coefficient.

- Uniform air temperature along the fin height: application of the fin theory

The $\varepsilon$-NTU method needs the use of fin efficiency in order to get a solution of heat transfer through any heat exchanger (Kays and London, 1984). This efficiency is calculated following the fin theory, which is developed assuming a uniform temperature for surrounding air in contact with the fin. Martínez-Ballester et al. (2011), and Martínez-Ballester et al. (2013a) and (2013b) studied extensively the effect of this assumption on the air-side performance of minichannel condensers and $\mathrm{CO}_{2}$ gas coolers. They reported in their study that the temperature of air close to the tube wall is much different from the bulk air temperature. This fact could have an important impact on local mechanisms controlling the heat and mass transfer, e.g. dehumidification. 
Chapter 1.

However, presence of dehumidification process while modeling minichannel evaporators results to more assumptions such as:

\section{- Uniform humidity ratio along the fin height}

As mentioned earlier, the fin theory is based on the assumption of uniform air temperature along the fin height. This implies that the humidity ratio of the air is also uniform in the same direction. This assumption could result to a misprediction of the latent heat transferred, especially for the air near the fin roots.

\section{- No consideration of partial dehumidification scenarios}

Many evaporator models in literature, such as Kim and Bullard (2001), Wu and Webb (2002), Jiang et al. (2006), Jin et al. (2011), and Zhao et al. (2012), do not account for partial dehumidification scenarios. They usually assume that the whole evaluated segment is totally dry or totally wet according to the tube temperature or average temperature of tube and fin. However, as explained in Sub-section 1.4.2, the fin performance is dramatically influenced by the amount of water condensed on the surface, especially in the partially wet fin region. Accordingly, we can conclude that the misprediction of the actual dehumidifying condition of the fin (totally dry, totally wet, or partially wet fin) could obviously affect the sensible and latent heat transfer in evaporators.

\section{- Constant saturation line slope within the whole segment}

To solve the wet fin differential equation (Equation 1.12) a proper relationship between the saturated air humidity ratio and the corresponding surface temperature is required. Many of evaporator models (Ragazzi, 1995; Jiang, 2003; Huang et al., 2015) employ the McQuiston's constant (Equation 1.19) within the whole evaluated evaporator segment. This constant is usually evaluated at the fin base condition or calculated as an average value between fin base and tip conditions (Mirth and Ramadhyani, 1993). This constant is very simple and converts the wet fin equation to a linear homogeneous differential equation which has a general solution quite similar to the dry fin. However, this methodology does not represent the actual physical behavior of saturated humidity ratio on the psychrometric chart (Chapter 6, Figure 6.1). Moreover, calculating this constant as an average value between base and tip temperatures for a partially wet fin is physically inappropriate because under this situation one of the fin roots temperatures is higher than the dew point of surrounding air. 
Introduction and Mathematical Background

To overcome these drawbacks, and to give a better representation of saturation curve on psychrometric chart, many authors suggested a linear relationship (Equation 1.20) between saturated humidity ratio and corresponding surface temperature such as Elmahdy and Biggs (1983), Wu and Bong (1994), and Sharqawy and Zubair (2007) and (2008). Some others (Coney et al., 1989c; Chen, 1991) suggested a quadratic relationship. In addition to Liang et al. (2000) who proposed a more complicated cubic relationship in his plate-fin-tube heat exchanger model.

The quadratic and cubic relationships are more accurate than the linear relationship. However, they convert the fin governing equation to a nonlinear nonhomogeneous differential equation. This type of equations requires special and complicated numerical methods, such as Adomian decomposition method (ADM), to get a proper solution (Kundu 2009). On the other hand, the linear relationship is more common and represents a convenient way to solve the wet fin differential equation. For the mentioned reasons, in the current work the linear approximation of saturation curve is employed.

\subsection{Research Motivations}

The main motivations of the current work are based on the following:

- Micro/Minichannel technology is relatively new. It has been employed since while in the automotive applications. However because of its many advantages, this technology now begins to but feet in all HVAC\&R applications.

- The implementation of minichannels in evaporators lagged behind the condenser application because of many problems and concerns, such as the instability of refrigerant flow, accumulation of condensed water, and frosting.

- Many heat exchanger models in literature utilize the classical modeling methods which based on many implicit assumptions. Although these assumptions simplify the modeling process, however, they have many drawbacks as discussed before.

- There are many authors (Asinari et al., 2004; Martínez-Ballester et al., 2011; Yin et al., 2015) who evaluated extensively the effect of the classical modeling assumptions on the air-side performance of minichannel gas coolers and condensers. However, from the literature review, the author have not found any model which is capable of assessing the impact of these assumptions on the air-side performance of minichannel evaporators, especially under different dehumidifying conditions. 
Chapter 1.

- The need to develop an accurate and reliable simulation tool for MCHXs, especially evaporators, to aid their design and save the cost of experimental campaigns.

\section{$1.7 \quad$ Research Objectives}

Based on the previous motivations, the following points summarize the main objectives of the current thesis:

- To develop and verify a comprehensive two-dimensional model (Fin2D-W) for the air-side analysis of minichannel evaporators. This model will take into account the 2D heat conduction in any wall element (fin or tube), partial dehumidification scenarios, change in the saturation line slope, and unmixed air along the fin height.

- To develop and verify a more simplified one-dimensional model (Fin1D-MB). This model will retain only the most important heat and mass transfer phenomena, which will be identified by the Fin2D-W model, in order to reduce the computational time while maintaining the solution accuracy.

- To integrate the Fin1D-MB air-side module in the IMST-ART ${ }^{\circledR}$ simulation program (IMST-ART, 2010) to evaluate the total performance of minichannel evaporators (air- and refrigerant-side).

- To validate the numerical results of the IMST-ART ${ }^{\circledR}$ program against experimental data and numerical models that already existed in the literature for different MCHX geometries, refrigerants, and operating conditions.

\subsection{Thesis Organization}

The current chapter (Chapter 1) firstly presents a brief introduction of MCHXs, and their advantages and disadvantages; then introduces a mathematical analysis of the modeling of simultaneous heat and mass transfer. Finally, it reviews the state of the art related to the scope of current work and lists the motivations and objectives of the presented thesis.

In order to achieve the objectives of the present thesis two numerical models which account for the air-side performance of minichannel evaporator are going to be developed and verified. Chapter 2 presents the first model, which is referred to as Fin2D-W. This model is used to evaluate, in a more fundamental way, all the proposed effects and assumptions, along with their impacts on the predicted heat and 
Introduction and Mathematical Background

mass transfer rates. Chapter 2 consists of the governing equations and their numerical discretization scheme, case study, verification study, and a comparison of the airside heat transfer results between the classical $\varepsilon$-NTU and Fin2D-W models, without and with the presence of temperature difference (superheat) between the evaporator tubes.

According to the results and conclusions of Chapter 2 and in order to reduce the modeling complexity and computational cost, a more simplified model which is referred to as Fin1D-MB is introduced in Chapter 3. The novelty of this model that it employs the fundamental fin theory coupled with the moving boundaries technique for the air-side. This scheme simplifies the discretization of air flow and fin wall, and captures the actual dehumidifying condition for tubes and fins. The main contents of this chapter are: the governing equations, discretization scheme, solution methodology, verification study, and a comparative study between the Fin1D-MB and Fin2D-W results.

In order to evaluate the whole minichannel evaporator, the Fin1D-MB model has to be integrated into the IMST-ART ${ }^{\circledR}$ simulation program. After the integration process, the proposed numerical model will be validated against experimental data and numerical models existed in the literature. The complete results of this study are presented in Chapter 4.

Chapter 5 comprises the main conclusions and list of publications related to the current thesis. The future modifications and enhancements for the presented work are introduced in the final section of this chapter.

The last chapter of the thesis (Chapter 6 ) contains the appendices. The first appendix is dedicated to the psychrometric relationships and correlations used in the current work, while, the second one describes the $\mathrm{C}++$ modeling structure for the Fin2D-W and Fin1D-MB models. The third appendix contains the elements of matrix B, which is used to calculate the average fin temperature in the Fin1D-MB model (Chapter 3, Equation 3.19). 



\section{Chapter 2.}

\section{Fin2D-W Model}

"Only those who riskgoing too far can possibly find out how far they can go"

-T.S. Elliot 
Chapter 2.

\subsection{Introduction}

In this chapter, a fundamental numerical approach to minichannel evaporator modeling under dehumidifying conditions is presented. This numerical approach takes into account the 2D heat conduction in any wall element (tube or fin) and partial dehumidification scenarios, does not apply the fin theory, and captures a detailed representation of air properties. The model, referred to as Fin2D-W, subdivides the heat exchanger into segments and cells (air, refrigerant, fin wall, and tube wall), to which a system of energy conservation equations is applied without traditional heat exchanger modeling assumptions. Unlike the models previously presented in Chapter 1, the Fin2D-W model employs less classical assumptions.

From the literature review, we did not locate any model similar to the current one, especially for evaporators which operate under partially wet conditions. There are two similar models, but they were mainly developed for minichannel gas coolers and condensers. The first model was presented by Asinari et al. (2004) for simulating a fully three-dimensional crossflow in compact transcritical $\mathrm{CO}_{2}$ gas coolers. However, they used a hybrid discretization scheme, which uses both the finite element and the finite volume methods. The second model, which the current model is based on, was developed by Martínez-Ballester et al. (2011) to simulate the heat transfer in minichannel $\mathrm{CO}_{2}$ gas coolers and condensers. Their $2 \mathrm{D}$ model, which is based on the finite volume discretization method, is the most similar to the present model.

After a numerical verification, a comparative study is conducted between the current model results and the results of the traditional $\varepsilon$-NTU method based on two different models of simultaneous heat and mass transfer (single and dual potential models). Different refrigeration and air conditioning applications have been selected which represent various inlet conditions to the evaporator. The main goals of the present chapter are:

- to understand the various phenomena, and heat and mass transfer mechanisms associated with the process of cooling and dehumidification;

- to assess the impact of some classical modeling assumptions, which are usually used in the modeling of heat exchangers, in the air-side performance of minichannel evaporators under different dehumidifying conditions and values of superheat;

- to identify which assumptions and phenomena have the greatest influence and which have a negligible effect on the modeling of minichannel evaporators. 
This will help in developing a simpler model, with higher calculation speed and reasonable accuracy compared to the Fin2D-W model.

\subsection{Development of the Fin2D-W Model}

\subsubsection{Evaporator discretization}

(a)

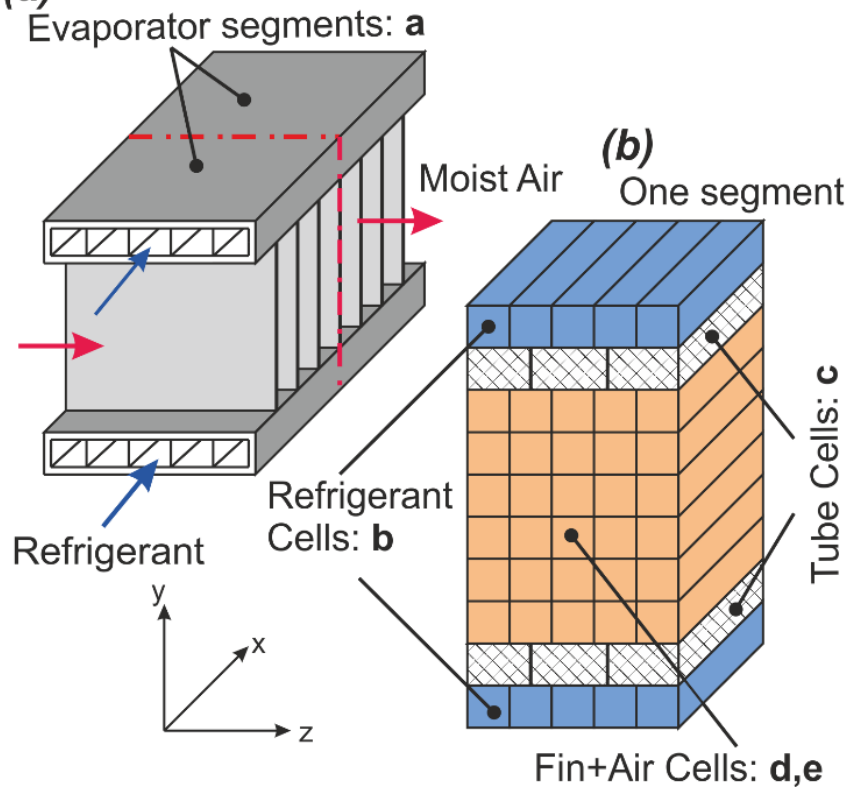

Figure 2.1. (a) Main discretization of tubes in minichannel evaporator. (b) General concept of discretization in one evaporator segment.

Figure 2.1 $a$ presents the main scheme used to discretize tubes in a minichannel evaporator. The tubes are discretized along the $x$-direction (refrigerant flow) in a number of segments "a". Each segment (Figure $2.1 b$ ) consists of two streams of refrigerant (top and bottom flow) that are split into " $b$ " channels in the $z$-direction (air flow); two flat tubes (top and bottom) that are discretized into "c" cells in the $z$-direction. Both air flow and fins are discretized into two dimensions: "d" cells in the $y$-direction and "e" cells in the $z$-direction. This is summarized in the context as a grid: $\{\mathrm{a}, \mathrm{b}, \mathrm{c}, \mathrm{d}, \mathrm{e}\}$. For the illustration in nomenclature, the numerical example shown in Figure 2.1 corresponds to a grid of $\{2,5,3,6,5\}$. But, the actual discretization grid used in the current study is defined later in Section 2.6. 
Chapter 2.

All grid dimensions are independent, with the only exception being that the air and fin have the same discretization. The heat is transferred by convection from the moist air cells to the fin cells, as well as, to the unfinned area of the tube wall in contact at the top and bottom. Then the fin cells conduct the heat along the $y-z$ plane and also to the wall cells in contact with the fin roots. The tube cells exchange the heat by conduction between each other in the $x-z$ plane and transfer it by convection to the refrigerant cells.

\subsubsection{Governing equations}

In this section, the mathematical analysis of the governing differential equations and the corresponding boundary conditions are established. The dual potential method, proposed by McQuiston (1975), is adopted in the combined heat and mass transfer modeling because of many advantages as discussed in Chapter 1, Sub-section 1.4.1. Finally, the numerical discretization of the governing equations is presented.

\subsubsection{Mathematical analysis}

The following assumptions are made to simplify the analysis:

a) the thermal conductivity of the fin and tube walls, and latent heat of condensation of the water vapor are constant;

b) the fluids flow is steady with uniform inlet velocity distribution;

c) the thermal resistance associated with the presence of thin water film due to condensation is small and may be neglected; and

d) the effect of pressure drop due to fluids flow is neglected.

a) Wall (fin or tube) analysis

Figure 2.2 shows the energy balance within a differential control volume of the fin wall under steady-state condition. Where (the rate of heat conduction at $y, z)+($ the heat generated $)=($ the rate of heat conduction at $y+\mathrm{d} y, z+\mathrm{d} z)$. It should be noted that the energy balance for the tube wall element is similar to the fin wall element, however, it is applied on the $x-z$ plane instead of the $y-z$ plane. 


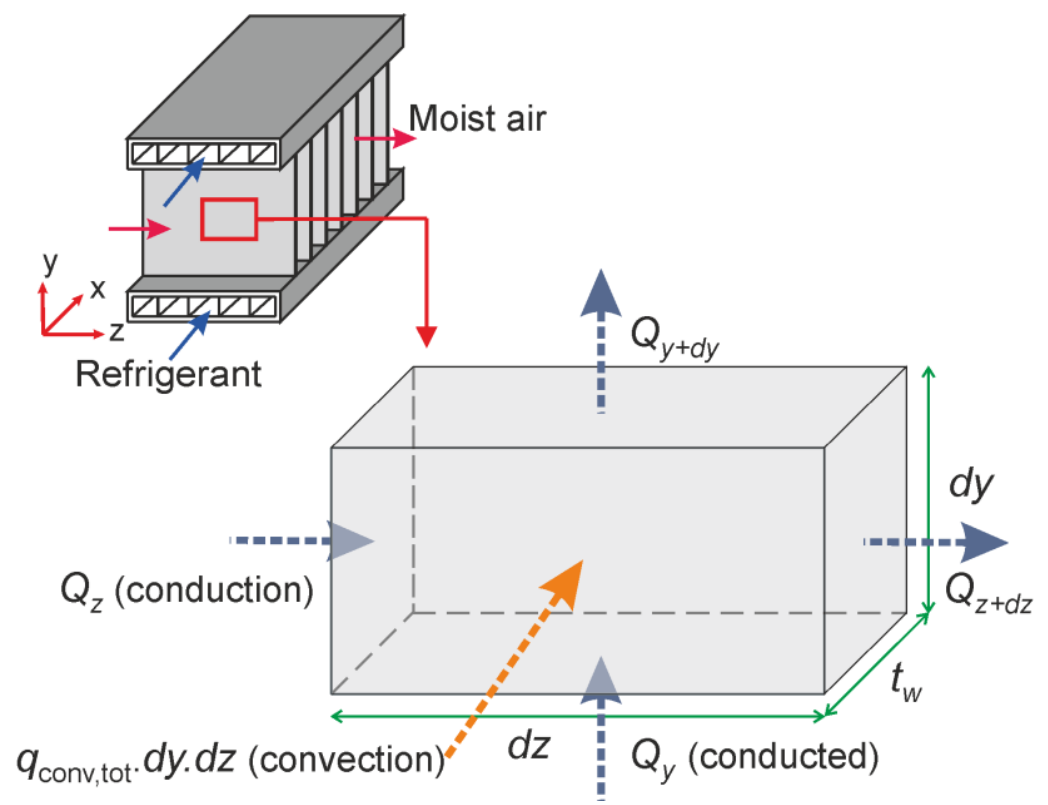

Figure 2.2. Energy balance of a differential control volume of the fin wall.

$$
\left[Q_{z}+Q_{y}\right]+q_{\mathrm{tot}} \cdot d z \cdot d y=\left[\left(Q_{z}+\frac{\partial Q_{z}}{\partial z} d z\right)+\left(Q_{y}+\frac{\partial Q_{y}}{\partial y} d y\right)\right]
$$

where $(d z \cdot d y)$ represents the element face area. Rearranging Equation (2.1) yields to

$$
-\frac{\partial Q_{z}}{\partial z} d z-\frac{\partial Q_{y}}{\partial y} d y+q_{\mathrm{tot}} \cdot d z \cdot d y=0
$$

The conduction heat rates through an isotropic material may be evaluated from Fourier's law

$$
\begin{aligned}
& Q_{z}=-k_{w} \cdot d y \cdot t_{w} \cdot \frac{\partial T_{c}}{\partial z} \\
& Q_{y}=-k_{w} \cdot d z \cdot t_{w} \cdot \frac{\partial T_{c}}{\partial y}
\end{aligned}
$$

where $k_{w}$ and $t_{w}$ are the thermal conductivity and thickness of the wall control volume, respectively. $T_{c}$ is the temperature of wall element evaluated at the centroid. 
Chapter 2.

Substituting Equations (2.3) and (2.4) into Equation (2.2) and dividing out the element face area $(d z \cdot d y)$, we obtain

$$
\frac{\partial}{\partial z}\left(k_{w} \cdot t_{w} \cdot \frac{\partial T_{c}}{\partial z}\right)+\frac{\partial}{\partial y}\left(k_{w} \cdot t_{w} \cdot \frac{\partial T_{c}}{\partial y}\right)+q_{\mathrm{tot}}=0
$$

The third term $\left(q_{\mathrm{tot}}\right)$ in Equation (2.5) represents the total heat flux from/into the centroid of wall element. The evaluation of this term differs depending on the type of fluid (moist air or refrigerant).

For the evaporators which operate under dehumidifying conditions, the total convection heat flux from moist air to the wall element surface is the summation of sensible heat flux due to temperature difference of moist air and wall surface; and the latent heat flux due to the humidity ratio difference between the flowing air stream and the saturated air at the wall surface, as it can be seen in Figure 2.3.

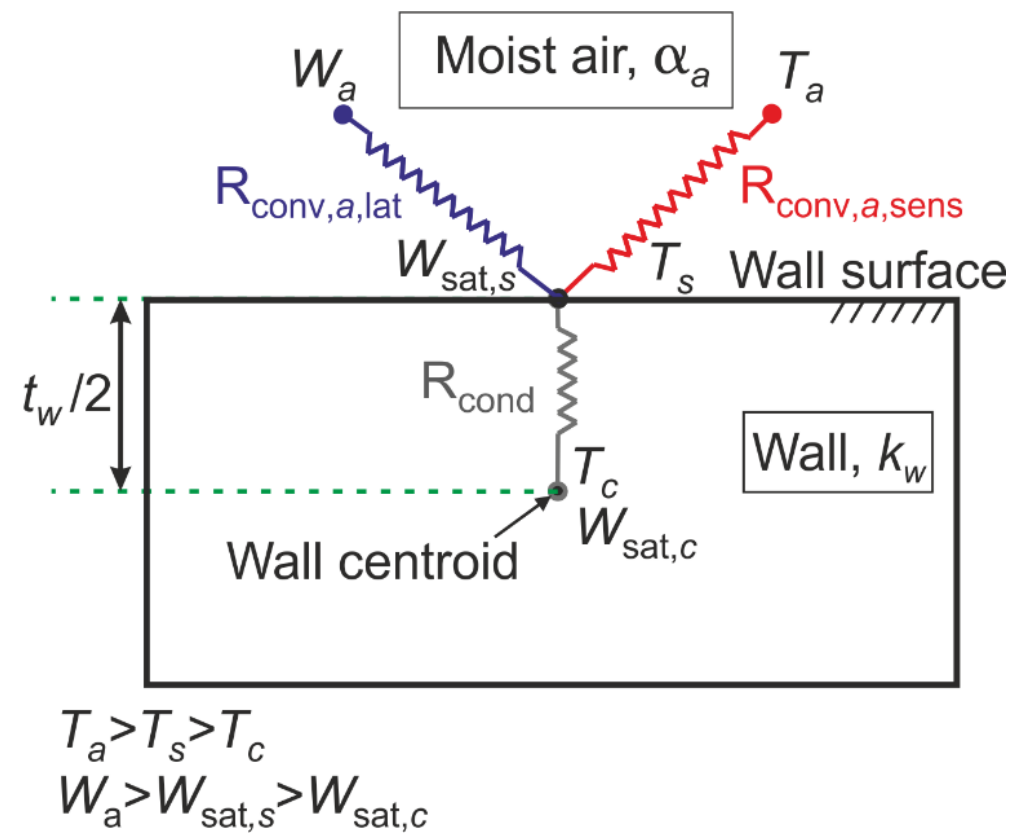

Figure 2.3. Equivalent thermal resistance between the moist air and the wall element.

The total heat flux for air-side $q_{\mathrm{tot}, a}$ is given by

$$
q_{\mathrm{tot}, a}=q_{\mathrm{cond}}=q_{\mathrm{conv}, a, \mathrm{tot}}=q_{\mathrm{conv}, a, \mathrm{sens}}+q_{\mathrm{conv}, a, \mathrm{lat}}
$$


where the conduction heat flux across the half thickness of the wall element is equal to

$$
q_{\text {cond }}=k_{w} \cdot \frac{T_{s}-T_{c}}{t_{w} / 2} \Rightarrow \mathrm{R}_{\text {cond }}=\frac{t_{w} / 2}{k_{w}}
$$

The total convection heat transfer rate is expressed by Equation (1.9). However, to simplify this equation, Sharqawy and Zubair (2008) proposed a linearization scheme for the saturated humidity ratio (Equation 1.22). Substituting Equation (1.22) into Equation (1.9) and dividing out the contact surface area, we can obtain

$$
\begin{array}{r}
q_{\mathrm{conv}, a, \text { tot }}=q_{\mathrm{conv}, a, \text { sens }}+q_{\mathrm{conv}, a, \text { lat }}=\alpha_{a}\left(T_{a}-T_{s}\right)+\alpha_{a} \cdot \beta\left(W_{a}-a_{a, s}-b_{a, s} \cdot T_{s}\right) \\
\text { where } \beta=\frac{h_{f g}}{L e^{2 / 3} \cdot C_{p, m a}}, b_{a, s}=\frac{W_{a}-W_{\mathrm{sat}, s}}{T_{d p}-T_{s}} \text {, and } a_{a, s}=W_{\mathrm{sat}, s}-\left(\frac{W_{a}-W_{\mathrm{sat}, s}}{T_{d p}-T_{s}}\right) T_{s} .
\end{array}
$$

Equation (2.8) expresses the total convection heat flux (sensible and latent) from the air to the wall surface. $b_{\mathrm{a}, \mathrm{s}}$ is the slope of saturation line between the air and wall surface.

By rearranging Equation (2.8), we obtain the following expression

$$
q_{\mathrm{conv}, a, \text { tot }}=\alpha_{\mathrm{wet}, a}\left(T_{a}^{*}-T_{s}\right) \Rightarrow \mathrm{R}_{\mathrm{conv}, a, \text { tot }}=\frac{1}{\alpha_{\mathrm{wet}, a}}
$$

where

$$
\begin{array}{ll}
\alpha_{\text {wet }, a}=\alpha_{a}\left(1+\beta \cdot b_{a, s}\right) & \begin{array}{l}
\text { is the total heat transfer coefficient for the air-side under } \\
\text { wet conditions, which accounts for sensible and latent } \\
\text { heat transfer, if there is no dehumidification then } \alpha_{\text {wet }, a} \\
\alpha_{a} ; \text { and }
\end{array} \\
T_{a}^{*}=\frac{T_{a}+\beta\left(W_{a}-a_{a, s}\right)}{1+\beta \cdot b_{a, s}} & \begin{array}{l}
\text { is the modified temperature for moist air, if there is no } \\
\text { dehumidification then } T_{a}^{*}=T_{a} .
\end{array}
\end{array}
$$

From Equations (2.7) and (2.9), the total equivalent thermal resistance between the moist air and the wall element centroid can be evaluated as follows:

$$
\mathrm{R}_{\text {tot }, a}=\mathrm{R}_{\text {cond }}+\mathrm{R}_{\text {conv }, a, \text { tot }}=\frac{t_{w} / 2}{k_{w}}+\frac{1}{\alpha_{\text {wet }, a}}
$$


Chapter 2.

and the final expression for the total heat flux between the moist air and the wall element is

$$
q_{\mathrm{tot}, a}=U_{\mathrm{wet}, a}\left(T_{a}^{*}-T_{c}\right)
$$

where

$$
U_{\text {wet }, a}=\frac{1}{\mathrm{R}_{\mathrm{tot}, a}}=\frac{1}{\frac{t_{w}}{2 \cdot k_{w}}+\frac{1}{\alpha_{\mathrm{wet}, a}}}
$$

is the overall heat transfer coefficient for the airside under wet conditions. It accounts for the total (sensible and latent) convection resistance and the conduction resistance within a half thickness of the wall cell.

A similar expression to that shown in Equation (2.11) is used to evaluate the total heat flux between the refrigerant and the wall element; however, in the refrigerant side only sensible heat flux is found.

$$
q_{\mathrm{tot}, r}=U_{r}\left(T_{r}-T_{c}\right)
$$

where $T_{r}$ is the refrigerant temperature, while $U_{r}=\frac{1}{\mathrm{R}_{\mathrm{tot}, r}}=\frac{1}{\frac{t_{w}}{2 \cdot k_{w}}+\frac{1}{\alpha_{r}}} \begin{aligned} & \text { is the overall heat transfer coefficient for the refrigerant- } \\ & \text { side. It accounts for the sensible convection resistance } \\ & \text { and the conduction resistance within a half thickness of } \\ & \text { the wall cell. } \alpha_{r} \text { is the refrigerant heat transfer coefficient. }\end{aligned}$

\section{b) Moist air analysis}

In the Fin2D-W evaporator model, the air is dehumidified and cooled with decreasing the humidity ratio and dry-bulb temperature, respectively. The mass balance, taking into account the Chilton-Colburn analogy, on the moist air control volume gives:

$$
\frac{\partial W_{a}}{\partial z}=\left\{\begin{array}{l}
\frac{-\alpha_{a} \cdot P_{a, w}}{\dot{m}_{a} \cdot C_{p, m a} \cdot L e^{2 / 3}}\left(W_{a}-W_{\text {sat }, s}\right), \text { if }\left(T_{s}<T_{d p}\right) \\
0, \text { if }\left(T_{s} \geq T_{d p}\right)
\end{array}\right.
$$

where $C_{p, m a}=C_{p, d a}+\left(C_{p, w v} \cdot W_{a}\right)$ 
$P_{a, w}$ is the contact perimeter between the air and corresponding wall element. $C_{p, d a}$ is the specific heat of dry air, while $C_{p, w v} \approx 1860 \mathrm{~J} / \mathrm{kg} \cdot \mathrm{K}$ is the specific heat of water vapor at constant pressure.

While, the heat balance gives

$$
\frac{\partial T_{a}}{\partial z}=\frac{-\alpha_{a} \cdot P_{a, w}}{\dot{m}_{a} \cdot C_{p, m a}}\left(T_{a}-T_{s}\right)
$$

\section{c) Refrigerant analysis}

The heat balance on the refrigerant control volume is evaluated by Equation (2.15), which is quite similar to Equation (2.14); however, the rate of change in refrigerant enthalpy $h_{r}$ is used instead of the rate of change in temperature

$$
\frac{\partial h_{r}}{\partial x}=\frac{-\alpha_{r} \cdot P_{r, w}}{\dot{m}_{r}}\left(T_{r}-T_{s}\right)
$$

where $\dot{m}_{r}$ is the mass flow rate of refrigerant, and $P_{r, w}$ is the contact perimeter between the refrigerant and wall element.

\subsubsection{Boundary conditions}

For solving the previous system of equations a set of boundary conditions is needed. Inlet conditions and velocity distributions are known for air. The wall edges are considered to be adiabatic with the surrounding. Only two tubes of the whole evaporator are going to be modeled in this chapter, so an additional boundary condition is necessary. As a result, the both tubes are assumed to have a symmetry condition, adiabatic-section at half the channel height. This condition implies that the heat transferred from a tube to each of the adjacent tubes is the same.

\subsubsection{Numerical discretization of the governing equations}

The FVM (Patankar, 1980) has been adopted along with the semi-explicit method for wall temperature linked equation (SEWTLE), proposed by Corberán et al. (2001), to discretize the governing equations.

Every fluid cell (refrigerant or air) has two nodes, which correspond to the inlet and the outlet in the fluid flow direction. The wall cells (tube or fin) have only one node located at the centroid of the cell, as shown in Figure 2.4. 
Chapter 2.

All cell's local variables are referred to the value in these nodes; e.g. $T_{i}^{\text {in }}$ and $T_{i}^{\text {out }}$ are the temperature at the inlet and outlet, respectively, of a fluid cell $i$ (refrigerant or air). $T_{c, j}$ is the temperatures of a wall cell $j$ (tube or fin) defined at the centroid.

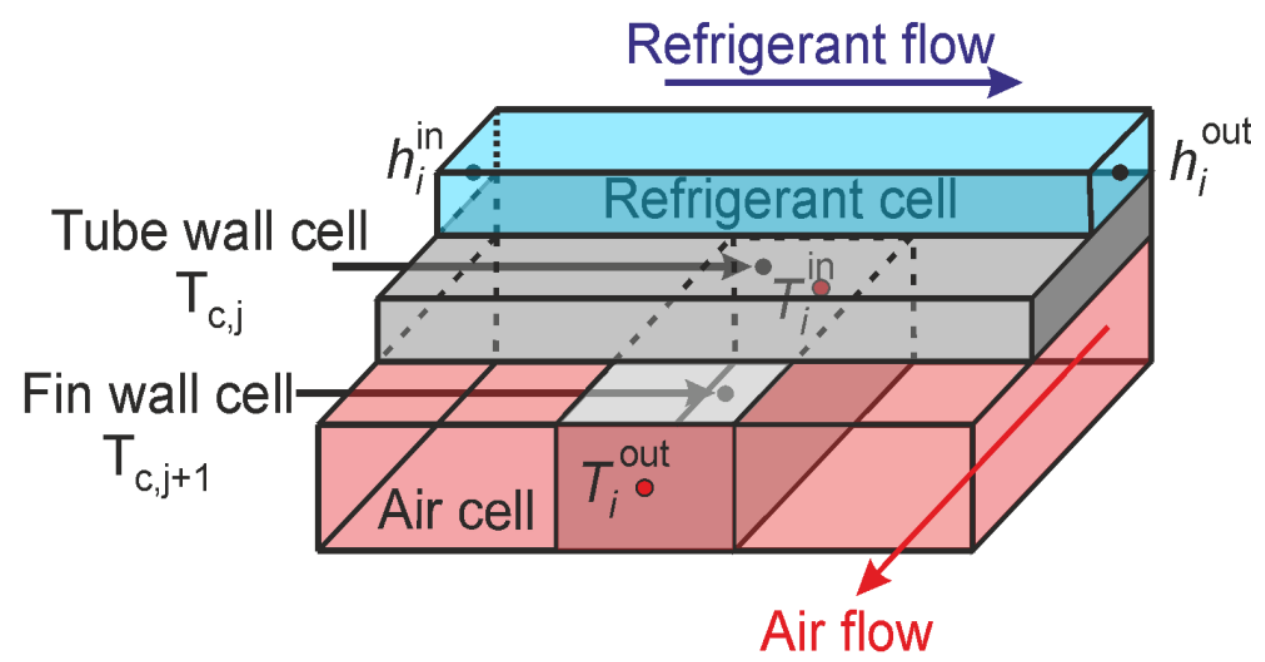

Figure 2.4. Cells schematic and definition of the cell nodes.

The discretization of governing equations does not present any special difficulty, expect for the estimation of the integral of the total heat fluxes into/from the fluids in contact with a considered piece of wall, which are expressed in Equations (2.11) and (2.12). This integration must be consistent with the integrations of the coincident terms of fluid energy and mass balances equations (Equations 2.13, 2.14, and 2.15).

The numerical scheme corresponding to a linear fluid temperature variation (LFTV), as explained in Corberán et al. (2001), is employed for the discretization of the heat and mass transfer terms in the governing Equation. This numerical scheme is basically based on assuming a piecewise distribution of the fluid temperature and humidity ratio (in the case of moist air) along the fluid cell. The discretization of the 2D heat conduction term in Equation (2.5) has been made by the classical finite difference approach according to the adopted FVM.

The final numerical discretization scheme of the governing equations for walls (fin and tube), moist air, and refrigerant are explained next. 


\section{a) Discretization of wall governing equations}

The discretization of Equation (2.5) for any wall cell $(j)$ in contact with $n_{j}$ fluid cells $\left(i=1-n_{j}\right)$ is

$$
\lambda_{j} \cdot T_{c, j}-\lambda_{j-f} \cdot T_{c, f}-\sum_{k=\mathrm{W}, \mathrm{E}, \mathrm{S}, \mathrm{N}} \lambda_{j-k} \cdot T_{c, k}=\sum_{i=1}^{n_{j}} q_{\mathrm{tot}, i j} \cdot P_{i j} \cdot \Delta s_{i j}
$$

where

$$
\begin{aligned}
& \lambda_{j-\mathrm{W}}=\frac{k_{j-\mathrm{W}} \cdot A_{j-\mathrm{W}}}{\delta l_{j-\mathrm{W}}}, \quad \lambda_{j-\mathrm{E}}=\frac{k_{j-\mathrm{E}} \cdot A_{j-\mathrm{E}}}{\delta l_{j-\mathrm{E}}}, \quad \lambda_{j-\mathrm{S}}=\frac{k_{j-\mathrm{S}} \cdot A_{j-\mathrm{S}}}{\delta l_{j-\mathrm{S}}}, \\
& \lambda_{j-\mathrm{N}}=\frac{k_{j-\mathrm{N}} \cdot A_{j-\mathrm{N}}}{\delta l_{j-\mathrm{N}}}, \quad \lambda_{j-f}=\frac{k_{j-f} \cdot A_{j-f}}{\delta l_{j-f}}, \text { and } \lambda_{j}=\sum_{k=\mathrm{W}, \mathrm{E}, \mathrm{S}, \mathrm{N}} \lambda_{j-k} .
\end{aligned}
$$

$\Delta s_{i j}$ is the contact length between the fluid cell $i$ and corresponding wall cell $j$ along the fluid flow direction. All $\lambda_{j-k}$ terms refer to the thermal conductance between the current wall cell $j$ and the adjacent wall cell in the direction $k$. The direction references used in the tube wall cells are different from the directions used in the fin wall cells, the two schematics used in the current model are shown in Figure 2.5. The term $\lambda_{j-f}$ is evaluated only if the current cell $j$ is a tube cell, to account for the heat conduction between the current tube cell and adjacent fin cell.

The total heat flux term (the right-hand-side of Equation 2.16) is evaluated as follows:

$$
q_{\mathrm{tot}, i j}=\left\{\begin{array}{l}
U_{\mathrm{wet}, a, i j}\left(\bar{T}_{i j}^{*}-T_{c, j}\right), \text { if } i \text { is an air cell } \\
U_{r, i j}\left(\bar{T}_{i}-T_{c, j}\right), \text { if } i \text { is a refrigerant cell }
\end{array}\right.
$$

where

$$
\begin{array}{ll}
\bar{T}_{i}=\frac{T_{i}^{\text {in }}+T_{i}^{\text {out }}}{2} & \text { is the average temperature within the fluid cell } i \text {; and } \\
\bar{T}_{i j}^{*}=\frac{\left.T_{i j}^{*}\right|^{\text {in }}+\left.T_{i j}^{*}\right|^{\text {out }}}{2} \quad \begin{array}{l}
\text { is the average modified temperature for moist air, for dry con- } \\
\text { ditions (no dehumidification) } \bar{T}_{i j}^{*}=\bar{T}_{i} .
\end{array}
\end{array}
$$


Chapter 2.

a)

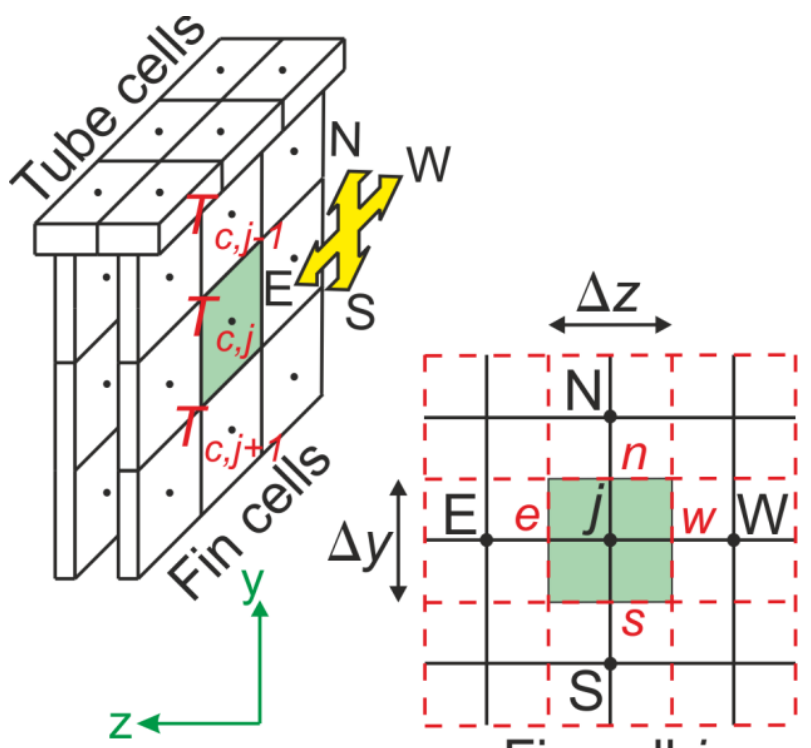

Fin cell $j$

b)

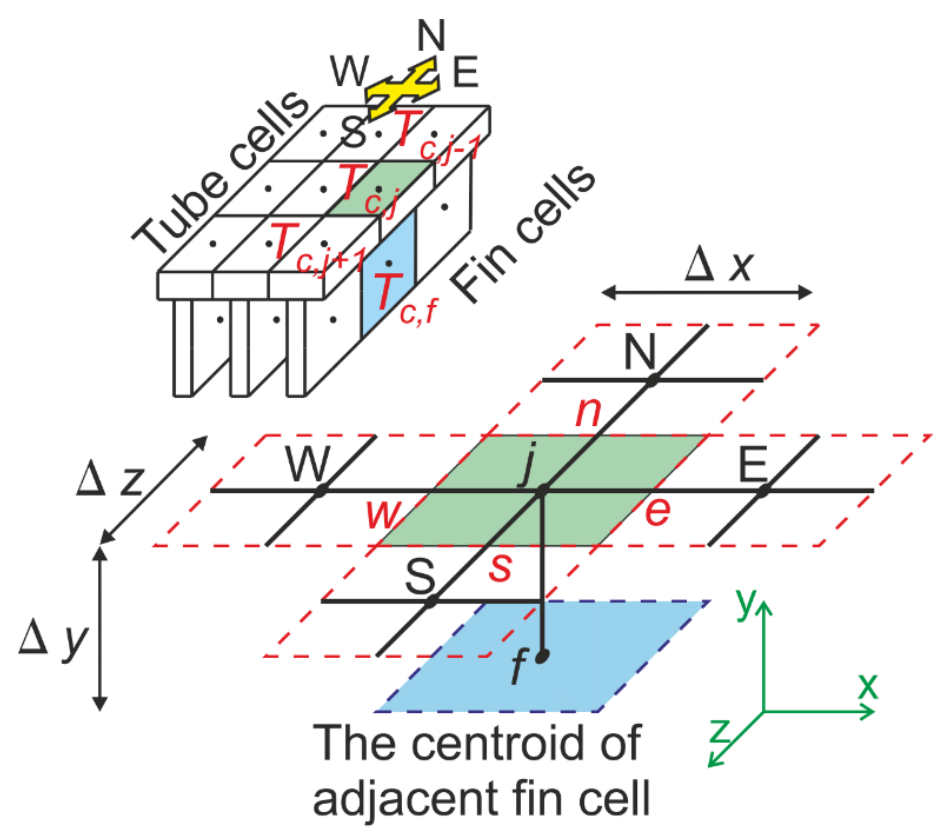

Figure 2.5. Direction references. ( $a$ ) For fin wall cells. (b) For tube wall cells. 


\section{b) Discretization of moist air governing equations}

After discretizing the mass and heat balances equations (Equations 2.13 and 2.14), the outlet air humidity ratio from any air cell $i$ in contact with $n_{i}$ wall cells $\left(j=1, n_{i}\right)$ is expressed as

$$
W_{i}^{\text {out }}=\frac{\left[1-\left(\frac{1}{2} \sum_{j=1}^{n_{i}} \frac{\alpha_{D, i j} \cdot P_{i j}}{\dot{m}_{i}} \cdot \Delta s_{i}\right)\right] \cdot W_{i}^{\text {in }}+W_{\text {sat }, s, j} \cdot \sum_{j=1}^{n_{i}} \frac{\alpha_{D, i j} \cdot P_{i j}}{\dot{m}_{i}} \cdot \Delta s_{i}}{\left[1+\left(\frac{1}{2} \sum_{j=1}^{n_{i}} \frac{\alpha_{D, i j} \cdot P_{i j}}{\dot{m}_{i}} \cdot \Delta s_{i}\right)\right]}
$$

while the outlet air temperature is given by

$$
T_{i}^{\text {out }}=\frac{\left[1-\left(\frac{1}{2} \sum_{j=1}^{n_{i}} \frac{\alpha_{a, i j} \cdot P_{i j}}{\dot{m}_{i} \cdot \bar{C}_{p, m a, i}} \cdot \Delta s_{i}\right)\right] \cdot T_{i}^{\text {in }}+T_{s, j} \cdot \sum_{j=1}^{n_{i}} \frac{\alpha_{a, i j} \cdot P_{i j}}{\dot{m}_{i} \cdot \bar{C}_{p, m a, i}} \cdot \Delta s_{i}}{\left[1+\left(\frac{1}{2} \sum_{j=1}^{n_{i}} \frac{\alpha_{a, i j} \cdot P_{i j}}{\dot{m}_{i} \cdot \bar{C}_{p, m a, i}} \cdot \Delta s_{i}\right)\right]}
$$

c) Discretization of refrigerant governing equations

The discretization of the refrigerant heat balance equation (Equation 2.15) gives

$$
\Delta h_{i}=-\sum_{j=1}^{n_{i}} \frac{\alpha_{r, i j} \cdot P_{i j}}{\dot{m}_{i}}\left(\bar{T}_{i}-T_{s, j}\right) \Delta s_{i}
$$

For the one-phase flow, Equation (2.20) becomes similar to Equation (2.19) for air. Whereas, for the two-phase flow the outlet temperature depends on the outlet pressure of the refrigerant.

\subsection{General Description of the Numerical Solution}

Figure 2.6 presents the flowchart for the numerical solution applied in the present work. After providing the evaporator data then discretizing it to tube, fin, air, and refrigerant cells; the initialization process starts. The fluid outlet properties are initialized for both fluids (air and refrigerant) with the corresponding inlet properties. Any wall cell is initialized using the average temperature of the fluid cells in contact 
Chapter 2.

with it. Afterward, the corresponding saturated humidity ratio at the wall surface is calculated. Finally, the mass flow rate for each fluid cell is determined.

Secondly, the iterative procedure starts. It consists of two main steps: fluid calculations and wall calculations. In the first step, the fluid outlet humidity ratio (in the case of the moist air), temperature, and enthalpy are calculated using Equations (2.18), (2.19), and (2.20), respectively. However in case of evaluating the moist air, an extra check is required to ensure that the outlet air humidity ratio does not exceed the saturation condition for the same outlet dry-bulb temperature.

If the outlet humidity ratio of the air exceeded the saturation condition, a correction procedure is implemented, as demonstrated in Figure 2.7, to reallocate the outlet air point on the saturation curve. In this procedure, the outlet air enthalpy is kept constant, and an iterative (Newton-Raphson) loop is used to recalculate new outlet air temperature and humidity ratio. Finally, the amount of total heat transfer from/to each fluid cell is calculated and stored. If there is a dehumidification process, the amount of condensed water is also calculated.

In the second step of the iterative procedure, the wall (fin and tube) cells temperatures are calculated using Equation (2.16). In the presence of 2D LHC, Equation (2.16) shows that the wall cell depends on the wall temperature of the adjacent wall cells; when there is no LHC, the exact solution at this step consists of explicit calculations. To determine any wall cell temperature at the presence of LHC, it is necessary to solve a system of linear equations involving all the wall cells temperatures.

If we take into account that it is not worth to obtain the exact solution in each step, the best methodologies to deal with this calculation are:

- Using for each tube cell equation, the values of temperature of adjacent tube cells corresponding to the previous iteration. This way converts Equation (2.16) into an explicit equation, but this method needs much time to converge.

- Line-by-Line iteration method (Patankar, 1980). This technique converts the system of equations into a tri-diagonal system of equations, which can be solved easily.

- Block-by-Block (Patankar, 1980). It is based on the line-by-line method, but it adds a correction to the solution after finishing each iteration. It has the advantage of faster convergence than the line-by-line method, but it needs twice the number of operations. 
Inputs:

- Evaporator geometry.

- Inlet air and refrigerant properties.

- Number of air and refrigerant circuits.

- Fin and tube discretization schemes.

Initialization process:

- Discretizing the evaporator (walls and fluids) to cells.

- Initializing the fluids (air and refrigerant) properties.

- Initializing the wall (fin and tube) temperature field.

- Determining the mass flow rate in each fluid cell.

- Initializing the solver (determining the criteria of the residual calculation and initializing the iteration counter).

\section{Iterative process:}

- Fluid cells calculations (outlet Temperature, humidity ratio, and enthalpy).

- Wall cells calculations (temperatures and saturated humidity ratio at the centroid and surface).

- Residual calculations for all evaporator cells.
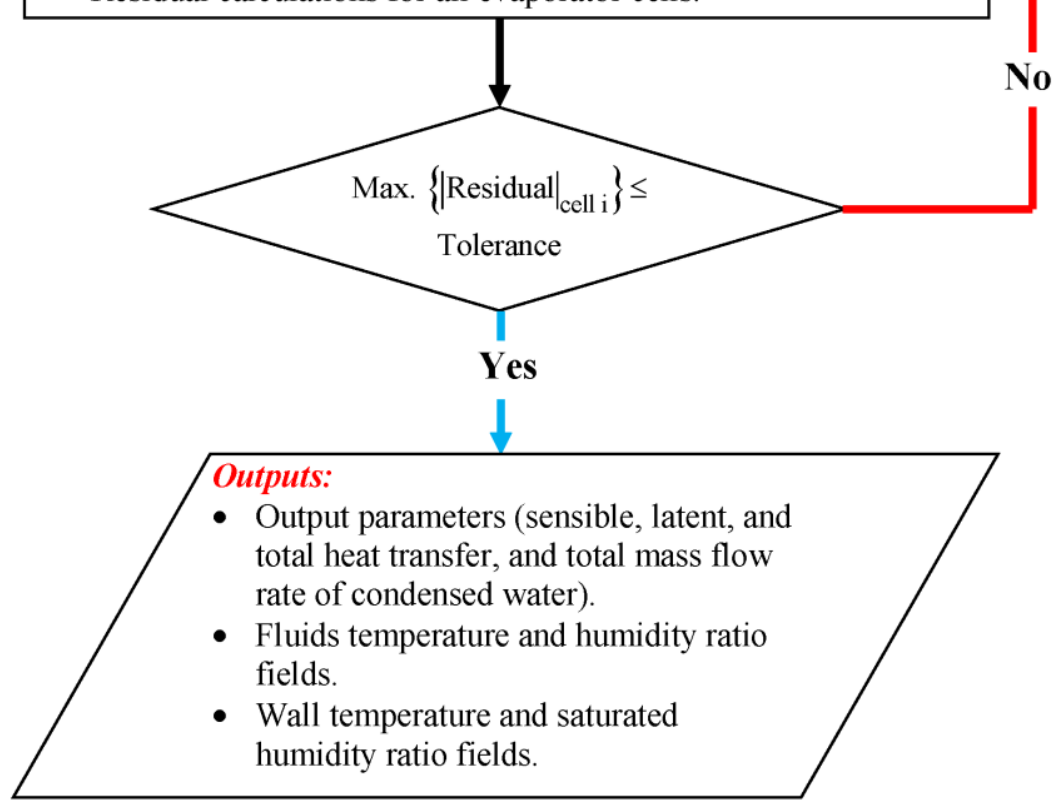

Figure 2.6. Flowchart of the numerical solution for the Fin2D-W model. 


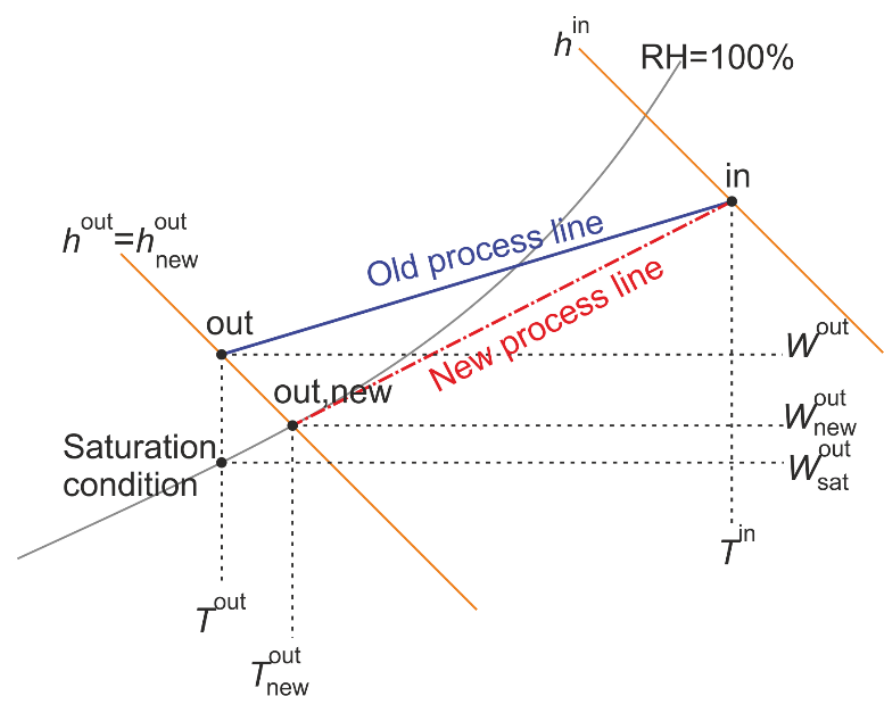

Figure 2.7. Correction procedure for the exceeding outlet air points.

In the current model the solution of wall governing equations is obtained firstly by the line-by-line method then the results are refined by the block-by-block technique after each iteration.

The residual for each cell (wall or fluid) is calculated as a scaled absolute heat balance in that cell. In each iteration, the value of the global residual is updated as the maximum value from all evaporator cells. At the end of each iterative process the value of the global residual is compared with the defined tolerance value.

The last process in the numerical solution is the outputs of results. After the global residual has reached the accepted tolerance, a special function is used to output all the heat and mass transfer parameters (sensible, latent, and total heat transfer rates), temperature fields, and humidity ratio fields.

\subsection{Case Study and Evaporator Dimensions}

In the presented case study, a minichannel evaporator which was tested by Zhao et al. (2001) is modeled. The minichannel used is shown in Figure 2.8.

The evaporator comprises of two microchannel unit slabs. A schematic diagram and picture of one of these unit slabs, besides a picture of fins and tubes, are shown in Figures 2.9, 2.10, and 2.11, respectively. 


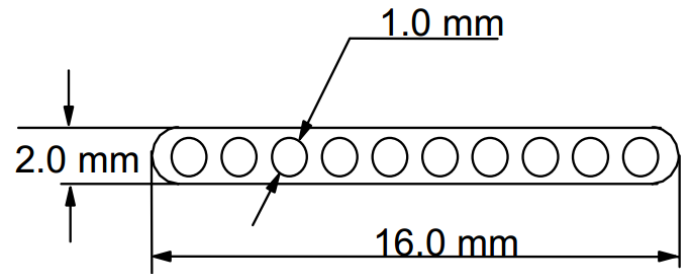

Figure 2.8. Minichannel tube used by Zhao et al. (2001).

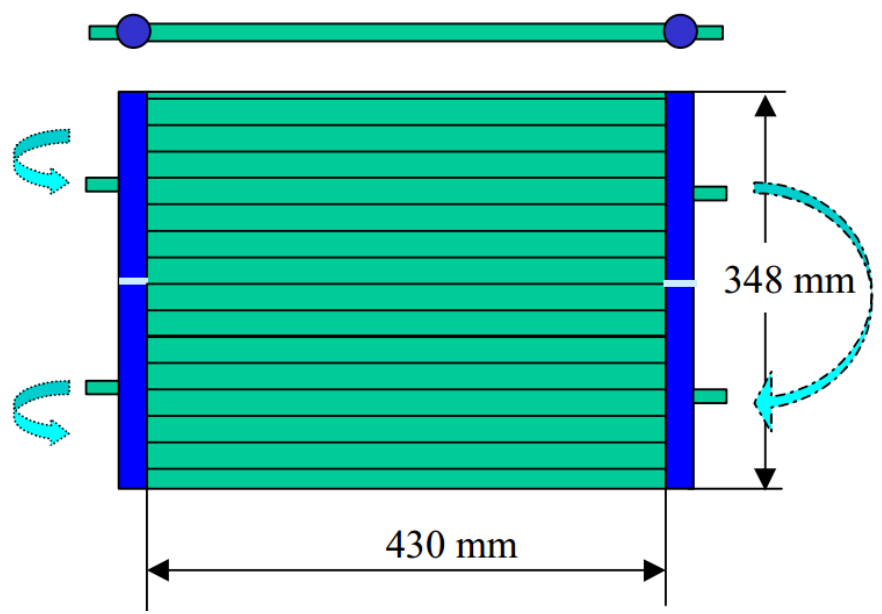

Figure 2.9. Schematic of a minichannel unit slab (Zhao et al., 2001).

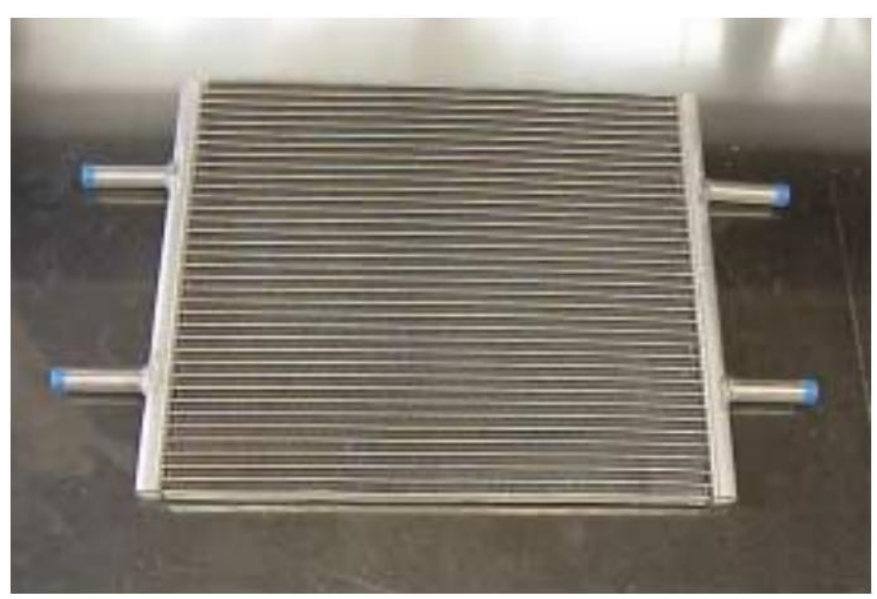

Figure 2.10. Picture of a unit slab (Zhao et al., 2001). 


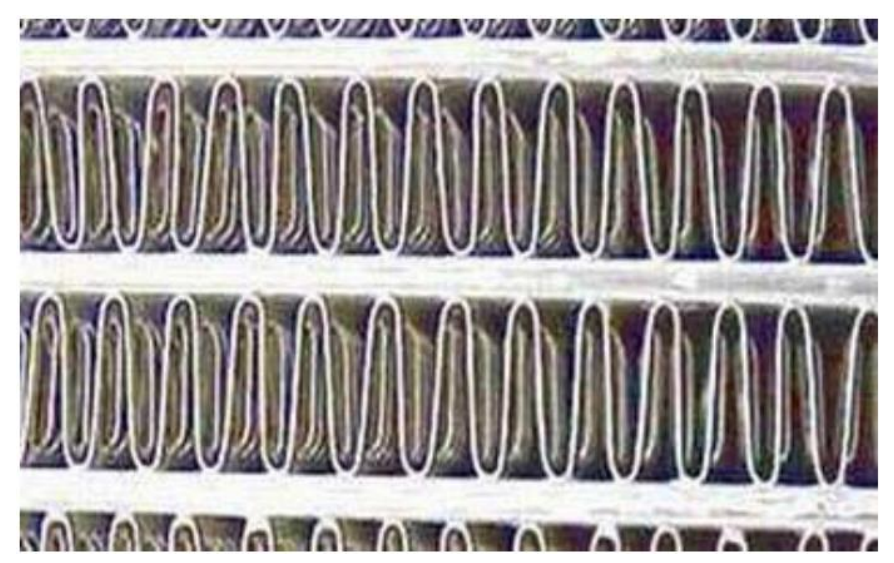

Figure 2.11. Picture of fins and tubes (Zhao et al., 2001).

The reference case study is shown in Figure 2.12. It consists of two tubes with their fins attached. Only the tube length (along the refrigerant flow direction) has been modified according to the scope of the current work; because the heat and mass transfer mechanisms are independent of the tube length and the number of tubes for the developed model. The refrigerant has only one pass along the evaporator with the same mass flow rate in both tubes. Table 2.1 summarizes the most important geometric data for the case study.

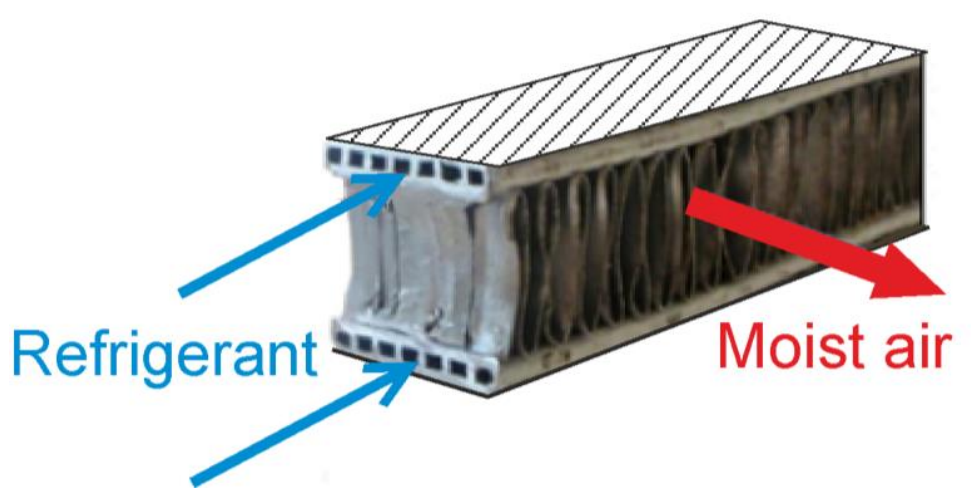

Figure 2.12. Schematic of the evaporator portion under study.

These geometrical specifications are sufficient to study the phenomena encountered in this kind of heat exchangers and to evaluate the sources of deviations between the different modeling approaches; since, the relevant dimension to be discretized, in 
order to face the main prediction challenges which have been discussed, is the fin height.

Table 2.1. Geometry of the case study.

\begin{tabular}{lclclc}
\hline $\begin{array}{l}\text { Tube length [cm] } \\
\text { (refrigerant flow direction) }\end{array}$ & 8.6 & Fin pitch [mm] & 1.59 & $\begin{array}{l}\text { Channel diam- } \\
\text { eter [mm] }\end{array}$ & 1 \\
$\begin{array}{l}\text { Tube depth [mm } \\
\text { (air flow direction) }\end{array}$ & 16 & $\begin{array}{l}\text { Fin thickness } \\
\text { [mm] }\end{array}$ & 0.152 & $\begin{array}{l}\text { Number of } \\
\text { channels }\end{array}$ & 10 \\
Tube thickness [mm] & 0.5 & Fin height $[\mathrm{mm}]$ & 8 & \\
\hline
\end{tabular}

For evaluating the thermodynamic and transport properties of the refrigerant and dry air, REFPROP ${ }^{\circledR}$ (Lemmon et al., 2002) was used; while the moist air properties were evaluated by the psychrometric relationships and charts which were presented in ASHRAE (2009) and they are summarized in Chapter 6, Section 6.1. The air properties were locally evaluated, whereas the refrigerant properties were assumed as uniform and evaluated as averaged values between corresponding values at the inlet and outlet of the studied evaporator portion, since the current study only focuses on the air-side analysis. The thermal conductivity of the fin and tube walls was estimated to be $173 \mathrm{~W} / \mathrm{m}^{2} \cdot \mathrm{K}$.

\subsection{Numerical Verification of the Fin2D-W Model}

It is necessary to verify the current model before employing it to produce detailed solutions of heat and mass transfer in the equivalent piece of the minichannel evaporator (Figure 2.12). With this purpose in mind, a series of systematic checks against operational cases were performed.

The detailed discretization of the air flow in the $y$-direction (between tubes) which is adopted in Fin2D-W makes it difficult to compare Fin2D-W predictions with those of analytical solutions. So the verification study consisted mainly of two scenarios which have an analytical solution:

- Air-side verification (V1): For the refrigerant, the infinite heat capacity rate $\left(\dot{m}_{r} \cdot C_{p, r}\right)$ was imposed which results in no temperature change for the refrigerant. Also, the $2 \mathrm{D} \mathrm{LHCs}\left(\mathrm{LHC}_{\mathrm{x}}\right.$ and $\left.\mathrm{LHC}_{\mathrm{z}}\right)$ in the tube and $\mathrm{LHC}_{\mathrm{z}}$ in the fin were disabled because the available analytical solutions do not account for these effects. The detailed discretization of the air flow in the Fin2D-W model accounts for non-uniform air temperature and humidity ratio along the $y$-direction (along the fin height). Since this effect is not taken into account by any 
Chapter 2.

analytical solution, the fin and air were only discretized in the $z$-direction (air flow direction); whereas only one cell was used along the $y$-direction. This discretization was adopted to make a valid comparison between the results of the Fin2D-W model and analytical case. On the other hand, it is not possible to capture the fin temperature variation with only one cell along the $y$-direction; thus, the value of the thermal conductivity of the fin in this direction was set as infinite. Under this situation, the fin efficiency was equal to unity, and the fin wall temperature was uniform along the $y$-direction. The numerical solution was compared with the analytical one based on a zero heat capacity ratio heat exchanger (Bergman et al., 2011), $\varepsilon=1$-exp (-NTU).

- Fin temperature profile verification (V2): the fin conductivity in the $y$-direction had a value corresponding to the case study. Two cases were studied, without and with the presence of temperature difference between fin roots (for totally wet and dry conditions). The analytical relationships for the fin temperature distribution and efficiency were taken from Wu and Bong (1994) and Sharqawy and Zubair (2008). These relationships assume a uniform air temperature and humidity ratio along the $y$-direction, and uniform air properties and heat transfer coefficient. Thus, to avoid the air temperature variation along the $\mathrm{y}$ and $\mathrm{z}$ directions, the infinite air heat capacity $\left(\dot{m}_{a} \cdot C_{p, m a}\right)$ was imposed. The refrigerant heat capacity rate was also assumed to be infinite to obtain a uniform tube wall temperature along all fin roots. The fin was discretized only along the $y$-direction. In the $z$-direction only one fin cell was used, so there was no $\mathrm{LHC}_{\mathrm{z}}$ in the fin.

Figure 2.13 shows the error of the numerical solution with reference to the analytical one for the case of V1 under totally wet and totally dry fin conditions. The figure demonstrates that the error tends to diminish very quickly by increasing the number of air/fin and tube wall cells $(\mathrm{N})$ used in the $z$-direction. It can be observed that the error is already very small for $\mathrm{N}=5$. 

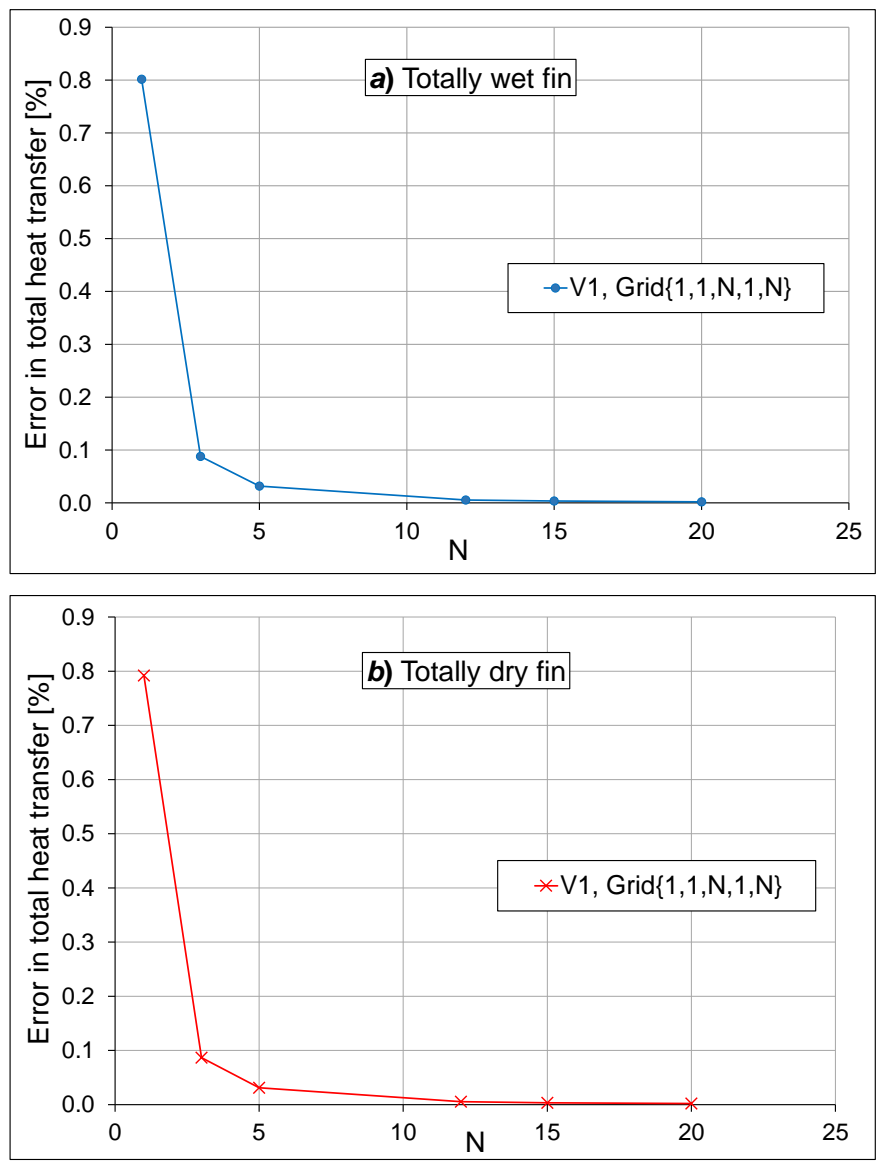

Figure 2.13. V1 results of the Fin2D-W model. (a) For totally wet fin condition. (b) For totally dry fin condition.

The results of V2 are depicted in Figures 2.14 and 2.15 for the totally wet and dry conditions as a function of the number of fin cells in the $y$-direction, respectively. Two situations were considered: equal tube temperatures at the bottom and the top, and a temperature difference of $5 \mathrm{~K}$ between tubes. $\theta$ is the difference between the fin temperature and the air temperature. It can be observed from the figures that there is a very good agreement between the numerical and analytical temperature profiles for all the scenarios studied, especially with the increase in number of the fin cells in the $y$-direction. 
Chapter 2.
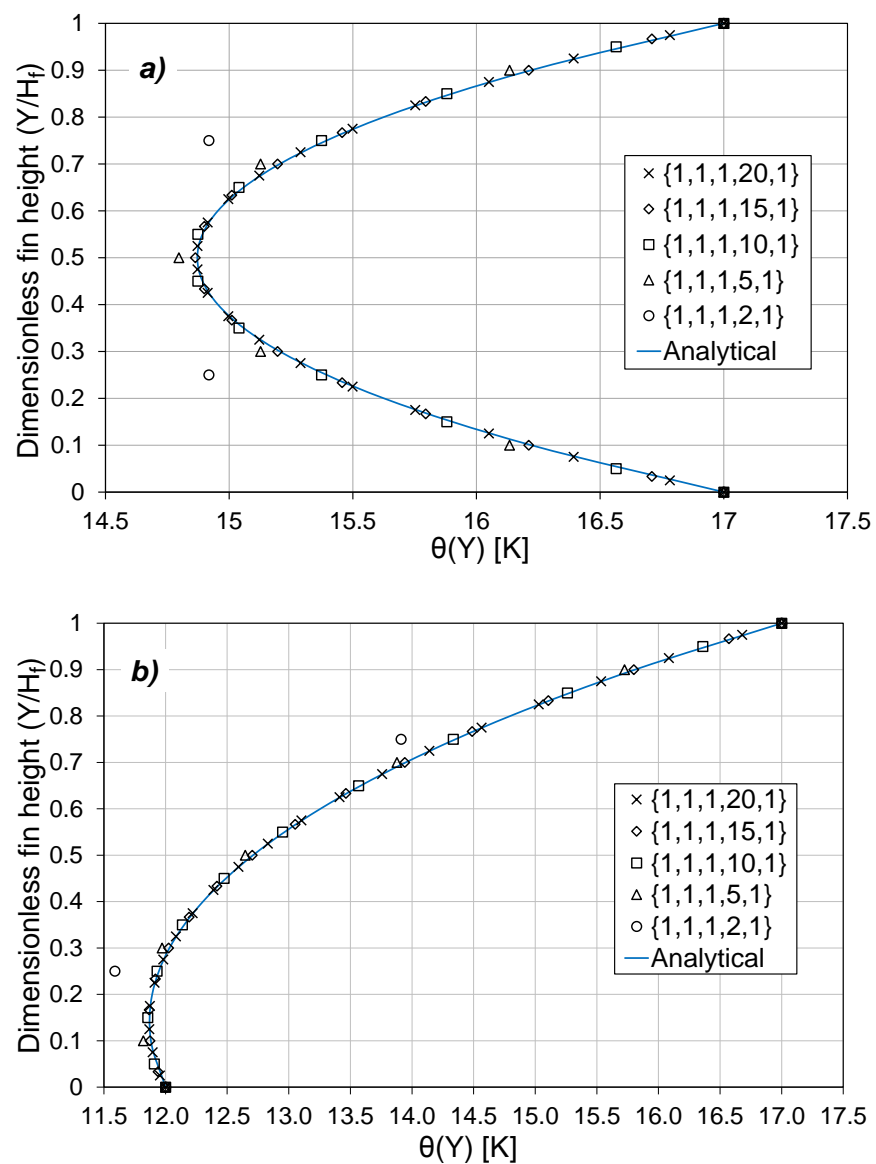

Figure 2.14. V2 results of the Fin2D-W model for a totally wet fin. (a) No temperature difference between tubes. $(b)$ Temperature difference of $5 \mathrm{~K}$ between tubes. 

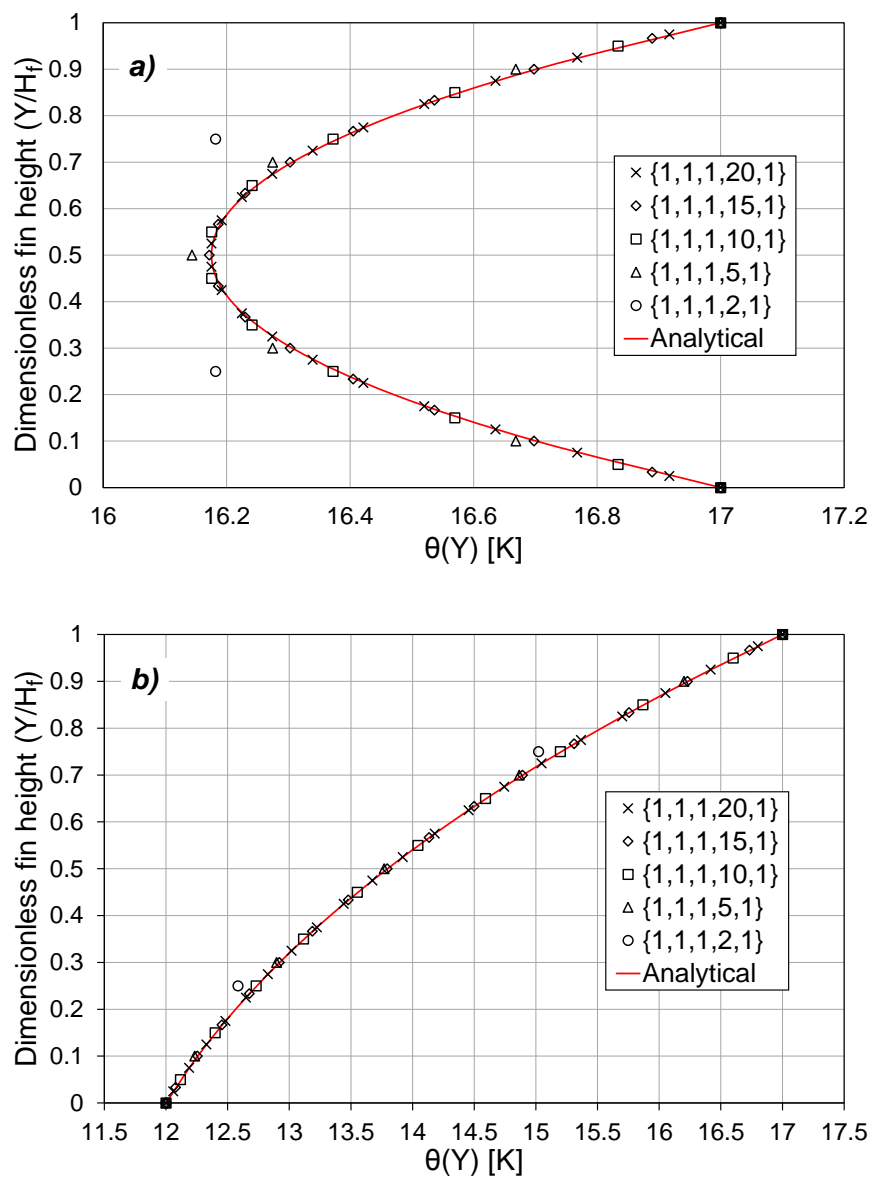

Figure 2.15. V2 results of the Fin2D-W model for a totally dry fin. (a) No temperature difference between tubes. $(b)$ Temperature difference of $5 \mathrm{~K}$ between tubes.

It can be concluded that at the same location on the fin, temperature difference between the air and fin surface is smaller for a wet fin than for a dry one. Thus, the surface temperature increases (because of the release of latent heat of condensation) when there is moisture condensation, the higher the relative humidity, the higher the surface temperature becomes. 
Chapter 2.

\subsection{A Comparative Study between the Classical \&-NTU Approach and the Fin2D-W Model.}

Once the Fin2D-W model has been verified it can be used as the reference to check the error made by the classical modeling methods for heat exchangers and study the impact of their implicit assumptions on the air-side performance of minichannel evaporators.

The most renowned classical modeling method is the logarithmic mean temperature difference or enthalpy difference method. The major disadvantage of this method that the outlet conditions for both air and refrigerant have to be known. Nevertheless, this method could still be used for the analysis; however, the procedure would require more iterations. One way to simplify the heat transfer rate calculations and reduce or eliminate the iterations in the solution of the discretized heat exchanger is to apply the $\varepsilon-\mathrm{NTU}$ method (Kays and London, 1984). This method is based on the heat transfer effectiveness $(\varepsilon)$ which is the ratio between the actual heat transfer and maximum possible heat transfer rates. Effectiveness relations of the heat exchangers typically involve the dimensionless group $U A_{d} /\left(\dot{m} \cdot C_{p}\right)_{\min }$. This quantity is called the number of transfer units (NTU); where $U A_{s}$ is the thermal conductance for heat exchanger, and $\left(\dot{m} \cdot C_{p}\right)_{\min }$ is the minimum heat capacity.

Most of the simulation models divide the evaporator tube into segments along the refrigerant flow with its corresponding fins. Once the evaporator has been divided into segments, the adiabatic fin-tip-assumption at half the height and classical $\varepsilon$-NTU relationships for heat exchangers are employed to solve the heat and mass transfer for each segment (Kays and London (1984) for dry cases, and Ragazzi (1995) for wet cases). This method simplifies the solution and reduces the calculation time, but on the other hand, it has many drawbacks, as discussed extensively by MartínezBallester et al. (2010). However, presence of the dehumidification process shows some other drawbacks including the following.

1. Uniform air temperature and humidity ratio along the $y$ - and $z$-directions: the $\varepsilon$-NTU approach assumes that the air temperature and humidity ratio are constant along the $y$-direction (fin height); since the $\varepsilon$-NTU approach uses the fin theory which is developed under this assumption. This assumption deviates from the reality because the temperature of the air flowing close to the tube and fin roots becomes much closer to the wall temperature. Consequently, the humidity ratio of the air in these regions becomes very close to 
the saturation condition. Additionally, fin theory assumes uniform air temperature and humidity ratio along the $z$-direction (air flow direction). However, the impact of this assumption could be reduced by discretizing the fin along this direction. Applying the fin discretization in $z$-direction makes the assumption of uniform air temperature and humidity ratio to be only applied along the $y$-direction.

2. No accounting for partially wet fin conditions: actually, depending on the local dew point of surrounding air, fin roots temperatures, and fin efficiency, the fin surface can be fully dry, fully wet, or partially wet. In the $\varepsilon$-NTU approach, the identification of the surface temperature below or above the dew point along both the tube and the associated fin appears to be difficult. Thus, in this approach, the whole segment is usually assumed to be either completely dry or completely wet based on the following condition proposed by Jiang, et al. (2006), which is widely used by many other authors in the literature. If the average surface temperature of the walls (fin and tube) $\bar{T}_{s}$ is less than the average dew point temperature of the surrounding air $\bar{T}_{d p}$, then the entire segment will be assumed to be totally wet; otherwise, it will be assumed to be totally dry. The average surface temperature of the wall is calculated under the dry fin condition assumption as follows:

$$
\bar{T}_{s}=\eta_{f, \text { dry }}\left(T_{f B}-\bar{T}_{a}\right)+\bar{T}_{a}
$$

3. Constant saturation line slope $b$ within the entire segment: in the $\varepsilon$-NTU method, the slope $b$ of the saturation line is assumed to be constant for the entire segment. It is usually evaluated at the fin mean temperature or as the average value between the fin base and tip conditions.

In the current study only the air-side of the evaporator is considered. In the Fin2DW modeling, the evaporator piece defined in the case study was discretized in a detailed grid $\{3,1,10,30,10\}$. This discretization grid was adopted according to the verification results of the proposed model, additionally, it gives the best combination between the calculation speed and solution accuracy. However, for the classical $\varepsilon$ NTU modeling the fins were assumed to be adiabatic at half the height which resulted in two segments (upper and lower), as shown in Figure 2.16. Each segment was treated separately using the corresponding adiabatic-fin-tip efficiency (for wet or dry condition) and thermal effectiveness relationship. 


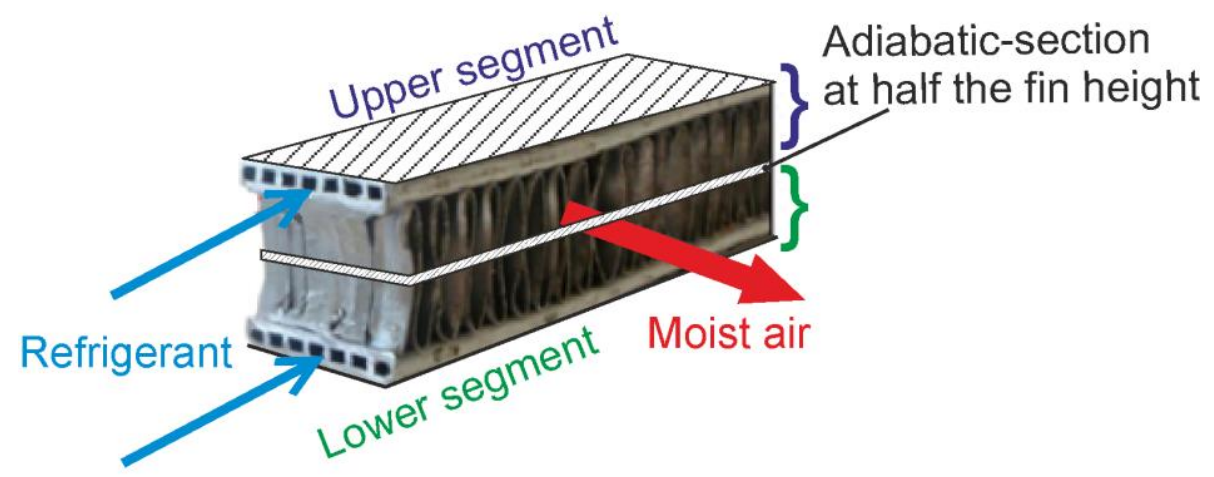

Figure 2.16. Schematic of the equivalent evaporator portion used in the $\varepsilon$-NTU modeling.

The $\varepsilon$-NTU model was developed within the Microsoft Excel ${ }^{\circledR} 2013$ and Engineering Equation Solver (EES) (Klein, 2004).

To allow a fair and clear comparison in same conditions between the two models, the following assumptions are made: the tube temperatures are assumed to be known and specified, the air-side heat transfer coefficient is constant, and the properties of moist air are also constant. Accordingly, the thermal effectiveness relationship used in the $\varepsilon$-NTU model is similar to that used in verification study.

The air-side sensible heat transfer coefficient $\alpha_{a}$ was assumed to be $\approx 48 \mathrm{~W} / \mathrm{m}^{2} \cdot \mathrm{K}$, which is considered to be a normal average value in air-to-refrigerant heat exchangers (Bergman et al., 2011). Since the air velocity does not change, the heat transfer coefficient remained the same for all the cases under study. For moist air, the Lewis number is close to unity (Coney et al., 1989c), so a Lewis number of unity was assumed in the current study.

Three inlet air cases, which represent different applications of refrigeration and air conditioning, have been chosen. In each case, a different range of tube temperatures has been selected to simulate and evaluate the evaporator performance under different dehumidifying conditions. Those cases are defined next.

- Case I: high-temperature refrigeration applications. Most vegetables and fruits are stored, in the short term, in a temperature range varying from 7.2 to $15.6{ }^{\circ} \mathrm{C}$ and relative humidity range of 80 to $95 \%$ to prevent dehydration 
(Whitman et al., 2012). In the current study, the evaporator inlet air conditions were kept at $14{ }^{\circ} \mathrm{C}$ and a dew point of $12.39^{\circ} \mathrm{C}(\approx 90 \% \mathrm{RH})$.

- Case II: air-conditioning (cooling and dehumidification) applications. ASHRAE (2011) specified general guidelines for temperature and humidity applicable to offices and common areas. For example, in summer, the indoor temperature should range from 23.3 to $26.7^{\circ} \mathrm{C}$ while the relative humidity should range from 50 to $60 \%$. According to the previous thermal comfort definition of ASHRAE, the inlet air conditions to the evaporator in the current case were set at $27{ }^{\circ} \mathrm{C}$ and a dew point temperature of $17.2{ }^{\circ} \mathrm{C}(\approx 55 \% \mathrm{RH})$.

- Case III: heat pump drying applications. Heat pump dryers have been known to be energy efficient when used in conjunction with drying operations. The hot humid air which exits from the drying process is forced to flow through an evaporator for cooling and removing the excess moisture before heating it again through the condenser to increase its potential for humidity transport. Pendyala et al. (1986) stated that in typical drying applications, for example cloth drying, the air conditions are in the range of 25 to $65{ }^{\circ} \mathrm{C}$ and 40 to $100 \% \mathrm{RH}$. So in the current situation, the evaporator inlet air conditions were fixed at a dry bulb temperature of $40{ }^{\circ} \mathrm{C}$ and a dew point of $32.69{ }^{\circ} \mathrm{C}$, which corresponds to $\approx 67 \% \mathrm{RH}$.

Table 2.2 summarizes the different inlet air cases for the evaporator, which were also used in the verification study.

Table 2.2. Inlet air conditions used in the simulations.

\begin{tabular}{lccccc}
\hline & $T_{a}^{\text {in }}\left[{ }^{\circ} \mathrm{C}\right]$ & $\mathrm{RH}_{a}^{\text {in }}[\%]$ & Inlet velocity $[\mathbf{m} / \mathbf{s}]$ & $\mathbf{G}_{a}\left[\mathbf{k g} / \mathbf{m}^{2} \cdot \mathbf{s}\right]$ & $\begin{array}{c}\text { Inlet pressure } \\
{[\mathbf{k P a}]}\end{array}$ \\
\hline \hline Case I & 14 & 90 & & & \\
Case II & 27 & 55 & 3.0 & 3.34 & 100 \\
Case III & 40 & 67 & & & \\
\hline
\end{tabular}

The current comparative study is divided into two further sub-studies: in the first sub-study, there is no temperature difference between tubes; while in the second one there is a temperature difference between the upper and lower tubes. Each sub-study is discussed in details as follows. 
Chapter 2.

\subsubsection{Equal temperature for the upper and lower tubes (no superheat)}

Figures 2.17 to 2.19 show the relative deviations, based on the Fin2D-W results, in heat transfer rates between the classical $\varepsilon$-NTU method and the present numerical model for the three inlet air cases under study. In the current study there is no temperature difference between upper and lower tubes, this means that the two tubes always have the same temperature. It can be noticed that the difference between the single and dual potential models is very small and does not affect the results much. It is worth mentioning that $\mathrm{Wu}$ and Bong (1994) and Sharqawy and Zubair (2008) reported a similar result in their analytical analysis of a totally wet straight fin.

\subsubsection{Analysis of a totally dry fin}

The fin is considered fully dry if the temperature of its surface at any location is equal to or greater than the surrounding air dew point temperature. Under this situation, only sensible heat transfer occurs between the air and the wall.

It can be concluded from Figures 2.17-2.19 (parts $a$ and $c$ ) that for each inlet air case, the deviation in sensible and total heat for the totally dry fin is not affected by the change in the tube temperature. This deviation could result from the assumption of a constant air temperature between tubes, which is adopted by the $\varepsilon$-NTU approach. However, the temperature of air close to the tube wall and fin roots is actually very different from the bulk air temperature. This fact has an important impact on local effects controlling the heat transfer, and contributes significantly to the deviation between the $\varepsilon$-NTU method and the current model results. Similar results and conclusions were reported by Martínez-Ballester et al. (2010).

The value of the average deviation in sensible heat transfer rate for the three inlet air cases is $3.94 \%$. The deviation value decreases very slightly $(0.1 \%$ in total $)$ with an increase in the moist air specific heat, which depends on the humidity ratio of the air. 
Fin2D-W Model
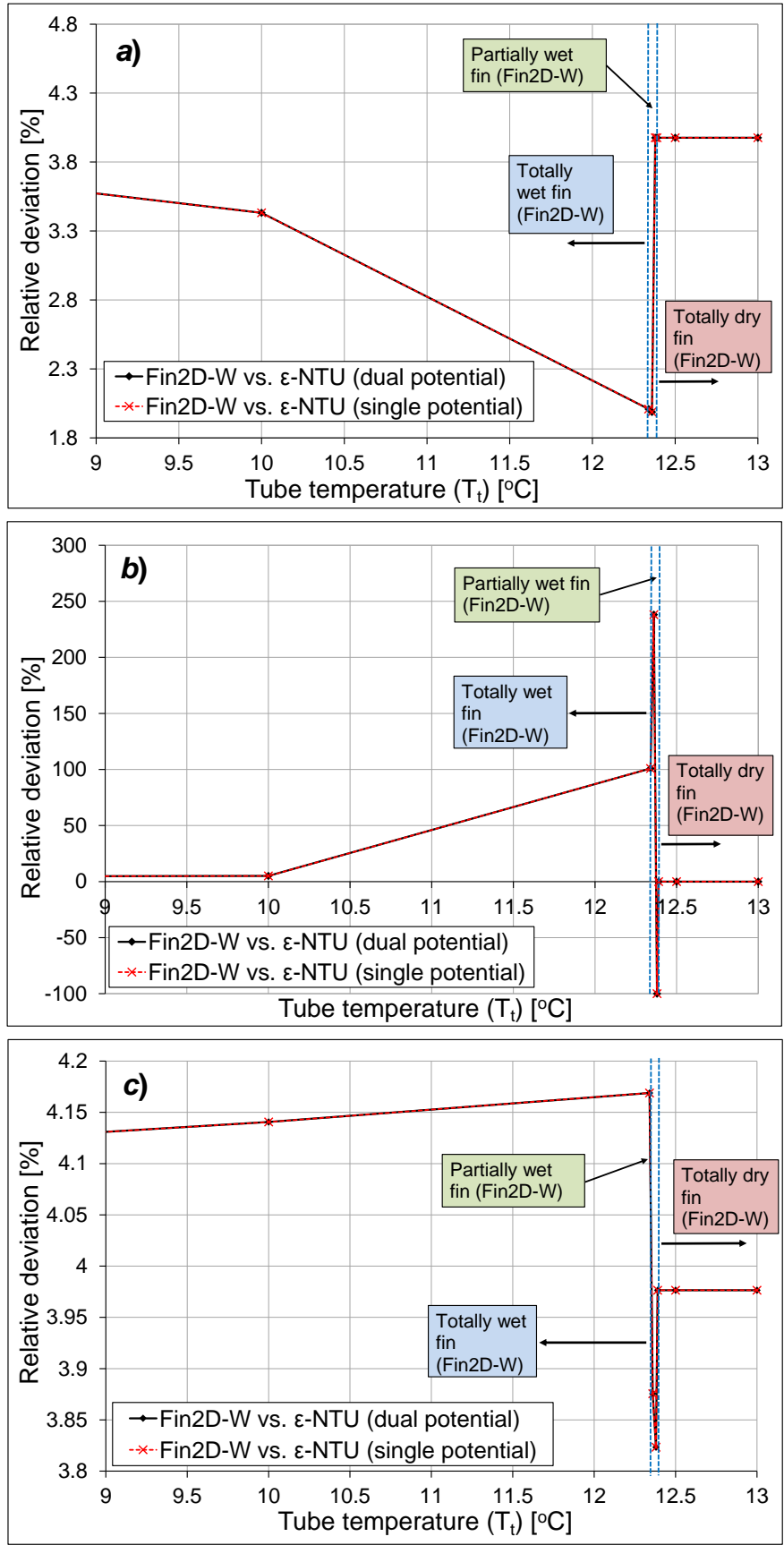

Figure 2.17. Relative deviations in $(a)$ sensible, $(b)$ latent, and $(c)$ total heat transfer rates between the $\varepsilon$-NTU and Fin2D-W models, for Case I (without superheat). 
Chapter 2.
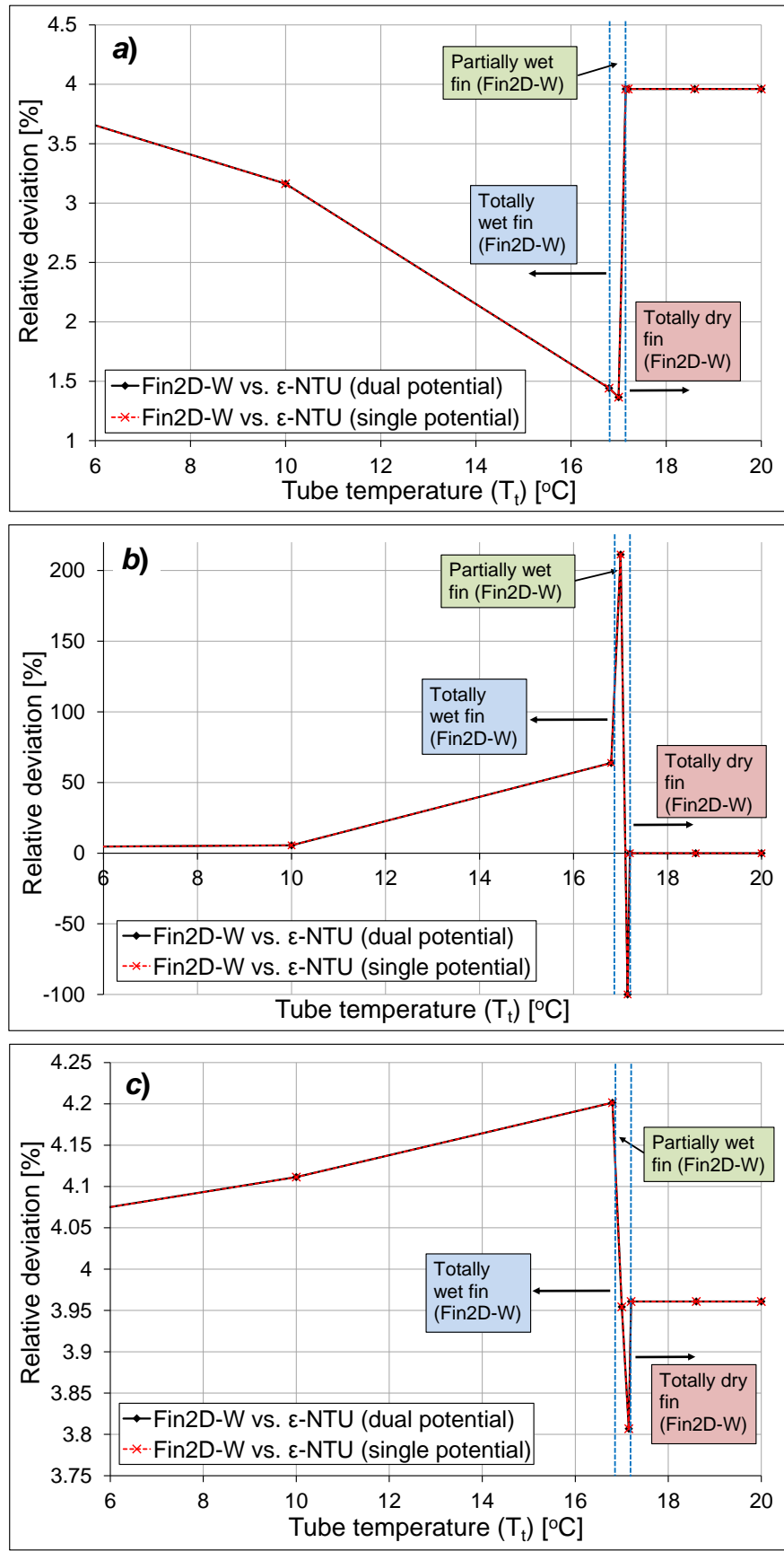

Figure 2.18. Relative deviations in $(a)$ sensible, $(b)$ latent, and $(c)$ total heat transfer rates between the $\varepsilon$-NTU and Fin2D-W models, for Case II (without superheat). 

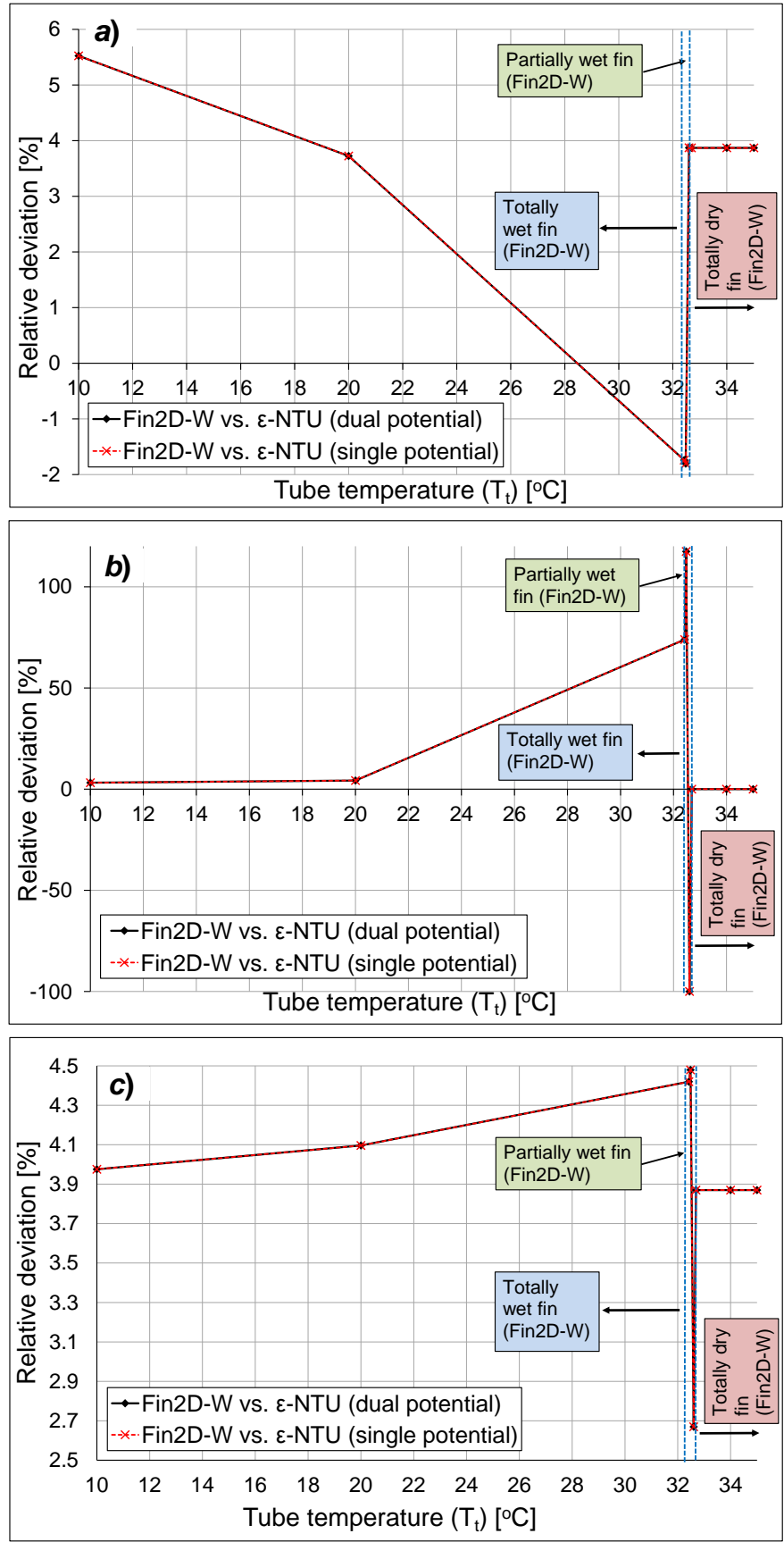

Figure 2.19. Relative deviations in $(a)$ sensible, $(b)$ latent, and $(c)$ total heat transfer rates between the $\varepsilon$-NTU and Fin2D-W models, for Case III (without superheat). 
Chapter 2.

\subsubsection{Analysis of a partially wet fin}

A partially wet fin is a transition condition between totally dry and totally wet conditions. In this scenario, the tube temperature is slightly less than the dew point of air. This results in some locations on the fin surface having a temperature lower than the average dew point of the surrounding air, and thus, simultaneous heat and mass transfer occurs. Meanwhile, the remaining fin surface still has a temperature higher than the dew point of the surrounding air, which results in only sensible heat transfer.

The range of partially wet fins is very small, as it can be seen in Figures 2.17, 2.18, and 2.19 . The maximum range is about $0.5^{\circ} \mathrm{C}$. Normally, the multi-louvered fin that is employed in minichannel evaporators is short with an average height of $8 \mathrm{~mm}$ and a very small thickness of $\approx 0.1 \mathrm{~mm}$. These specifications lead to a very high fin efficiency, even under wet conditions, which could result in this small partially wet fin range.

At the beginning of the partially wet region, the classical $\varepsilon$-NTU method still considers the fin to be totally dry because the average segment wall temperature is still higher than the average dew point of air; this results in an underestimation of the latent heat by $100 \%$ compared with numerical results. Figure 2.20 shows the fin temperature profile, the amount of water condensed from the air in milligrams per hour, and the air temperature and humidity ratio profiles in both longitudinal and transverse directions, for Case III at tube temperature $\mathrm{T}_{t}=32.60{ }^{\circ} \mathrm{C}$. It can be clearly observed that the $\varepsilon$-NTU method fails to predict the fin status, and the fin is actually under a partially wet condition.

With a further decrease in the tube temperature, the percentage of the wet region is increased, and the $\varepsilon$-NTU method starts to assume a totally wet fin. This assumption results in an overestimation of the latent heat compared with the Fin2D-W model and a rapid increase in the deviation between the two approaches for all inlet air cases, as seen in Figures 2.17b, 2.18b, and 2.19b. Numerical results for Case II are illustrated in Figure 2.21, where the $\mathrm{T}_{\mathrm{t}}=17.0^{\circ} \mathrm{C}$. It can be seen that the wet region nearly occupies $40 \%$ of the fin surface area, while the rest remains dry. 

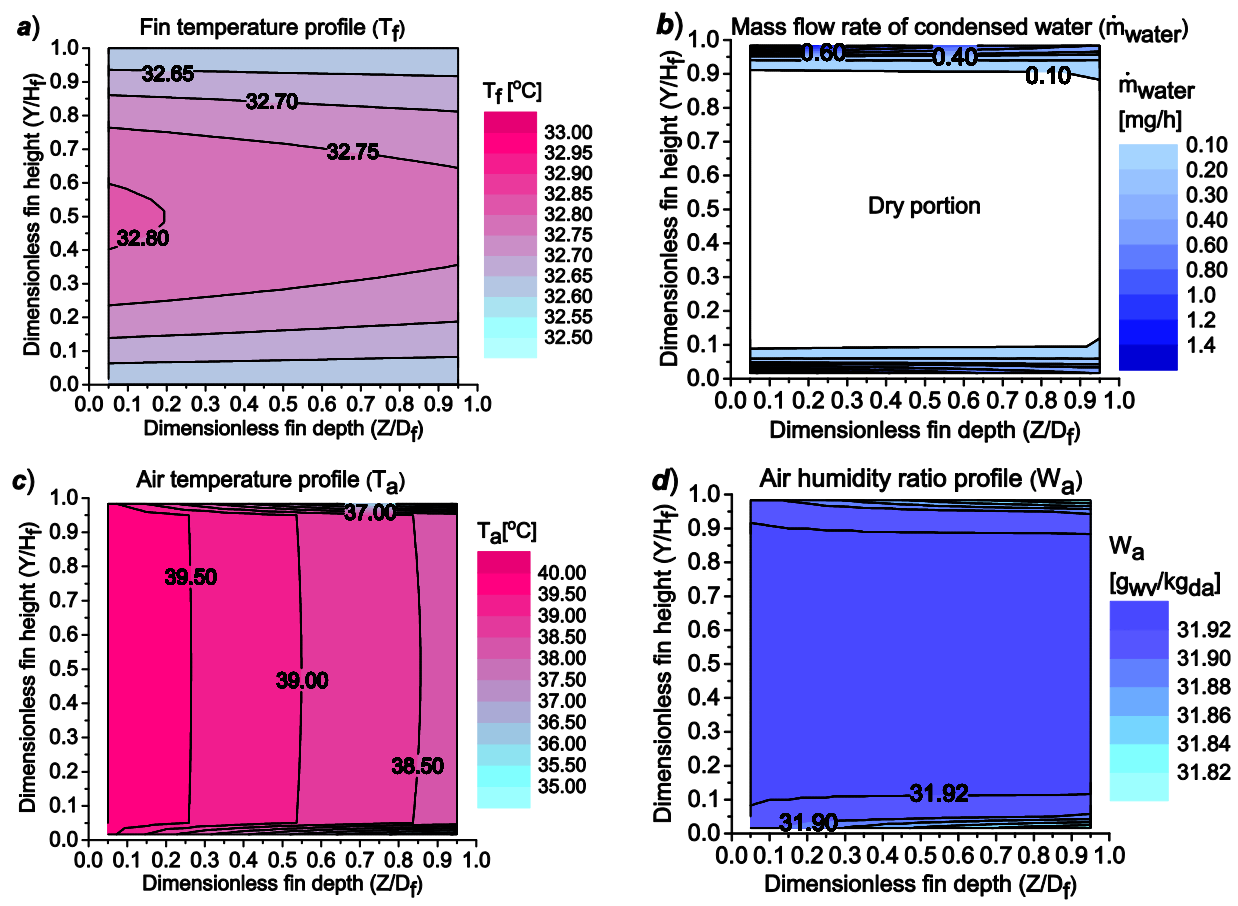

Figure 2.20. (a) Fin temperature profile. (b) Mass flow rate of condensed water. (c) Air temperature profile. $(d)$ Air humidity ratio profile for Case III at $\mathrm{T}_{\mathrm{t}}=32.60^{\circ} \mathrm{C}$.

The misprediction of the fin condition and the latent heat transfer rate by the $\varepsilon$-NTU approach also affects the sensible heat transfer rate in the partially wet region. The assumption of a totally wet fin, even though the fin is actually under the partially wet condition, results in an increase in the fin surface temperature due to the release of latent heat of condensation. A higher fin temperature results in a lower heat transfer potential between air and fin, which causes a decrease in the relative deviation of the sensible heat transfer rate. As shown in Figure 2.19a, in the case of extremely high air temperature and $\mathrm{RH}$, as encountered in Case III, the assumption of a totally wet fin results in a higher estimation of condensed water on the fin surface, which substantially suppresses the sensible heat transfer rate. Consequently, the $\varepsilon$-NTU method starts to underpredict the amount of sensible heat by $1.8 \%$ compared with Fin2D-W model. 
Chapter 2.
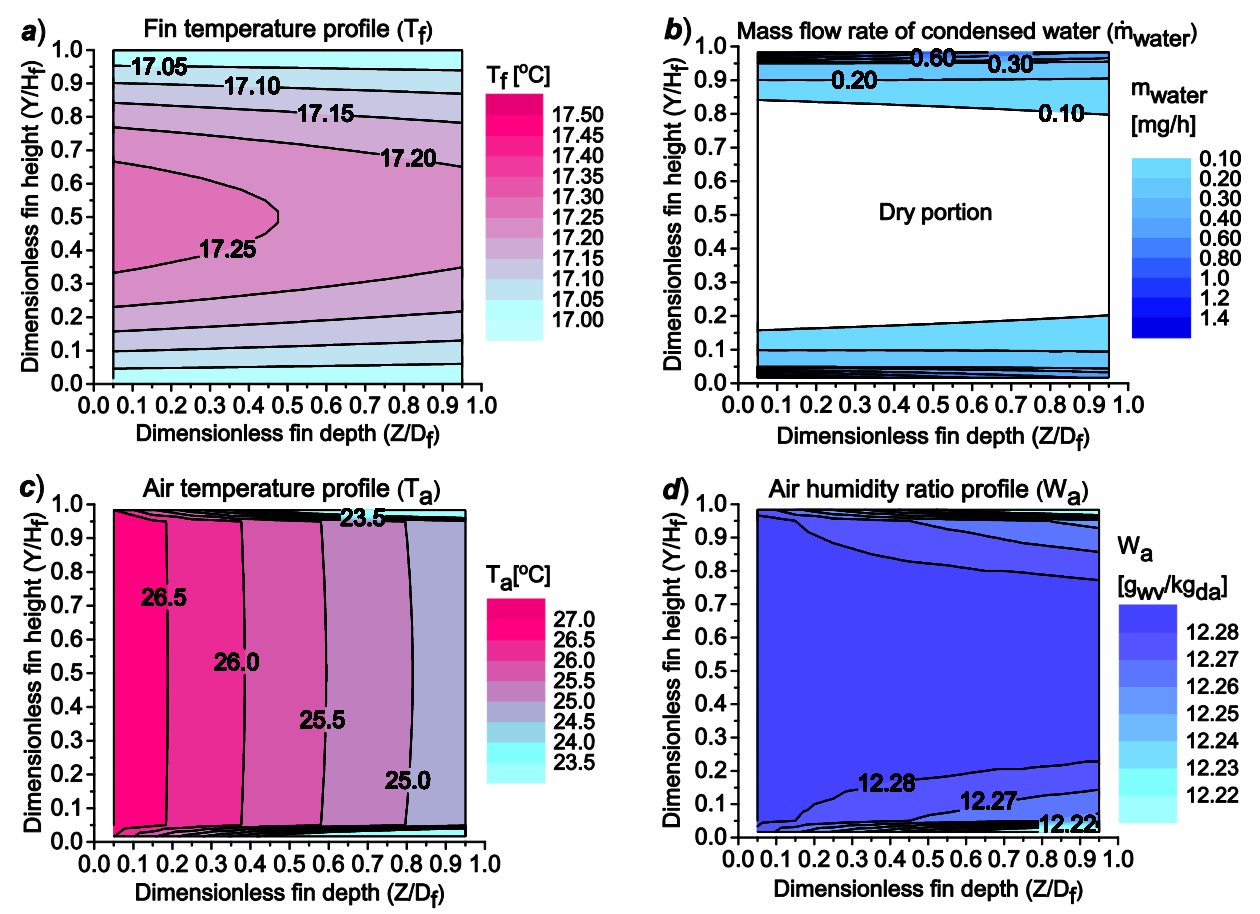

Figure 2.21. (a) Fin temperature profile. (b) Mass flow rate of condensed water. (c) Air temperature profile. $(d)$ Air humidity ratio profile for Case II at $\mathrm{T}_{\mathrm{t}}=17.0^{\circ} \mathrm{C}$.

\subsubsection{Analysis of a totally wet fin}

With a further decrease in the tube temperature, the entire fin surface becomes much lower than the dew point of the surrounding air, and the fin becomes totally wet as depicted in Figure 2.22 for Case III at $\mathrm{T}_{\mathrm{t}}=10.0^{\circ} \mathrm{C}$. Furthermore, it can be seen from Figure 2.22 (parts $c$ and $d$ ) that the air temperature and humidity ratio profiles along the fin height are generally flat. Nevertheless, there are remarkable temperature and humidity ratio gradients in the portions near the tubes, which approximately occupy $10 \%$ of the fin height.

At the beginning of the totally wet region, the deviation in latent heat transfer rate starts to decrease rapidly because the two approaches (Fin2D-W and $\varepsilon$-NTU) now predict the same fin condition. Further lowering of the tube temperature results in a small decrease in the relative deviations of the latent and total heat transfer rates and in an increase in the relative deviation of the sensible heat transfer rate. The average 
relative deviation (ARD) values in sensible, latent, and total heat transfer rates for the three cases studied under the totally wet condition are shown in Table 2.3.
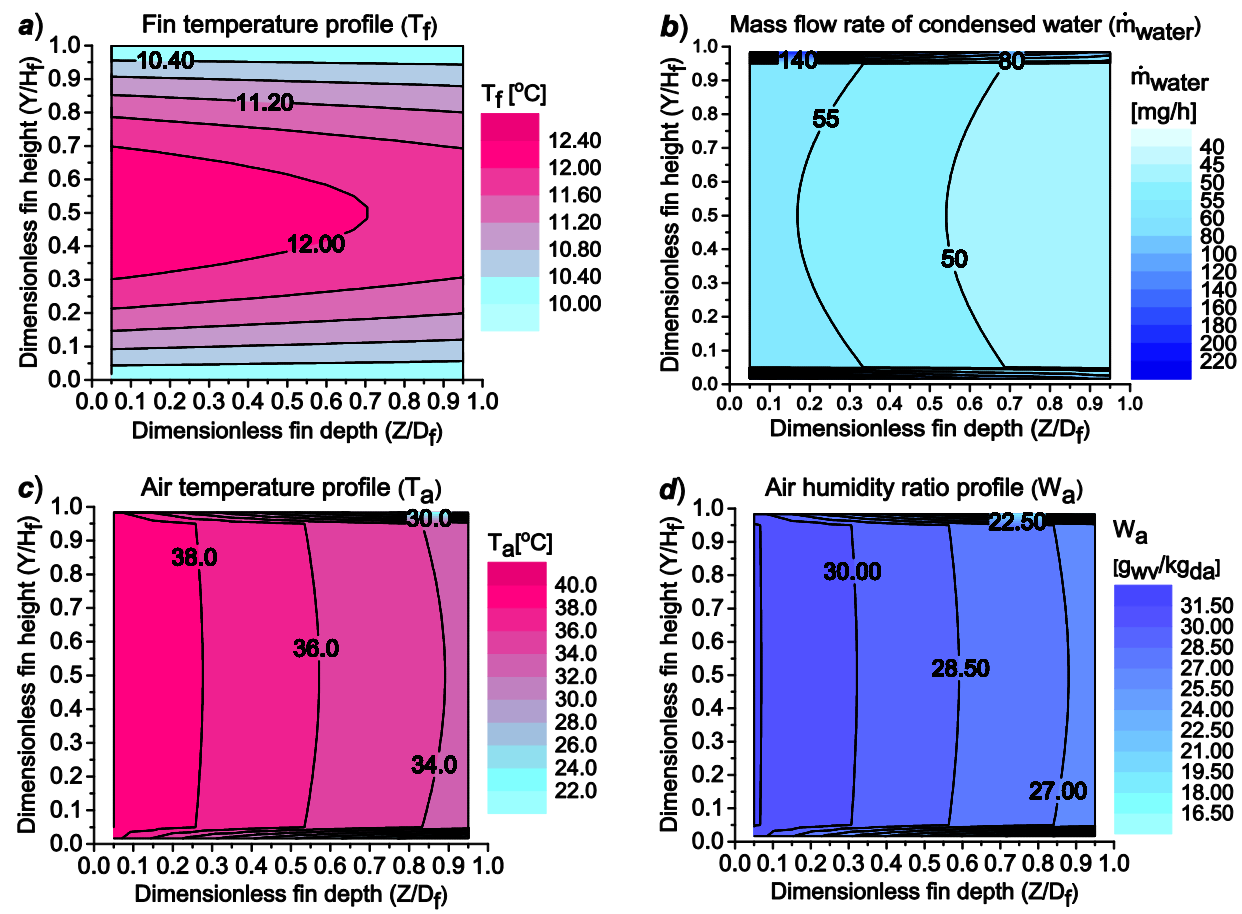

Figure 2.22. (a) Fin temperature profile. (b) Mass flow rate of condensed water. (c) Air temperature profile. $(d)$ Air humidity ratio profile for Case III at $T_{t}=10.0^{\circ} \mathrm{C}$.

It can be concluded from the results that generally the $\varepsilon$-NTU method overpredicts the sensible, latent, and total heat transfer rates in the fully wet region, except in Case III at the beginning of the totally wet fin, where the $\varepsilon$-NTU method slightly underpredicts the amount of sensible heat transfer. The assumption of no temperature variation of the air along the $y$-direction, which also results in a constant humidity ratio within the same direction, could be one of the reasons for this deviation in results. Also, the way of calculating the saturation line slope $b$, which is usually assumed by the $\varepsilon$-NTU method to be constant for the whole segment, could contribute to this deviation. However, in the current Fin2D-W model, this slope is calculated individually at each wall cell based on the surface wall temperature and the average conditions of the adjacent air cells. 
Chapter 2.

Table 2.3. Average relative deviation* (ARD) in heat transfer rates under totally wet condition (without superheat) [\%].

\begin{tabular}{lcccc}
\hline & Case I & Case II & Case III & Total average for the three cases studied \\
\hline \hline Sensible heat & 3.54 & 3.10 & 3.70 & 3.45 \\
Latent heat & 28.38 & 19.48 & 20.86 & 22.91 \\
Total heat & 4.12 & 4.11 & 4.10 & 4.11 \\
\hline
\end{tabular}

* Relative deviation between the $\varepsilon$-NTU and Fin2D-W models [\%]=[( $\left.\left.Q_{\varepsilon \text {-NTU }}-Q_{\text {Fin2D-w }}\right) / Q_{\text {Fin2D-w }}\right] \times 100$

\subsubsection{Presence of a temperature difference between the upper and lower tubes (superheat)}

In the previous study, the same temperature for the upper and lower tubes was always assumed, accordingly the assumption of adiabatic-fin-tip at half the height is exactly correct under this case. However, in evaporators there is usually a region of superheat. This subsequently results in a temperature difference between adjacent tubes which, in turns, results in a significant temperature gradient in the fin regardless the fin efficiency. Under this situation, the assumption of adiabatic-fin-tip at half the height, which prevents the heat conduction between tubes, is not valid any more.

Hence, in the current study the Fin2D-W model is employed to mainly evaluate the impact of this assumption on the air-side performance of minichannel evaporators under different dehumidifying conditions; and for scenarios with different degree of temperature difference between tubes due to the refrigerant superheat. A range of lower and upper tubes temperatures has been selected to simulate presence of a refrigerant superheat in the evaporator tubes. The superheat $(\mathrm{SH})$, in the current study, is defined as the difference between upper tube temperature $\mathrm{T}_{\mathrm{ut}}$ and lower tube temperature $T_{l t}$. This scenario corresponds to a case in which the refrigerant evaporates in the bottom tube while is superheated in the upper one. 

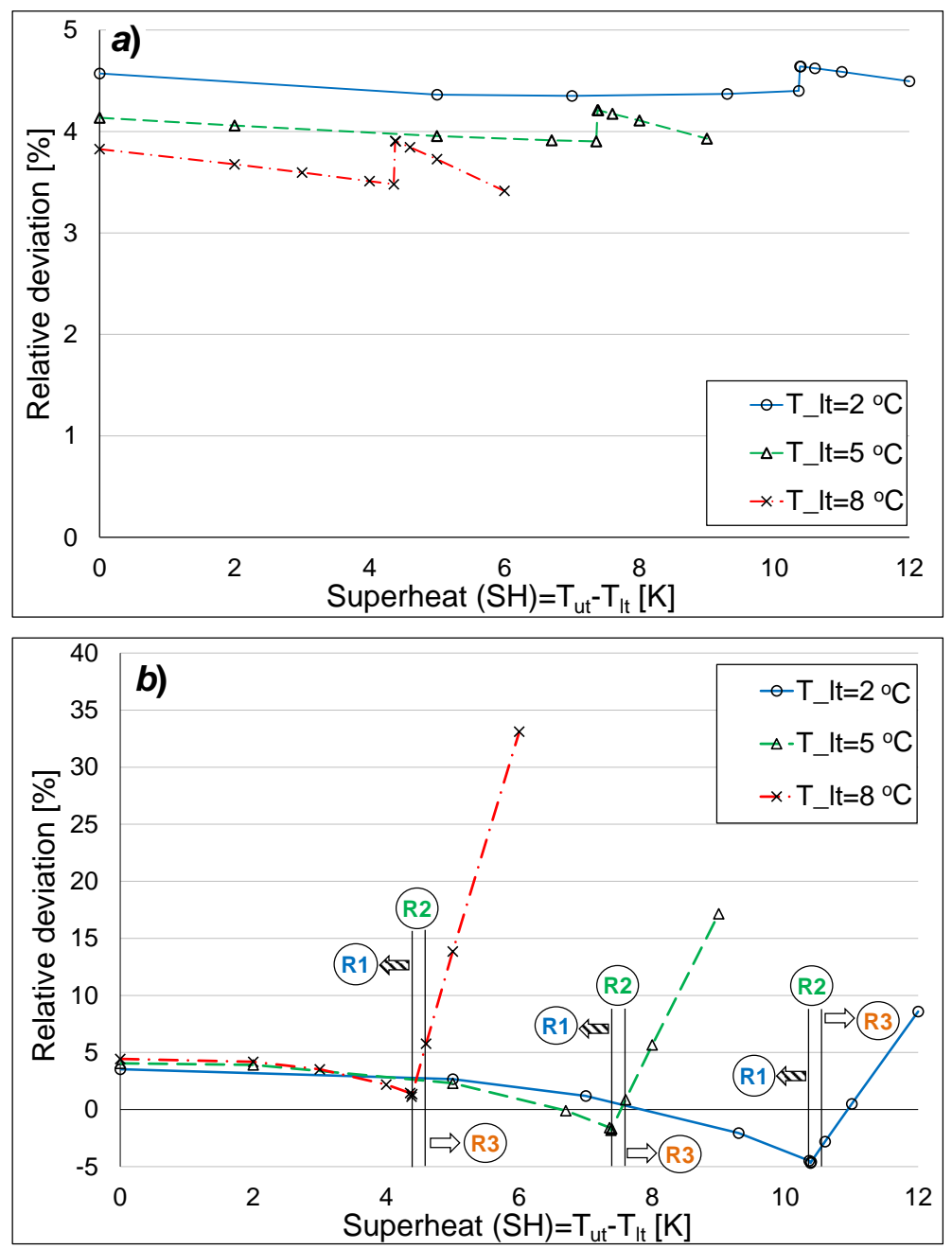

Figure 2.23. Relative deviations in $(a)$ sensible and $(b)$ latent heat transfer rates between the $\varepsilon$ NTU and Fin2D-W models, for Case I (with superheat).

Figures 2.23-2.25 (part $a$ ) show the relative deviations in sensible heat transfer rate between the two models. The average values of these deviations for Cases I, II, and III are $4.10 \%, 3.30 \%$, and $2.0 \%$, respectively. The main source of these deviations is the assumption of uniform air temperature between tubes, which is adopted by the $\varepsilon$ NTU model. It is worth mentioning that Martínez-Ballester et al. (2011) reported similar deviations for the sensible heat transfer results in a comparative study between the $\varepsilon$-NTU approach and a $2 \mathrm{D}$ numerical model for minichannel $\mathrm{CO}_{2}$ gas cooler. 
Chapter 2.
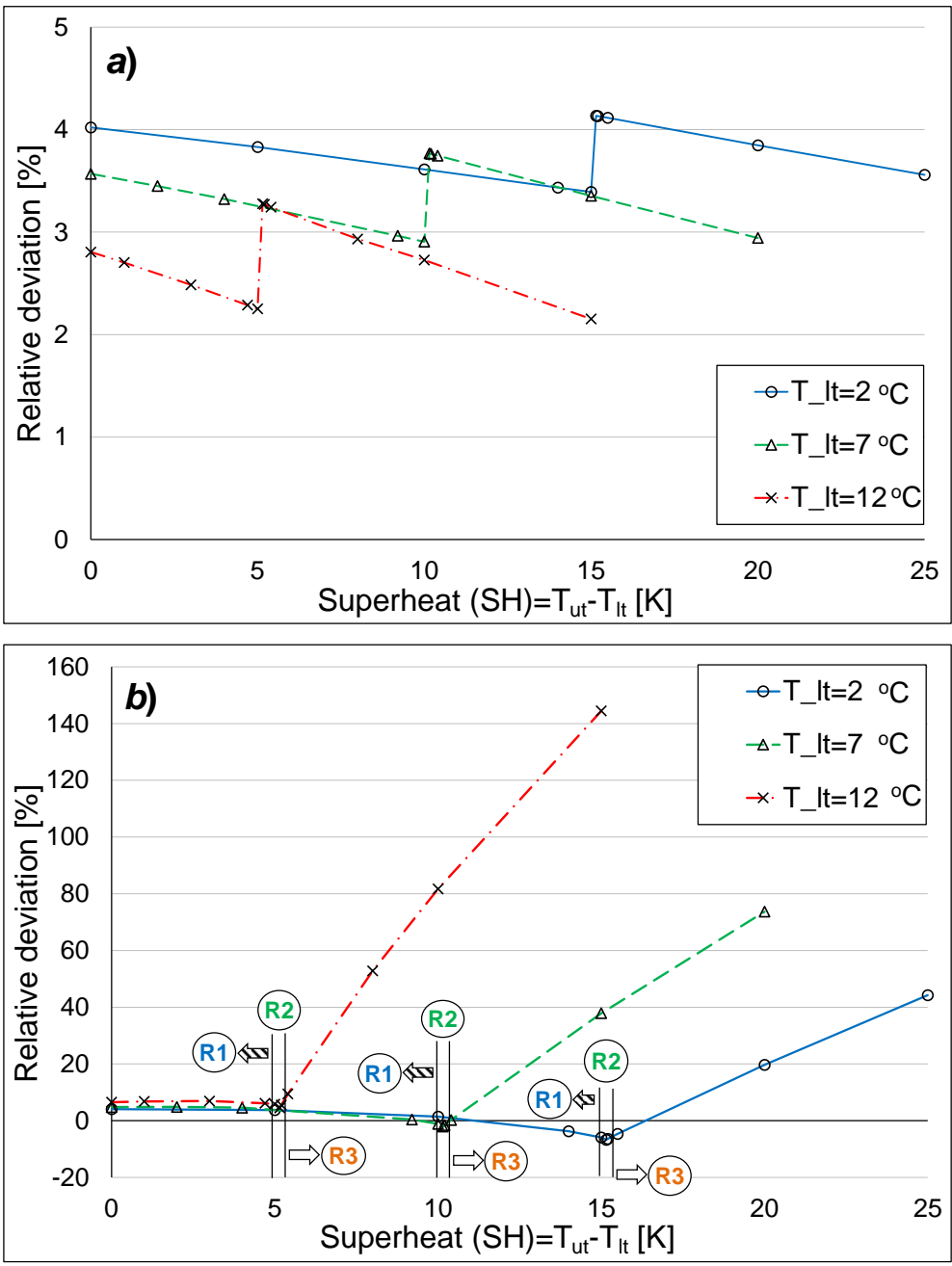

Figure 2.24. Relative deviations in $(a)$ sensible and $(b)$ latent heat transfer rates between the $\varepsilon$ NTU and Fin2D-W models, for Case II (with superheat). 

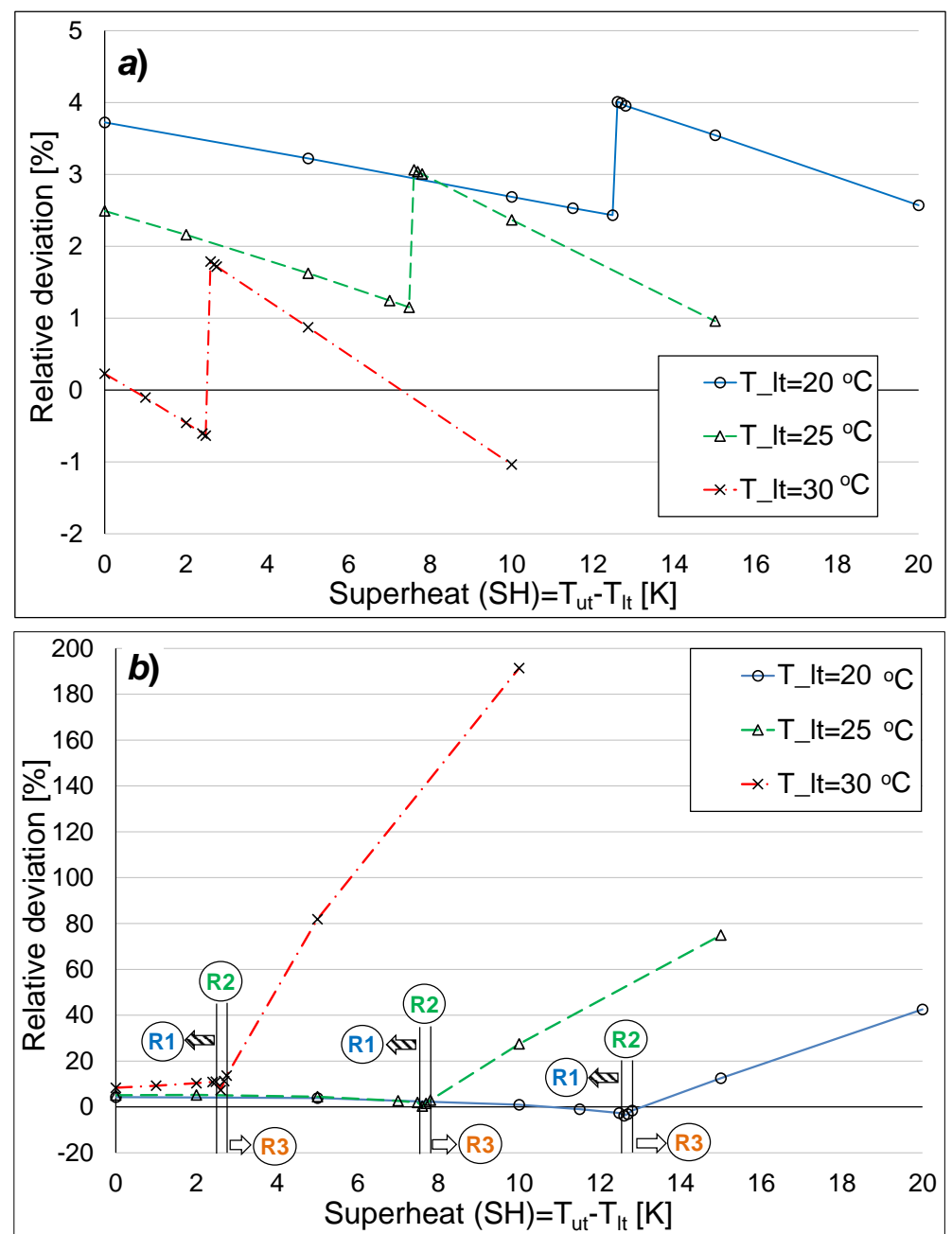

Figure 2.25. Relative deviations in $(a)$ sensible and $(b)$ latent heat transfer rates between the $\varepsilon$ NTU and Fin2D-W models, for Case III (with superheat).

The main disadvantage of the $\varepsilon$-NTU model that it does not account for partial dehumidification scenarios, so with the increase in superheat it tends to convert the fin condition suddenly from totally wet to a half wet fin. This, in turn, affects the average fin temperature, because of the change in the released amount of latent heat of water condensation, and subsequently the sensible heat transfer rate. This could explain the sudden increase in relative deviations in sensible heat transfer rate between the two models in the transition region, as shown in Figures 2.23a, 2.24a, and 2.25a. 
Chapter 2.

The relative deviations in latent heat transfer rate between the $\varepsilon$-NTU and Fin2D-W models, based on the Fin2D-W model results, for the three inlet air cases under study are illustrated in Figures 2.23-2.25 (part $b$ ). In the first region (R1) both models assume a totally wet fin, however, it can be seen in these figures that the $\varepsilon$-NTU model generally overpredicts the latent heat transfer rate compared with the Fin2D$\mathrm{W}$ model. The assumption of uniform humidity ratio along the fin height could be the main responsible of these differences in results.

With a further increase in superheat, the second region (R2) starts. Despite the average fin temperature (Equation 2.21) is used by the $\varepsilon$-NTU model for estimating the fin condition, once the fin root temperature becomes very close or equal to the dew point of surrounding air the $\varepsilon$-NTU model immediately converts the status of upper half of the fin from totally wet to totally dry. This is the consequence of high fin efficiency which usually exists in minichannel heat exchangers. On the other hand, the Fin2D-W model still treats the whole fin as totally wet within this region. Usually, R2 is small and this discrepancy in the fin condition does not affect the results so much. However, for some studied conditions, the $\varepsilon$-NTU model underestimates the latent heat transfer rate compared with the Fin2D-W model, as it can be seen in Figures $2.23 b, 2.24 b$, and $2.25 b$.

To understand more the deviations between the two models in this region; the fin temperature profile and mass flux of condensed water, at half the fin depth along the air flow direction ( $z$-direction), for a point in $\mathrm{R} 2$ are shown in Figure 2.26. This point represents CaseII, when $\mathrm{T}_{\mathrm{lt}}=2.0^{\circ} \mathrm{C}$ and $\mathrm{SH}=15.15 \mathrm{~K}$. It can be clearly observed that the $\varepsilon$-NTU model fails to predict the actual fin temperature profile, which subsequently results to a misprediction of the real dehumidifying condition of the fin and latent heat transfer rate, compared with the Fin2D-W model.

In the third region (R3), unlike the $\varepsilon$-NTU model which always assumes that the upper half of the fin is totally dry while the lower half is totally wet; the Fin2D-W model considers any dehumidifying condition of the fin, from $0 \%$ to $100 \%$ wet. It can be noticed from Figures 2.23-2.25 (part $b$ ) that the deviations in latent heat transfer rate exponentially increase with the increase in superheat, especially with the increase in lower tube temperature. The values of these deviations are up to $33 \%$, $144 \%$, and $191 \%$ for Cases I, II, and III, respectively. 

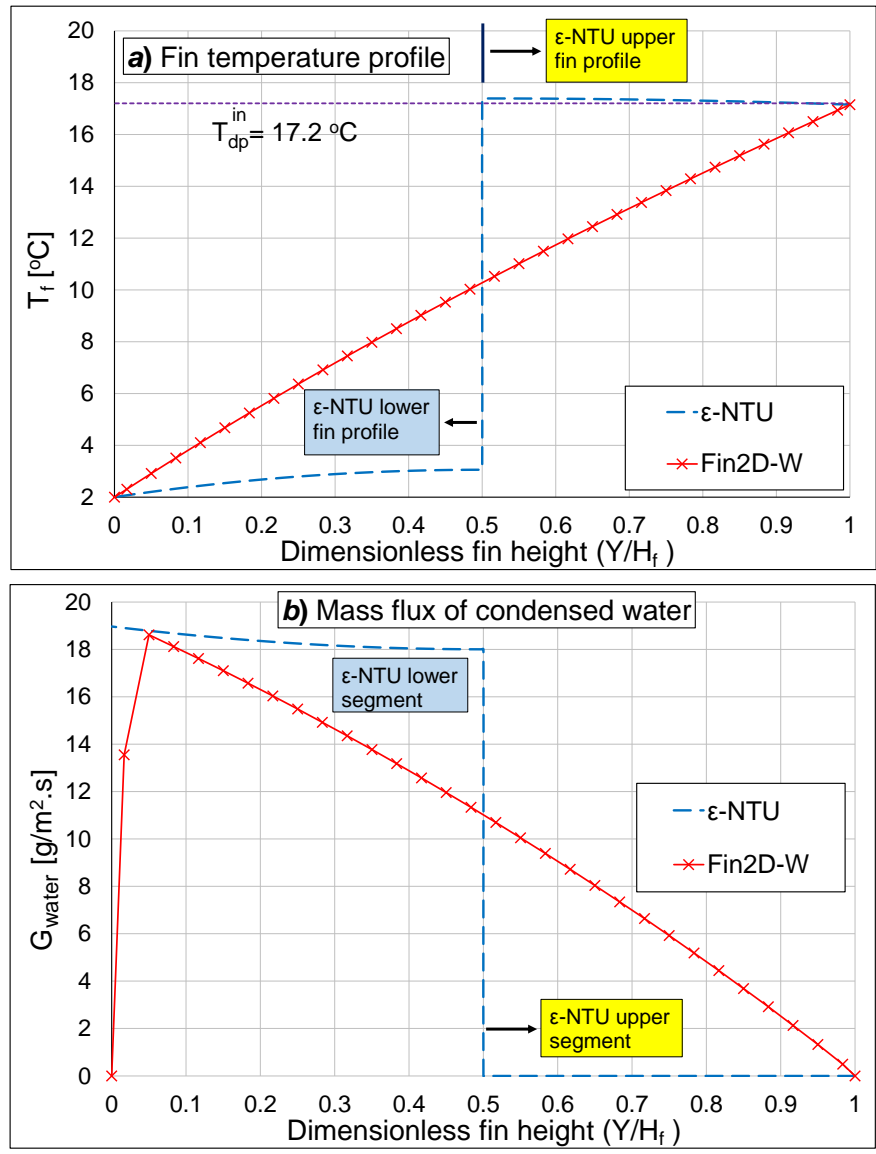

Figure 2.26. (a) Fin temperature profile and $(b)$ mass flux of condensed water, at half the fin depth, for a point in $\mathrm{R} 2$. This represents Case $\mathrm{II}$, when $\mathrm{T}_{\mathrm{lt}}=2.0^{\circ} \mathrm{C}$ and $\mathrm{SH}=15.15 \mathrm{~K}$.

The assumption of adiabatic-fin-tip efficiency at half the height, which is usually adopted by the classical $\varepsilon$-NTU approach, results in a non-continuous fin temperature profile; while the Fin $2 \mathrm{D}-\mathrm{W}$ model considers a continuous temperature profile. This discrepancy leads to considerable differences as the superheat increases. The fin temperature profile resulted from the $\varepsilon$-NTU model is also affected by the high fin efficiency, which subsequently results in an average fin temperature that is too close to the tube wall temperature. This fact, besides the assumption of non-mixed air in the $y$-direction and the misprediction of actual fin condition, can lead to these substantial deviations between the two models, which depend on superheat value and tube temperature. 
Chapter 2.

To clarify more the impact of adiabatic-fin-tip assumption at half the height on the heat transfer results, Figure 2.27 depicts the fin temperature profile and the amount of condensed water at half the fin depth, for a point in R3.
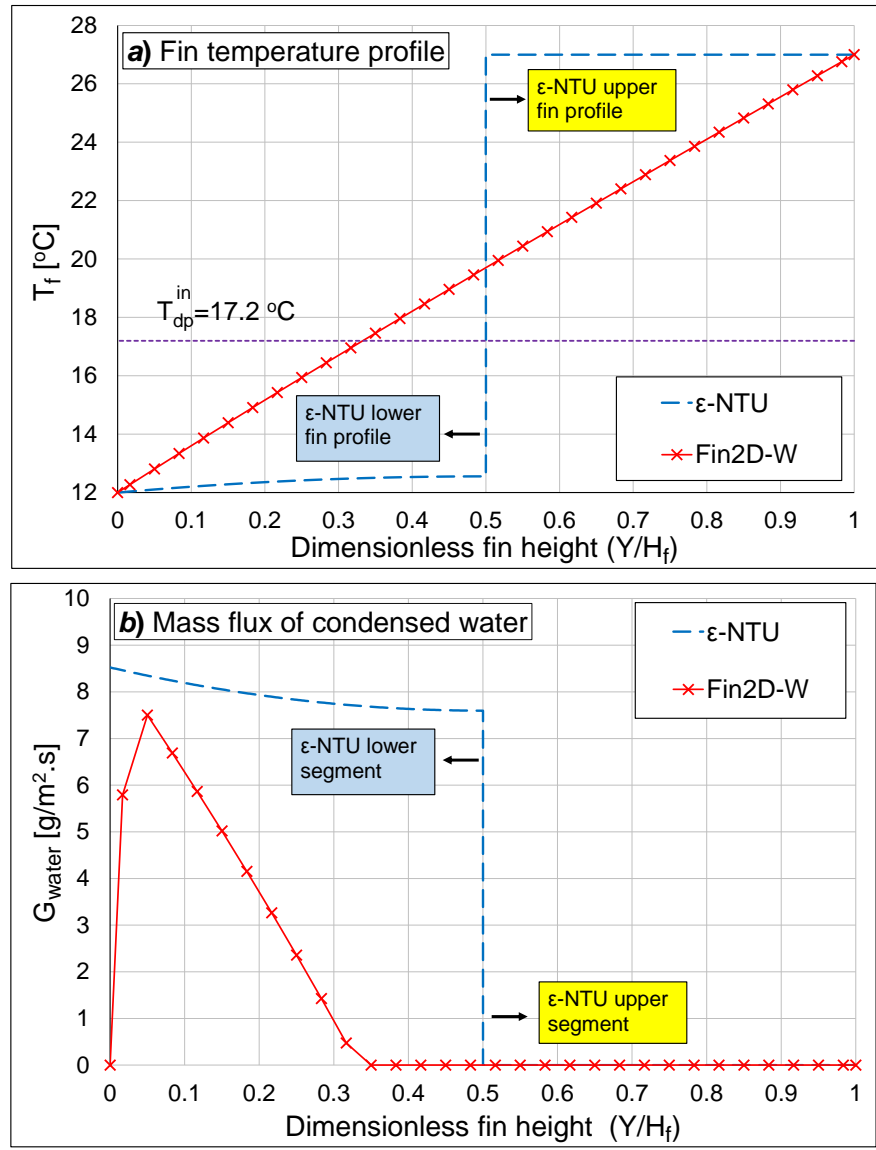

Figure 2.27. (a) Fin temperature profile and $(b)$ mass flux of condensed water, at half the fin depth, for a point in $R 3$. This represents Case II, when $T_{1 t}=12.0^{\circ} \mathrm{C}$ and $S H=15.0 \mathrm{~K}$.

This figure represents an extreme condition for Case II, where $\mathrm{T}_{\mathrm{lt}}=12.0{ }^{\circ} \mathrm{C}$ and $\mathrm{SH}=15.0 \mathrm{~K}$. It can be seen that the Fin2D-W model predicts that approximately $35 \%$ of the fin surface is wet, while the rest is dry. However, the $\varepsilon$-NTU model assumes that the upper portion ( $50 \%$ of the fin height) does not exchange either the heat or the mass with the surrounding air because the temperature of the whole upper portion is equal to the inlet air temperature. Whereas, the entire lower portion is assumed to be totally wet with an average fin temperature $\approx 12.37^{\circ} \mathrm{C}$, which is very close to the lower tube temperature. 
Figure 2.28 shows the relative deviations in total heat transfer rate between the $\varepsilon$ NTU and Fin2D-W models against the superheat for the three cases studied. This gives a general idea about how far the classical modeling assumptions influence the global air-side performance of minichannel evaporators.

It can be clearly noticed that the large deviations in latent heat transfer rate, especially in the partially wet region (R3), significantly affect the deviations in total heat transfer rate. The values of these deviations, between the two models, for Case I, II, and III are up to $16 \%, 30 \%$, and $52 \%$, respectively.

The ARD values in latent and total heat transfer rates for the three lower tube temperatures for each inlet air case are presented in Table 2.4.

Table 2.4. Average relative deviation (ARD) in latent and total heat transfer rates between the $\varepsilon$-NTU and Fin2D-W models (with superheat) [\%].

\begin{tabular}{ccccccc}
\hline Case & \multicolumn{2}{c}{$\mathbf{R 1}$} & \multicolumn{2}{c}{$\mathbf{R 2}$} & \multicolumn{2}{c}{$\mathbf{R 3}$} \\
& $\begin{array}{c}\text { ARD in } \\
\text { latent heat }\end{array}$ & $\begin{array}{c}\text { ARD in } \\
\text { total heat }\end{array}$ & $\begin{array}{c}\text { ARD in } \\
\text { latent heat }\end{array}$ & $\begin{array}{c}\text { ARD in } \\
\text { total heat }\end{array}$ & $\begin{array}{c}\text { ARD in } \\
\text { latent heat }\end{array}$ & $\begin{array}{c}\text { ARD in } \\
\text { total heat }\end{array}$ \\
\hline \hline I & 1.70 & 2.91 & -1.72 & 1.48 & 9.20 & 6.30 \\
II & 3.0 & 3.0 & -1.13 & 1.87 & 43.0 & 13.2 \\
III & 5.0 & 3.0 & 2.30 & 2.0 & 50.0 & 19.50 \\
\hline
\end{tabular}

According to the results of the current study, it can be concluded that the latent heat transfer under wet conditions has an influential contribution to the total heat transfer rate in minichannel evaporators, and it should not be neglected anyhow. However, to estimate correctly the latent heat transfer rate, it is very important to identify firstly the actual dehumidifying condition for the fin and tube. 
Chapter 2.
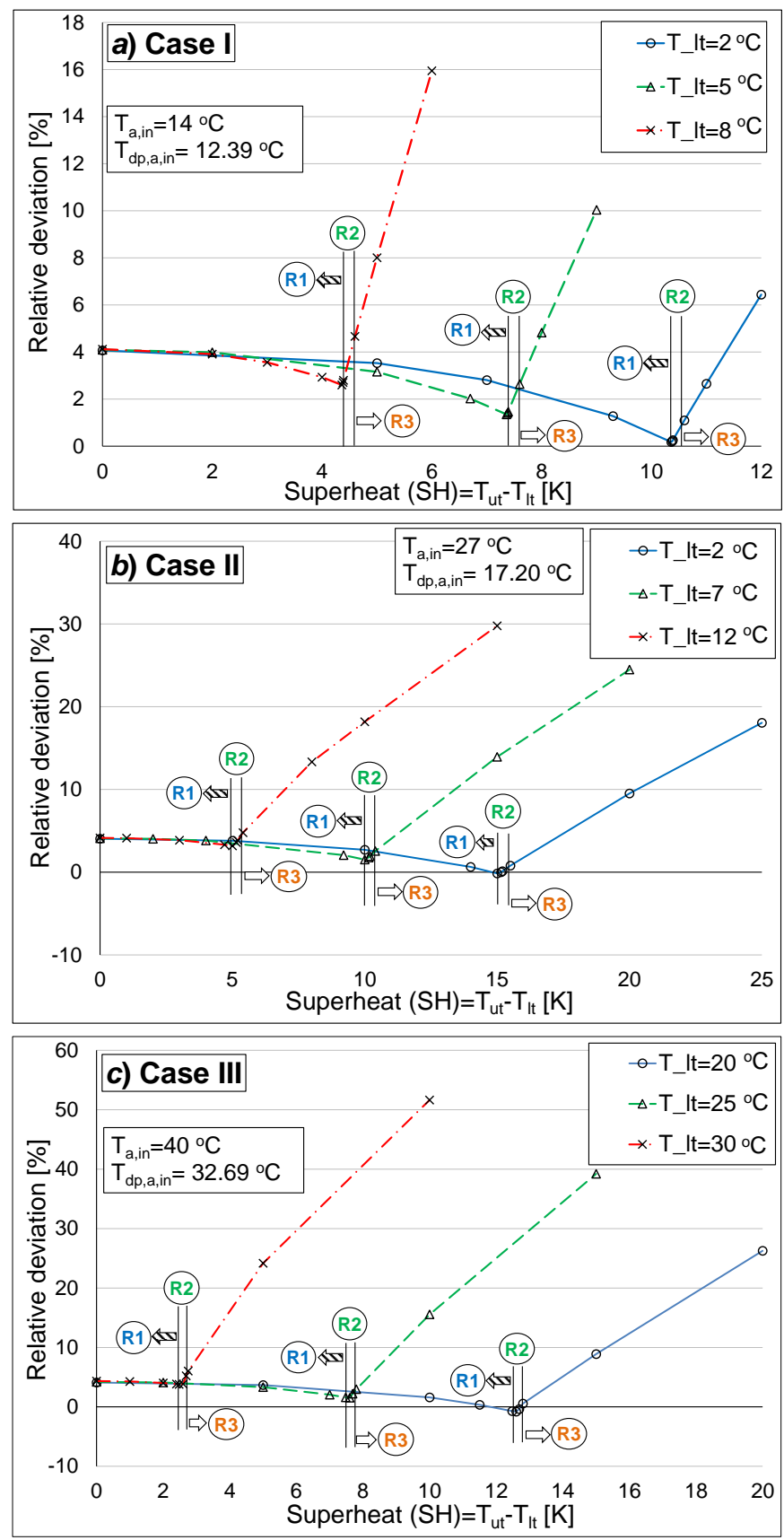

Figure 2.28. Relative deviations in total heat transfer rate between the $\varepsilon$-NTU and Fin2D-W models, for (a) Case I, (b) Case II, and (c) Case III. 


\subsection{Summary}

A 2D numerical model (Fin2D-W) which accounts for the air-side performance of minichannel evaporators was presented. The Fin2D-W model takes into account the 2D heat conduction in any wall element, partial dehumidification scenarios, tube-totube heat conduction, and captures a detailed representation of air flow in both longitudinal and transverse directions.

After verification against an analytical solution, two comparative studies between the classical $\varepsilon$-NTU and Fin2D-W models were made under different dehumidifying conditions.

The first study was implemented under the condition of similar temperatures for upper and lower tubes (without superheat). Under this condition, the widely used assumption of adiabatic-fin-tip at half the height is exactly correct. The results showed that in the regions of totally dry and wet fins, the $\varepsilon-\mathrm{NTU}$ model predicts the total heat transfer rate quite well, compared with the Fin2D-W model. The main source of deviations between the two models is the assumption of uniform air temperature and humidity ratio along the fin height. Moreover, the $\varepsilon$-NTU model's assumption of constant saturation line slope within the whole evaporator segment could contribute to these deviations.

In the region of partially wet fin, the deviations between the two models significantly increase. The $\varepsilon$-NTU model does not account for partial dehumidification scenarios, consequently, it always mispredicts the actual dehumidifying condition of the fin, compared with the presented model. However, these deviations do not affect the results so much, due to the high fin efficiency which resulted in a narrow range of the partially wet fin region of a maximum of $0.5^{\circ} \mathrm{C}$.

The second study was performed when a temperature difference between the adjacent tubes, due to refrigerant superheat, existed. Under this case, the assumption of adiabatic-fin-tip at half the height is not valid anymore.

The results revealed that this assumption, which is usually adopted by the $\varepsilon$-NTU method, prevents the heat conduction between tubes and results to a discontinuity in the fin temperature profile. This, in turn, results in a large deviations in the average fin temperature and corresponding saturated humidity ratio, compared with the 
Chapter 2.

Fin2D-W model. Subsequently, the $\varepsilon$-NTU model fails to predict the actual fin condition and the sensible and latent heat transfer rates, especially in the partially wet fin region.

However, the main advantages of the $\varepsilon$-NTU approach are the simplicity and calculation speed. It was about five times faster than the Fin2D-W model, for all the cases studied. This makes the $\varepsilon$-NTU method one of the most favorite approaches for modeling the heat exchangers.

Accordingly, the next objective will be to develop a less complicated model compared to the Fin2D-W model. This future model will capture the partial dehumidification scenarios and tube-to-tube heat conduction as the Fin2D-W model does, but with higher computational speed like the $\varepsilon$-NTU approach. 


\title{
Chapter 3. \\ Fin1D-MB Model
}

\author{
"Imagination creates reality" \\ -Richard Wagner
}


Chapter 3.

\subsection{Introduction}

According to the results of Chapter 2, the main objective of the current chapter is to develop a simpler model, which will be referred to as Fin1D-MB. The proposed model is able to retain the most important phenomena as the Fin2D-W model but with a much lower computational cost. To this end, a novel discretization scheme is proposed. This scheme is based on the fundamental fin theory coupled with the moving boundaries technique for the air-side. After the verification of the Fin1D-MB model, a comparison of the air-side results of the presented model with the Fin2D$\mathrm{W}$ model will be presented to check the degree of success in achieving this objective.

\subsection{Description of the Fin1D-MB Model}

As mentioned before, the present model is based on the Fin2D-W model. However, some new features and techniques are considered in order to reduce computation time and achieve reasonable accuracy. These modifications are summarized as follows:

- The studies of Asinari et al. (2004) and Martínez-Ballester et al. (2011) on minichannel condensers revealed that the longitudinal heat conduction (LHC) in the fin along the air flow direction had a negligible effect on the predicted performance results. Moreover, several current fin surfaces have cuts in this direction at which the effect of LHC can be neglected. In the present model, this effect is canceled, which means no thermal connections between adjacent fin cells along the air flow direction.

- The Fin2D-W model requires a detailed 2D discretization of the fin wall and air flow, to obtain an accurate temperature and humidity ratio profiles. This is the consequence of not applying the fin theory which, in turn, requires a long computation time. To solve this issue in the current model, the fundamental fin theory (Chapter 1, Equations 1.25 and 1.28) is adopted to obtain a onedimensional temperature profile in the direction between the tubes (along the fin height). Accordingly, the fin is physically discretized only in the direction of the air flow. Equations (1.25) and (1.28) are the general differential equations for the totally wet and dry fins, respectively. These equations have to be coupled to get an expression which is capable of representing a continuous temperature profile for the entire fin under any dehumidifying condition. However, to identify the locations and sizes of the dry and wet portions within 
the fin surface, a further discretization along the fin height is required according to the dehumidifying condition. It should be noted that Equations (1.25) and (1.28) do not imply the classical adiabatic-fin-tip assumption (in the crosssection at half the fin height) since boundary conditions have not yet been applied.

- The results of Martínez-Ballester et al. (2011), in addition to the results presented in Chapter 2, Section 2.6, revealed that the air temperature and humidity ratio profiles are quite flat along the direction between the tubes, except for the air close to the tubes, which has obvious temperature and humidity ratio gradients. The portion of the fin which is occupied by the air close to the tubes is small compared with the rest, approximately $1 / 30$ of the fin height. Nevertheless, Martínez-Ballester et al. (2013a) developed a Fin1Dx3 model which takes into account this temperature gradient. Their model discretizes the fin into three pieces along the fin height in addition to the discretization in the air flow direction. The fin pieces near the tubes have the same height, which is referred to as fin height ratio. This ratio is fixed and can be adjusted according to the fin geometry and operating conditions. Nevertheless, this discretization scheme is incompatible with the proposed Fin1D-MB model. The Fin2D-W results revealed that the misprediction of the correct fin condition (totally dry, totally wet, or partially wet) predominates the heat transfer deviations more than the assumption of uniform air temperature and humidity ratio between tubes. Furthermore, Martínez-Ballester et al. (2013b) implemented a comparative study between a detailed 2D gas cooler model and a simpler 1D model. In their 1D model, as in the proposed model in this chapter, the fins were discretized only in the air flow direction, and a uniform air temperature profile was assumed along the fin. They found that the total deviation between the 1D and 2D models only reached a maximum of $2 \%$. Accordingly, in the current work, the effect of non-mixed air between the tubes is neglected. Furthermore, the discretization of the fin along the fin height is implemented according to the dehumidifying condition of the fin, as mentioned in the previous point.

\subsubsection{Evaporator discretization}

The evaporator tubes are discretized along the $x$-direction (refrigerant flow direction) to $\mathrm{N}_{\mathrm{s}}$ segments, as shown in Figure 3.1a. Each segment (Figure 3.1b) consists of: a refrigerant flow that is split into $\mathrm{N}_{\mathrm{r}, \mathrm{z}}$ channels in the $z$-direction (air flow direction); 
Chapter 3.

upper and lower flat tubes which are discretized into $\mathrm{N}_{\mathrm{t}, \mathrm{z}}$ cells in the $z$-direction; air flow and fins which are discretized into the same number of cells in the $z$-direction, where $\mathrm{N}_{\mathrm{a}, \mathrm{z}}=\mathrm{N}_{\mathrm{f}, \mathrm{z}}$. The discretization for an evaporator is summarized in the following as a grid: $\left\{\mathrm{N}_{\mathrm{s}}, \mathrm{N}_{\mathrm{r}, \mathrm{z}}, \mathrm{N}_{\mathrm{t}, \mathrm{z}}, \mathrm{N}_{\mathrm{a}, \mathrm{z}}\right\}$.

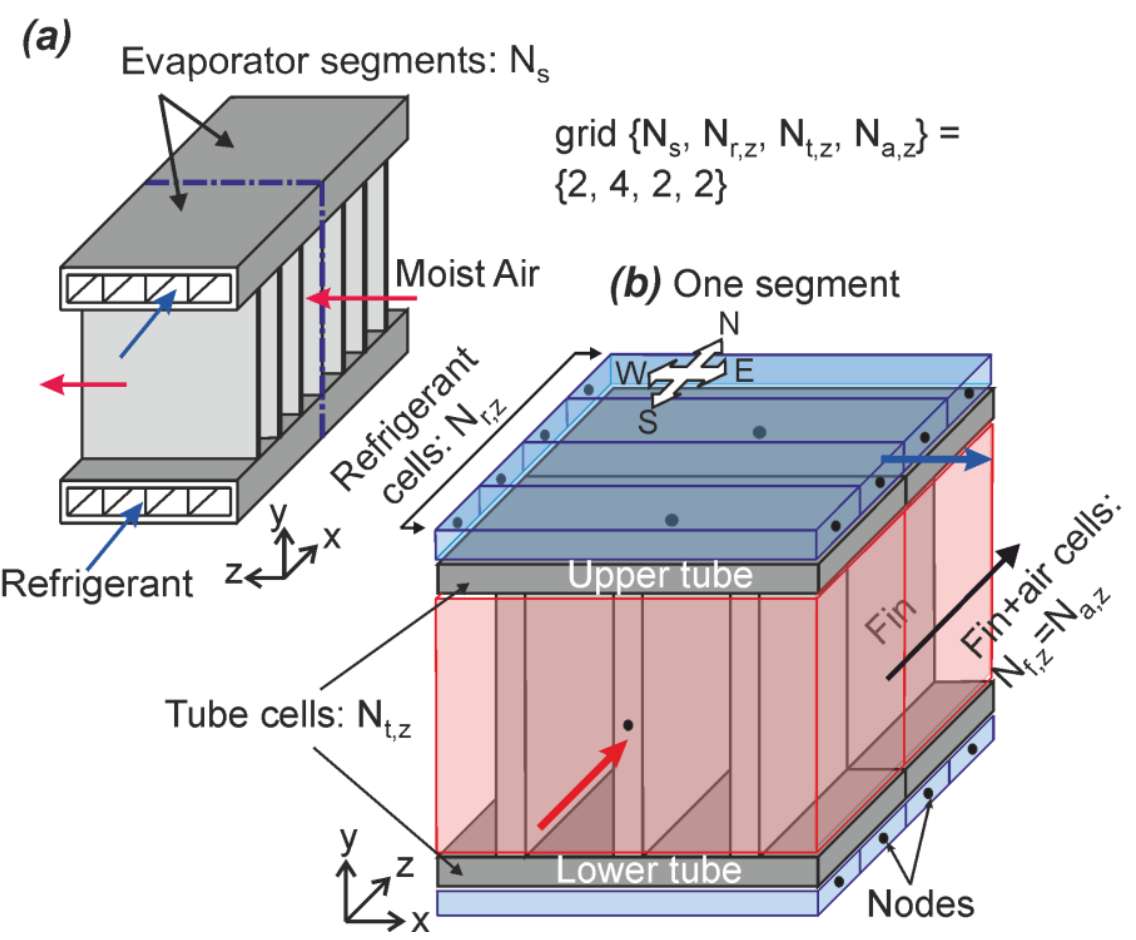

Figure 3.1. (a) Discretization of evaporator tubes into segments. (b) Schematic representation of a segment discretization into cells.

\subsubsection{Governing equations}

Each fluid cell (either refrigerant or air) has two nodes, which correspond to the inlet and outlet sections in the fluid flow direction. The tube wall cells have only one node located at the centroid of the cell, as shown in Figure 3.1b. It can be seen that the fins do not have any nodes because a continuous function governs in this case. In the current model, the assumption of uniform air properties along the fin height ( $y$-direction) is applied, In addition to the other assumptions that used for developing the Fin2D-W model (Chapter 2, Sub-section 2.2.2). 


\subsubsection{Tube wall analysis}

The energy conservation equation within any tube wall cell $t$ in contact with $n_{a}$ air cells, $n_{r}$ refrigerant cells, and $n_{f}$ fin cells can be written as:

$$
\begin{aligned}
\nabla\left(k_{t} \cdot \nabla T_{c, t}\right) & d V+\sum_{r=1}^{n_{r}} U_{r, t}\left(T_{r}-T_{c, t}\right) d A_{r, t}+ \\
& \sum_{a=1}^{n_{a}} U_{\text {wet }, a, t}\left(T_{a, t}^{*}-T_{c, t}\right) d A_{a, t}+\sum_{f=1}^{n_{f}}-\left.d Q_{\text {cond }, f}\right|_{\text {fin root }}=0
\end{aligned}
$$

It should be noted that a linearization scheme is used in Equation (3.1) to relate the saturated air humidity ratio to its corresponding surface tube wall temperature (Elmahdy and Biggs, 1983), where $W_{\mathrm{sat}, s, t}=a_{a, t}+b_{a, t} \cdot T_{s, t}$.

$T_{c, t}$ is the temperature evaluated at the centroid of the tube wall cell $t$. Equation (3.1) is very similar to Equation (2.5); however, the last term $\left(Q_{\text {cond }, f}\right)$ is introduced to evaluate the heat transfer by conduction between the tube wall cell and the fin root in contact with it. Additionally,

$U_{r, t}=1 /\left[\left(t_{t} / 2 \cdot k_{t}\right)+\left(1 / \alpha_{r, t}\right)\right]$

$U_{\text {wet }, a, t}=1 /\left[\left(t_{t} / 2 \cdot k_{t}\right)+\left(1 / \alpha_{\text {wet }, a, t}\right)\right]$

$\alpha_{\mathrm{wet}, a, t}=\alpha_{a, t}\left(1+\beta_{a} \cdot b_{a, t}\right)$,

$\beta_{a}=h_{f g} / C_{p, m a} \cdot L e^{2 / 3}$

$b_{a, t}=\left(W_{a}-W_{\text {sat }, s, t}\right) /\left(T_{d p}-T_{s, t}\right)$

$T_{a, t}^{*}=\frac{T_{a}+\beta_{a}\left[W_{a}-\left(W_{\mathrm{sat}, s, t}-b_{a, t} \cdot T_{s, t}\right)\right]}{1+\beta_{a} \cdot b_{a, t}}$ is the overall heat transfer coefficient for the refrigerant-side, where $t_{t}$ is the wall thickness of the tube cell; is the overall heat transfer coefficient for the air-side under wet conditions;

is the total heat transfer coefficient for the air-side under wet conditions;

is the slope of saturated humidity ratio line (Sharqawy and Zubair, 2008); and

is the modified temperature for moist air.

$T_{a}, W_{a}, T_{d p}, C_{p, m a}, \alpha_{a}$ are the moist air temperature, humidity ratio, dew point, specific heat, and sensible heat transfer coefficient, respectively. $T_{s, t}$ and $W_{\text {sat }, s, t}$ are the tube wall temperature and saturated humidity ratio evaluated at the surface, respectively. 
Chapter 3.

\subsubsection{Fin wall analysis}

The physical discretization of the fin is $1 \mathrm{D}$. However, to capture the actual fin condition, it has to be virtually discretized into three portions (fp1, fp2, and fp3) in the $y$-direction, as it can be seen in Figure 3.2a. Each portion has its independent local coordinates and temperature function. The lower portion (fp1) and upper portion (fp3) are always assumed to be fully wet, while the middle one (fp2) is always assumed to be fully dry.

The area of each portion is specified depending on $\zeta_{1}$ and $\zeta_{2}$, which define the boundaries between wet and dry portions. These virtual boundaries are movable from one fin cell to another depending on the fin tip and base temperatures, $T_{f T}$ and $T_{f B}$, as well as the dew point of surrounding air. This is the reason for the model's name: "Fin1D" because it applies a one-dimensional equation for each fin/air connection and "MB" because it adopts the moving boundaries technique to identify the wet and dry portions of the fin.
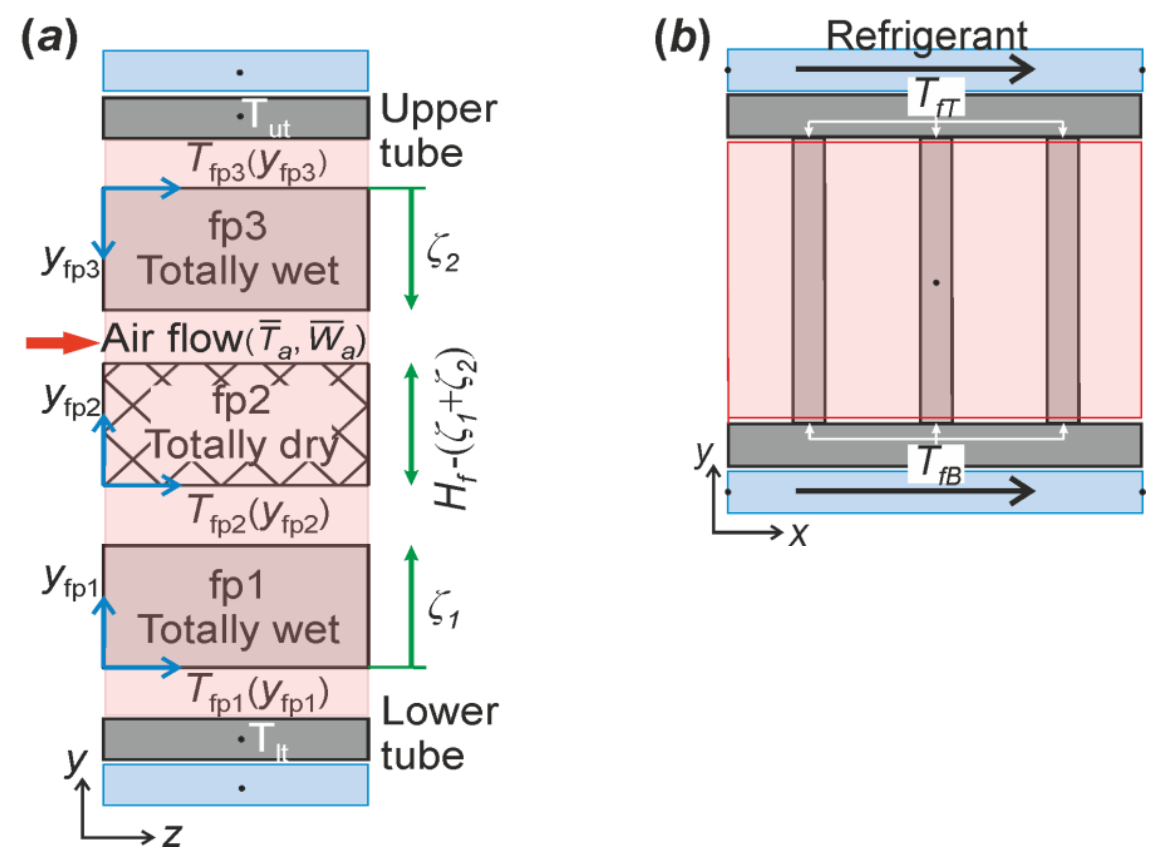

Figure 3.2. (a) $y$ - $z$ plane, which shows the virtual discretization of the fin in $y$-direction and boundaries between wet and dry portions, $\zeta_{1}$ and $\zeta_{2}$. (b) $y$-x plane, which shows the locations of $T_{f B}$ and $T_{f}$. 
Therefore, each fin cell has a composed governing equation (Equation 3.2) which consists of three sub-functions that present a continuous temperature profile for the entire fin under any dehumidifying condition.

$$
\theta_{a, f}(y) \begin{cases}\theta_{a, \mathrm{fp} 1}\left(y_{\mathrm{fp} 1}\right)=C_{1} e^{M \cdot y_{\mathrm{fp} 1}}+C_{2} e^{-M \cdot y_{\mathrm{fp} 1}}-\psi & 0 \leq y_{\mathrm{fp} 1} \leq \zeta_{1} \\ \theta_{a, \mathrm{fp} 2}\left(y_{\mathrm{fp} 2}\right)=C_{3} e^{m \cdot y_{\mathrm{fp} 2}}+C_{4} e^{-m \cdot y_{\mathrm{fp} 2}} & 0 \leq y_{\mathrm{fp} 2} \leq H_{f}-\left(\zeta_{1}+\zeta_{2}\right) \\ \theta_{a, \mathrm{f} \mathrm{p} 3}\left(y_{\mathrm{fp} 3}\right)=C_{5} e^{M \cdot y_{\mathrm{fp} 3}}+C_{6} e^{-M \cdot y_{\mathrm{fp} 3}}-\psi & 0 \leq y_{\mathrm{fp} 3} \leq \zeta_{2}\end{cases}
$$

where $\theta$ is the temperature difference between surrounding air and fin temperature. $\psi$ is a parameter which includes the effect of moist air humidity ratio on the fin temperature profile (Chapter 1, Equation 1.25). $H_{f}$ is the total fin height. $m$ and $M$ are the dry and wet fin parameters, respectively. They were defined in Chapter 1, Equations (1.16) and (1.25), respectively. The unknown constants from $C_{1}$ to $C_{6}$ must be evaluated from the boundary conditions (B.C.) of the heat transfer problem along the fin height; i.e., the temperature field must be continuous and derivable. Therefore, the boundary conditions required to evaluate these constants are:

$$
\text { B.C. }\left\{\begin{array}{l}
\theta_{a, \mathrm{fp} 1}\left(y_{\mathrm{fp} 1}=0\right)=\theta_{a, f B}=T_{a}-T_{f B} \\
\theta_{a, \mathrm{fp} 1}\left(y_{\mathrm{fp} 1}=\zeta_{1}\right)=\theta_{a, \mathrm{fp} 2}\left(y_{\mathrm{fp} 2}=0\right) \\
\left.\frac{d \theta_{a, \mathrm{fp} 1}}{d y_{\mathrm{fp} 1}}\right|_{y_{\mathrm{fp} 1}=\zeta_{1}}=\left.\frac{d \theta_{a, \mathrm{fp} 2}}{d y_{\mathrm{fp} 2}}\right|_{y_{\mathrm{fp} 2}=0} \\
\theta_{a, \mathrm{fp} 3}\left(y_{\mathrm{fp} 3}=0\right)=\theta_{a, f T}=T_{a}-T_{f T} \\
\theta_{a, \mathrm{fp} 2}\left(y_{\mathrm{fp} 2}=H_{f}-\left(\zeta_{1}+\zeta_{2}\right)\right)=\theta_{a, \mathrm{fp} 3}\left(y_{\mathrm{fp} 3}=\zeta_{2}\right) \\
\left.\frac{d \theta_{a, \mathrm{fp} 2}}{d y_{\mathrm{fp} 2}}\right|_{y_{\mathrm{fp} 2}=H_{f}-\left(\zeta_{1}+\zeta_{2}\right)}=-\left.\frac{d \theta_{a, \mathrm{fp} 3}}{d y_{\mathrm{fp} 3}}\right|_{y_{\mathrm{fp} 3}=\zeta_{2}}
\end{array}\right.
$$

Equation (3.2) and its boundary conditions assume uniform air temperature and humidity ratio along y-direction within the air cell in contact with the evaluated fin cell. So, $\bar{T}_{a}$ and $\bar{W}_{a}$ represent the integrated mean values for air temperature and humidity ratio within the cell, respectively. The locations of $T_{f B}$ and $T_{f T}$ are illustrated in Figure $3.2 b$.

By applying the boundary conditions (Equation 3.3) into Equation (3.2), it is possible to define the fin temperature $T_{f}$ as follows. 
Chapter 3.

$$
T_{f}(y)=\left\{\begin{array}{l}
T_{\mathrm{fp} 1}\left(y_{\mathrm{fp} 1}\right)=\bar{T}_{a}-\theta_{a, \mathrm{fp} 1}\left(y_{\mathrm{fp} 1}\right) \\
T_{\mathrm{fp} 2}\left(y_{\mathrm{fp} 2}\right)=\bar{T}_{a}-\theta_{a, \mathrm{fp} 2}\left(y_{\mathrm{fp} 2}\right) \\
T_{\mathrm{fp} 3}\left(y_{\mathrm{fp} 3}\right)=\bar{T}_{a}-\theta_{a, \mathrm{fp} 3}\left(y_{\mathrm{fp} 3}\right)
\end{array}\right\}=\left[\mathrm{A}\left(y_{\mathrm{fp} 1}, y_{\mathrm{fp} 2}, y_{\mathrm{fp} 3}\right)\right] \cdot\left[\begin{array}{l}
\bar{T}_{a} \\
T_{f B} \\
T_{f T} \\
\bar{\psi}
\end{array}\right]
$$

where $T_{\mathrm{fp} 1}, T_{\mathrm{fp} 2}$, and $T_{\mathrm{fp} 3}$ are the first, second and third fin portion temperature, respectively. $\mathrm{A}\left(y_{\mathrm{fp} 1}, y_{\mathrm{fp} 2}, y_{\mathrm{fp} 3}\right)$ is a $3 \times 4$ matrix that depends on the local coordinates, fin geometry, $\mathrm{m}, \mathrm{M}, \zeta_{1}$, and $\zeta_{2}$.

Figure 3.3 shows an example of a temperature profile, which resulted from using Equation (3.4), for a typical fin in minichannel evaporator under the partial dehumidification scenario. In this example, the values of $\bar{T}_{a}, \bar{T}_{d p}$, and $\bar{\psi}$ are $27{ }^{\circ} \mathrm{C}, 17.2$ ${ }^{\circ} \mathrm{C}$, and $-6.33 \mathrm{~K}$, respectively. The fin base and tip temperatures are $17{ }^{\circ} \mathrm{C}$ and 17.1 ${ }^{\circ} \mathrm{C}$, respectively; while the value of $m \cdot H_{f}$ equals 0.5 . This numerical example gives a general idea how the Fin1D-MB model estimates the dehumidifying condition of the fin and its composed temperature profile. It can be observed that the fin, under this situation, comprises three portions. The first fin portion (fp1) is wet and occupies approximately $20 \%$ of the total fin height, the second fin portion (fp2) is dry and occupies approximately $70 \%$ of the total fin height, and the third fin portion (fp3) is wet and occupies approximately $10 \%$ of the total fin height.

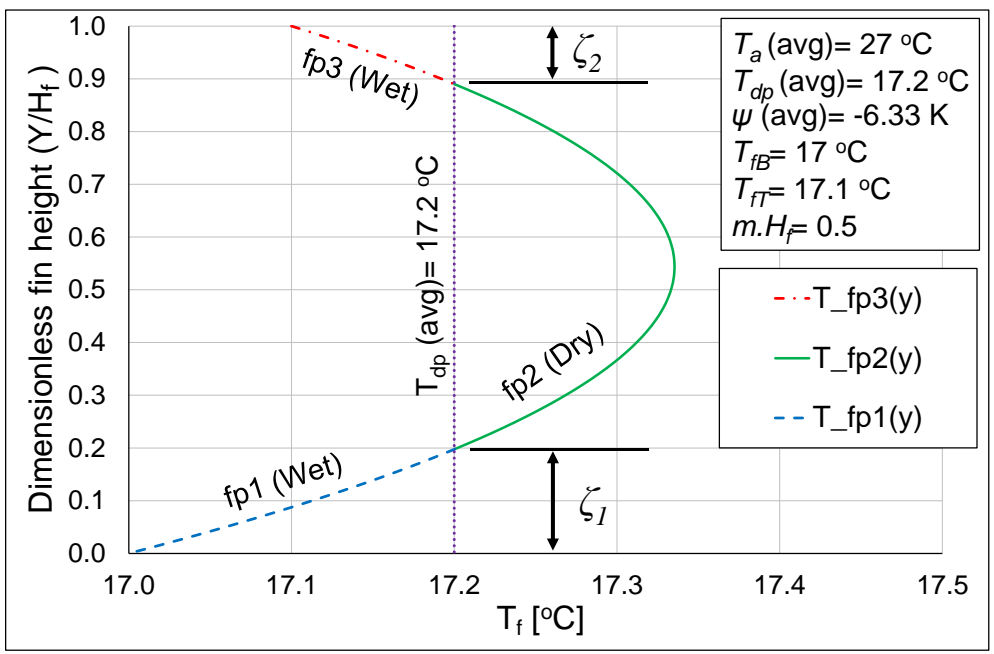

Figure 3.3. A numerical example of the estimated fin temperature profile in the Fin1D-MB model. 


\subsubsection{Moist air analysis}

Equation (3.5) shows the heat rate balance within an air cell $a$ in contact with a fin cell $f$, which is discretized into three portions $(\mathrm{fp}=1-3)$, and $n_{t}$ tube cells $\left(t=1-n_{t}\right)$.

$$
\dot{m}_{a} \cdot C_{p, m a} \cdot d T_{a}=-d Q_{\mathrm{sens}, a, f}-\sum_{t=1}^{n_{t}} \alpha_{a, t}\left(T_{a}-T_{s, t}\right) d A_{a, t}
$$

where $\dot{m}_{a}$ is the mass flow rate of air across the cell, and $A_{a, t}$ is the contact surface area between the air and tube cells. $Q_{\text {sens }, a, f}$ is the sensible heat transferred to the adjacent fin cell $f$, which can be expressed as:

$$
d Q_{\mathrm{sens}, a, f}=\sum_{\mathrm{fp}=1}^{3} \alpha_{a, \mathrm{fp}} \cdot \theta_{a, \mathrm{fp}} \cdot d z d y_{\mathrm{fp}}
$$

The mass balance within any air cell is:

$$
\dot{m}_{a} \cdot d W_{a}=-d \dot{m}_{\mathrm{water}, a, f}-\sum_{t=1}^{n_{t}} \alpha_{D_{a, t}}\left(W_{a}-W_{\mathrm{sat}, s, t}\right) d A_{a, t}
$$

$\dot{m}_{\text {water }, a f f}$ is the mass flow rate of condensed water to the adjacent fin cell $f$, which is calculated as:

$$
d \dot{m}_{\mathrm{water}, a, f}=\sum_{\mathrm{fp}=1}^{3} \alpha_{D_{a, \mathrm{fp}}} \cdot \omega_{a, \mathrm{fp}} \cdot d z d y_{\mathrm{fp}}
$$

where

$$
\begin{array}{ll}
\alpha_{D}=\frac{\alpha_{a}}{L e^{2 / 3} \cdot C_{p, m a}} \quad \begin{array}{l}
\text { is the mass transfer coefficient for air-side which based } \\
\text { on Chilton-Colburn analogy; and }
\end{array} \\
\omega_{a, \mathrm{fp}}=W_{a}-W_{\text {sat,fp }}\left\{T_{\mathrm{fp}}\left(y_{\mathrm{fp}}\right)\right\} \begin{array}{l}
\text { is the humidity ratio difference between the surround- } \\
\text { ing air and saturated air evaluated at specific fin por- } \\
\text { tion temperature. }
\end{array}
\end{array}
$$

In Equation (3.7) the air cell can only exchange the mass with the tube cells and fin portions whose temperatures are below the dew point of the air (dehumidification process exists). If any of these is above or equal to the dew point of air, it is not considered in the mass balance. 
Chapter 3.

\subsubsection{Refrigerant analysis}

The energy balance in each refrigerant cell $r$ in contact with $n_{t}$ tube wall cells $t=1-n_{t}$ is explained in Equation (3.9).

$$
\dot{m}_{r} \cdot d h_{r}=-\sum_{t=1}^{n_{t}} \alpha_{r, t}\left(T_{r}-T_{s, t}\right) d A_{r, t}
$$

where $\dot{m}_{r}$ is the mass flow rate of refrigerant across the cell, $\alpha_{r}$ is the sensible heat transfer coefficient for refrigerant-side, and $A_{r, t}$ is the contact surface area between the refrigerant and tube cells.

The boundary conditions, which were stated in Chapter 2, Sub-sub-section 2.2.2.2, are also applicable to the Fin1D-MB model.

\subsubsection{Numerical scheme}

The finite volume method is applied to discretize the governing equations described in the previous sub-section. However, it is necessary to assume temperature and humidity ratio profiles for the fluids to obtain the estimation of the integral of the heat and mass transfer between the fluids and the corresponding piece of wall (Equation 3.1 ) in the fluid flow direction. This integration must be consistent with the integration of the coincident terms in Equations (3.5), (3.7), and (3.9). The linear fluid temperature variation (LFTV) scheme was employed for both fluids, as suggested by Corberán et al. (2001) for this application. After discretizing the Laplacian term in Equation (3.1) using the classical finite difference approach, besides applying the LFTV scheme; Equation (3.1) can be now expressed as follows:

$$
\begin{aligned}
\lambda_{t} \cdot T_{c, t}-\sum_{k=\mathrm{W}, \mathrm{E}, \mathrm{S}, \mathrm{N}} \lambda_{t-k} \cdot T_{c, k} & =\sum_{r=1}^{n_{r}} U_{r, t}\left(\bar{T}_{r}-T_{c, t}\right) P_{r, t} \cdot \Delta x_{r, t}+ \\
& \sum_{a=1}^{n_{a}} U_{\mathrm{wet}, a, t}\left(\bar{T}_{a, t}^{*}-T_{c, t}\right) P_{a, t} \cdot \Delta z_{a, t}+\left.\sum_{f=1}^{n_{f}} Q_{\mathrm{cond}, f}\right|_{\text {fin root }}
\end{aligned}
$$

where

$$
\bar{T}_{r}=\frac{T_{r}^{\text {in }}+T_{r}^{\text {out }}}{2}, \bar{T}_{a, t}^{*}=\frac{\left.T_{a, t}^{*}\right|^{\text {in }}+\left.T_{a, t}^{*}\right|^{\text {out }}}{2}, \lambda_{t-\mathrm{W}}=\frac{k_{t} A_{t-\mathrm{W}}}{\delta l_{t-\mathrm{W}}}, \lambda_{t-\mathrm{E}}=\frac{k_{t} A_{t-\mathrm{E}}}{\delta l_{t-\mathrm{E}}}, \lambda_{t-\mathrm{S}}=\frac{k_{t} A_{t-\mathrm{S}}}{\delta l_{t-\mathrm{S}}},
$$




$$
\lambda_{t-\mathrm{N}}=\frac{k_{t} A_{t-\mathrm{N}}}{\delta l_{t-\mathrm{N}}} \text {, and } \lambda_{t}=\sum_{k=\mathrm{W}, \mathrm{E}, \mathrm{S}, \mathrm{N}} \lambda_{t-k} .
$$

The direction reference used in the current model is shown in Figure 3.1b. All $\lambda_{t-k}$ terms refer to the conductance between a tube cell $t$ and the adjacent tube cell in the $k$ direction. $P_{r, t}$ and $P_{a, t}$ are the contact perimeters between the refrigerant and tube cells, and air and tube cells, respectively.

The LFTV scheme is also applied in Equation (3.9) to evaluate the outgoing temperature of a refrigerant cell $r$ :

$$
T_{r}^{\text {out }}=\frac{T_{r}^{\text {in }}\left(1-0.5 \sum_{t=1}^{n_{t}} \mathrm{NTU}_{r, t}\right)+\sum_{t=1}^{n_{t}} \mathrm{NTU}_{r, t} \cdot T_{s, t}}{\left(1+0.5 \sum_{t=1}^{n_{t}} \mathrm{NTU}_{r, t}\right)}
$$

where $\mathrm{NTU}_{r, t}=\frac{\alpha_{r, t} \cdot A_{r, t}}{\dot{m}_{r} \cdot \bar{C}_{p, r}}$

Equation (3.11) is used for a one-phase flow, whereas for two-phase flow the outlet temperature depends on the outlet pressure.

To obtain the outgoing temperature and humidity ratio of the air, Equations (3.5) and (3.7) have to be solved. However, the integration of Equations (3.6) and (3.8) must be done previously. The total sensible heat transferred to the fin cell can be expressed as:

$$
\int d Q_{\mathrm{sens}, a, f}=\int \sum_{\mathrm{fp}=1}^{3} \alpha_{a, \mathrm{fp}} \cdot \theta_{a, \mathrm{fp}} \cdot d z d y_{\mathrm{fp}}=\sum_{\mathrm{fp}=1}^{3} \alpha_{a, \mathrm{fp}} \cdot A_{a, \mathrm{fp}} \cdot \bar{\theta}_{a, \mathrm{fp}}
$$

where $\bar{\theta}_{a, \mathrm{fp}}$ is the integrated mean value of $\theta_{a, \mathrm{fp}}\left(y_{\mathrm{fp}}\right)$ for each fin portion.

While, the total mass transferred to the fin surface is given by:

$$
\int d \dot{m}_{\mathrm{water}, a, f}=\int \sum_{\mathrm{fp}=1}^{3} \alpha_{D_{a, \mathrm{fp}}} \cdot \omega_{a, \mathrm{fp}} \cdot d z d y_{\mathrm{fp}}=\sum_{\mathrm{fp}=1}^{3} \alpha_{D_{a, \mathrm{fp}}} \cdot A_{a, \mathrm{fp}} \cdot \bar{\omega}_{a, \mathrm{fp}}
$$


Chapter 3.

where $\bar{\omega}_{a, \mathrm{fp}}=\bar{W}_{a}-a_{a, f}-b_{a, f}\left(\bar{T}_{a}-\bar{\theta}_{a, \mathrm{fp}}\right), \bar{W}_{a}=\frac{W_{a}^{\mathrm{in}}+W_{a}^{\mathrm{out}}}{2}, \bar{T}_{a}=\frac{T_{a}^{\mathrm{in}}+T_{a}^{\mathrm{out}}}{2}$

$a_{a, f}$ and $b_{a, f}$ are parameters which resulted from the linearization process of saturated humidity ratio curve, where $W_{\text {sat } f}(\mathrm{y})=a_{a, f}+b_{a, f} T_{f}(\mathrm{y})$ as it was defined in $\mathrm{Wu}$ and Bong (1994), and Sharqawy and Zubair (2008). These parameters are evaluated between the average dew point of surrounding air and the minimum fin root temperature (either the fin base or tip), as shown in Figure 3.4.

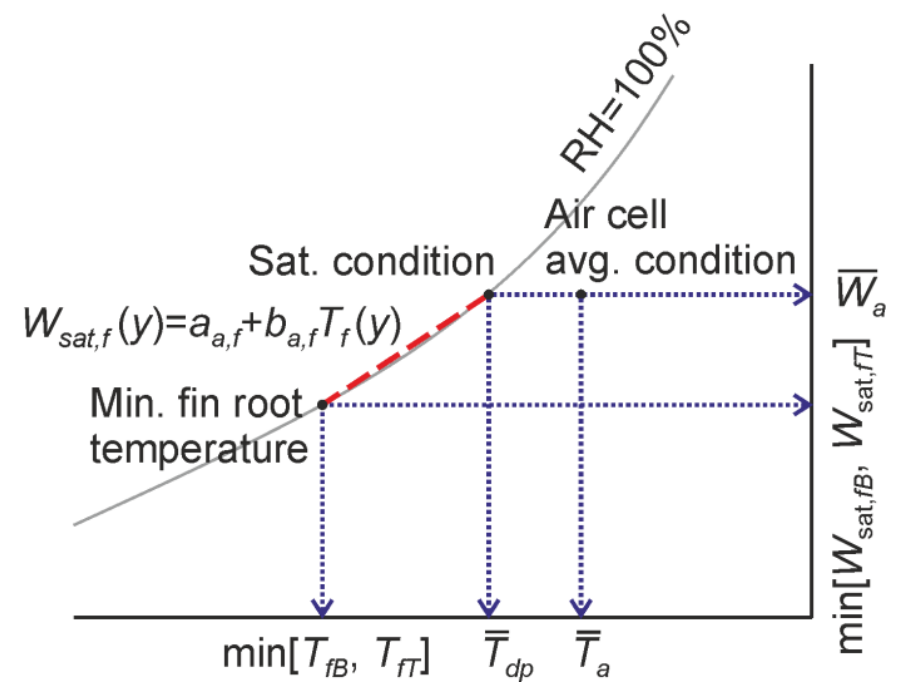

Figure 3.4. Linearization scheme of saturated humidity ratio curve used in the Fin1D-MB model for wet fin analysis.

The novelty of the current model is the implementation of integration of the fin temperature function. This integration takes into account the effect of different dehumidifying conditions on the fin temperature profile and heat conduction between tubes through the fin. Instead of using the current approach, other evaporator models in the literature assume adiabatic section at half the fin height. Subsequently, the adiabatic-fin-tip efficiency, for totally dry or wet condition, is applied. However, some models, which use the adiabatic-fin-tip efficiency, tried to apply more or less artificial approaches in order to include heat conduction between tubes (Lee and Domanski, 1997; Singh et al., 2008). 
Substituting Equations (3.12) and (3.13) into Equations (3.5) and (3.7), respectively. Consequently, the sensible heat transfer rate from the air cell to the corresponding fin cell and tubes is expressed as follows:

$$
\dot{m}_{a} \cdot \bar{C}_{p, m a} \cdot \Delta T_{a}=-\sum_{\mathrm{fp}=1}^{3} \alpha_{a, \mathrm{fp}} \cdot A_{a, \mathrm{fp}} \cdot \bar{\theta}_{a, \mathrm{fp}}-\sum_{t=1}^{n_{t}} \alpha_{a, t}\left(\bar{T}_{a}-T_{s, t}\right) P_{a, t} \cdot \Delta z_{a, t}
$$

while the mass transfer rate is

$$
\dot{m}_{a} \cdot \Delta W_{a}=-\sum_{\mathrm{fp}=1}^{3} \alpha_{D_{a, \mathrm{fp}}} \cdot A_{a, \mathrm{fp}} \cdot \bar{\omega}_{a, \mathrm{fp}}-\sum_{t=1}^{n_{t}} \alpha_{D_{a, t}}\left(\bar{W}_{a}-W_{\mathrm{sat}, s, t}\right) P_{a, t} \cdot \Delta z_{a, t}
$$

Rearranging Equations (3.14) and (3.15), taking into account LFTV approach for the air flow along the $z$-direction, gives.

$$
2\left(\bar{T}_{a}-T_{a}^{\mathrm{in}}\right)=-\sum_{\mathrm{fp}=1}^{3} \mathrm{NTU}_{a, \mathrm{fp}} \cdot \bar{\theta}_{a, \mathrm{fp}}-\sum_{t=1}^{n_{t}} \mathrm{NTU}_{a, t}\left(\bar{T}_{a}-T_{s, t}\right)
$$

where $\mathrm{NTU}_{a, \mathrm{fp}}=\frac{\alpha_{a, \mathrm{fp}} \cdot A_{a, \mathrm{fp}}}{\dot{m}_{a} \cdot \bar{C}_{p, m a}}$, and $\mathrm{NTU}_{a, t}=\frac{\alpha_{a, t} \cdot A_{a, t}}{\dot{m}_{a} \cdot \bar{C}_{p, m a}}$.

$$
2\left(\bar{W}_{a}-W_{a}^{\mathrm{in}}\right)=-\sum_{\mathrm{fp}=1}^{3} \mathrm{NMTU}_{a, \mathrm{fp}} \cdot \bar{\omega}_{a, \mathrm{fp}}-\sum_{t=1}^{n_{t}} \mathrm{NMTU}_{a, t}\left(\bar{W}_{a}-W_{\mathrm{sat}, s, t}\right)
$$

where $\mathrm{NMTU}_{a, \mathrm{fp}}=\frac{\alpha_{a, \mathrm{fp}} \cdot A_{a, \mathrm{fp}}}{\dot{m}_{a} \cdot \bar{C}_{p, m a} \cdot L e^{2 / 3}}$, and NMTU ${ }_{a, t}=\frac{\alpha_{a, t} \cdot A_{a, t}}{\dot{m}_{a} \cdot \bar{C}_{p, m a} \cdot L e^{2 / 3}}$.

Equations (3.16) and (3.17) involve the term $\bar{\theta}_{a, \mathrm{fp}}$ which corresponds to $\bar{T}_{a}-\bar{T}_{\mathrm{fp}}$. The average fin portion temperature $\bar{T}_{\text {fp }}$ can be obtained by integrating Equation (3.4). This results in the following equation: 


$$
\bar{T}_{f}=\left\{\begin{array}{l}
\bar{T}_{\mathrm{fp} 1} \\
\bar{T}_{\mathrm{fp} 2} \\
\bar{T}_{\mathrm{fp} 3}
\end{array}\right\}_{f}\left[\begin{array}{c}
\frac{\int_{0}^{\zeta_{1}}\left[A\left(y_{\mathrm{fp} 1}, y_{\mathrm{fp} 2}, y_{\mathrm{fp} 3}\right)\right]_{1, \mathrm{j}} \cdot d y_{\mathrm{fp} 1}}{\zeta_{1}} \\
\frac{\int_{0}^{H_{f}-\left(\zeta_{1}+\zeta_{2}\right)}\left[A\left(y_{\mathrm{fp} 1}, y_{\mathrm{fp} 2}, y_{\mathrm{fp} 3}\right)\right]_{2, \mathrm{j}} \cdot d y_{\mathrm{fp} 2}}{H_{f}-\left(\zeta_{1}+\zeta_{2}\right)} \\
\frac{\zeta_{2}\left[A\left(y_{\mathrm{fp} 1}, y_{\mathrm{fp} 2}, y_{\mathrm{fp} 3}\right)\right]_{3, \mathrm{j}} \cdot d y_{\mathrm{fp} 3}}{\zeta_{2}}
\end{array}\right] \cdot\left[\begin{array}{l}
\bar{T}_{a} \\
T_{f B} \\
T_{f T} \\
\bar{\psi}
\end{array}\right]
$$

Now, if $\bar{T}_{\mathrm{fp} 1}, \bar{T}_{\mathrm{fp} 2}$ and $\bar{T}_{\mathrm{fp} 3}$ are subtracted from $\bar{T}_{a}$ and rearranging the result, then $\bar{\theta}_{a, f}$ can be expressed as:

$$
\bar{\theta}_{a, f}=\left\{\begin{array}{l}
\bar{\theta}_{a, \mathrm{fp} 1} \\
\bar{\theta}_{a, \mathrm{fp} 2} \\
\bar{\theta}_{a, \mathrm{fp} 3}
\end{array}\right\}_{a, f}=\left\{\begin{array}{l}
\bar{T}_{a}-\bar{T}_{\mathrm{fp} 1} \\
\bar{T}_{a}-\bar{T}_{\mathrm{fp} 2} \\
\bar{T}_{a}-\bar{T}_{\mathrm{fp} 3}
\end{array}\right\}=[\mathrm{B}] \cdot\left[\begin{array}{l}
\bar{T}_{a} \\
T_{f B} \\
T_{f T} \\
\bar{\psi}
\end{array}\right]
$$

[B] is a $3 \times 4$ matrix that depends on the same parameters as $\left[\mathrm{A}\left(y_{\mathrm{fp} 1}, y_{\mathrm{fp} 2}, y_{\mathrm{fp} 3}\right)\right]$ excepting the spatial coordinates. A detailed description of its components is illustrated in Chapter 6, Section 6.3. $\bar{\theta}_{a, f}$ has an interesting characteristic like $T_{f}(y)$, that it is expressed as a pseudo-linear function with respect to $\bar{T}_{a}, T_{f B}, T_{f T}$, and $\bar{\psi}$. The advantage of using pseudo-linear functions is that they make it possible to solve all the proposed equations using a fast iterative method with good convergence.

Substituting Equation (3.19) into Equations (3.16) and (3.17) results in the average air temperature and humidity ratio for each air cell as well as the outlet air temperature and humidity ratio. 


$$
\begin{aligned}
& \bar{T}_{a}\left\{2+\mathrm{NTU}_{a, \mathrm{fp} 1} \cdot \mathrm{B}_{1,1}+\mathrm{NTU}_{a, \mathrm{fp} 2} \cdot \mathrm{B}_{2,1}+\mathrm{NTU}_{a, \mathrm{fp} 3} \cdot \mathrm{B}_{3,1}+\sum_{t=1}^{n_{t}} \mathrm{NTU}_{a, t}\right\}= \\
& \left\{\begin{array}{l}
2 T_{a}^{\mathrm{in}}-\left[\mathrm{NTU}_{a, \mathrm{fp} 1} \cdot \mathrm{B}_{1,2}+\mathrm{NTU}_{a, \mathrm{fp} 2} \cdot \mathrm{B}_{2,2}+\mathrm{NTU}_{a, \mathrm{fp} 3} \cdot \mathrm{B}_{3,2}\right] T_{f B}- \\
{\left[\mathrm{NTU}_{a, \mathrm{fp} 1} \cdot \mathrm{B}_{1,3}+\mathrm{NTU}_{a, \mathrm{fp} 2} \cdot \mathrm{B}_{2,3}+\mathrm{NTU}_{a, \mathrm{fp} 3} \cdot \mathrm{B}_{3,3}\right] T_{f T}-} \\
{\left[\mathrm{NTU}_{a, \mathrm{fp} 1} \cdot \mathrm{B}_{1,4}+\mathrm{NTU}_{a, \mathrm{fp} 2} \cdot \mathrm{B}_{2,4}+\mathrm{NTU}_{a, \mathrm{fp} 3} \cdot \mathrm{B}_{3,4}\right] \bar{\psi}+\sum_{t=1}^{n_{t}} \mathrm{NTU}_{a, t} \cdot T_{s, t}}
\end{array}\right\} \\
& \bar{W}_{a}\left\{2+\mathrm{NMTU}_{a, \mathrm{fp} 1}+0+\mathrm{NMTU}_{a, \mathrm{fp} 3}+\sum_{t=1}^{n_{t}} \mathrm{NMTU}_{a, t}\right\}= \\
& \int 2 W_{a}^{\mathrm{in}}+a_{a, f}\left[\mathrm{NMTU}_{a, \mathrm{fp} 1}+0+\mathrm{NMTU}_{a, \mathrm{fp} 3}\right]- \\
& {\left[b_{a, f}\left(\mathrm{NMTU}_{a, \mathrm{fp} 1}\left(\mathrm{~B}_{1,1}-1\right)+0+\mathrm{NMTU}_{a, \mathrm{fp} 3}\left(\mathrm{~B}_{3,1}-1\right)\right)\right] \bar{T}_{a}-} \\
& \left\{\left[b_{a, f}\left(\mathrm{NMTU}_{a, \mathrm{fp} 1} \cdot \mathrm{B}_{1,2}+0+\mathrm{NMTU}_{a, \mathrm{fp} 3} \cdot \mathrm{B}_{3,2}\right)\right] T_{f B}-\right. \\
& {\left[b_{a, f}\left(\mathrm{NMTU}_{a, \mathrm{fp} 1} \cdot \mathrm{B}_{1,3}+0+\mathrm{NMTU}_{a, \mathrm{fp} 3} \cdot \mathrm{B}_{3,3}\right)\right] T_{f T}-} \\
& \left.\left[b_{a, f}\left(\mathrm{NMTU}_{a, \mathrm{fp} 1} \cdot \mathrm{B}_{1,4}+0+\mathrm{NMTU}_{a, \mathrm{fp} 3} \cdot \mathrm{B}_{3,4}\right)\right] \bar{\psi}+\sum_{t=1}^{n_{t}} \mathrm{NMTU}_{a, t} \cdot W_{\mathrm{sat}, s, t}\right]
\end{aligned}
$$

It can be noticed in Equation (3.21) that the terms corresponding to the mass transfer between the second portion of the fin cell (fp2) and surrounding air are equal to zero. This is because this portion is always assumed to be totally dry.

\subsection{Solution Methodology}

The general solution method is based on the semi-explicit method for wall-temperature linked equations (SEWTLE), proposed by Corberán et al. (2001), with some differences due to the particular characteristics of the presented model in this chapter.

The proposed system of equations consists of a system of non-linear equations. The solution of such system of equations needs an iterative methods since the coefficients and properties are complex and depend strongly on the temperature and humidity ratio fields. Corberán et al. (2001) stated that it is not worth finding the exact solution for such a system, then recalculating the coefficients and starting again until convergence can be reached. To reduce the iteration time, they proposed a better strategy by combining the iterative calculation of the solution with the continuous updating 
Chapter 3.

of the coefficients, in such a way that both calculations progress together toward the solution of the nonlinear problem.

Figure 3.5 represents the solution methodology and procedures applied in the current Fin1D-MB model.

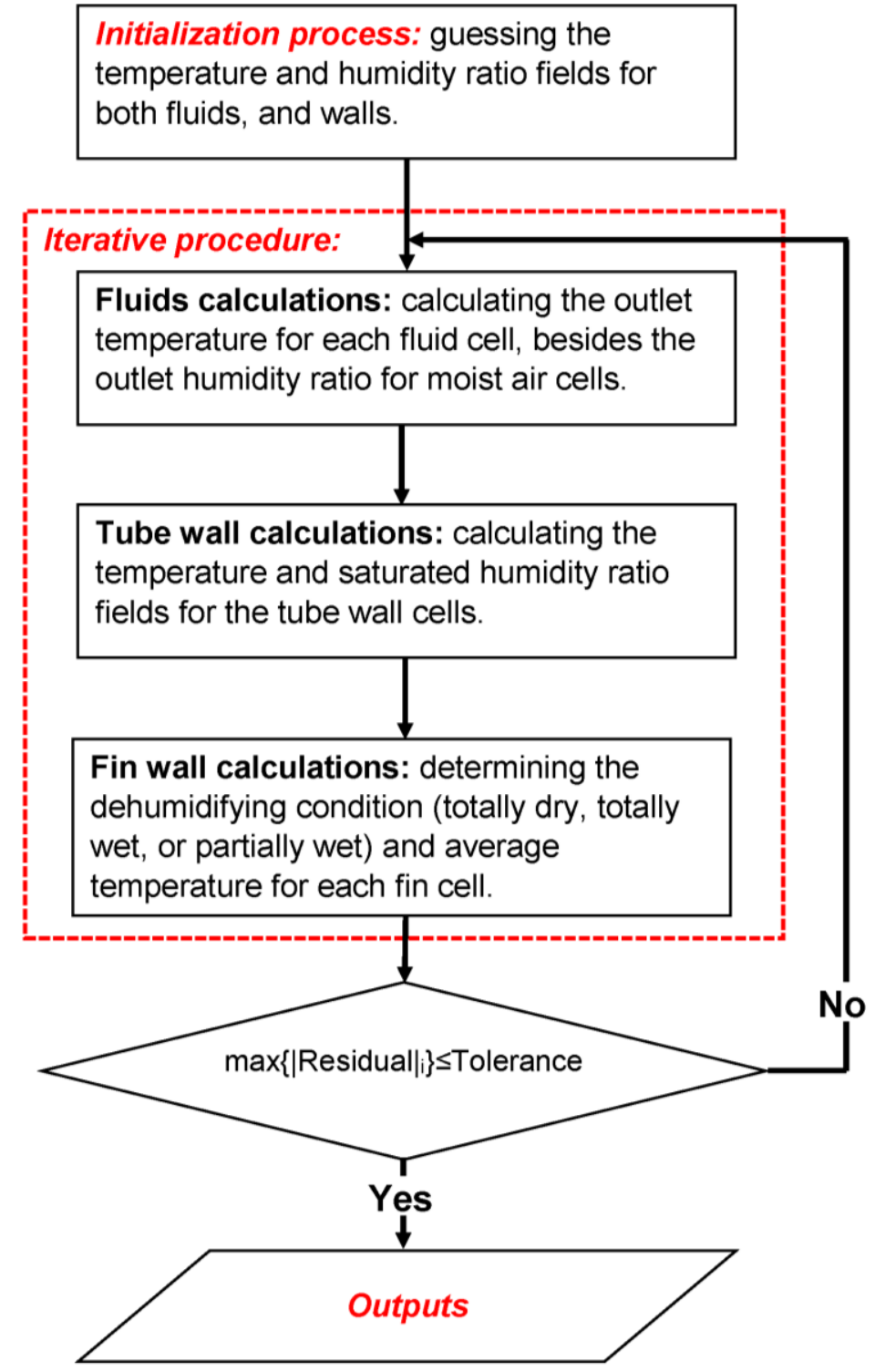

Figure 3.5. Flowchart of the numerical solution for the Fin1D-MB model. 
After the initialization process, the iterative procedure begins, which consists of three main steps. The first step is to calculate the outlet temperature for all fluid cells using Equation (3.11) for refrigerant flow, and Equation (3.20) for air flow. Then, Equation (3.21) is used to calculate the outlet humidity ratio for air cells. In the first iteration the dehumidifying conditions of the fins have not yet been evaluated, so that all the fins are assumed to be totally dry $\left(\zeta_{1}=\zeta_{2}=0\right)$. The second step is to calculate the tube wall cells temperatures using Equation (3.10). It can be observed that this equation considers the 2D heat conduction between the current tube cell and neighboring cells, which results in a system of linear equations involving all the tube cells temperatures. To solve this system of equations, the line-by-line iteration method (Patankar, 1980) is adopted in the current model. This method converts the system of equations into a tri-diagonal system of equations, which can be solved easily. However, if the 2D heat conduction is neglected, the exact solution of Equation (3.10), in this situation, consists of explicit calculations.

The third step of the iterative procedure is to evaluate the dehumidifying condition of each fin cell (either to be totally dry, totally wet, or partially wet) then calculate its average temperature. Firstly, the fin cell dehumidifying condition is evaluated according to the fin cell root temperatures, average dew point temperature of the surrounding air, and the predicted temperature profile of the fin.

After identifying the real fin cell condition, the following equations are applied to calculate the exact length for each fin portion.

$$
\zeta_{1}=\frac{1}{m} \cdot \ln \left\{\begin{array}{l}
\frac{-1}{2\left(\theta_{a, f T} e^{m H_{f}}-\theta_{a, f B}\right)} \times \\
{\left[\begin{array}{l}
-\bar{\theta}_{d p} e^{3 m H_{f}}+\bar{\theta}_{d p} e^{m H_{f}}+ \\
\sqrt{\bar{\theta}_{d p}^{2} e^{6 m H_{f}}-2\left(2 \theta_{a, f B} \theta_{a, f T} e^{m H_{f}}+\bar{\theta}_{d p}^{2}-2 \theta_{a, f B}^{2}\right) e^{4 m H_{f}}+}
\end{array} e^{-m H_{f}}\right.}
\end{array}\right\}
$$




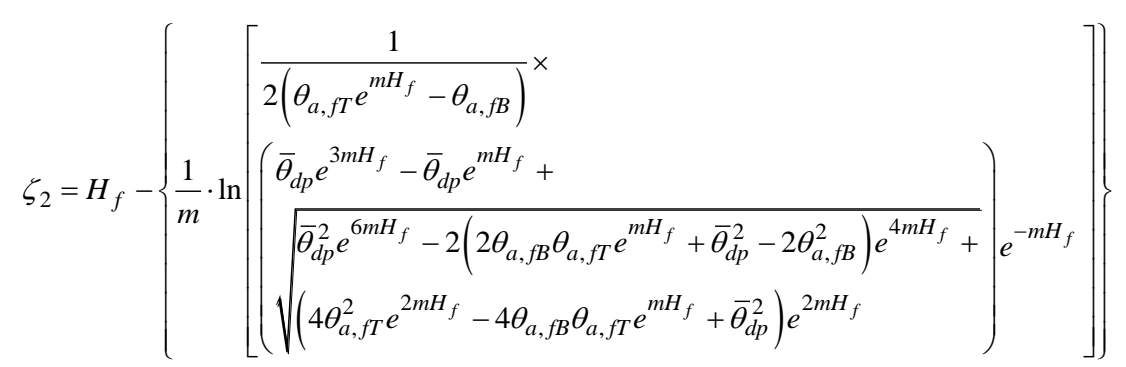

where, $\bar{\theta}_{d p}=\bar{T}_{a}-\bar{T}_{d p}, \theta_{a, f B}=\bar{T}_{a}-T_{f B}$, and $\theta_{a, f T}=\bar{T}_{a}-T_{f T}$.

Finally, $\zeta_{1}$ and $\zeta_{2}$ are used in Equation (3.19) to determine the average fin cell temperature. It can be noted that the calculation process of obtaining the fin wall temperature field is explicit. The iterative process continues until the value of the residual converges to the required tolerance.

\subsection{Numerical Verification of the Fin1D-MB Model}

The same case study and assumptions which were introduced before in Chapter 2, Section 2.4 have been also employed in the verification process for the Fin1D-MB model, and later in the comparative study between the Fin1D-MB and Fin2D-W numerical models.

The verification process consisted of two basic steps. The first step is the air-side verification study (V1), in which the conductivity of the tube and fin was assumed to be infinite, and the fin was discretized only in the direction of air flow ( $z$-direction). The second one is the mesh independent verification study (V2), in which the effect of fin/air discretization on the numerical solution was evaluated.

In the V1, the numerical solution was compared with the analytical one based on a heat exchanger with zero heat capacity ratio (Bergman et al., 2011), where $\varepsilon=1$-exp (-NTU).

Figure 3.6 illustrates the results of the first verification study V1. It can be noted that the error in total heat transfer rate, for both cases totally wet and dry, rapidly diminishes after $\mathrm{N}=5$. Where $\mathrm{N}$ represents the number of fin/air and tube cells in the $z$ direction. 

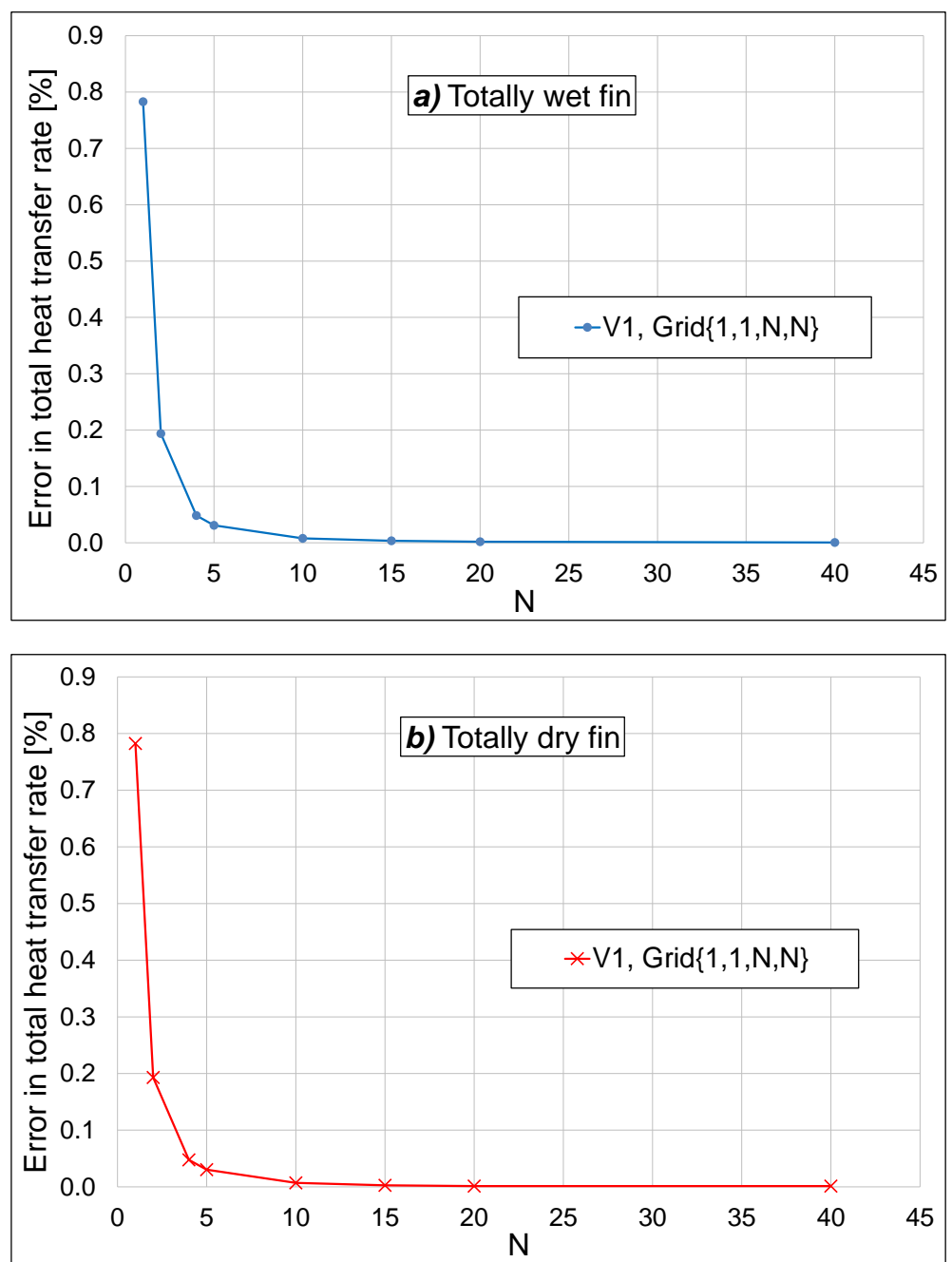

Figure 3.6. V1 results of the Fin1D-MB model. (a) For a totally wet fin. $(b)$ For a totally dry fin.

The change of absolute residual in the total heat transfer rate with respect to $\mathrm{N}$ in the second verification study (V2) is depicted in Figure 3.7. It can be seen that the residual steadily tends to zero after $\mathrm{N}=10$. These results are useful for identifying the numerical grid which will be used in the next comparative study between the proposed Fin1D-MB model and the Fin2D-W model. 
Chapter 3.
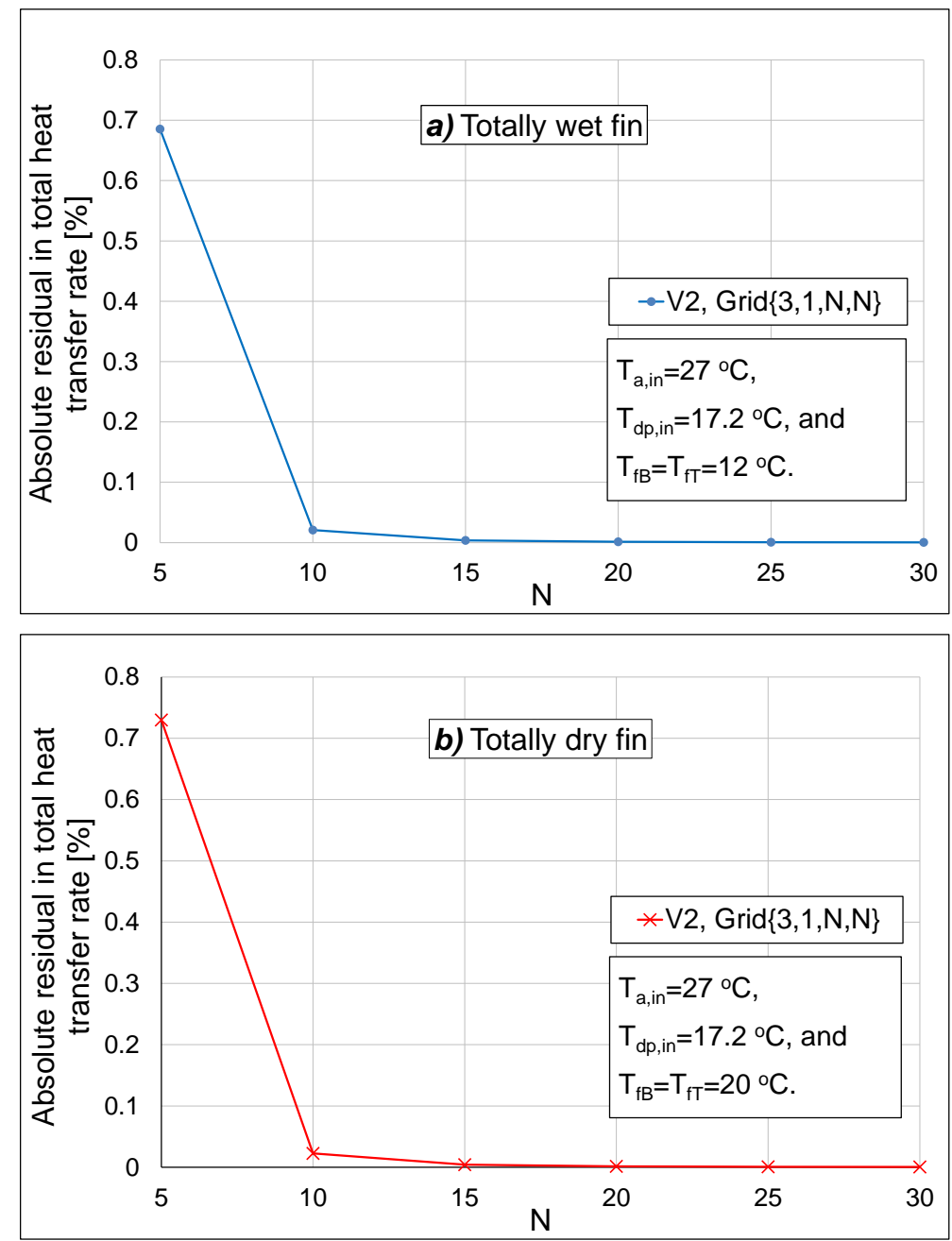

Figure 3.7. V2 results of the Fin1D-MB model. (a) For a totally wet fin. (b) For a totally dry fin.

\subsection{Comparison of the Heat Transfer Results between the Fin1D-MB and Fin2D-W Models}

In this study, the air-side heat transfer results from the present Fin1D-MB model are compared with those obtained by the Fin $2 \mathrm{D}-\mathrm{W}$ model. The evaporator segment in the case study was discretized into a grid of $\{3,1,10,10\}$, based on the previous verification studies. On the other hand, the Fin2D-W model adopted a grid of $\{3,1,10,30,10\}$, as it was explained in Chapter 2, Section 2.6. 
To allow a reasonable comparison, the same assumptions and inlet air cases to the evaporator (Case I, II, and III), which were defined before in Chapter 2, Section 2.6, are also applied in the current study. The lower tube temperature $T_{\text {lt }}$ is always assumed to be constant while the upper tube temperature $T_{u t}$ is gradually increased until reaching the inlet air temperature for each case. The difference between upper tube and lower tube temperatures is defined as the superheat ( $\mathrm{SH})$. To demonstrate representative values of $\mathrm{SH}$, different sets of lower tube temperatures have been selected for each case. This allows having similar differences between the lower tube temperature and dew point of inlet air. The results of the two models are compared below.

In Figures 3.8-3.10 (part $a$ ) the relative deviations in sensible heat transfer rate, based on the Fin2D-W model results, for the three inlet air cases studied are plotted against superheat values. It can be seen from these figures that the Fin1D-MB model always overpredicts the sensible heat transfer rate in an almost constant trend, regardless of the superheat value. The average values of the deviations in sensible heat transfer rate for Cases I, II, and III are $4.23 \%, 4.10 \%$, and $4.12 \%$, respectively. It can be also observed that the deviations are almost independent of inlet air conditions. The main source of these deviations is the assumption of uniform air temperature between the tubes adopted by the Fin1D-MB model. It is worth mentioning that Martínez-Ballester et al. (2013b) reported similar deviations in the sensible heat transfer rate in their comparative study of different numerical models for $\mathrm{CO}_{2}$ gas cooler.

The relative deviations in latent heat transfer rate between the two models are shown in Figures $3.8 b, 3.9 b$, and $3.10 b$. The results are divided into three regions according to the fin condition predicted by each model: the first region (R1) in which the fin is assumed to be totally wet by the two models; the second region (R2) in which the Fin1D-MB model assumes a partially wet fin condition, while the Fin2D-W model still assumes a totally wet fin condition; the third region (R3) in which the both models assume a partially wet fin condition.

At the beginning of $\mathrm{R} 1, \mathrm{SH}=0 \sim 4 \mathrm{~K}$, the Fin1D-MB always overpredicts the amount of latent heat transfer, and the deviations between the two models follow a steady trend in the three cases studied. Unlike the Fin2D-W model, the Fin1D-MB model assumes a uniform air humidity ratio along the fin height. This assumption contributes to the deviations in latent heat transfer rate in this region. With a further rise in 
Chapter 3.

superheat, the Fin1D-MB model tends to convert the fin condition from totally wet to partially wet earlier than the Fin2D-W model.
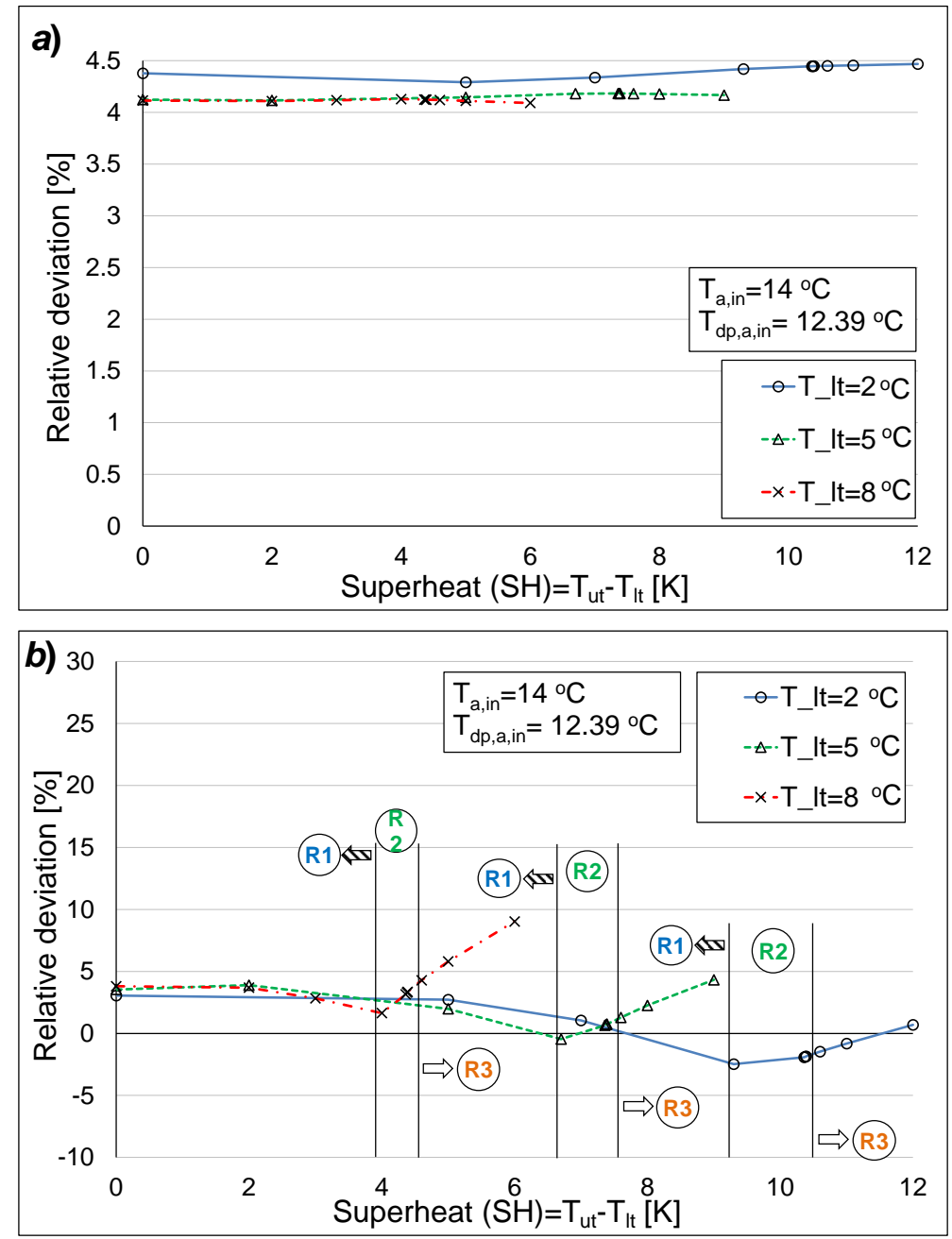

Figure 3.8. Relative deviations in $(a)$ sensible and $(b)$ latent heat transfer rates between the Fin1D-MB and Fin2D-W models, for Case I.

Consequently, the latent heat transfer rate predicted by the Fin1D-MB model starts to drop, but it is still higher than the Fin2D-W model. However, as the lower tube temperature continues to drop, the Fin1D-MB model begins to predict lower latent heat transfer rate than the Fin2D-W model. This situation results in negative deviations, for the most cases, at the end of R1, as shown in Figures 3.8-3.10 (part $b$ ). 
The values of the average relative deviation (ARD), based on the Fin2D-W model results, in latent heat transfer rate for the three lower tube temperatures for Cases I, I, and III are $2.52 \%, 2.30 \%$, and $2.80 \%$, respectively.
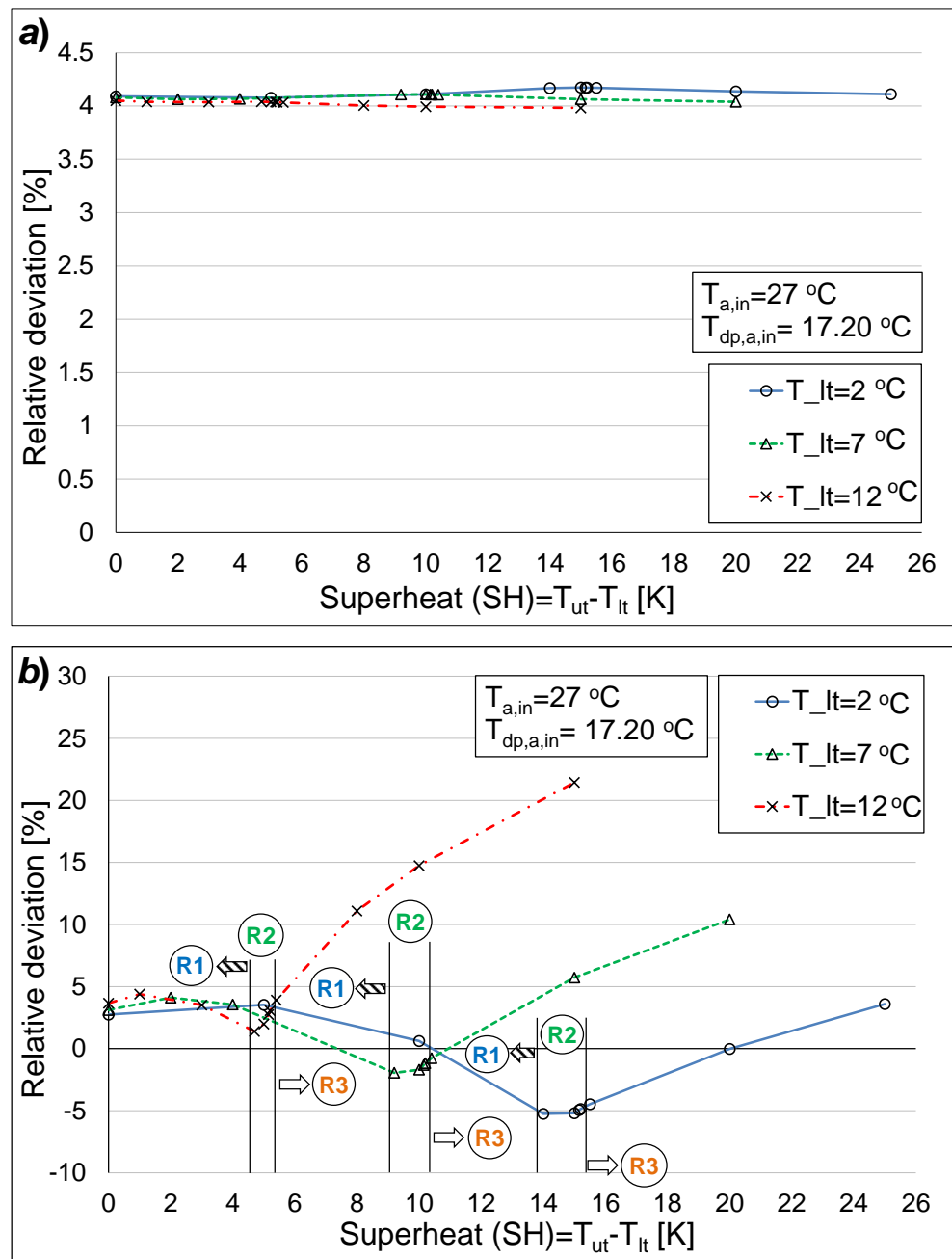

Figure 3.9. Relative deviations in $(a)$ sensible and $(b)$ latent heat transfer rates between the Fin1D-MB and Fin2D-W models, for Case II.

The R2 begins with the first anticipation of a partially wet fin by the Fin1D-MB model, while, the Fin2D-W model is still treating the fin as a totally wet within this region. Compared to the Fin2D-W model, this premature anticipation of a partially wet condition could be interpreted as being due to the different schemes used by the 
Chapter 3.

models to discretize the fin wall and air flow. Nevertheless, this disagreement is negligible, since the average relative deviation (ARD) values in latent heat transfer for the three lower tube temperatures for Cases I, II, and III are $0.41 \%,-1.44 \%$, and $0.42 \%$, respectively.
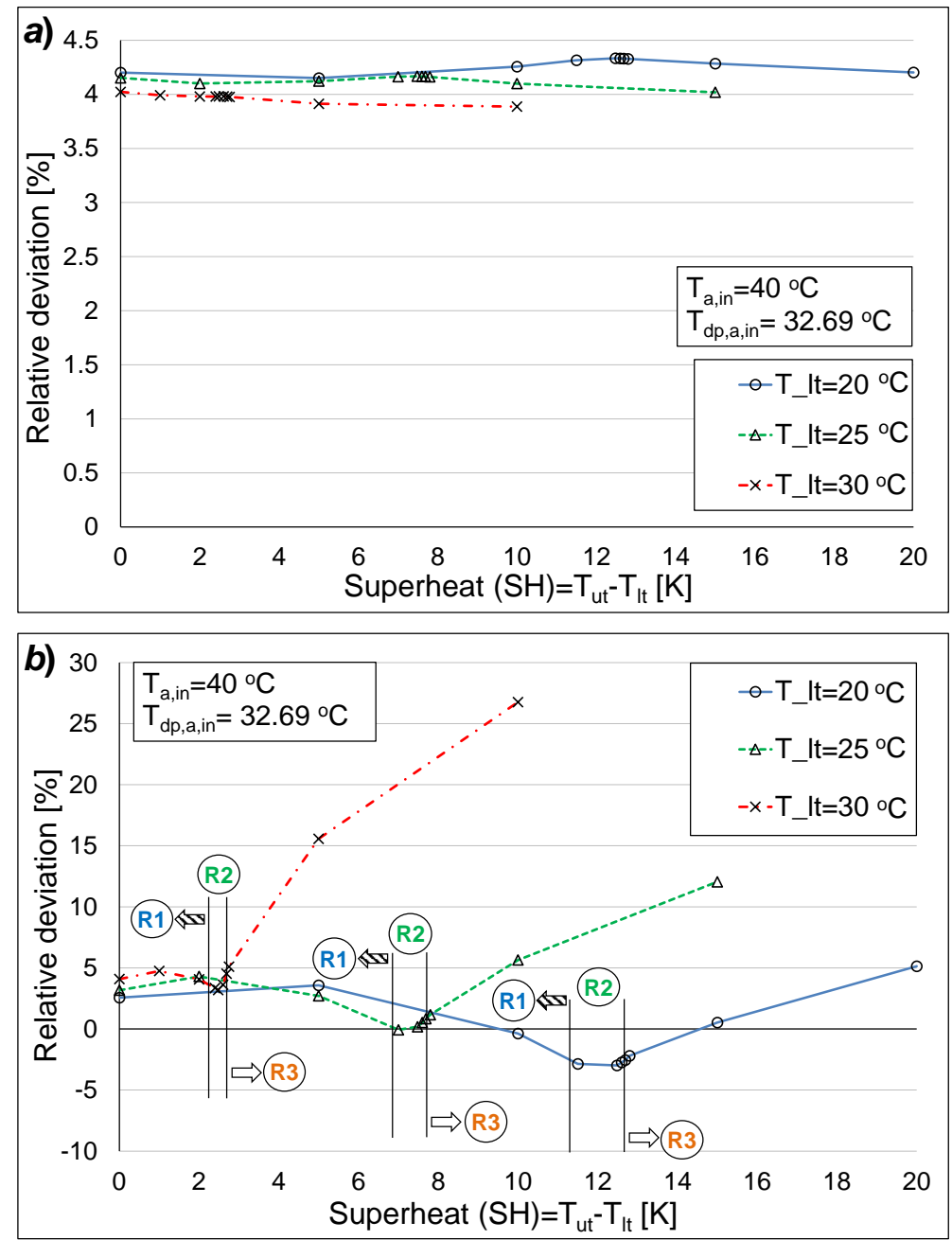

Figure 3.10. Relative deviations in $(a)$ sensible and $(b)$ latent heat transfer rates between the Fin1D-MB and Fin2D-W models, for Case III.

Nevertheless, the drop in the lower tube temperature could result in a lower prediction of latent heat transfer rate in $\mathrm{R} 2$, for some specific conditions, compared to the Fin2D-W model. This can be observed, for example, in Case I when $\mathrm{T}_{\mathrm{lt}}=2{ }^{\circ} \mathrm{C}$. 
When the Fin2D-W model treats the fin as partially wet, the third region R3 comes into action. Although both models have a similar capability to distinguish between the wet and dry portions along the fin height, the deviations in latent heat transfer rate in this region start to rise with higher superheat, as shown in Figures 3.8-3.10 (part $b$ ). To better identify the source of these deviations, Figure 3.11 presents the fin temperature profile and mass flux of condensed water at half the fin depth, for a specific point in R3. This point represents Case II at the most extreme condition, where $\mathrm{T}_{\mathrm{tt}}=12^{\circ} \mathrm{C}$ and $\mathrm{SH}=15 \mathrm{~K}$.
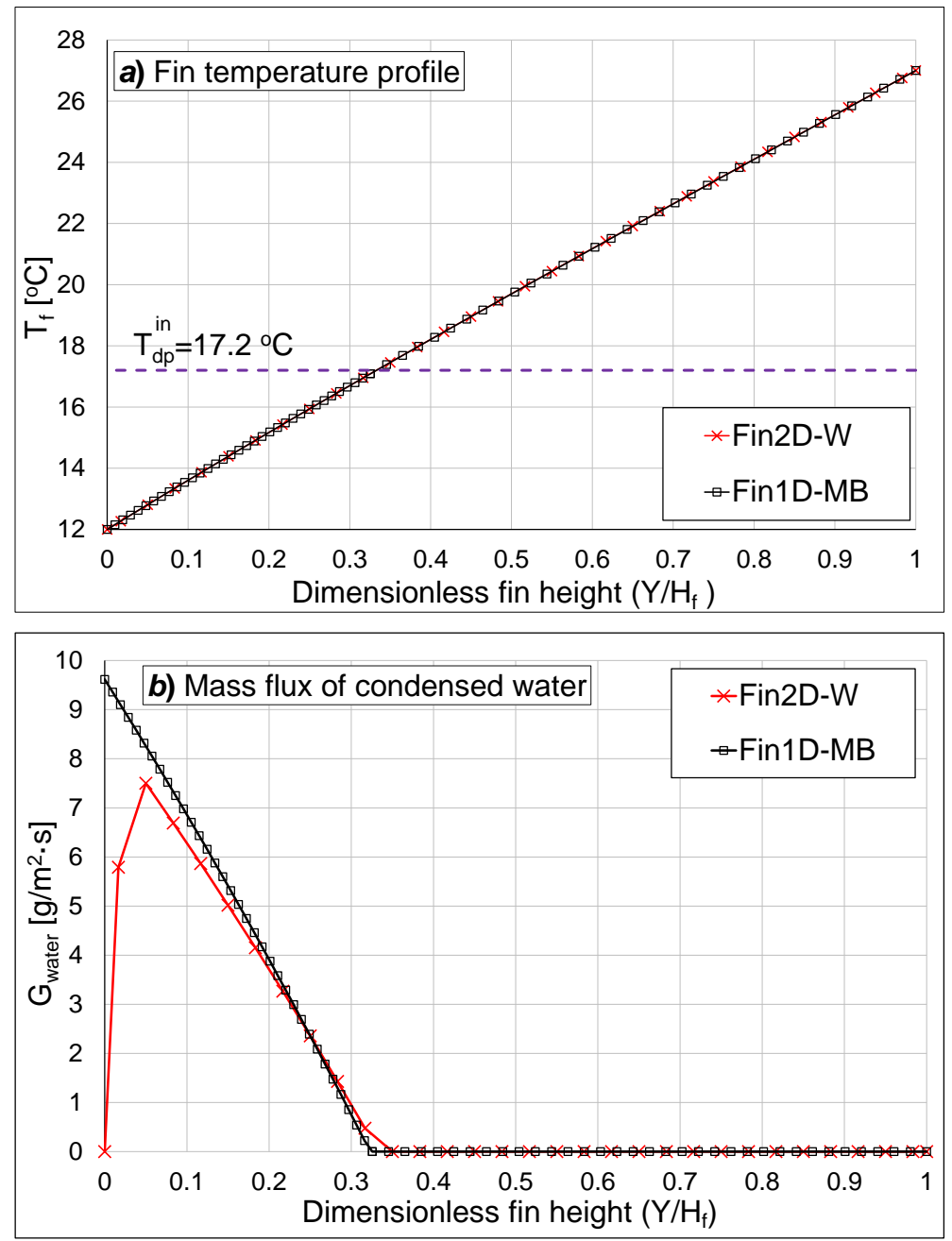

Figure 3.11. (a) Fin temperature profile and $(b)$ mass flux of condensed water, at half the fin depth, for a point in $\mathrm{R3}$. This represents Case II, when $\mathrm{T}_{\mathrm{lt}}=12^{\circ} \mathrm{C}$ and $\mathrm{SH}=15 \mathrm{~K}$. 
Chapter 3.

Figure 3.11 shows that the two models predict similar fin temperature profiles and dehumidifying condition, where approximately $35 \%$ of the fin is wet while the rest is dry. However, the main difference between the two models is that the Fin2D-W model allows for the non-mixed air along fin height and humidity ratio gradients near the tubes, unlike the Fin1D-MB model. The air cells near the bottom tube are very close to the saturation condition at the tube surface temperature. So, the potential of mass transfer, the difference between the air humidity ratios, tends to zero with approaching the lower tube surface. This subsequently results to that the Fin1DMB model clearly overpredicts the amount of condensed water within approximately $20 \%$ of the fin height near the bottom tube, as shown in Figure 3.11b. Generally, in the R3, the ARD values in latent heat transfer rate for the three lower tube temperatures for Cases I, II, and III are $2.82 \%, 5.90 \%$, and $7.75 \%$, respectively.

Since these deviations are related to the fin portion near the lower tube, then it will affect the latent heat transfer rate more as the wet region becomes smaller. This is the reason why the deviations between the two models increase with superheat. Anyhow, the effect of these deviations on the total heat transfer rate will become smaller since the latent heat contribution decreases with the increase in superheat.

From the previous discussion, we can conclude that analyzing separately the contribution of sensible and latent heat transfer may be misleading. Therefore, it is also necessary to illustrate the relative deviations in total heat transfer rate between the two models for the three inlet air cases studied, as shown in Figure 3.12.

As shown before in Figures 3.8-3.10 (part $b$ ), the maximum relative deviations in latent heat transfer rate for Case I, II, and III are 9\%, 21.40\%, and $26.80 \%$, respectively. However, it can be noted from Figure 3.12 that the relative deviations in total heat transfer rate, for the same situations, dropped down to $6.20 \%, 7.40 \%$, and $10 \%$ for Cases I, II, and III, respectively. 
Fin1D-MB Model
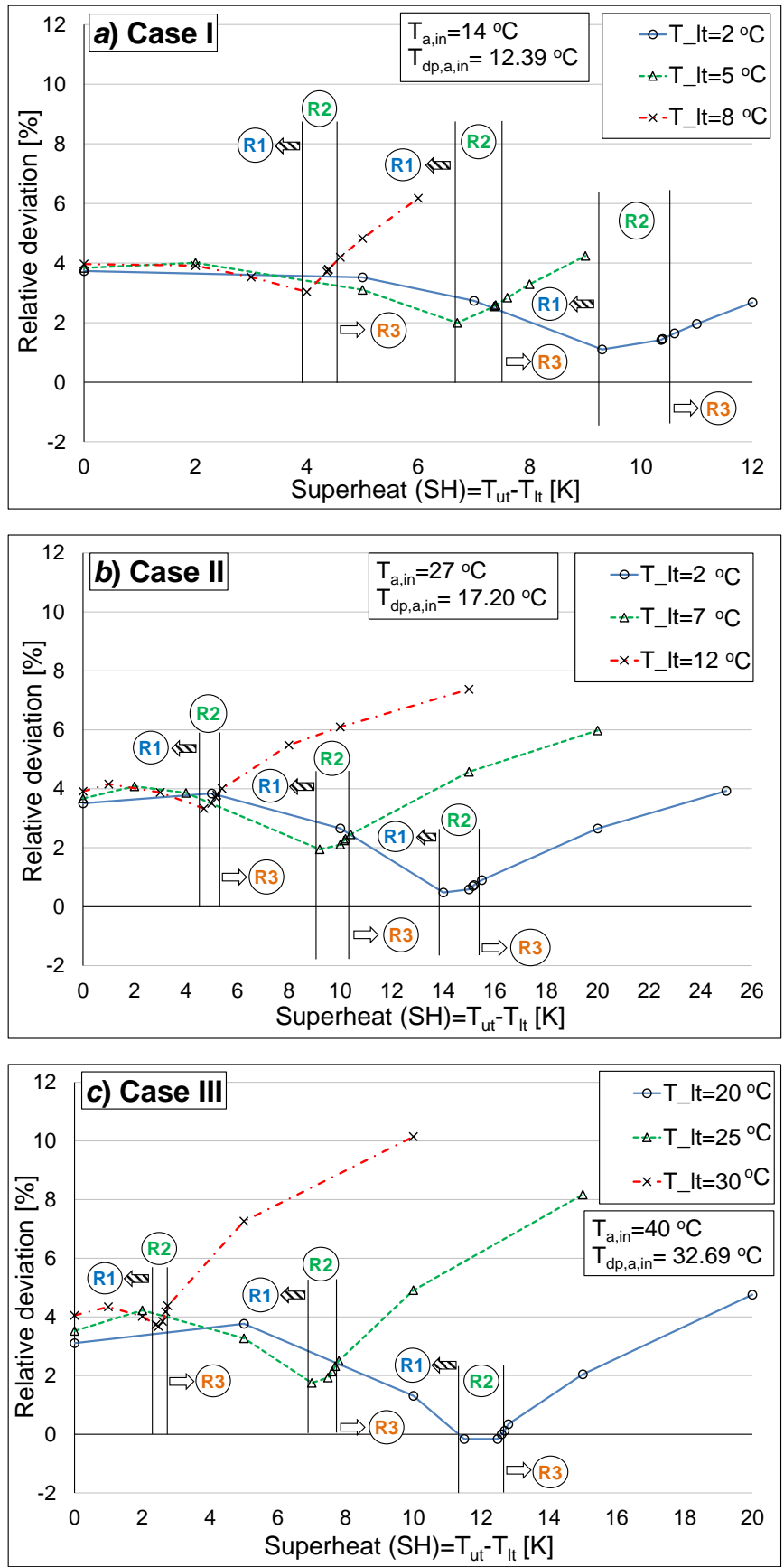

Figure 3.12. Relative deviations in total heat transfer rate between the Fin1D-MB and Fin2DW models, for (a) Case I, (b) Case II, and (c) Case III. 
Chapter 3.

The deviations in the total heat transfer rate between the Fin1D-MB and Fin2D-W models are still relatively high. However, they are much lower, for the same cases studied, compared to the deviations between the classical $\varepsilon$-NTU approach and the Fin2D-W model, which were approximately up to 52\% (Chapter 2, Figure 2.28). Also, it should be considered that the case studied comprises only two tubes. Additionally, in the current comparative study, the superheat is assumed to affect the entire piece of the evaporator. However, in actual evaporators the superheat region occupies a small area compared to the evaporator's total area. Moreover, extreme SH values are considered in the current study, up to $\approx 25 \mathrm{~K}$. It is expected that these deviations will significantly decrease in the case of evaluating a complete minichannel evaporator.

\subsection{Summary}

The objective of the current chapter was to develop a simpler model (Fin1D-MB) compared to the detailed comprehensive Fin2D-W model. The proposed model retains the most important phenomena as the Fin2D-W model, but with a much lower computational cost. The Fin1D-MB model utilizes innovative discretization techniques, which reduce the computation time and account for partial dehumidification scenarios, with a reasonable solution accuracy.

Compared to the Fin2D-W model, the Fin1D-MB model saved up to 95\% in computation time. This advantage is derived from using the fin theory, which noticeably reduces the complexity of the fin/air discretization scheme. Additionally, the proposed model precisely predicts the dehumidifying condition of the fin, as a consequence of adopting the technique of movable boundaries along the fin height. Nevertheless, the air-side heat transfer results showed that the relative deviations between the two models should be taken into consideration, especially in the partially wet fin region. The main source of these deviations could be the assumption of uniform air temperature and humidity ratio along the fin height adopted by the Fin1DMB model. These deviations are expected to decrease substantially while evaluating a complete minichannel evaporator.

In order to assess the overall performance of minichannel evaporators under dehumidifying conditions, a detailed comparative study between the Fin1D-MB model, experimental data, and other numerical models existed in the literature will be presented in the next chapter. 


\section{Chapter 4.}

Experimental Validation of the Fin1D-MB Model

"Every failure brings with it the seed of an equivalent success"

-Napoleon Hill 
Chapter 4.

\subsection{Introduction}

The previous numerical models, Fin2D-W and Fin1D-MB, were basically developed to study the air-side performance of minichannel evaporators. However, to assess the total performance of an evaporator, the air-side of the evaporator has to be connected to the refrigerant-side. This integration process needs a reliable and comprehensive simulation tool such as the IMST-ART ${ }^{\circledR}$.

The IMST-ART ${ }^{\circledR}$ program has been developed by the Institute for Energy Engineering, Technical University of Valencia (UPV). This program is capable of simulating any refrigerant circuit. Additionally, it can evaluate the performance of individual refrigeration components, such as compressors, condensers, evaporators, etc.

The Fin1D-MB model has been selected to be integrated, over the Fin2D-W model, because of its simplicity and calculation speed, besides, the reasonable solution accuracy. After integrating the Fin1D-MB model, it will be validated against experimental data and numerical models existed in the literature for different types of refrigerants and operating conditions.

\subsection{Discretization of MCHXs in the IMST-ART ${ }^{\circledast}$ Program}

Figure 4.1 presents an example of a MCHX that can be simulated by the IMST$\mathrm{ART}^{\circledR}$ program. This program can simulate any refrigerant circuitry arrangement: any number of refrigerant inlets and outlets; and any connection between different tube outlets/inlets at any location. Figure $4.2 a$ shows the discretization of an evaporator to segments, where the dashed lines correspond to the thermal connections between wall cells, whereas the thicker blue lines correspond to the refrigerant flow path.

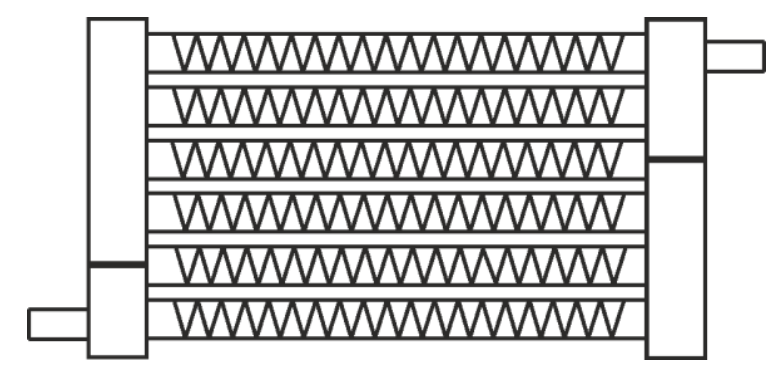

Figure 4.1. Example of a MCHX that can be simulated by the IMST-ART ${ }^{\oplus}$ program. 
First, the heat exchanger is discretized along the $x$-direction (refrigerant flow), resulting into $\mathrm{N}_{\mathrm{s}}$ segments per tube. Each segment (Figure 4.2b) consists of: a refrigerant flow that is divided into $\mathrm{N}_{\mathrm{r}, \mathrm{z}}$ channels in the $z$-direction; a flat tube which is discretized into $\mathrm{N}_{\mathrm{t}, \mathrm{z}}$ cells in the $z$-direction; air flow and fins which are always discretized into the same number of cells in the $z$-direction, so that $\mathrm{N}_{\mathrm{a}, \mathrm{z}}=\mathrm{N}_{\mathrm{f}, \mathrm{z}}$. Accordingly, the discretization for a MCHX is summarized in the following as a grid: $\left\{\mathrm{N}_{\mathrm{s}}\right.$, $\left.\mathrm{N}_{\mathrm{r}, \mathrm{z}}, \mathrm{N}_{\mathrm{t}, \mathrm{z}}, \mathrm{N}_{\mathrm{a}, \mathrm{z}}\right\}$.

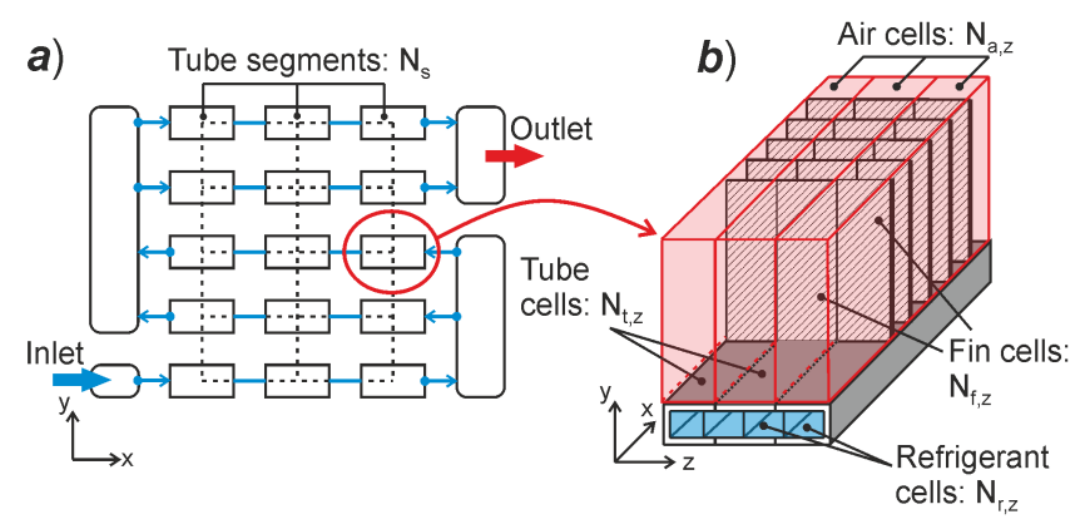

Figure 4.2. (a) Discretization of a MCHX to segments. (b) Schematic of a segment discretization into cells.

In the case of minichannel evaporators, the moist air exchange sensible and/or latent heat by convection with the tube and fin cells in contact. The fin cells, in turn, conduct the heat along the $y$-direction, and the bottom and top fin cells also conduct heat to the neighboring tube wall. Then, the tube cells transfer the total heat to the refrigerant cells in contact by convection, and to their neighboring tube cells on the plane $x-z$ by conduction. The refrigerant flows in the channels along the $x$-direction without any mixing between the channels.

Regarding the fluid cells, either air or refrigerant, there are two typologies: elemental cell and mixture cell. The elemental cell corresponds to the one described above, where the heat is exchanged with the surrounding tube and/or fin walls. The mixture cell is assumed to be adiabatic, and its function is collecting the fluid from a number of tubes and distributing it into the next tubes according to the heat exchanger circuitry. The inlet and outlet ports of each tube are connected to the corresponding mixture cells. The distribution of these mixture fluid cells and the definition of the tubes connected to them determine the flow path of each fluid. In the IMST-ART ${ }^{\circledR}$ 
Chapter 4.

program, any configuration can be fixed thus heat exchangers such as serpentine or parallel tube MCHXs can be simulated with any refrigerant circuitry.

\subsection{Refrigerant-side Heat Transfer Coefficient and Pressure Drop}

For a typical evaporator in a refrigeration cycle, the refrigerant at the inlet is in the two-phase region. After exchanging the heat with the high-temperature air, the refrigerant at the outlet becomes a gas with a degree of superheat. The heat transfer and pressure drop characteristics of the refrigerant in single-phase and two-phase regions are significantly different. Hence, different correlations are applied for each in the current study.

\subsubsection{Heat transfer correlations}

In the present model, the single-phase heat transfer coefficient is calculated using the correlation of Gnielinski (1976).

The two-phase flow boiling heat transfer (its coefficient is referred to as $\alpha_{r, t p}$ ) is a very complex process in which numerous phenomena are superimposed. The saturated liquid refrigerant generates vapor, which flows with much higher velocity than the liquid phase. Flow boiling heat transfer normally considers two heat transfer mechanisms to be important: nucleate boiling heat transfer (its coefficient is referred to as $\alpha_{r, n b}$ ) and convective boiling heat transfer (its coefficient is referred to as $\alpha_{r, c b}$ ). Nucleate flow boiling is similar to nucleate pool boiling except for any effect of the bulk flow on the growth and departure of the bubbles and the bubbles induced convection process. Convective boiling refers to convective process between the heated wall and the liquid-phase. The effect of nucleate boiling depends strongly on the surface roughness and the thickness of the liquid film while the contribution of convective boiling depends strongly on the mass velocity.

In the literature, many correlations have tried to describe empirically the very complex process of flow boiling by combining convective and nucleate boiling contributions. Usually, these correlations are based on one of the following models:

- The enhancement model, which assumes that the local flow boiling heat transfer coefficient is a function of an enhancement factor and liquid convective boiling heat transfer coefficient. This type of model has been proposed by Shah (1982). 
- The superposition model, which assumes that the local flow boiling heat transfer coefficient is the sum of nucleate and convective boiling components. Such a model has been developed by Chen (1963) and afterward modified by Gungor and Winterton (1986).

- The asymptotic model, which assumes that the local flow boiling heat transfer coefficient is a function of the relative dominance of nucleate boiling and convective boiling. It can be expressed as,

$$
\alpha_{t p}=\left[\left(\alpha_{c b}\right)^{n}+\left(\alpha_{n b}\right)^{n}\right]^{1 / n}
$$

Steiner and Taborek (1992) proposed $n=3$ based on parametric tests on their database for evaporation in vertical tubes.

Table 4.1 summarizes the two-phase heat transfer coefficient correlations which are used in the validation of the current Fin1D-MB model.

\subsubsection{Pressure drop correlations}

The total refrigerant-side pressure drop along the $x$-direction consists of frictional, acceleration, and gravitational pressure drop terms:

$$
\left(\frac{d p}{d x}\right)_{r, \text { tot }}=\left(\frac{d p}{d x}\right)_{r, \text { fric }}+\left(\frac{d p}{d x}\right)_{r, \text { acc }}+\left(\frac{d p}{d x}\right)_{r, \text { grav }}
$$

In the superheat region, the single-phase total pressure drop can be expressed as:

$$
\left(\frac{d p}{d x}\right)_{s p, \text { tot }}=\left.\frac{f_{G}}{2} \frac{\mathrm{G}_{r}^{2}}{D_{h} \cdot \rho_{G}}\right|_{s p, \text { fric }}+\left.\mathrm{G}_{r}^{2}\left[\frac{1}{\rho_{G}^{\text {out }}}-\frac{1}{\rho_{G}^{\text {in }}}\right]\right|_{s p, \text { acc }}+\left.g \rho_{G} \sin \xi\right|_{s p, \text { grav }}
$$

where $f$ is the Darcy friction factor and $\xi$ is the tube orientation in degrees.

However, in the two-phase region the total pressure drop for refrigerant-side can be expressed as:

$$
\left(\frac{d p}{d x}\right)_{t p, \text { tot }}=\left(\frac{d p}{d x}\right)_{t p, \text { fric }}+\left.\mathrm{G}_{r}^{2} \frac{d}{d x}\left(\frac{\dot{x}^{2}}{\rho_{G} \cdot \varphi}+\frac{(1-\dot{x})^{2}}{\rho_{G}(1-\dot{x})}\right)\right|_{t p \text {,acc }}+\left.g\left[\varphi \rho_{G}+(1-\varphi) \rho_{L}\right] \sin \xi\right|_{t, \text {,grav }}
$$

where $\dot{x}$ is the vapor quality. The void fraction $\varphi$ is modeled as a separated-flow, adopting Chisholm's (1972) correlation for the slip ratio. The correlations which are employed by the present model to evaluate the frictional pressure drop for refrigerant-side are summarized in Table 4.2. 
Chapter 4

Table 4.1. Two-phase heat transfer coefficient correlations

\begin{tabular}{|c|c|c|}
\hline Reference & Correlation & Applicability range \\
\hline $\begin{array}{l}\text { Bennett and Chen } \\
\text { (1980) }\end{array}$ & $\begin{array}{l}\alpha_{r, t p}=\alpha_{r, n b}+\alpha_{r, c b}, \text { where } \\
\alpha_{r, n b}=0.00122\left(\frac{k_{L}^{0.79} C_{p_{L}}^{0.45} \rho_{L}^{0.49}}{\sigma^{0.5} \mu_{L}^{0.29} h_{f g}^{0.24} \rho_{G}^{0.24}}\right)\left[T_{s, t}-T_{r, \text { sat }}\left(p_{r}\right)\right]^{0.24}\left[p_{r, s a t}\left(T_{s, t}\right)-p_{r}\right]^{0.75} S, \text { and } \\
\alpha_{r, c b}=\alpha_{r, L} \cdot F\left(X_{t t}\right) \cdot \operatorname{Pr}_{L}^{0.296} . \\
\alpha_{r, L}=0.023 \cdot \operatorname{Re}_{L}^{0.8} \cdot \operatorname{Pr}_{L}^{0.4}\left(\frac{k_{L}}{D_{h}}\right), \text { where } \operatorname{Re}_{L}=\frac{(1-\dot{x}) \mathrm{G}_{r} \cdot D_{h}}{\mu_{L}} . \\
S=\frac{1-\exp \left[-F\left(X_{t t}\right) \alpha_{r, L} \cdot X_{o} / k_{L}\right]}{F\left(X_{t t}\right) \alpha_{r, L} \cdot X_{o} / k_{L}}, \text { where } X_{o}=0.041\left(\frac{\sigma}{g\left(\rho_{L}-\rho_{G}\right)}\right)^{0.5} \cdot \\
F\left(X_{t t}\right)=\left\{\begin{array}{l}1.0, \text { for } X_{t t} \geq 10 \\
2.35\left(0.213+\frac{1}{X_{t t}}\right)^{0.736}, \text { for } X_{t t}<10 . \\
X_{t t}=\left(\frac{1-\dot{x}}{\dot{x}}\right)^{0.875}\left(\frac{\rho_{G}}{\rho_{L}}\right)^{0.5}\left(\frac{\mu_{L}}{\mu_{G}}\right)^{0.125} .\end{array}\right.\end{array}$ & $\begin{array}{l}p_{r}=1-34.8 \mathrm{bar} . \\
\dot{x}=0.01-0.71 . \\
q_{r}=6.2-2400 \mathrm{~kW} / \mathrm{m}^{2} . \\
\text { Liquid inlet velocity } \\
\text { range= } 0.06-4.5 \mathrm{~m} / \mathrm{s} . \\
\text { Fluids: water, methanol, } \\
\text { cyclohexane, pentane, } \\
\text { heptane, and benzene } \\
\text { (594 data points). } \\
\text { Vertical upward and } \\
\text { downward flow in tubes } \\
\text { and annuli. }\end{array}$ \\
\hline Cooper (1984) & $\alpha_{r, t p}=\alpha_{r, n b}=55\left(\frac{p_{r, \mathrm{sat}}}{p_{r, \mathrm{crit}}}\right)^{0.12}\left[-0.4343 \ln \left(\frac{p_{r, \mathrm{sat}}}{p_{r, \mathrm{crit}}}\right)\right]^{-0.55} \mathrm{M}_{\mathrm{mol}}^{-0.5} \cdot q_{r}^{0.67}$ & $\begin{array}{l}p_{r, \text { sat }} / p_{r, \text { crit }}=0.001-0.9 \\
M_{\mathrm{mol}}=2-200 \mathrm{~g} / \mathrm{mol}\end{array}$ \\
\hline
\end{tabular}


Experimental Validation of the Fin1D-MB Model

Hwang (1997)

$$
\begin{aligned}
& \alpha_{r, n b}=0.00122\left(\frac{k_{L}^{0.79} C_{p_{L}}^{0.5} \rho_{L}^{0.49}}{\sigma^{0.6} \mu_{L}^{0.29} h_{f g}^{0.24} \rho_{G}^{0.24}}\right)\left[T_{s, t}-T_{r, \mathrm{sat}}\left(p_{r}\right)\right]^{0.4}\left[p_{r, s a t}\left(T_{s, t}\right)-p_{r}\right]^{0.75} S, \text { and } \\
& \alpha_{r, c b}=\alpha_{r, L} \cdot F\left(X_{t t}\right) \cdot \operatorname{Pr}_{L}^{0.6} \cdot \\
& \alpha_{r, L}=0.023 \cdot \operatorname{Re}_{L}^{0.8} \cdot \operatorname{Pr}_{L}^{0.4}\left(\frac{k_{L}}{D_{h}}\right), \text { where } \operatorname{Re}_{L}=\frac{(1-\dot{x}) \mathrm{G}_{r} \cdot D_{h}}{\mu_{L}} . \\
& S=\frac{1-\exp \left[-F\left(X_{t t}\right) \alpha_{r, L} \cdot X_{o} / k_{L}\right]}{F\left(X_{t t}\right) \alpha_{r, L} \cdot X_{o} / k_{L}}, \text { where } X_{o}=0.05\left(\frac{\sigma}{g\left(\rho_{L}-\rho_{G}\right)}\right)^{0.5} . \\
& F\left(X_{t t}\right)=\left\{\begin{array}{l}
1.0, \text { for } X_{t t} \geq 10 \\
2.0\left(0.213+\frac{1}{X_{t t}}\right)^{0.736}, \text { for } X_{t t}<10 .
\end{array}\right. \\
& X_{t t}=\left(\frac{1-\dot{x}}{\dot{x}}\right)^{0.875}\left(\frac{\rho_{G}}{\rho_{L}}\right)^{0.5}\left(\frac{\mu_{L}}{\mu_{G}}\right)^{0.125} .
\end{aligned}
$$

Kandlikar and

Balasubramanian

(2004)

$\alpha_{r, t p}=\max \left(\alpha_{r, n b}, \alpha_{r, c b}\right)(1-\dot{x})^{0.8} \alpha_{r, L O}$, where

$\alpha_{r, n b}=0.6683 \cdot \mathrm{Co}^{-0.2} \cdot \mathrm{Fr}_{L O}+1058 \cdot \mathrm{Bo}^{0.7} \cdot \mathrm{F}_{f l}$, and $\alpha_{r, c b}=1.136 \cdot \mathrm{Co}^{-0.9} \cdot \mathrm{Fr}_{L O}+667.2 \cdot \mathrm{Bo}^{0.7} \cdot \mathrm{F}_{f l}$. $\mathrm{Co}=\left(\frac{1-\dot{x}}{\dot{x}}\right)^{0.8}\left(\frac{\rho_{G}}{\rho_{L}}\right)^{0.5}, \mathrm{Fr}_{L O}=\frac{\mathrm{G}_{r}^{2}}{g \cdot D_{h} \cdot \rho_{L}^{2}}, \mathrm{Bo}=\frac{q_{r}}{\mathrm{G}_{r} \cdot h_{f g}}$, and $\mathrm{F}_{f l}=1 \sim 3.3$ (based on refrigerant). $\alpha_{r, L O}=\frac{\operatorname{Re}_{L O} \operatorname{Pr}_{L}\left(f_{L O} / 2\right)\left(k_{L} / D_{h}\right)}{1+12.7\left(\operatorname{Pr}_{L}^{2 / 3}-1\right)\left(f_{L O} / 2\right)^{0.5}}$, for $10^{4} \leq \operatorname{Re}_{L O}=\frac{\mathrm{G}_{r} \cdot D_{h}}{\mu_{L}} \leq 5 \times 10^{6} ;$ and $\alpha_{r, L O}=\frac{\left(\operatorname{Re}_{L O}-1000\right) \operatorname{Pr}_{L}\left(f_{L O} / 2\right)\left(k_{L} / D_{h}\right)}{1+12.7\left(\operatorname{Pr}_{L}^{2 / 3}-1\right)\left(f_{L O} / 2\right)^{0.5}}$, for $3 \times 10^{3} \leq \operatorname{Re}_{L O}<10^{4}$,

where $f_{L O}=\left[1.58 \ln \left(\operatorname{Re}_{L O}\right)-3.28\right]^{-2}$.

For $1600 \leq \operatorname{Re}_{L O}<3000, \alpha_{r}, O$ is calculated by interpolation between $\operatorname{Re}_{L O}=1600$ and 3000 .

For $\mathrm{Re}_{L O}<1600, \alpha_{r, L O}$ is calculated from $\mathrm{Nu}_{L}=\frac{\alpha_{r, L O} \cdot D_{h}}{k_{L}}=$ constant.

For $\mathrm{Re}_{L O} \leq 100, \alpha_{r, t p}=\alpha_{r, n b}(1-\dot{x})^{0.8} \alpha_{r, L O}$.
It is similar to (Bennett \&

Chen, 1980); however,

some minor modifications

have been done to ac-

count for the $\mathrm{CO}_{2}$ flow

boiling.

$D_{h}=0.19-32.0 \mathrm{~mm}$.

$\mathrm{G}_{\mathrm{r}}=13-8179 \mathrm{~kg} / \mathrm{m}^{2} \cdot \mathrm{s}$. $q_{t r}=0.3-2280 \mathrm{~kW} / \mathrm{m}^{2}$. $p_{r}=0.4-64$ bar.

Fluids: water, R11, R12, R22, R113, R114, R152a, nitrogen, and neon. Based on 5246 data points. 
Chapter 4 .

Wojtan et al.

(2005)

$\alpha_{r, t p}=\frac{\theta_{\mathrm{dry}} \alpha_{r, G}+\left(2 \pi-\theta_{\mathrm{dry}}\right) \alpha_{r, L}}{2 \pi}$, where $\alpha_{r, L}=\left(\alpha_{r, n b}^{3}+\alpha_{r, c b}^{3}\right)^{1 / 3}$, and

$\alpha_{r, G}=0.023\left[\frac{\mathrm{G}_{r} \dot{x} D_{h}}{\varphi \cdot \mu_{G}}\right]^{0.8} \operatorname{Pr}_{G}^{0.4} \frac{k_{G}}{D_{h}}$.

$\alpha_{r, n b}=55\left(\frac{p_{r, \mathrm{sat}}}{p_{r, \text { crit }}}\right)^{0.12}\left[-0.4343 \ln \left(\frac{p_{r, \mathrm{sat}}}{p_{r, \text { crit }}}\right)\right]^{-0.55} \mathrm{M}_{\mathrm{mol}}^{-0.5} \cdot q_{r}^{0.67}$, and

$\alpha_{r, c b}=0.0133\left[\frac{4 \mathrm{G}_{r}(1-\dot{x}) \delta}{(1-\varphi) \mu_{L}}\right]^{0.69} \operatorname{Pr}_{L}^{0.4} \frac{k_{L}}{\delta}$.

$\varphi=\frac{\dot{x}}{\rho_{G}}\left\{[1-0.12(1-\dot{x})]\left(\frac{\dot{x}}{\rho_{G}}+\frac{1-\dot{x}}{\rho_{L}}\right)+\frac{1.18(1-\dot{x})\left[g \sigma_{r}\left(\rho_{L}-\rho_{G}\right)\right]^{0.25}}{\mathrm{G}_{r} \rho_{L}^{0.5}}\right\}^{-1}$.

0 , in slug, annular, and intermittent zones

$\theta_{\text {dry }}=\left\{\begin{array}{l}\theta_{\text {strat }}\left(\frac{\dot{x}}{x_{I A}}\right)\left[\frac{\mathrm{G}_{\text {wavy }}(\dot{x})-\mathrm{G}_{r}}{\mathrm{G}_{\text {wavy }}(\dot{x})-\mathrm{G}_{\text {strat }}(\dot{x})}\right]^{0.61} \dot{x}<\dot{x}_{\text {IA }}, \text { in slug-stratidfied-wavy zone } \\ \theta_{\text {strat }}\left[\frac{\mathrm{G}_{\text {wavy }}(\dot{x})-\mathrm{G}_{r}}{\mathrm{G}_{\text {wavy }}(\dot{x})-\mathrm{G}_{\text {strat }}(\dot{x})}\right]^{0.61}, \text { in stratified-wavy zone } \\ \theta_{\text {strat }}, \text { in stratified zone }\end{array}\right.$

$\theta_{\text {strat }}=2 \pi-2\left\{\begin{array}{l}\pi(1-\varphi)+\left(\frac{3 \pi}{2}\right)^{1 / 3}\left[1-2(1-\varphi)+(1-\varphi)^{1 / 3}-\varphi^{1 / 3}\right]- \\ \frac{1}{200}(1-\varphi) \varphi[1-2(1-\varphi)]\left[1+4\left((1-\varphi)^{2}+\varphi^{2}\right)\right]\end{array}\right\}$

$\delta$ is the liquid film thickness, and $\dot{x}_{I A}$ is the vapor quality at transition from intermittent to annular flow.

$\mathrm{G}_{\text {wavy }}(\dot{x})$, and $\mathrm{G}_{\text {strat }}(\dot{x})$ are the wavy and stratified flow transition mass velocities, respectively. $p_{r, \text { sat }} / p_{r, \text { crit }}=0.009-0.225$.

$\mathrm{Gr}=16.3-500 \mathrm{~kg} / \mathrm{m}^{2} \cdot \mathrm{s}$.

$\dot{x}=0.01-1.0$.

$q_{r}=0.44-71.600 \mathrm{~kW} / \mathrm{m}^{2}$

$D_{h}=10.9-16 \mathrm{~mm}$.

Fluids: R134a, R123,

R502, R402A, R404A

$\mathrm{R} 407 \mathrm{C}$, and ammonia. 
Experimental Validation of the Fin1D-MB Model

Table 4.2. Two-phase frictional pressure drop correlations.

\begin{tabular}{|c|c|c|}
\hline Reference & Correlation & Applicability range \\
\hline $\begin{array}{l}\text { Muller-Steinhagen } \\
\text { and Heck (1986) }\end{array}$ & $\begin{array}{l}\left(\frac{\Delta p}{\Delta x}\right)_{t p, \text { fric }}=\Gamma(1-\dot{x})^{1 / 3}+\beta \cdot \dot{x}^{3} \\
\Gamma=\alpha+2(\beta-\alpha) \dot{x} \\
\alpha=\left(\frac{\Delta p}{\Delta x}\right)_{L O}=\frac{f_{L O}}{2} \frac{\mathrm{G}_{r}^{2}}{D_{h} \cdot \rho_{L}}, \text { where } f_{L O}=\left\{\begin{array}{l}0.3164 \operatorname{Re}_{L O}^{-0.25}, \text { for } \operatorname{Re}_{L O} \geq 1187 \\
64 / \operatorname{Re}_{L O}, \text { for } \operatorname{Re}_{L O}<1187\end{array}\right. \\
\beta=\left(\frac{\Delta p}{\Delta x}\right)_{G O}=\frac{f_{G O}}{2} \frac{\mathrm{G}_{r}^{2}}{D_{h} \cdot \rho_{G}}, \text { where } f_{G O}=\left\{\begin{array}{l}0.3164 \operatorname{Re}_{G O}^{-0.25}, \text { for } \operatorname{Re}_{G O} \geq 1187 \\
64 / \operatorname{Re}_{G O}, \text { for } \operatorname{Re}_{G O}<1187\end{array}\right.\end{array}$ & $\begin{array}{l}\dot{x}=0-1 . \\
\text { Fluids: air-oil, air-water, water- } \\
\text { steam, argon-water, nitrogen, } \\
\text { R11, R12, R22, and air-kerosene } \\
\text { (9300 measurements). }\end{array}$ \\
\hline $\begin{array}{l}\text { Mishima and Hibiki } \\
\text { (1996) }\end{array}$ & $\begin{array}{l}\left(\frac{\Delta p}{\Delta x}\right)_{t p, \text { fric }}=\left(\frac{\Delta p}{\Delta x}\right)_{L} \Phi_{L}^{2} \\
\Phi_{L}^{2}=1+\frac{C}{X_{t t}}+\frac{1}{X_{t t}^{2}} \\
C=21\left[1-\exp \left(-0.319 \cdot D_{h}\right)\right] \\
X_{t t}^{2}=\left[\left(\frac{\Delta p}{\Delta x}\right)_{L} /\left(\frac{\Delta p}{\Delta x}\right)_{G}\right] \\
\left(\frac{\Delta p}{\Delta x}\right)_{L}=\frac{f_{L O}}{2} \frac{\mathrm{G}_{r}^{2}(1-\dot{x})^{2}}{D_{h} \cdot \rho_{L}}, \text { where } f_{L O}=\left\{\begin{array}{l}0.3164 \operatorname{Re}_{L O}^{-0.2}, \text { for } \operatorname{Re}_{L O} \geq 2000 \\
64 / \operatorname{Re}_{L O}, \text { for } \operatorname{Re}_{L O}<2000\end{array}\right. \\
\left(\frac{\Delta p}{\Delta x}\right)_{G}=\frac{f_{G O}}{2} \frac{\mathrm{G}_{r}^{2} \cdot \dot{x}^{2}}{D_{h} \cdot \rho_{G}}, \text { where } f_{G O}=\left\{\begin{array}{l}0.3164 \operatorname{Re}_{G O}^{-0.2}, \text { for } \operatorname{Re}_{G O} \geq 2000 \\
64 / \operatorname{Re}_{G O}, \text { for } \operatorname{Re}_{G O}<2000\end{array}\right.\end{array}$ & $\begin{array}{l}D_{h}=1-4 \mathrm{~mm} . \\
\text { Fluids: air-water mixture. }\end{array}$ \\
\hline
\end{tabular}




\section{Chapter 4}

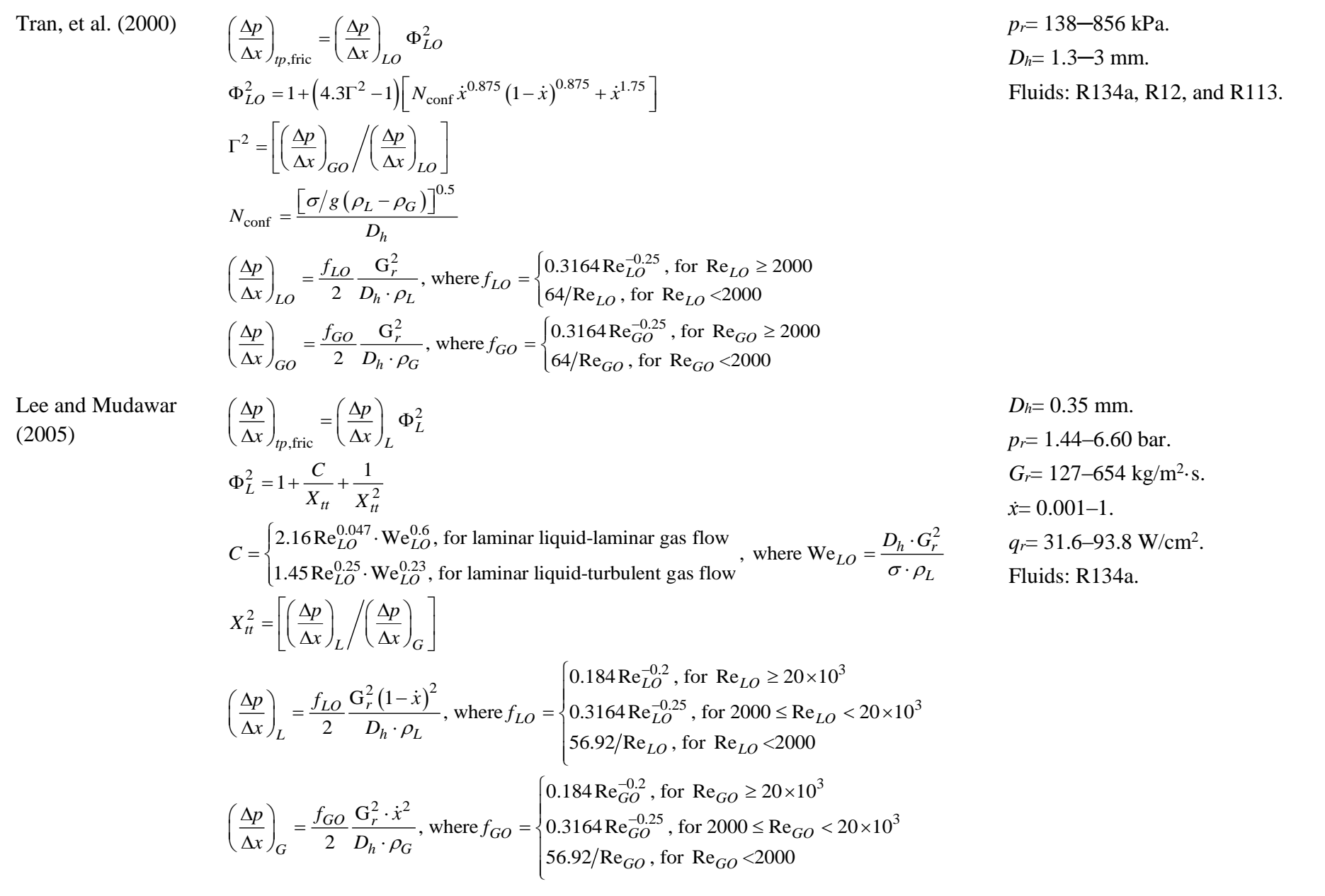


Experimental Validation of the Fin1D-MB Model

\subsection{Air-side Heat Transfer Coefficient and Pressure Drop}

For the air-side heat transfer coefficient and pressure drop of MCHXs, several correlations have been proposed by many authors in various studies. For most of these studies, the air-side heat transfer coefficient is mainly described by Chilton and Colburn $j$-factor, which takes this general form $j=\mathrm{Nu} / \mathrm{Re} \cdot \operatorname{Pr}^{1 / 3}$.

The total air-side pressure drop along the $z$-direction consists of frictional, acceleration, contraction, and expansion pressure drop terms according to the following expression:

$$
\left(\frac{d p}{d z}\right)_{a, \text { tot }}=\left(\frac{d p}{d z}\right)_{a, \text { fric }}+\left(\frac{d p}{d z}\right)_{a, \text { acc }}+\left(\frac{d p}{d z}\right)_{a, \text { cont }}+\left(\frac{d p}{d z}\right)_{a, \exp }
$$

The frictional and acceleration terms are calculated similarly to Equation (4.3). The pressure drop terms due to the sudden contraction and expansion in the heat exchanger are obtained following Kays and London (1984).

Kim and Bullard (2002a) and (2002b) compared their air-side heat transfer and friction factor correlations with test data from several other MCHX geometries. They reported that their correlations predicted the data well, especially for heat exchangers having greater flow depth. This makes Kim's correlations widely accepted by many authors in the literature. Therefore, they are adopted in the current model.

For dry surfaces, Kim and Bullard (2002a) developed the $j_{a}$ and $f_{a}$ correlations for $\operatorname{Re}_{\mathrm{Lp}}=100-600$ and $F_{p} / L_{p}<1$ with root-mean-square (RMS) errors of \pm 14.5 and $\pm 7 \%$, respectively:

$$
\begin{gathered}
j_{a}=\operatorname{Re}_{L_{p}}^{-0.487}\left(\frac{L_{\alpha}}{90}\right)^{0.257}\left(\frac{F_{p}}{L_{p}}\right)^{-0.13}\left(\frac{H_{f}}{L_{p}}\right)^{-0.29}\left(\frac{D_{f}}{L_{p}}\right)^{-0.235} \times \\
\left(\frac{L_{l}}{L_{p}}\right)^{0.68}\left(\frac{D_{t}}{L_{p}}\right)^{-0.279}\left(\frac{t_{f}}{L_{p}}\right)^{-0.05}
\end{gathered}
$$

and

$$
f_{a}=\operatorname{Re}_{L_{p}}^{-0.781}\left(\frac{L_{\alpha}}{90}\right)^{0.444}\left(\frac{F_{p}}{L_{p}}\right)^{-1.682}\left(\frac{H_{f}}{L_{p}}\right)^{-1.22}\left(\frac{D_{f}}{L_{p}}\right)^{0.818}\left(\frac{L_{l}}{L_{p}}\right)^{1.97}
$$


Chapter 4.

For a louvered fin, $F_{p}, H_{f}, D_{f}$, and $t_{f}$ are the fin pitch, height, depth, and thickness, respectively. While, $L_{\alpha}, L_{p}$, and $L_{l}$ are the louver angle, pitch, and length, respectively.

For wet surfaces, Kim and Bullard (2002b) developed the $j_{a}$ and $f_{a}$ correlations for $\operatorname{Re}_{\mathrm{Lp}}=80-300$ and $F_{p} / L_{p}<1$ with RMS errors of \pm 16.9 and $\pm 13.6 \%$, respectively:

$$
\begin{gathered}
j_{a}=\operatorname{Re}_{L_{p}}^{-0.512}\left(\frac{L_{\alpha}}{90}\right)^{0.25}\left(\frac{F_{p}}{L_{p}}\right)^{-0.171}\left(\frac{H_{f}}{L_{p}}\right)^{-0.29}\left(\frac{D_{f}}{L_{p}}\right)^{-0.248} \times \\
\left(\frac{L_{l}}{L_{p}}\right)^{0.68}\left(\frac{D_{t}}{L_{p}}\right)^{-0.275}\left(\frac{t_{f}}{L_{p}}\right)^{-0.05}
\end{gathered}
$$

and

$$
f_{a}=\operatorname{Re}_{L_{p}}^{-0.798}\left(\frac{L_{\alpha}}{90}\right)^{0.395}\left(\frac{F_{p}}{L_{p}}\right)^{-2.635}\left(\frac{H_{f}}{L_{p}}\right)^{-1.22}\left(\frac{D_{f}}{L_{p}}\right)^{0.823}\left(\frac{L_{l}}{L_{p}}\right)^{1.97}
$$

\subsection{Validation of the Complete Fin1D-MB Model}

The validation of the complete Fin1D-MB model was conducted for evaporators operating with $\mathrm{R} 134 \mathrm{a}$ and $\mathrm{CO}_{2}$ (R744) with different geometries and under different operating conditions. The numerical grid size chosen was the one that gave a good balance between accuracy and computational cost. According to the definition given in Section 4.2, the discretization grid employed for all the predicted results was: $\{5,3,3,3\}$. Different combinations of refrigerant-side frictional pressure drop (FPD) and heat transfer coefficient (HTC) correlations (Tables 4.1 and 4.2) were applied to find the most suitable one that gives the best results regarding the heat transfer rates and pressure drop values. The results of the Fin1D-MB model validation are discussed in details in the next sub-sections.

\subsubsection{Validation of minichannel evaporators operating with R134a}

The current model was firstly validated against an experimental campaign which was implemented by the Thermal and Fluids Engineering Department, Technical University of Cartagena (UPCT). Secondly, it was validated against the numerical model of Yun et al. (2007). Yun's model was basically developed for $\mathrm{CO}_{2}$ evaporators; however, the model verification was conducted using R134a as working fluid. Each study is presented in details, respectively. 
The experimental campaign of the UPCT was carried out in a reversible air-to-refrigerant heat pump test facility, as shown in Figure 4.3, which mainly consists of three circuits: air, water, and refrigerant loops. The heat pump operates with R134a and it is equipped with: a multi-speed hermetic reciprocating compressor with a displacement of $34.38 \mathrm{~cm}^{3}$, a brazed plate condenser (water-to-refrigerant), and an electronic valve as the expansion device. The tested evaporator is a single slap minichannel heat exchanger, which was provided by Modine Co. It is $340 \mathrm{~mm}$ high, $483 \mathrm{~mm}$ wide, and $21.1 \mathrm{~mm}$ deep. It comprises 33 multiport flat tubes, which are arranged in four paths (8-6-7-12). Regarding the refrigerant-side, the tube is characterized by eight triangular ports with a hydraulic diameter equal to $0.78 \mathrm{~mm}$. The fins are louvered type with a density equal to 14 fin/inch.

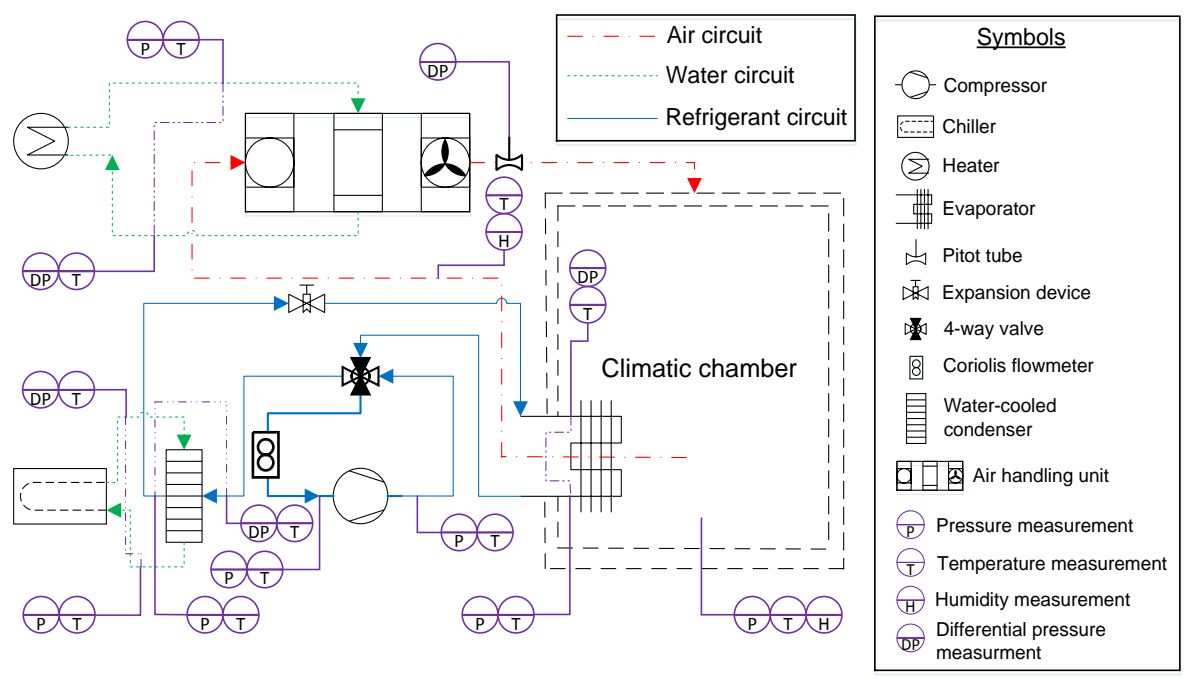

Figure 4.3. Schematic diagram of the test facility for the R134a air-to-refrigerant heat pump.

Table 4.3 shows the operating conditions which were specified as input data for the tested evaporator. The uncertainties for pressure, temperature, mass flow rate, compressor power, and compressor speed measurements were about $\pm 0.15 \%, \pm 0.3{ }^{\circ} \mathrm{C}$, $\pm 0.1 \%, \pm 0.5 \%$, and $\pm 0.1 \mathrm{~Hz}$, respectively. The energy balance between the air-side and refrigerant-side was within $\pm 5 \%$. The Inlet parameters to the model were refrigerant superheat, inlet quality, inlet air temperature and relative humidity, and inlet mass flow rate of refrigerant and air. Whereas, the inlet refrigerant temperature, refrigerant-side pressure drop, outlet air temperature, and refrigerant-side cooling capacity were the selected parameters to validate the proposed model. Figures 4.4-4.7 compare simulation results with the experimental data. 
Chapter 4.

Table 4.3. Operating conditions for the UPCT's R134a evaporator.

\begin{tabular}{llll}
\hline Air & \multicolumn{3}{l}{ Refrigerant } \\
\hline \hline Inlet dry-bulb temperature $\left[{ }^{\circ} \mathrm{C}\right]$ & 7 & Inlet mass flow rate $[\mathrm{kg} / \mathrm{h}]$ & $32.4-38$ \\
Inlet relative humidity $[\%]$ & $73-89$ & Inlet vapor quality $[-]$ & $0.22-0.24$ \\
Inlet flow rate $\left[\mathrm{m}^{3} / \mathrm{h}\right]$ & $890-1890$ & Outlet superheat $[\mathrm{K}]$ & $7.9-12.6$ \\
\hline
\end{tabular}

For nomenclature representation, the combination of refrigerant-side correlations is illustrated as, the abbreviation of FPD correlation + the abbreviation of HTC correlation. Table 4.4 lists the abbreviations of the refrigerant-side correlations that have been previously introduced in Tables 4.1 and 4.2.

Table 4.4. Abbreviations of the refrigerant-side FPD and HTC correlations used in the validation.

\begin{tabular}{llll}
\hline \multicolumn{2}{c}{ Refrigerant-side FPD correlations } & \multicolumn{2}{c}{ Refrigerant-side HTC correlations } \\
\hline \hline Reference & Abbreviation & Reference & Abbreviation \\
\hline \hline Muller-Steinhagen and Heck & MSH & Bennett and Chen (1980) & BC \\
$\begin{array}{l}\text { (1986) } \\
\text { Mishima and Hibiki (1996) }\end{array}$ & MH & Cooper (1984) & CO \\
Tran et al. (2000) & TWF & Hwang (1997) & HW \\
Lee and Mudawar (2005) & LM & Kandlikar and & KB \\
& & Balasubramanian (2004) & Wojtan et al. (2005) \\
\hline
\end{tabular}

Figure 4.4 compares the calculated inlet refrigerant temperatures $T_{r, i n}$ with the measured ones for different refrigerant-side FPD and HTC correlations. It can be observed that the best three combinations of correlations which give the best prediction of $\mathrm{T}_{\mathrm{r}, \mathrm{in}}$ are: $\mathrm{LM}+\mathrm{CO}, \mathrm{MH}+\mathrm{KB}$, and $\mathrm{MH}+\mathrm{WUT}$, respectively. Table 4.5 summarizes the mean absolute error (MAE) and standard deviation (SD) values for the predicted inlet refrigerant temperature.

It is worth mentioning that Mahmoud and Karayiannis (2013) reported a similar result for the Cooper correlation. They presented a detailed comparison of the flow boiling heat transfer coefficient for R134a in stainless steel micro tubes with 21 macro and microscale correlations and models. The experimental database that was used in the comparison included the data for 1.1 and $0.52 \mathrm{~mm}$ diameter tubes, mass flux range of $100-500 \mathrm{~kg} / \mathrm{m}^{2} \cdot \mathrm{s}$, and system pressure range of 6-10 bar. Their results reveled that Cooper's correlation predicted $63.7 \%$ of all data (5152 data points) within $\pm 30 \%$ error bands with a MAE value of $35 \%$. This is much better than the assessed macro and microscale correlations, despite it was originally developed for pool boiling applications. 
Experimental Validation of the Fin1D-MB Model
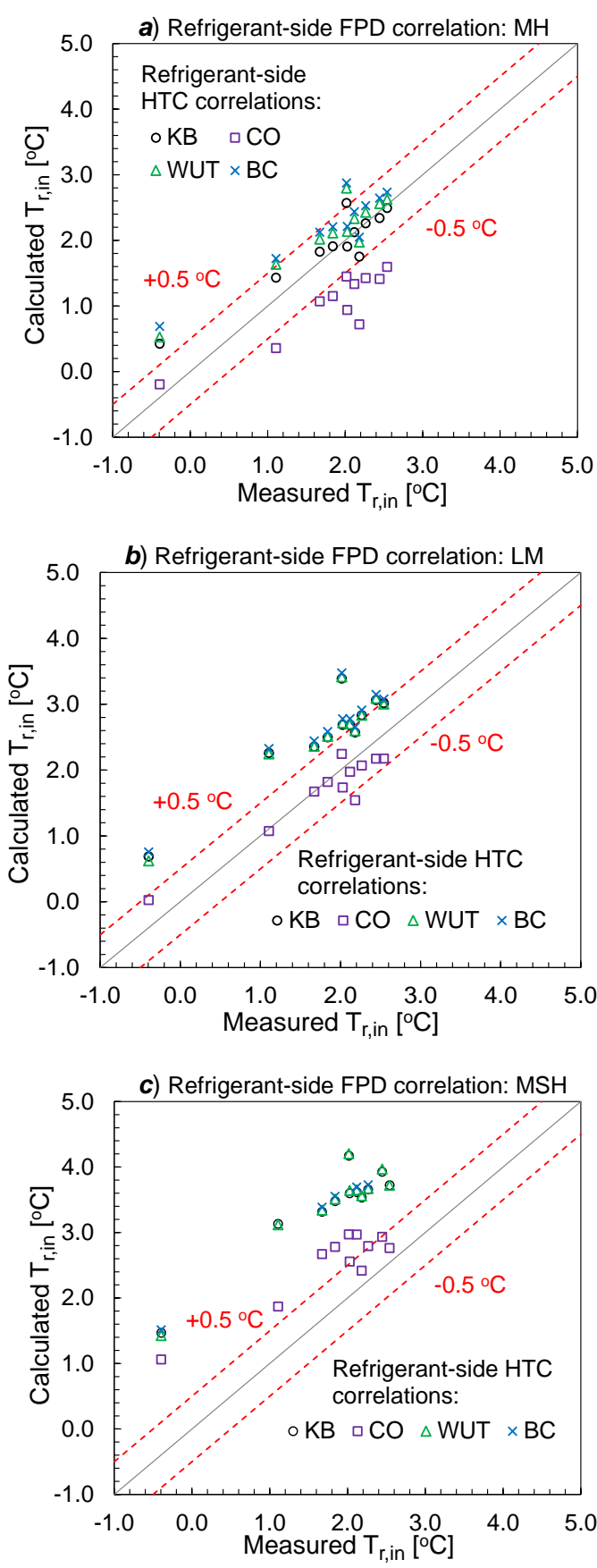

Figure 4.4. Comparison of the inlet refrigerant temperature $T_{r, i n}$ between the calculated and measured values of the UPCT's R134a evaporator. 
Chapter 4.

Table 4.5. MAE and SD values of the calculated $T_{r \text {,in }}$ (UPCT's $R 134 a$ evaporator).

\begin{tabular}{lcccccc}
\hline $\begin{array}{l}\text { Refrigerant-side } \\
\text { FPD correlation }\end{array}$ & \multicolumn{2}{c}{ MH } & \multicolumn{2}{c}{ LM } & \multicolumn{2}{c}{ MSH } \\
\hline \hline Refrigerant-side & & \multicolumn{3}{c}{ MAE and SD for $\mathrm{T}_{\mathrm{r}, \text { in }}\left[ \pm^{\circ} \mathrm{C}\right]$} \\
HTC correlation & MAE & SD & MAE & SD & MAE & SD \\
\hline \hline KB & $\mathbf{0 . 2 4}$ & $\mathbf{0 . 2 5}$ & 0.75 & 0.3 & 1.62 & 0.28 \\
CO & 0.81 & 0.31 & 0.24 & 0.18 & 0.72 & 0.35 \\
WUT & 0.34 & 0.27 & 0.75 & 0.29 & 1.64 & 0.27 \\
BC & 0.42 & 0.29 & 0.83 & 0.3 & 1.67 & 0.15 \\
\hline
\end{tabular}

The calculated refrigerant-side pressure drop $\Delta \mathrm{p}_{\mathrm{r}}$ against the measured data are depicted in Figure 4.5, for different HTC and FPD correlations. It can be seen that the combinations of $\mathrm{MH}+\mathrm{KB}, \mathrm{MH}+\mathrm{CO}$, and $\mathrm{LM}+\mathrm{CO}$ give the most appropriate prediction results for the $\Delta \mathrm{p}_{\mathrm{r}}$, respectively. The values of MAE and SD of the calculated $\Delta \mathrm{p}_{\mathrm{r}}$ are shown in Table 4.6.

Finally, it can be concluded that the best combination of refrigerant-side FPD and HTC correlations, regarding the refrigerant pressure drop and inlet temperature results, is $\mathrm{MH}+\mathrm{KB}$. The combination of $\mathrm{LM}+\mathrm{CO}$ and $\mathrm{MH}+\mathrm{WUT}$ also predict the data quite well. However, the correlations of $\mathrm{CO}$ and WUT were originally developed for pool boiling and macroscale applications, respectively.

Table 4.6. MAE and SD values for the calculated $\Delta \mathrm{p}_{\mathrm{r}}$ (UPCT's R134a evaporator).

\begin{tabular}{lcccccc}
\hline $\begin{array}{l}\text { Refrigerant-side } \\
\text { FPD correlation }\end{array}$ & \multicolumn{2}{c}{ MH } & \multicolumn{2}{c}{ LM } & \multicolumn{2}{c}{ MSH } \\
\hline \hline Refrigerant-side & \multicolumn{3}{c}{ MAE and SD for $\Delta \mathrm{p}_{\mathrm{r}}[ \pm \%]$} \\
\cline { 2 - 7 } HTC correlation & MAE & SD & MAE & SD & MAE & SD \\
\hline \hline KB & $\mathbf{9 . 1 2}$ & $\mathbf{7 . 1 8}$ & 21.08 & 6.53 & 42.68 & 6.93 \\
CO & 9.98 & 3.73 & 10.02 & 5.40 & 36.70 & 7.11 \\
WUT & 11.06 & 7.97 & 21.31 & 6.06 & 43.57 & 6.50 \\
BC & 13.02 & 8.83 & 23.03 & 6.48 & 46.33 & 4.88 \\
\hline
\end{tabular}



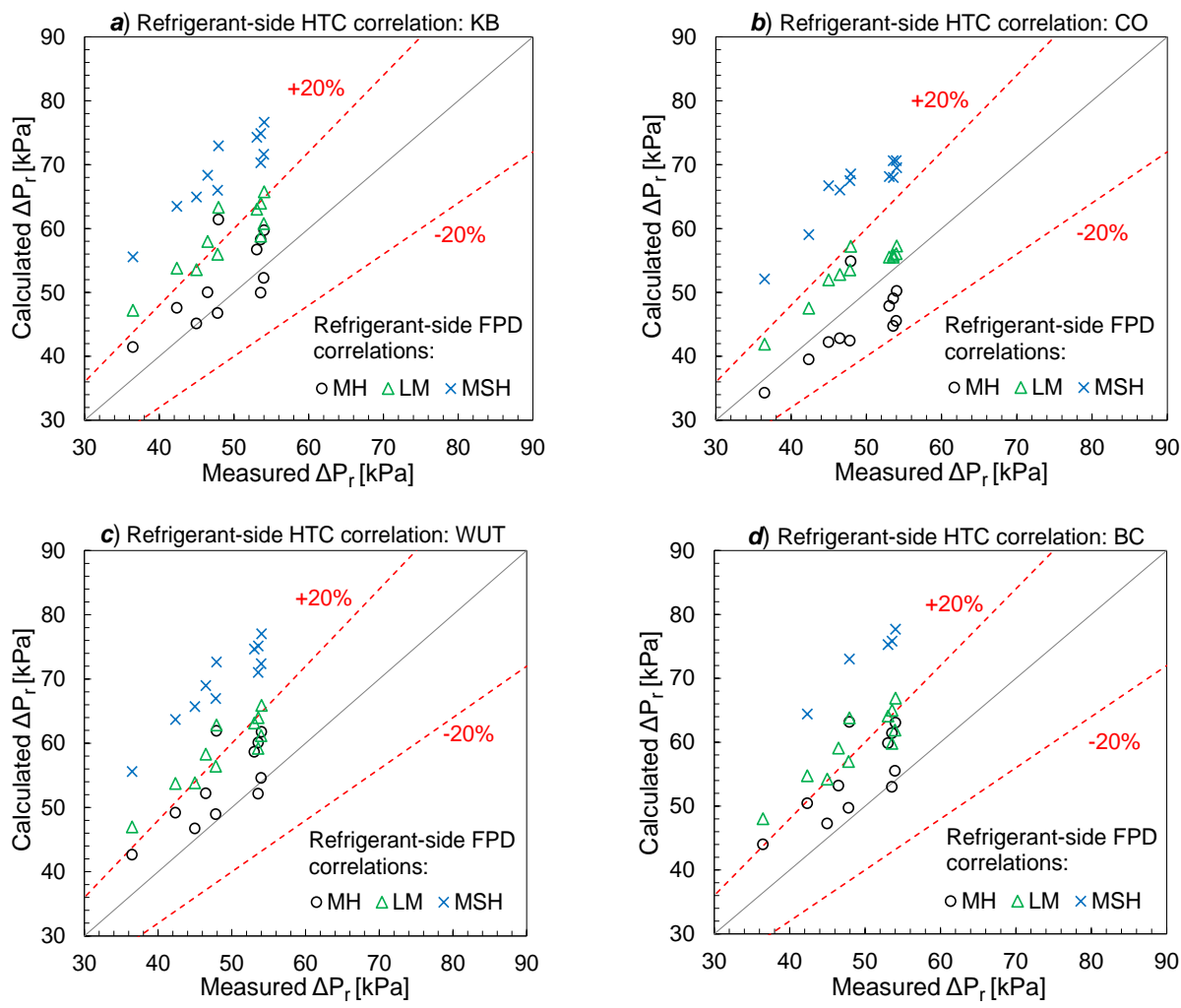

Figure 4.5. Comparison of the refrigerant-side pressure drop $\Delta \mathrm{p}_{\mathrm{r}}$ between the calculated and measured values of the UPCT's R134a evaporator.

Figures 4.6 and 4.7 compare the predicted outlet air temperature $\mathrm{T}_{\mathrm{a}, \text { out }}$ and refrigerant-side cooling capacity $\mathrm{Q}_{\mathrm{r}}$ with the experimental measurements, respectively. For the air-side HTC and FPD calculations, Kim's correlations (Equations 4.6-4.9) were used; while, for the refrigerant-side, the combination of $\mathrm{MH}+\mathrm{KB}$ correlations was applied.

The good prediction of inlet refrigerant temperature, with a MAE of $\pm 0.24{ }^{\circ} \mathrm{C}$, and outlet air temperature, with a MAE of $\pm 0.43{ }^{\circ} \mathrm{C}$, has a positive impact on the predicted cooling capacity as shown in Figure 4.7. It can be clearly noted that the predicted values of cooling capacity are within $\pm 5 \%$ error bands. 
Chapter 4.

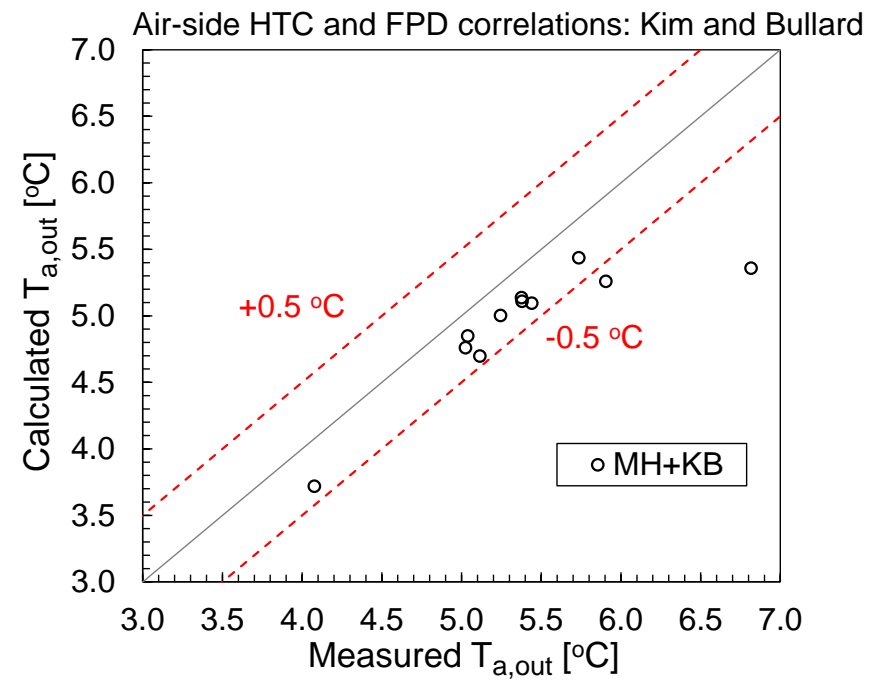

Figure 4.6. Comparison of the outlet air temperature $T_{a, o u t}$ between the calculated and measured values of the UPCT's R134a evaporator.

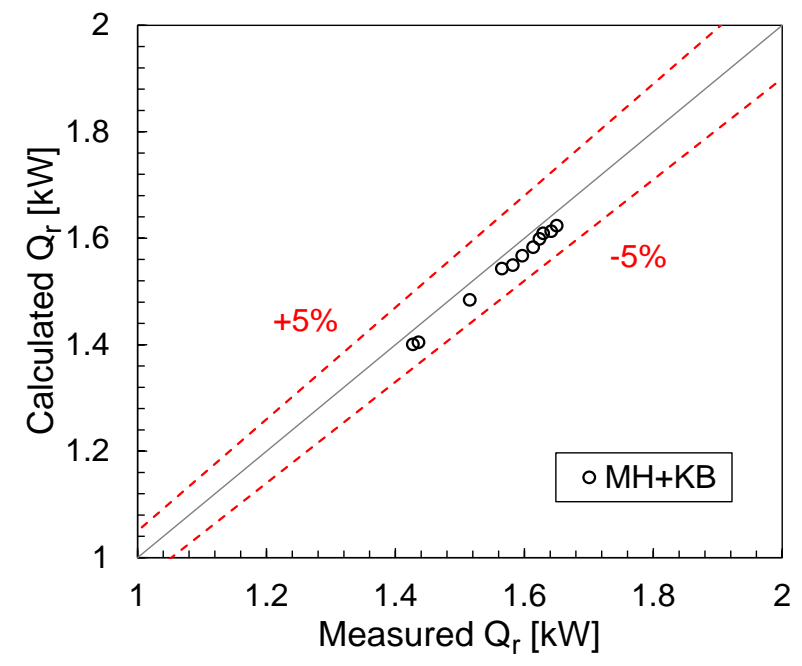

Figure 4.7. Comparison of the refrigerant-side cooling capacity $\mathrm{Q}_{\mathrm{r}}$ between the calculated and measured values of the UPCT's R134a evaporator. 
Experimental Validation of the Fin1D-MB Model

The present Fin1D-MB model was also validated against the minichannel evaporator model of Yun et al. (2007). They verified their model with R134a minichannel evaporator under various test conditions. The specifications of the evaporator used in their study are shown in Table 4.7. The shape of inside holes of the minichannel is rectangular, and its hydraulic diameter is $1.53 \mathrm{~mm}$.

Table 4.7. Specifications of the R134a minichannel evaporator (Yun et al., 2007).

\begin{tabular}{ll}
\hline Items & Specification \\
\hline \hline Heat exchanger length $[\mathrm{mm}]$ & 657.0 \\
Heat exchanger height $[\mathrm{mm}]$ & 65.8 \\
Tube number & 7 \\
Tube depth $[\mathrm{mm}]$ & 18.0 \\
Tube pitch $[\mathrm{mm}]$ & 8.7 \\
Tube thickness [mm] & 1.7 \\
Port number & 7 \\
Fin height $[\mathrm{mm}]$ & 7.3 \\
Fin depth [mm] & 18.0 \\
Fin pitch [mm] & 1.4 \\
Fin thickness [mm] & 0.16 \\
\hline
\end{tabular}

Figure 4.8 shows the predicted and measured heat transfer rates with the change in air flow rate. The inlet air dry and wet-bulb temperatures were 20 and $14{ }^{\circ} \mathrm{C}$, respectively; while, the inlet refrigerant flow rate and quality were $60 \mathrm{~kg} / \mathrm{h}$ and 0.05 , respectively. It can be observed that the Fin1D-MB model shows a good correlation with the Yun's model and experimental data. The combinations of MH+WUT and $\mathrm{MH}+\mathrm{BC}$ correlations predict the total heat transfer rate with MAE values, based on Yun's experimental data, of $\pm 1.2 \%$ and $\pm 2.6 \%$, respectively. On the other hand, Yun's model demonstrates a MAE of $\pm 5.8 \%$ in total heat transfer rate compared to the experimental data. 
Chapter 4.

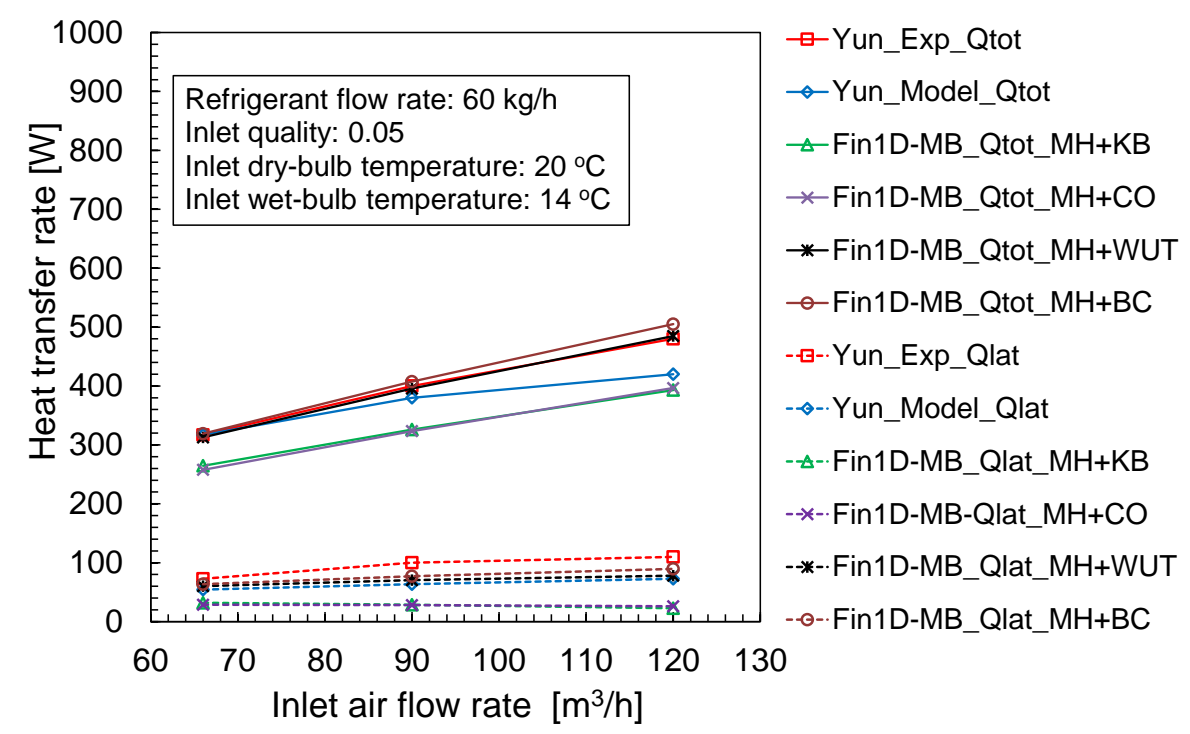

Figure 4.8. Total and latent heat transfer rates vs. inlet air flow rate, for the Fin1D-MB model and the model of Yun et al. (2007).

\subsubsection{Validation of a minichannel evaporator operating with $\mathrm{CO}_{2}$}

In the current study, the minichannel evaporator utilized by Beaver et al. (1999) in an air-conditioning system based on the transcritical $\mathrm{CO}_{2}$ cycle was simulated by using the current Fin1D-MB model. The target heat exchanger consists of one slab of 41 tubes, which are arranged in one pass. The details of minichannel tube used and general specifications of the tested R744 evaporator are shown in Figure 4.9 and Table 4.8, respectively.

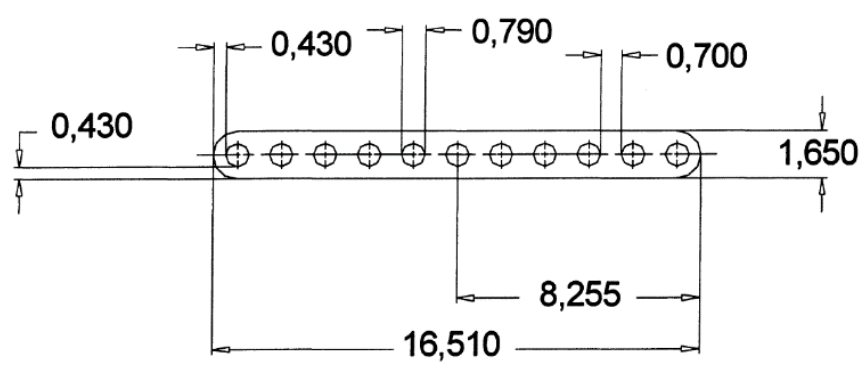

Figure 4.9. Cross-section of minichannel tube used in the R744 evaporator (Beaver et al., 1999). 
The test conditions for the R744 evaporator were as follows:

- Inlet air temperature: $26.5^{\circ} \mathrm{C}$

- Inlet air humidity ratio: $14-55 \%$

- Air flow rate: $2000-2450 \mathrm{~m}^{3} / \mathrm{h}$

- Inlet refrigerant pressure: $4100-5000 \mathrm{kPa}$

- Inlet quality: $0.16-0.4$

- Refrigerant mass flow rate: $127-170 \mathrm{~kg} / \mathrm{h}$

This range of conditions allows simulating the evaporator under different dry and wet conditions. The inlet refrigerant pressure, inlet vapor quality, inlet air temperature and relative humidity, and inlet mass flow rates for air and refrigerant have been selected, in the current study, as the inputs of the Fin1D-MB model. On the other hand, the air-side cooling capacity, refrigerant-side pressure drop, and outlet air temperature are the outputs which have been selected to validate the model.

Table 4.8. Specifications of the R744 minichannel evaporator (Beaver et al., 1999)

\begin{tabular}{ll}
\hline Items & Specification \\
\hline \hline Finned length [mm] & 820.0 \\
Finned width [mm] & 440.0 \\
Tube number & 41 \\
Tube depth [mm] & 16.51 \\
Tube thickness [mm] & 1.65 \\
Port number & 11 \\
Fin height [mm] & 8.9 \\
Fin depth [mm] & 16.5 \\
Fin density [fpi] & 17 \\
Fin thickness [mm] & 0.1 \\
\hline
\end{tabular}

In this study, the correlation of Tran et al. (2000) (TWF) was utilized to predict the $\mathrm{CO}_{2}$ frictional pressure drop. However, to predict a proper value of refrigerant-side HTC, different correlations (Table 4.1) were applied. The air-side HTC and FPD were estimated using Equations (4.6)-(4.9). Figure 4.10 shows the calculated airside cooling capacity $Q_{a}$ values versus the measured ones for different refrigerantside HTC correlations. 
Chapter 4.

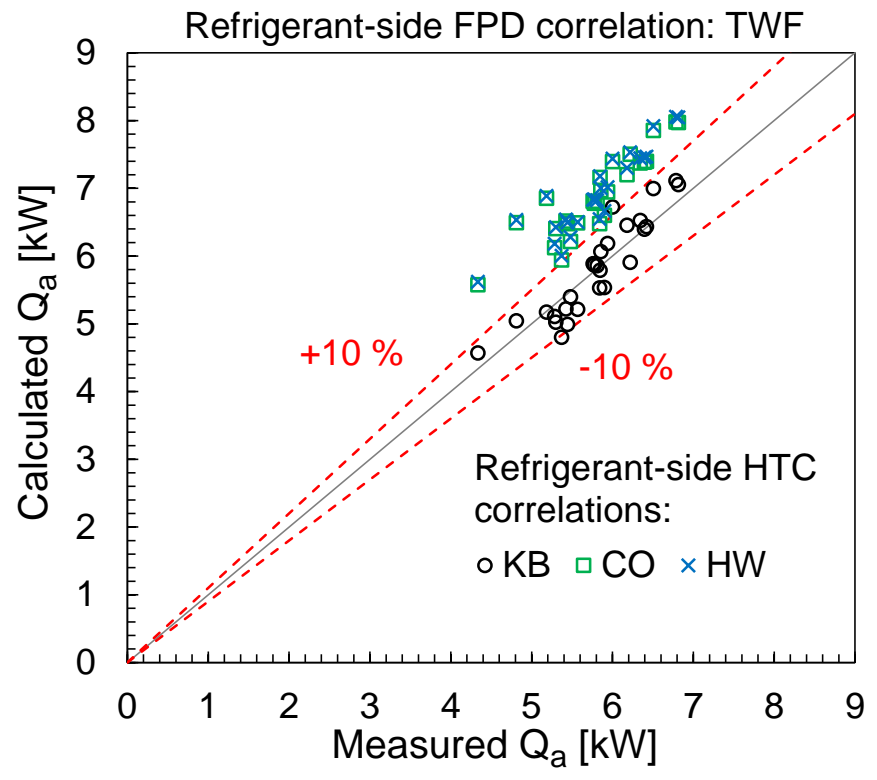

Figure 4.10. Predicted vs. measured air-side cooling capacity, $Q_{a}$, of Beaver et al.

(1999).

The results in Figure 4.10 show that the combination of TWF+KB correlations successfully estimates the cooling capacity within $\pm 10 \%$ error bands, with MAE and SD values of $\pm 4.3 \%$ and $\pm 3 \%$, respectively.

According to the previous results, the ratio of predicted to measured refrigerant-side pressure drop versus the refrigerant mass flow rate are illustrated in Figure 4.11 for the combination of TWF+KB correlations. Generally, the proposed model underpredicts the refrigerant-side pressure drop compared to the experimental data. However, the maximum deviation between the predicted and measured values is $11 \mathrm{kPa}$.

Finally, Figure 4.12 compares the calculated outlet air temperature values with the measured values. It can be seen that approximately $60 \%$ of the predicted data are within $\pm 1.0{ }^{\circ} \mathrm{C}$ error bands with MAE and SD values of \pm 0.9 and $\pm 0.6{ }^{\circ} \mathrm{C}$, respectively. 
Experimental Validation of the Fin1D-MB Model

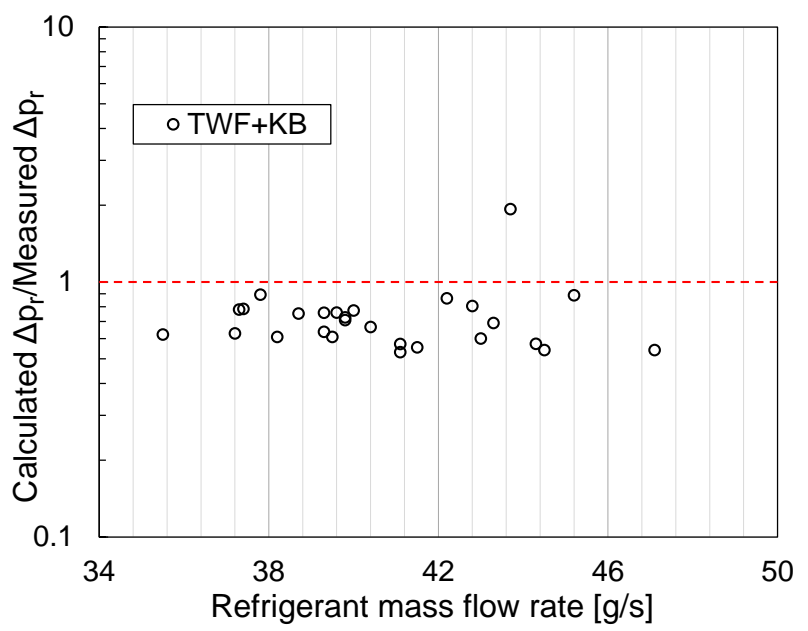

Figure 4.11. Ratio of predicted to measured refrigerant-side pressure drop vs. refrigerant mass flow rate for the R744 evaporator.

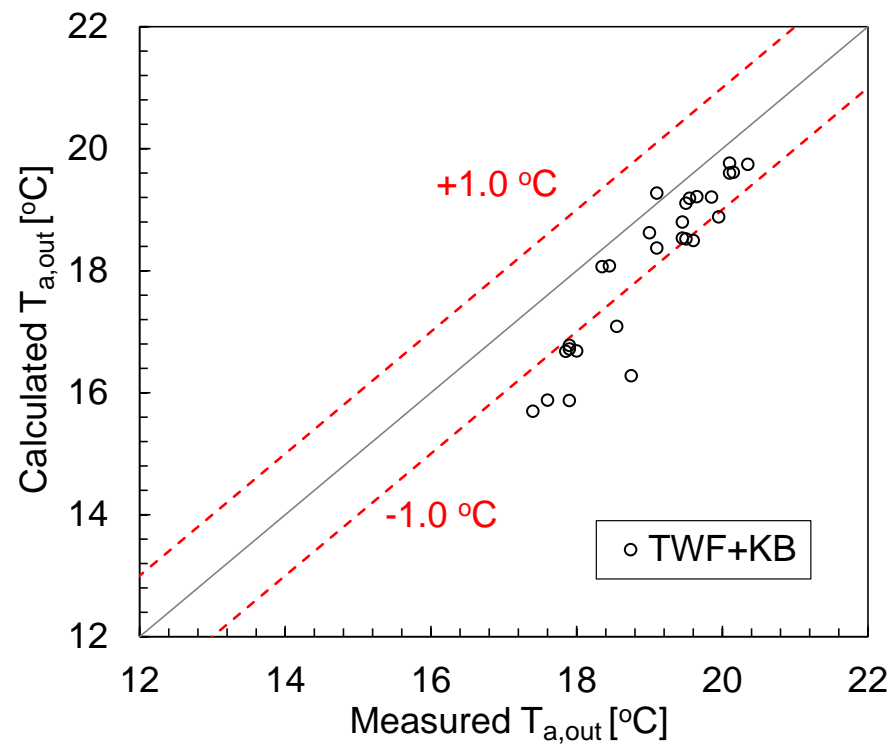

Figure 4.12. Predicted vs. measured outlet air temperature, $T_{a, o u t}$ of Beaver et al. (1999). 
Chapter 4.

\subsection{Summary}

The Fin1D-MB model was integrated into the IMST-ART ${ }^{\circledR}$ program to evaluate the overall performance of minichannel evaporators under dehumidification. The Fin1D-MB model has been chosen because of its simplicity and calculation speed compared with the Fin2D-W model.

The widely used correlations of Kim and Bullard (2002a) and (2002b) were adopted in the current model to estimate the air-side heat transfer coefficient and pressure drop for dry and wet conditions. Different combinations between the refrigerant-side frictional pressure drop and heat transfer coefficient correlations were tested, in order to find the best combination regarding the heat transfer and pressure drop results.

The validation of the proposed model was implemented for different MCHX geometries, refrigerants, and operating conditions. For the R134a evaporators studied, the Fin1D-MB model predicted the cooling capacity and refrigerant-side pressure drop within $\pm 5 \%$ and $\pm 20 \%$ error bands, respectively. For the $\mathrm{CO}_{2}$ (R744) evaporator studied, the presented model estimated the cooling capacity within $\pm 10 \%$ error bands while the maximum deviation in refrigerant pressure drop was $11 \mathrm{kPa}$. 


\title{
Chapter 5.
}

\section{Conclusions and}

\section{Future Work}

\author{
"Then, to Allah (God) belongs praise, Lord of the heavens and Lord of \\ the earth, Lord of all Being" \\ -The Holy Quran (45:36)
}


Chapter 5.

\subsection{Conclusions}

In the first part of the presented thesis, two numerical models accounting for the airside performance of minichannel evaporators under dehumidification were developed and verified. They are considered to be fundamental numerical approaches and preliminary steps to evaluate the impact of different classical assumptions on the modeling of minichannel evaporators. This allows developing a complete numerical model which only considers the most influential assumptions and heat and mass transfer phenomena.

The first model, which is referred to as Fin2D-W, discretizes the evaporator walls and fluids into cells, for which energy and mass balances are applied. The Fin2D-W model takes into account the two-dimensional heat conduction in any wall element, different dehumidifying scenarios for fin and tube, and detailed representation of air properties in longitudinal and transverse directions. A comparative study was implemented between the Fin2D-W model and classical $\varepsilon$-NTU approach. This study was made under different dehumidifying conditions, without and with the presence of temperature difference between the adjacent tubes. The main conclusions of this study are summarized next.

a) Without a temperature difference between the tubes (no superheat):

- For the totally dry fin, the $\varepsilon$-NTU approach overestimated the sensible heat transfer rate by approximately $4 \%$, relative to the Fin2D-W results. The main source of this deviation could be the assumption of uniform air temperature between tubes.

- For the partially wet fin, the $\varepsilon$-NTU approach always fails to predict the actual fin status because it does not account for partially wet scenarios. This resulted in significant deviations, especially in latent heat transfer, between the two approaches.

- The high fin efficiency, even under the wet condition, resulted in a narrow range of the partially wet fin of a maximum of $0.5 \mathrm{~K}$. However, a further increase is anticipated in the partially wet fin range in the presence of temperature difference between the neighboring tubes.

- For the totally wet fin, the $\varepsilon$-NTU approach generally overpredicts the sensible, latent, and total heat transfer rates for all inlet air cases studied. The average relative deviations in sensible, latent, and total heat transfer were $3.45 \%$, $22.91 \%$, and $4.11 \%$, respectively. The main source of divergence between the 
Conclusions and Future Work

two approaches is the assumption of constant air temperature and humidity ratio between tubes.

- The $\varepsilon-N T U$ approach was five times faster than the Fin2D-W model, for all the cases studied.

b) With a temperature difference between the tubes (superheat):

- The $\varepsilon$-NTU model is not able to capture the precise dehumidifying condition of the fin, compared to the Fin2D-W model. It only considers three fin conditions $0 \%, 50 \%$, and $100 \%$ wet fin. This is because of the discontinuity in the fin temperature profile, which is a consequence of adapting the adiabatic-fintip assumption. In addition to this assumption, the high fin efficiency which usually exists in minichannel heat exchangers makes the heat transfer results very sensitive to the tube temperature.

- In the region of totally wet fin, the relative deviations in total heat transfer were up to $4.33 \%$.

- In the region of partially wet fin, the deviations between the two approaches start to increase significantly with the increase in superheat value, especially the deviations in latent heat transfer. This is the consequence of using adiabatic-fin-tip assumption at half the height, which results in large differences in the fin temperature profile and dehumidifying condition between the two models. The relative deviations in total heat transfer between the two approaches for Cases I, II, and III were up to $16 \%, 30 \%$, and $52 \%$, respectively.

The second model, which is referred to as Fin1D-MB, retains the essential heat and mass transfer phenomena as the Fin2D-W model, but with much lower computational cost. The Fin1D-MB model is based on the one-dimensional fin theory in conjunction with the technique of movable boundaries between wet and dry portions along the fin height. This innovative scheme substantially reduces the complexity of evaporator discretization, and allows capturing the tube-to-tube heat conduction and actual dehumidifying condition of the fin. Unlike the Fin2D-W model, the Fin1DMB model implicitly assumes uniform air temperature and humidity ratio along the fin height. A comparison of the heat transfer results between the Fin1D-MB and Fin2D-W models was made under different dehumidifying conditions and values of superheat. The general conclusions of this study are: 
Chapter 5.

- Compared to the Fin2D-W model, the Fin1D-MB model saved up to 95\% of the computation time for all cases studied. This advantage is derived from using the one-dimensional fin theory.

- The Fin1D-MB model also predicted the real dehumidifying condition of the fin quite well for all the situations studied. This is the consequence of adopting the moving boundaries technique along the fin height.

- In the fully wet fin region, the Fin1D-MB model predicts slightly higher heat transfer results than the Fin2D-W model. The relative deviations in total heat transfer in this region were up to $4.34 \%$ for the three cases studied.

- In the partially wet fin region, the deviations in total heat transfer rate increased by up to $10 \%$. Nevertheless, these deviations are expected to decrease while evaluating a complete minichannel evaporator.

- Although both models predict similar fin temperature profiles and dehumidifying conditions, the main source of deviations in heat transfer results, especially in latent heat transfer, is the assumption of uniform air temperature and humidity ratio along the fin height adopted by the Fin1D-MB model.

In the second part of the current thesis, the Fin1D-MB model was integrated into the IMST-ART ${ }^{\circledR}$ simulation program to assess the general performance of minichannel evaporators (air- and refrigerant-side). The Fin1D-MB model was selected because of its simplicity and calculation speed, compared to the Fin2D-W model. After integrating the Fin $1 \mathrm{D}-\mathrm{MB}$ model, it was validated against experimental data and numerical models existed in the literature. The validation process was achieved for different MCHX geometries, refrigerants, and operating conditions. The global conclusions of these studies are listed below.

- For UPCT's R134a evaporator: the Fin1D-MB model successfully predicted the inlet refrigerant temperature, refrigerant-side pressure drop, outlet air temperature, and cooling capacity within error bands of $\pm 0.5{ }^{\circ} \mathrm{C}$ (with a MAE of $\pm 0.24{ }^{\circ} \mathrm{C}$ ), $\pm 20 \%$ (with a MAE of $\pm 9.12 \%$ ), $\pm 0.5{ }^{\circ} \mathrm{C}$ (with a MAE of \pm 0.43 ${ }^{\circ} \mathrm{C}$ ), and $\pm 5 \%$ (with a MAE of $\pm 1.8 \%$ ), respectively.

- For Yun's R134a evaporator: the proposed model estimated the total heat transfer rate quite well with a MAE of $\pm 1.2 \%$.

- For Beaver's $\mathrm{CO}_{2}$ (R744) evaporator: the Fin1D-MB model predicted the cooling capacity within $\pm 10 \%$ error bands with a MAE of $\pm 4.3 \%$. Additionally, it predicted approximately $60 \%$ of the outlet air temperature values within $\pm 1.0^{\circ} \mathrm{C}$ error bands with a MAE of $\pm 0.9^{\circ} \mathrm{C}$. Regarding the refrigerant- 
Conclusions and Future Work

side pressure drop, the maximum deviation between the predicted and measured values was $11 \mathrm{kPa}$.

\subsection{List of Publications}

The publications related to the presented thesis are listed in chronological order as follows:

- Hassan, A.H., Martinez-Ballester, S., Gonzálvez-Maciá, J. 2016. Two-dimensional numerical modeling for the air-side of minichannel evaporators accounting for partial dehumidification scenarios and tube-to-tube heat conduction. International Journal of Refrigeration, 67: 90-101.

- Hassan, A.H., Gonzálvez-Maciá, J., Martinez-Ballester, S., García-Cascales, J-.R. 2016. Development and Validation of a Minichannel Evaporator Model under Different Dehumidifying Conditions. $16^{\text {th }}$ International Refrigeration and Air Conditioning Conference at Purdue, July 11-14, West Lafayette, USA.

- Hassan, A.H., Martinez-Ballester, S., Gonzálvez-Maciá, J. 2016. Comparison of one-dimensional and two-dimensional numerical models for air-side performance of a minichannel evaporator under dehumidification. VIII Iberian Congress/VI Ibero-American Congress of Refrigeration Sciences and Technologies, May 3-6, Coimbra, Portugal.

- Hassan, A.H., Martínez-Ballester, S., Gonzálvez-Maciá, J. 2015. Effect of heat conduction through the fins on the air side performance of minichannel evaporators under dehumidifying conditions. $24^{\text {th }}$ IIR International Congress of Refrigeration, August 16-22, Yokohama, Japan.

- Hassan, A.H., Martinez-Ballester, S., Gonzálvez-Maciá, J. 2015. A comparative study between a two-dimensional numerical minichannel evaporator model and a classical effectiveness-NTU approach under different dehumidifying conditions. Science and Technology for the Built Environment, 21(5): 681-692.

- Hassan A.H., Gonzálvez-Maciá J., Martinez-Ballester S. 2015. Evaluación del efecto del sobrecalentamiento en el modelado de la deshumidificación para un evaporador de minicanales. In: IX Congreso Nacional de Ingeniería Termodinámica: libro de actas, pp. 329-336.

- Hassan, A.H., Martinez-Ballester, S., Gonzálvez-Maciá, J. 2014. Impact of dehumidification modelling on the performance prediction for minichannel 
Chapter 5.

evaporators. $15^{\text {th }}$ International Refrigeration and Air Conditioning Conference at Purdue, July 14-17, West Lafayette, USA.

- Hassan, A.H., Gonzálvez-Maciá, J., Martinez-Ballester, S. 2014 . Air-side performance of a minichannel evaporator under different dehumidifying scenarios. In: Avances en Ciencias y Técnicas del Frio VII: libro de actas, pp. 96-105.

- Hassan, A.H., Gonzálvez-Maciá, J., Martinez-Ballester, S. 2014. Development and validation of a minichannel evaporator 2D model under dehumidification. A poster in: $1^{\text {st }}$ Meeting of PhD Students at UPV, June $12^{\text {th }}$, Valencia, Spain.

\subsection{Future Work}

In order to improve the present numerical model, regarding the computational cost and reliability, the following enhancements, tests, and modifications should be considered in the future:

- Implementing and testing additional HTC and FPD correlations for both airand refrigerant-side.

- Testing the current model against further heat exchanger geometries, refrigerants, and operating conditions.

- Improving the numerical scheme to allow simulating multi-slab minichannel evaporators.

- Modifying the air-side governing equations to account for frost formation and air maldistribution.

- Modeling the refrigerant maldistribution and pressure drop in the headers of minichannel evaporators. 


\section{Chapter 6.}

Appendices

"A person who never made a mistake never tried anything new"
-Albert Einstein 
Chapter 6.

\subsection{Appendix A: Psychrometric Relationships and Charts}

\subsubsection{Introduction}

Psychrometrics uses thermodynamic properties to analyze conditions and processes involving moist air. This appendix discusses perfect gas relations and their use in common heating, cooling, and humidity control problems. Formulas developed by Herrmann et al. (2009) may be used where greater precision is required.

Hyland and Wexler (1983a) and (1983b), Nelson and Sauer Jr. (2002), and Herrmann et al. (2009) developed formulas for thermodynamic properties of moist air and water modeled as real gases. However, perfect gas relations can be substituted in most air-conditioning problems. Kuehn et al. (1998) showed that errors are less than $0.7 \%$ in calculating humidity ratio, enthalpy, and specific volume of saturated air at standard atmospheric pressure for a temperature range of -50 to $50^{\circ} \mathrm{C}$. Furthermore, these errors decrease with decreasing pressure.

\subsubsection{Thermodynamic properties of water at saturation}

The water vapor saturation pressure is required to determine a number of moist air properties, principally the saturation humidity ratio. The saturation pressure over liquid water for the temperature range of 0 to $200{ }^{\circ} \mathrm{C}$ is given by the following formula (Hyland and Wexler, 1983b):

$$
\ln p_{w v, s a t}=C_{1} / T+C_{2}+C_{3} T+C_{4} T^{2}+C_{5} T^{3}+C_{6} \ln T
$$

where

$p_{w v, \text { sat }}$ is the water vapor saturation pressure $[\mathrm{Pa}]$,

$T$ is the absolute temperature $[\mathrm{K}]$,

$C_{1}=-5.8002206 \times 10^{3}$,

$C_{2}=1.3914993$,

$C_{3}=-4.8640239 \times 10^{-2}$

$C_{4}=4.1764768 \times 10^{-5}$

$C_{5}=-1.4452093 \times 10^{-8}$, and

$C_{6}=6.5459673$. 


\subsubsection{Perfect gas relationships for dry and moist air}

When moist air is considered a mixture of independent perfect gases (i.e., dry air and water vapor), each is assumed to obey the perfect gas equation of state as follows:

Dry air:

$$
p_{d a} \cdot V=n_{d a} \cdot R_{\text {unv }} \cdot T
$$

Water vapor:

$$
p_{w v} \cdot V=n_{w v} \cdot R_{\mathrm{unv}} \cdot T
$$

where

$p_{d a} \quad$ is the partial pressure of dry air,

$p_{w v}$ is the partial pressure of water vapor,

$V \quad$ is the total mixture volume,

$n_{d a}$ is the number of moles of dry air,

$n_{w v} \quad$ is the number of moles of water vapor, and

$R_{\mathrm{unv}}$ is the universal gas constant $=8314.472[\mathrm{~J} / \mathrm{kmol} \cdot \mathrm{K}]$.

The mixture also obeys the perfect gas equation:

$$
p_{\mathrm{atm}} \cdot V=n \cdot R_{\mathrm{unv}} \cdot T
$$

or

$$
\left(p_{w v}+p_{d a}\right) \cdot V=\left(n_{w v}+n_{d a}\right) \cdot R_{\mathrm{unv}} \cdot T
$$

where $p_{\text {atm }}$ is the total mixture pressure, in the current work it is equal to the standard atmospheric pressure $=101325 \mathrm{~Pa}$, and $n$ is the total number of moles in the mixture. From Equations (6.4) to (6.5), the mole fractions of dry air and water vapor are, respectively,

$$
x_{d a}=p_{d a} /\left(p_{d a}+p_{w v}\right)=p_{d a} / p_{\mathrm{atm}}
$$

and

$$
x_{w v}=p_{w v} /\left(p_{d a}+p_{w v}\right)=p_{w v} / p_{\mathrm{atm}}
$$

\subsubsection{Humidity ratio, $W$}

Humidity ratio of a given moist air sample is defined as the ratio of the mass of water vapor to the mass of dry air in the sample: 
Chapter 6.

$$
W=\frac{m_{w v}}{m_{d a}}
$$

$W$ equals the mole fraction ratio $x_{w v} / x_{d a}$ multiplied by the ratio of molecular masses $(18.015268 / 28.966=0.621945)$ :

$$
W=0.621945 \frac{x_{w v}}{x_{d a}}
$$

From Equations (6.6), (6.7), and (6.8), the humidity ratio $W$ is

$$
W=0.621945 \frac{p_{w v}}{p_{\mathrm{atm}}-p_{w v}}
$$

\subsubsection{Specific enthalpy of moist air, $h$}

The enthalpy of a mixture of perfect gases equals the sum of the individual partial enthalpies of the components. Therefore, the specific enthalpy of moist air can be written as follows:

$$
h=h_{d a}+W \cdot h_{w v, \text { sat }}
$$

where $h_{d a}$ is the specific enthalpy for dry air in $\mathrm{J} / \mathrm{kg}_{\mathrm{da}}$ and $h_{w v \text {,sat }}$ is the specific enthalpy for saturated water vapor in $\mathrm{J} / \mathrm{kg}_{\text {water }}$ at the temperature of the mixture. As an approximation,

$$
\begin{gathered}
h_{d a}=C_{p, d a} \cdot T_{d b} \approx 1006 \cdot T_{d b} \\
h_{w v, \text { sat }}=h_{w v, \text { sat }}^{0}+C_{p, w v} \cdot T_{d b} \approx 2501000+1860 \cdot T_{d b}
\end{gathered}
$$

where

$C_{p, d a}$ is the specific heat of the dry air,

$h_{w v \text {,sat }}^{0}$ is the enthalpy of saturated water vapor at $0^{\circ} \mathrm{C}$,

$C_{p, w v}$ is the specific heat of water vapor, and

$T_{d b} \quad$ is the air dry-bulb temperature in ${ }^{\circ} \mathrm{C}$.

The moist air specific enthalpy in $\mathrm{J} / \mathrm{kg}_{\mathrm{da}}$ then becomes 


$$
h=1006 \cdot T_{d b}+W\left(2501000+1860 \cdot T_{d b}\right)
$$

\subsubsection{Humidity parameters involving saturation}

\subsubsection{Saturated humidity ratio, $W_{\text {sat }}$}

It is the humidity ratio of moist air saturated with respect to water (or ice) at the same temperature $T$ and atmospheric pressure $p_{\text {atm. }}$.

$$
W_{\text {sat }}=0.621945 \frac{p_{w v, \text { sat }}}{p_{\text {atm }}-p_{w v \text {,sat }}}
$$

\subsubsection{Degree of saturation, $\mu$}

It is the ratio of air humidity ratio $W$ to humidity ratio of saturated moist air $W_{\text {sat }}$ at the same temperature and pressure.

$$
\mu=\left.\frac{W}{W_{\mathrm{sat}}}\right|_{T, p_{\mathrm{atm}}}
$$

\subsubsection{Relative humidity, $R H$}

It is the ratio of the partial pressure of water vapor $p_{w v}$ to saturation pressure of water vapor $p_{w v, \text { sat }}$ in the absence of air at the given temperature $T$.

$$
\mathrm{RH}=\left.\frac{p_{w v}}{p_{w v, \mathrm{sat}}}\right|_{T, p_{\text {atm }}}=\frac{\mu}{1-(1-\mu)\left(p_{w v, \mathrm{sat}} / p_{\text {atm }}\right)}
$$

\subsubsection{Thermodynamic wet-bulb and dew point temperature}

\subsubsection{Wet-bulb temperature, $T_{w b}$}

For any state of moist air, a temperature $T^{*}$ exists at which liquid (or solid) water evaporates into the air to bring it to saturation at exactly this same temperature and total pressure (Harrison, 1965). During adiabatic saturation, saturated air is expelled at a temperature equal to that of the injected water. 
Chapter 6.

Therefore, if the process is strictly adiabatic, conservation of enthalpy at constant total pressure requires that

$$
h+\left(W_{\mathrm{sat}}^{*}-W\right) h_{\mathrm{water}, \mathrm{sat}}^{*}=h_{\mathrm{sat}}^{*}
$$

where $W_{\mathrm{sat}}^{*}, h_{\mathrm{water}, \text { sat }}^{*}, h_{\mathrm{sat}}^{*}$ are functions only of temperature $T^{*}$ for a fixed value of pressure. The value of $T^{*}$ that satisfies Equation (6.18) for given values of $h, W$, and $p$ is the thermodynamic wet-bulb temperature $T_{w b}$.

Substituting the approximate perfect gas relation (Equation 6.14) for $h$, the corresponding expression for $h_{\text {sat }}^{*}$, and the approximate relation for saturated liquid water

$$
h_{\mathrm{water}, \mathrm{sat}}^{*} \approx 4186 \cdot T_{w b}
$$

into Equation (6.18), and solving for the humidity ratio,

$$
W=\frac{\left(2501000-2326 \cdot T_{w b}\right) W_{\mathrm{sat}}^{*}-1006\left(T_{d b}-T_{w b}\right)}{2501+1860 \cdot T_{d b}-4186 \cdot T_{w b}}
$$

where $T_{w b}$ and $T_{d b}$ are in ${ }^{\circ} \mathrm{C}$. Trial-and-error or numerical solution method is required to solve Equation (6.20).

\subsubsection{Dew point temperature, $T_{d p}$}

The dew point temperature $T_{d p}$ of moist air with humidity ratio $W$ and pressure $p_{\text {atm }}$ was defined as the solution $T_{d p}\left(p_{\mathrm{atm}}, W\right)$ of $W_{\mathrm{sat}}\left(p_{\mathrm{atm}}, T_{d p}\right)$. For perfect gases, this reduces to

$$
p_{w v, \mathrm{sat}}\left(T_{d p}\right)=p_{w v}=\left(p_{\mathrm{atm}} \cdot W\right) /(0.621945+W)
$$

The value of water vapor saturation pressure at the dew point temperature could be obtained from Equation (6.1). Alternatively, the dew point temperature can be calculated directly by the following equation (Peppers, 1988):

Between dew points of 0 and $93^{\circ} \mathrm{C}$,

$$
T_{d p}=C_{7}+C_{8} \cdot\left(\ln p_{w v}\right)+C_{9} \cdot\left(\ln p_{w v}\right)^{2}+C_{10} \cdot\left(\ln p_{w v}\right)^{3}+C_{11}\left(p_{w v}\right)^{0.1984}
$$

where

$T_{d p}$ is the dew point temperature [ $\left.{ }^{\circ} \mathrm{C}\right]$, 
$P_{w v}$ is the water vapor partial pressure [Kpa],

$C_{7}=6.54$,

$C_{8}=14.526$,

$C_{9}=0.7389$,

$C_{10}=0.09486$, and

$C_{11}=0.4569$.

\subsubsection{Psychrometric charts}

A psychrometric chart graphically represents the thermodynamic properties of moist air. A chart with coordinates of enthalpy and humidity ratio provides convenient graphical solutions of many moist air problems with a minimum of thermodynamic approximations. ASHRAE developed many psychrometric charts for different altitudes and pressures. Figure 6.1 represents the one for sea-level pressure (101.325 $\mathrm{kPa}$ ). All charts use oblique-angle coordinates of enthalpy and humidity ratio, and are consistent with the properties computation methods of Goff (1945) and (1949), as well as, Hyland and Wexler (1983a). 
Chapter 6.

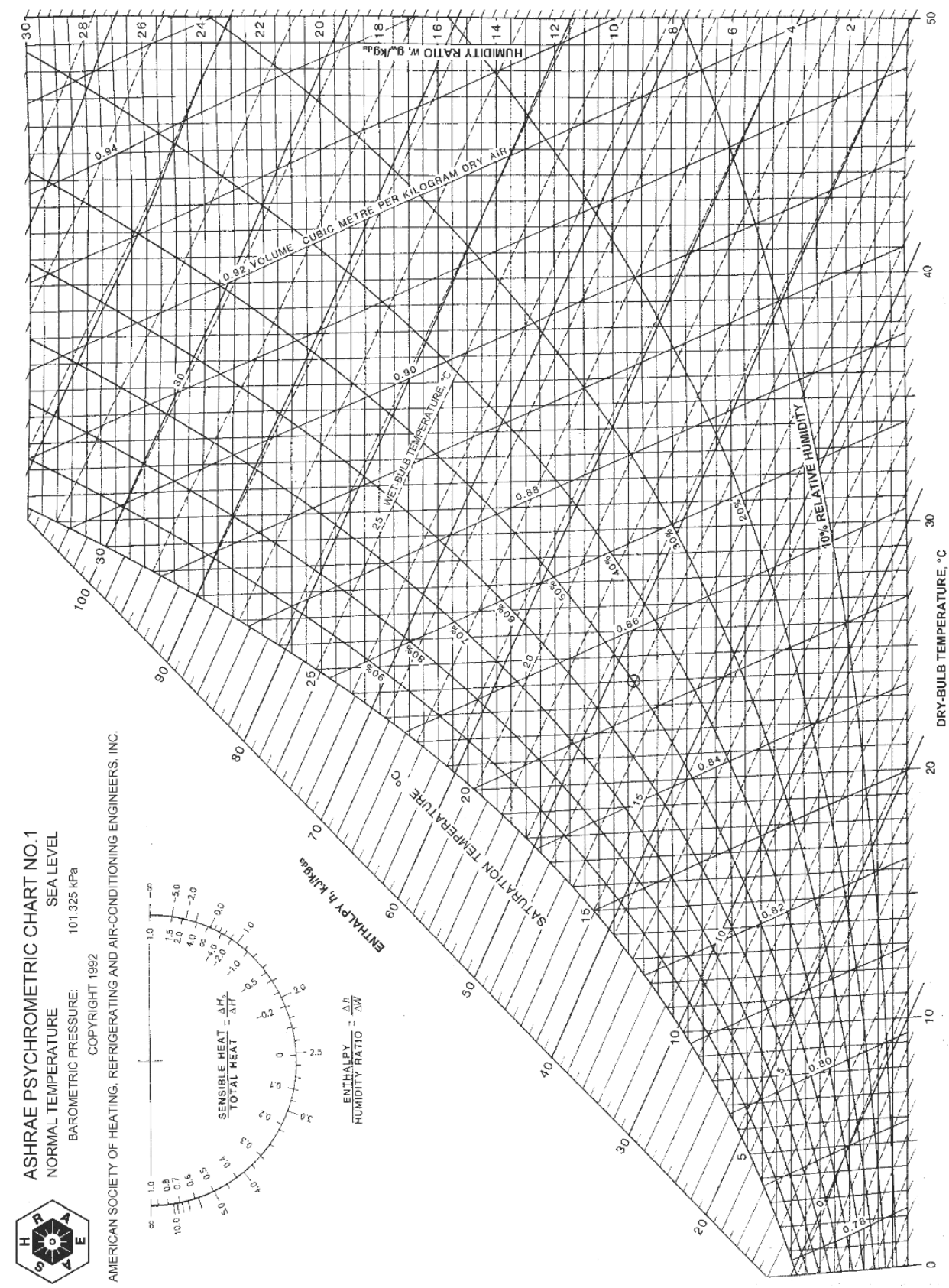

Figure 6.1. ASHRAE psychrometric chart for sea-level pressure (101.325 kPa). 


\subsection{Appendix B: C++ Modeling Structure}

\subsubsection{Introduction}

Firstly, the main concepts which are used to transform a heat exchanger to a set of cells, nodes, and connections will be introduced. Figure 6.2 presents a simple example of a heat exchanger and its discretization scheme.

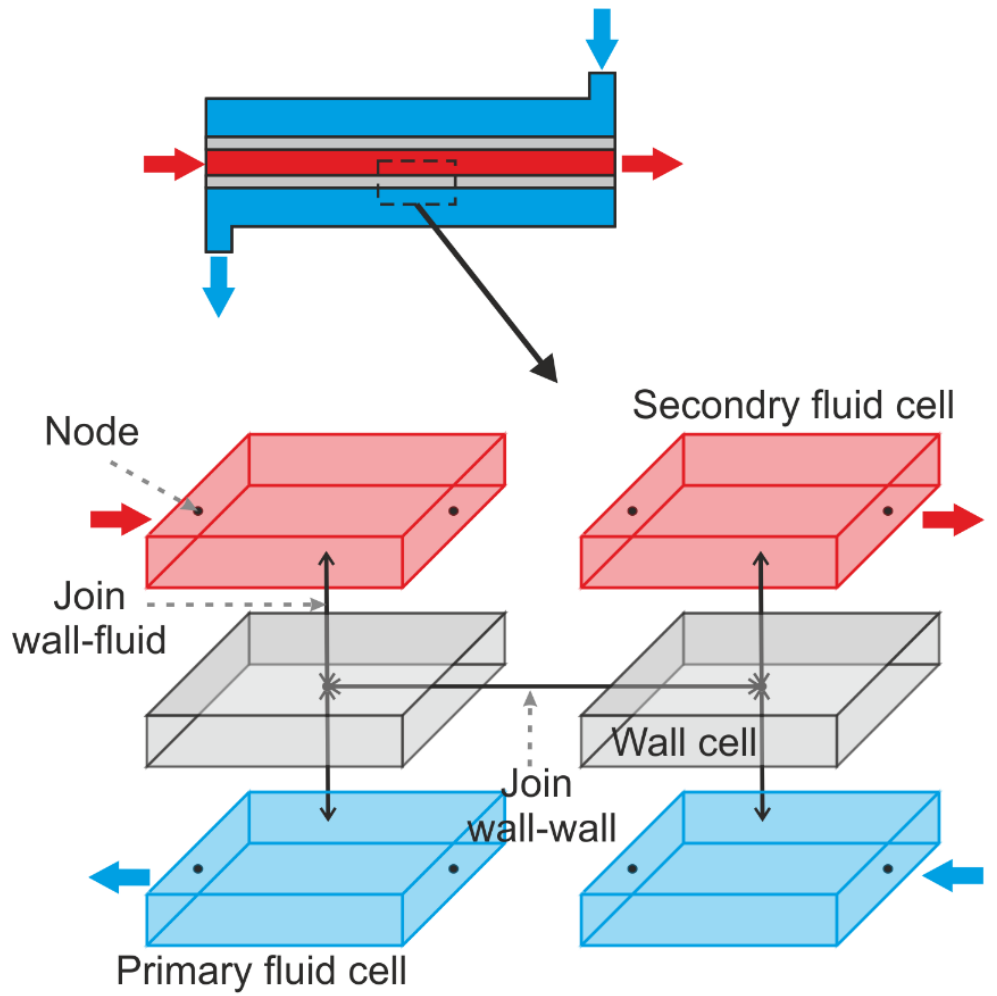

Figure 6.2. General discretization scheme for a heat exchanger.

The cells represent control volumes for primary or secondary fluids and wall. For fluid cells, the nodes define the properties of the sections where they are located; while the nodes which are located in the centroid of wall cells represent the properties of the whole cell. These provisions must be consistent with the discretization of the governing equations, which describe the physical behavior of each cell. This discretization process and technique will be discussed in details in the upcoming sections. 
Chapter 6.

The last discretization element is the joins which define the type of connection between the neighboring cells, wall-wall or wall-fluid join. These joins symbolize the processes which are resulted from the interaction between any two elements. For example, the heat and mass transfer coefficients are defined by wall-fluid join, as it is a result of the interaction between the both cells.

The current numerical models (Fin2D-W and Fin1D-MB) have been developed by the $\mathrm{C}++$ programming language. The main advantage of this language that it is based on the object-oriented programming (OOP). This advanced technique allows representing each physical entity of the heat exchanger as an object from a specific class.

Using this concept in the modeling process allows for a better modularization of the calculations, and an elaborate and efficient numerical model.

The objects can only access to the information stored in themselves or to other objects which share the same element. The objects diagram (Figure 6.3) is very useful for understanding the physical model. Usually, the object has the name, or similar name, of its corresponding class.

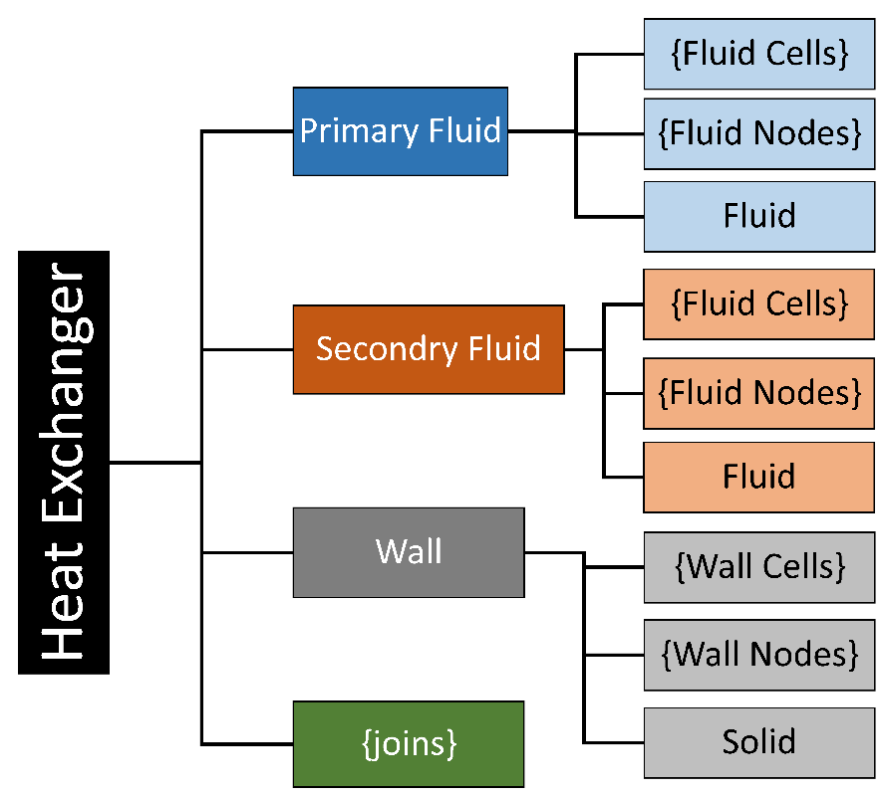

Figure 6.3. $\mathrm{C}++$ Objects used in the current models.

It can be noted that some objects carry " \{\} " they are a vector of objects of the same class, otherwise they are scalars. 
The classes diagram (Figure 6.4) is useful for the model programming. The class actually defines the characteristic of the object.

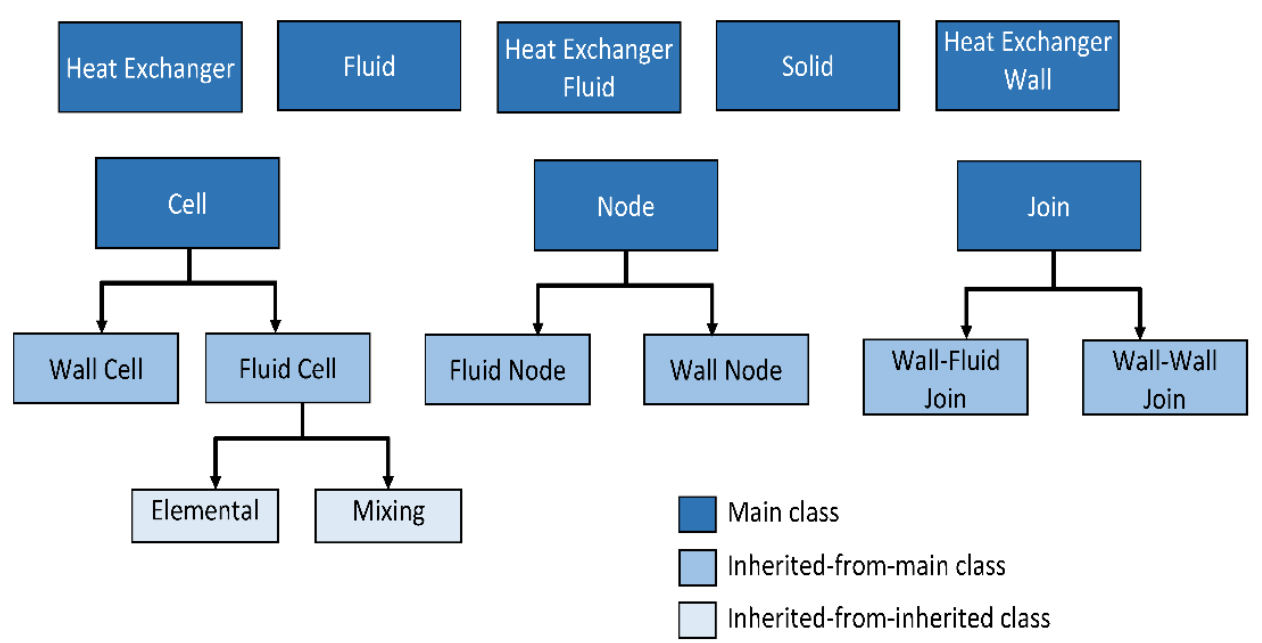

Figure 6.4. $\mathrm{C}++$ Classes adopted in the present models.

The main features of each model class are explained next. These features are grouped into different methods and attributes for each class.

\subsubsection{Classes of the evaporator models (Fin2D-W and Fin1D-MB)}

\section{a) Heat Exchanger}

This is the global class, its objects can access to any information. Its members (functions and variables) control the flow of the whole program and all other objects from different classes.

It has two objects from the Heat Exchanger Fluid class (one for the primary fluid and the other for secondary fluid), one object from the Heat Exchanger Wall class, and a vector of objects from the Joins class (in the upcoming sub-sections the types of these joins are explained).

Its functions include: initialization of the evaporator topology, initialization of the temperature and humidity ratio fields for the whole heat exchanger, initialization of the mass flow rates along the evaporator, execution of the fluids and wall calculations, evaluation of the final solution parameters and exportation of the results to an external file. 
Chapter 6.

b) Fluid

This class represents the pure thermodynamic concept of a certain fluid. All the fluid properties, such as specific heat, conductivity, viscosity, dew point of air, etc., are calculated and stored by the members of this class. It can also access to an external library to get any properties for a specific fluid to facilitate the calculations procedure.

\section{c) Heat Exchanger Fluid}

It includes an object from the Fluid class, a vector of objects from the Fluid Cell class (consisting of all discretized fluid cells), and finally a vector of objects from the Fluid Node class (these nodes are discussed later). Its primary function is to organize and execute the calculation procedures to all the fluid cells.

\section{d) Cell}

This is a main generic class which represents any cell for the heat exchanger (fluid or wall). It contains the position information (Cartesian spatial coordinates) of each cell and basic geometrical parameters such as the volume of the cell. It also stores the identity (numerical id number) of the cell to ease the identification of each cell during the calculations. However, this class does not do any action itself unless identifying firstly the type of cell (fluid or wall) which represents.

\section{e) Fluid Cell}

This class defines the fluid cells; it inherits the attributes, members, and methods of the primary Cell class. When discretizing the evaporator to cells, it is important to keep in mind that the fluid cell could contain zones of fixed mass flow rate, bifurcations, or unions. So while discretization, the following methodology has been adopted.

When the mass flow rate is constant, the flow domain could be discretized to cells which contain one node at the inlet and another node at the exit. When a bifurcation or union appears, a mixing cell is inserted which has several nodes for the inlet or exit. These cells only attempt to represent the singularity of the bifurcation or union. The general discretization scheme for the fluid flow is plotted in Figure 6.5.

Therefore, the fluid cell could be elemental (with constant mass flow rate), or mixing (contains bifurcation or union). Generally, any object from the Fluid Cell class stores 
Appendices

a vector of objects from inlet nodes, a vector of objects from exit nodes, and the type of the cell.

Although this class has the calculation method for the cell, however, the main calculations are done in other classes (Elemental and Mixing Fluid Cell classes) which are derived from it.

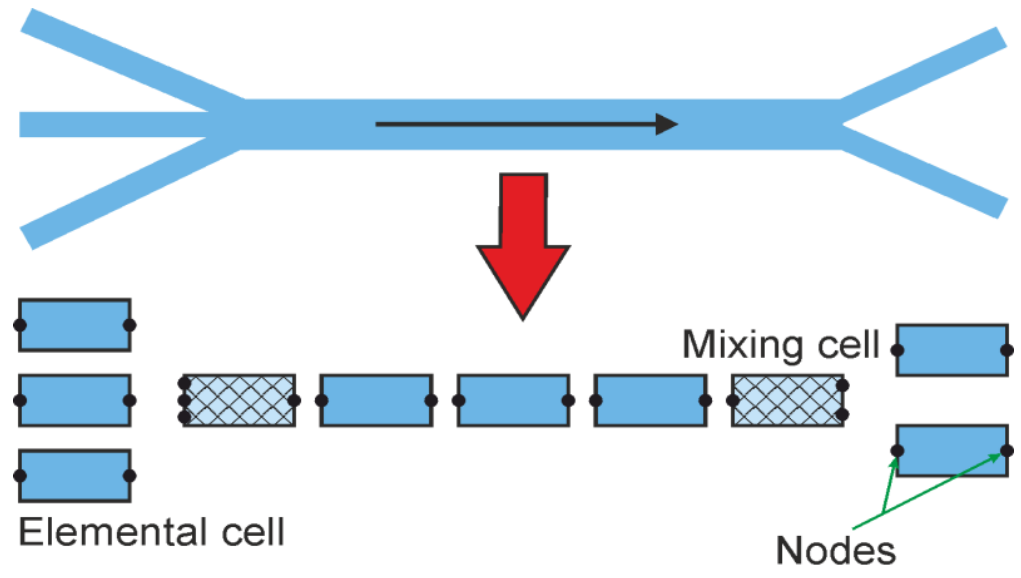

Figure 6.5. General discretization scheme for fluid flow.

\section{f) Elemental Fluid Cell}

As mentioned above, this cell represents the portion of fluid where the mass flow rate is constant. This class inherits the attributes, members, and methods of the Fluid Cell class. It stores all the parameters which are related to the cell such as the heat transfer from/to the cell, however, it does not store the temperature, humidity ratio, pressure, etc. because those parameters are related to the nodes.

The primary objectives of this class are: performing the heat and mass balances for each cell, calculating the residual for each iteration, and finally calculating and storing the sensible, latent, and total heat transfer rates.

\section{g) Mixing Fluid Cell}

This class represents the singularity of the bifurcation or union. Like the Elemental Fluid Cell class, it inherits the attributes, members, and methods of the Fluid Cell class. The singularity of the bifurcation or union is assumed to be adiabatic with differential size as shown in Equations (6.23) and (6.24). 
Chapter 6.

$$
\begin{gathered}
\dot{m}_{\text {node }, i}^{\text {out }}=\sum_{i}^{N_{\text {nodes }}^{\text {in }}} \dot{m}_{\text {node }, i}^{\text {in }} / N_{\text {nodes }}^{\text {out }} \\
h_{\text {node }, i}^{\text {out }}=\left.\sum_{i}^{N_{\text {nodes }}^{\text {in }}} h \cdot \dot{m}\right|_{\text {node }, i} ^{\text {in }} /\left(\sum_{i}^{N_{\text {nodes }}^{\text {in }}} \dot{m}_{\text {node }, i}^{\text {in }} / N_{\text {nodes }}^{\text {out }}\right)
\end{gathered}
$$

where $\dot{m}$ and $h$ are the mass flow rate and enthalpy, respectively.

\section{h) Node}

This is a main class which represents a point in the space of any cell. There are two types of nodes: fluid cell node and wall cell node, which are defined later.

\section{i) Fluid Node}

This class inherits all the members of the main node class. It represents a point in the fluid cell space in which the average fluid properties, of a specific section of the cell, are stored. Any fluid node contains information about the thermodynamic properties of the fluid which flows across a specific section, where this node is found. These thermodynamic properties are, for example, temperature, humidity ratio, relative humidity, dew point, enthalpy, etc.

\section{j) Heat Exchanger Wall}

This class represents the entire wall for the heat exchanger, all divisions between the primary and secondary fluids including the fins. Its contents and functions are similar to the Heat Exchanger Fluid class. It has an object from the main Solid class and a vector of objects from Wall Cell class.

\section{k) Solid}

This class is analogous to the Fluid class. It stores and calculates all the thermal properties related to the wall material, such as the thermal conductivity.

\section{l) Wall Cell}

It is like the Fluid Cell class, inherits its properties from the main Cell class. Physically, it is similar to the fluid cell but for wall. It stores the cell geometrical variables such as the thickness, perimeter, etc. Unlike the fluid cell, the wall cell has only one 
type. It contains several functions to do all the wall cell calculations, regarding the tubes and fins.

m) Wall Node

In the solid case, this node is located at the centroid of the wall cell. It stores the average values of the wall cell thermal properties, such as the temperature.

n) Join

As seen in Figure 6.2, this class represents the physical interaction between any two adjacent cells. Its primary function is to determine the type of this interaction, whether it is a wall-to-wall join or fluid-to-wall join. Each type of these joins has a distinct class as discussed below.

\section{o) Wall-Fluid Join}

This class contains the necessary parameters to calculate the convection heat and mass transfer (dehumidification) between the wall cell and the adjacent fluid cell. It contains all the references between the adjacent cells. Also, it has functions to calculate many coefficients and parameters related to the process of heat and mass transfer such as: overall heat transfer coefficient for dry and wet cases, sensible heat transfer coefficient for primary and secondary fluids, total heat transfer coefficient for wet case, etc.

\section{p) Wall-Wall Join}

The only function of this class is to determine and store some parameters which are related to the longitudinal heat conduction between the adjacent wall cells; such as the distance between the nodes of the adjacent cells, the cross-sectional area perpendicular to the heat conduction, etc. 
Chapter 6.

\subsection{Appendix C: Matrix [B] Coefficients}

Matrix $\mathbf{B}$ is a $3 \times 4$ matrix which is employed in the Fin1D-MB model (Equation 3.19). It contains all the components which are required to evaluate the average temperature for a fin cell.

\subsubsection{Components of $B_{1, j}$}

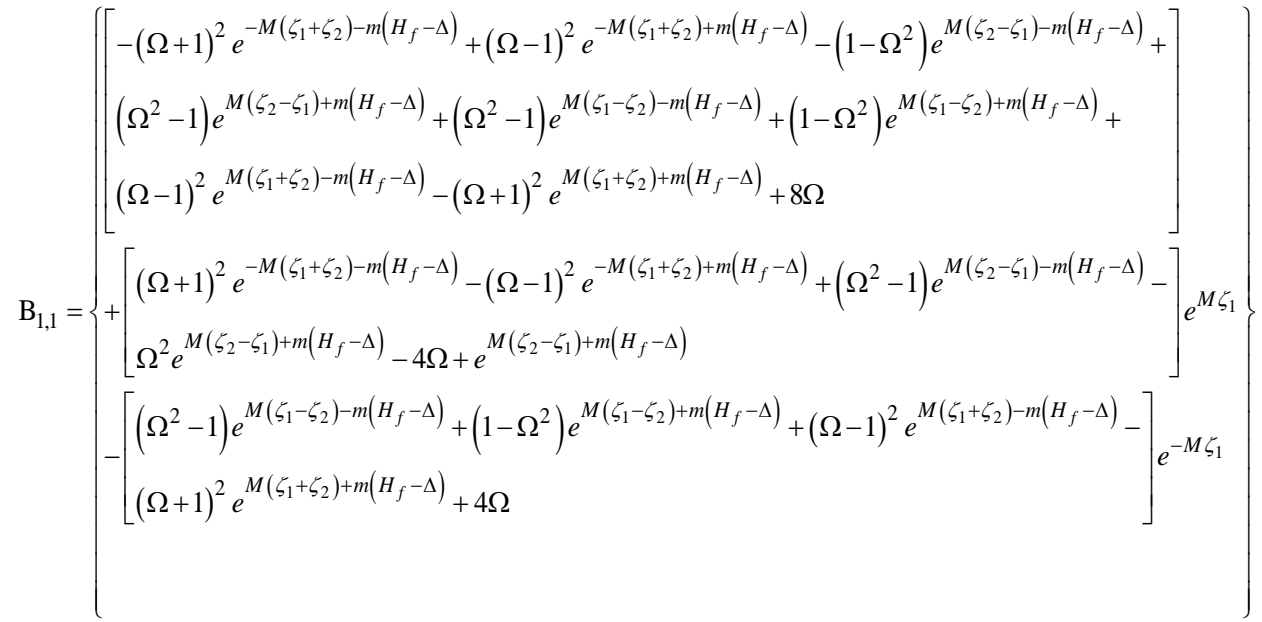

$$
\begin{aligned}
& \left\{M \zeta_{1}\left[\begin{array}{l}
(1+\Omega)^{2} e^{-M\left(\zeta_{1}+\zeta_{2}\right)-m\left(H_{f}-\Delta\right)}-(\Omega-1)^{2} e^{-M\left(\zeta_{1}+\zeta_{2}\right)+m\left(H_{f}-\Delta\right)}+\left(\Omega^{2}-1\right) e^{M\left(\zeta_{1}-\zeta_{2}\right)-m\left(H_{f}-\Delta\right)} \\
+(\Omega-1)^{2} e^{M\left(\zeta_{2}-\zeta_{1}\right)-m\left(H_{f}-\Delta\right)}+\left(1-\Omega^{2}\right) e^{M\left(\zeta_{2}-\zeta_{1}\right)+m\left(H_{f}-\Delta\right)}+\left(1-\Omega^{2}\right) e^{M\left(\zeta_{1}-\Delta\right)}-(1+\Omega)^{2} e^{M\left(\zeta_{1}+\zeta_{2}\right)+m\left(H_{f}-\Delta\right)}
\end{array}\right]\right\}
\end{aligned}
$$




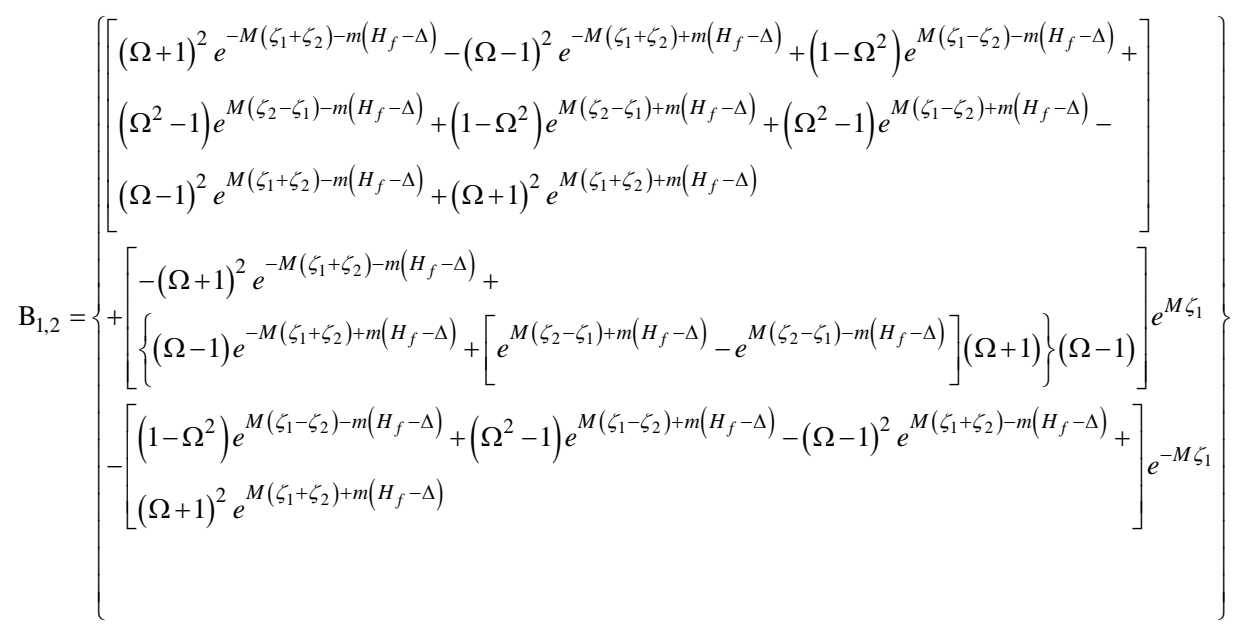

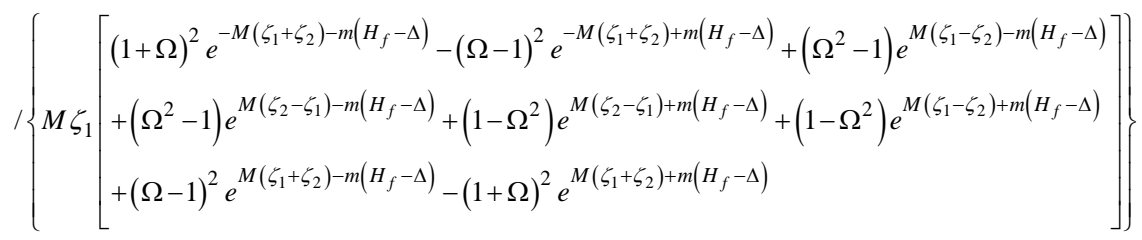

$$
\begin{aligned}
& \mathrm{B}_{1,3}=\left\{\begin{array}{l}
{[-8 \Omega]} \\
+[4 \Omega] e^{M \zeta_{1}} \\
-[-4 \Omega] e^{-M \zeta_{1}}
\end{array}\right\} \\
& \left\{M \zeta_{1}\left[\begin{array}{l}
(1+\Omega)^{2} e^{-M\left(\zeta_{1}+\zeta_{2}\right)-m\left(H_{f}-\Delta\right)}-(\Omega-1)^{2} e^{-M\left(\zeta_{1}+\zeta_{2}\right)+m\left(H_{f}-\Delta\right)}+\left(\Omega^{2}-1\right) e^{M\left(\zeta_{1}-\zeta_{2}\right)-m\left(H_{f}-\Delta\right)} \\
+(\Omega-1)^{2} e^{M\left(\zeta_{2}+\zeta_{2}\right)-m\left(H_{f}-\Delta\right)}-(1+\Omega)^{2} e^{M\left(\zeta_{1}+\zeta_{2}\right)+m\left(H_{f}-\Delta\right)}+\left(1-\Omega^{2}\right) e^{M\left(\zeta_{2}-\zeta_{1}\right)+m\left(H_{f}-\Delta\right)}+(1)^{M\left(\zeta_{1}-\zeta_{2}\right)+m\left(H_{f}-\Delta\right)}
\end{array}\right]\right\}
\end{aligned}
$$




\section{Chapter 6.}

$\left.\mathrm{B}_{1,4}=\left\{\begin{array}{l}{\left[\begin{array}{l}-(\Omega+1)^{2} e^{-M\left(\zeta_{1}+\zeta_{2}\right)-m\left(H_{f}-\Delta\right)}+(\Omega-1)^{2} e^{-M\left(\zeta_{1}+\zeta_{2}\right)+m\left(H_{f}-\Delta\right)}+\left(1-\Omega^{2}\right) e^{M\left(\zeta_{2}-\zeta_{1}\right)-m\left(H_{f}-\Delta\right)}+ \\ \left(\Omega^{2}-1\right) e^{M\left(\zeta_{2}-\zeta_{1}\right)+m\left(H_{f}-\Delta\right)}+\left(\Omega^{2}-1\right) e^{M\left(\zeta_{1}-\zeta_{2}\right)-m\left(H_{f}-\Delta\right)}+\left(1-\Omega^{2}\right) e^{M\left(\zeta_{1}-\zeta_{2}\right)+m\left(H_{f}-\Delta\right)}+ \\ (\Omega-1)^{2} e^{M\left(\zeta_{1}+\zeta_{2}\right)-m\left(H_{f}-\Delta\right)}-(\Omega+1)^{2} e^{M\left(\zeta_{1}+\zeta_{2}\right)+m\left(H_{f}-\Delta\right)}+2(\Omega-1) e^{-M \zeta_{2}+m\left(H_{f}-\Delta\right)}+ \\ 2(\Omega+1) e^{-M \zeta_{2}-m\left(H_{f}-\Delta\right)}+2(\Omega+1) e^{M \zeta_{2}+m\left(H_{f}-\Delta\right)}+2(\Omega-1) e^{M \zeta_{2}-m\left(H_{f}-\Delta\right)}- \\ 4 \Omega\left(e^{-M \zeta_{2}}-2+e^{M \zeta_{2}}\right)\end{array}\right]} \\ {\left[\begin{array}{l}(\Omega+1)^{2} e^{-M\left(\zeta_{1}+\zeta_{2}\right)-m\left(H_{f}-\Delta\right)}-(\Omega-1)^{2} e^{-M\left(\zeta_{1}+\zeta_{2}\right)+m\left(H_{f}-\Delta\right)}+\left(\Omega^{2}-1\right) e^{M\left(\zeta_{2}-\zeta_{1}\right)-m\left(H_{f}-\Delta\right)}+ \\ \left(1-\Omega^{2}\right) e^{M\left(\zeta_{2}-\zeta_{1}\right)+m\left(H_{f}-\Delta\right)}-(\Omega+1) e^{-M \zeta_{2}-m\left(H_{f}-\Delta\right)}+(1-\Omega) e^{-M \zeta_{2}+m\left(H_{f}-\Delta\right)}+ \\ (1-\Omega) e^{M \zeta_{2}-m\left(H_{f}-\Delta\right)}-(\Omega+1) e^{M \zeta_{2}+m\left(H_{f}-\Delta\right)}+2 \Omega\left(e^{-M \zeta_{2}}-2+e^{M \zeta_{2}}\right)\end{array}\right] e^{M \zeta_{1}}}\end{array}\right\}\right)-1$ 


\subsubsection{Components of $B_{2, j}$}

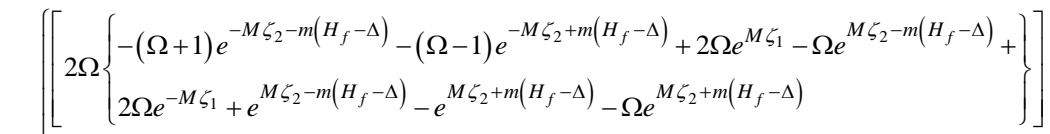

$$
\begin{aligned}
& \mathrm{B}_{2,1}=\left\{\begin{array}{l}
+\left[-2 \Omega\left\{-(\Omega+1) e^{-M \zeta_{2}-m\left(H_{f}-\Delta\right)}+(1-\Omega) e^{M \zeta_{2}-m\left(H_{f}-\Delta\right)}+(\Omega-1) e^{-M \zeta_{1}}+(\Omega+1) e^{M \zeta_{1}}\right\}\right] e^{m\left(H_{f}-\Delta\right)} \\
-\left[2 \Omega\left\{(1-\Omega) e^{-M \zeta_{2}+m\left(H_{f}-\Delta\right)}-(1+\Omega) e^{M \zeta_{2}+m\left(H_{f}-\Delta\right)}+(\Omega+1) e^{-M \zeta_{1}}+(\Omega-1) e^{M \zeta_{1}}\right\}\right] e^{-m\left(H_{f}-\Delta\right)}
\end{array}\right\} \\
& \left\{m\left(H_{f}-\Delta\right)\left[\begin{array}{l}
(1+\Omega)^{2} e^{-M\left(\zeta_{1}+\zeta_{2}\right)-m\left(H_{f}-\Delta\right)}-(\Omega-1)^{2} e^{-M\left(\zeta_{1}+\zeta_{2}\right)+m\left(H_{f}-\Delta\right)}+\left(\Omega^{2}-1\right) e^{M\left(\zeta_{1}-\zeta_{2}\right)-m\left(H_{f}-\Delta\right)} \\
+\left(\Omega^{2}-1\right) e^{M\left(\zeta_{2}-\zeta_{1}\right)-m\left(H_{f}-\Delta\right)}+\left(1-\Omega^{2}\right) e^{M\left(\zeta_{2}-\zeta_{1}\right)+m\left(H_{f}-\Delta\right)}+\left(1-\Omega^{2}\right) e^{M\left(\zeta_{1}-\zeta_{2}\right)+m\left(H_{f}-\Delta\right)} \\
+(\Omega-1)^{2} e^{M\left(\zeta_{1}+\zeta_{2}\right)-m\left(H_{f}-\Delta\right)}-(1+\Omega)^{2} e^{M\left(\zeta_{1}+\zeta_{2}\right)+m\left(H_{f}-\Delta\right)}
\end{array}\right]\right\}
\end{aligned}
$$

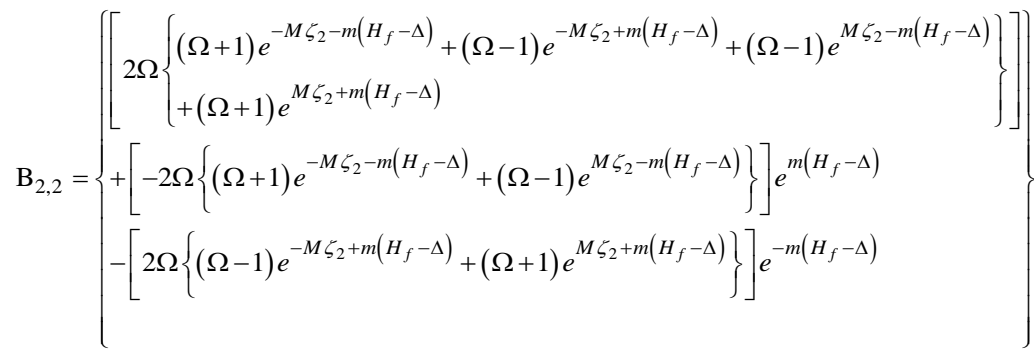

$$
\begin{aligned}
& \left\{m\left(H_{f}-\Delta\right)\left[\begin{array}{l}
(1+\Omega)^{2} e^{-M\left(\zeta_{1}+\zeta_{2}\right)-m\left(H_{f}-\Delta\right)}-(\Omega-1)^{2} e^{-M\left(\zeta_{1}+\zeta_{2}\right)+m\left(H_{f}-\Delta\right)}+\left(\Omega^{2}-1\right) e^{M\left(\zeta_{1}-\zeta_{2}\right)-m\left(H_{f}-\Delta\right)} \\
+\left(\Omega^{2}-1\right) e^{M\left(\zeta_{2}-\zeta_{1}\right)-m\left(H_{f}-\Delta\right)}+\left(1-\Omega^{2}\right) e^{M\left(\zeta_{2}-\zeta_{1}\right)+m\left(H_{f}-\Delta\right)}+\left(1-\Omega^{2}\right) e^{M\left(\zeta_{1}-\zeta_{2}\right)+m\left(H_{f}-\Delta\right)} \\
+(\Omega-1)^{2} e^{M\left(\zeta_{1}+\zeta_{2}\right)-m\left(H_{f}-\Delta\right)}-(1+\Omega)^{2} e^{M\left(\zeta_{1}+\zeta_{2}\right)+m\left(H_{f}-\Delta\right)}
\end{array}\right]\right\} \\
& \mathrm{B}_{2,3}=\left\{\begin{array}{l}
{\left[-4 \Omega^{2}\left(e^{M \zeta_{1}}+e^{-M \zeta_{1}}\right)\right]} \\
+\left[2 \Omega\left\{(\Omega-1) e^{-M \zeta_{1}}+(\Omega+1) e^{M \zeta_{1}}\right\}\right] e^{m\left(H_{f}-\Delta\right)} \\
-\left[-2 \Omega\left\{(\Omega+1) e^{-M \zeta_{1}}+(\Omega-1) e^{M \zeta_{1}}\right\}\right] e^{-m\left(H_{f}-\Delta\right)}
\end{array}\right\} \\
& \left\{m\left(H_{f}-\Delta\right)\left[\begin{array}{l}
(1+\Omega)^{2} e^{-M\left(\zeta_{1}+\zeta_{2}\right)-m\left(H_{f}-\Delta\right)}-(\Omega-1)^{2} e^{-M\left(\zeta_{1}+\zeta_{2}\right)+m\left(H_{f}-\Delta\right)}+\left(\Omega^{2}-1\right) e^{M\left(\zeta_{1}-\zeta_{2}\right)-m\left(H_{f}-\Delta\right)} \\
+\left(\Omega^{2}-1\right) e^{M\left(\zeta_{2}-\zeta_{1}\right)-m\left(H_{f}-\Delta\right)}+\left(1-\Omega^{2}\right) e^{M\left(\zeta_{2}-\zeta_{1}\right)+m\left(H_{f}-\Delta\right)}+\left(1-\Omega^{2}\right) e^{M\left(\zeta_{1}-\zeta_{2}\right)+m\left(H_{f}-\Delta\right)} \\
+(\Omega-1)^{2} e^{M\left(\zeta_{1}+\zeta_{2}\right)-m\left(H_{f}-\Delta\right)}-(1+\Omega)^{2} e^{M\left(\zeta_{1}+\zeta_{2}\right)+m\left(H_{f}-\Delta\right)}
\end{array}\right]\right\}
\end{aligned}
$$




\section{Chapter 6.}

$$
\begin{aligned}
& \left\{\left[\begin{array}{l}
(\Omega+1) e^{-M\left(\zeta_{1}+\zeta_{2}\right)-m\left(H_{f}-\Delta\right)}-2 \Omega e^{M \zeta_{2}-m\left(H_{f}-\Delta\right)}+e^{M\left(\zeta_{2}-\zeta_{1}\right)+m\left(H_{f}-\Delta\right)}+4 \Omega e^{-M \zeta_{1}}+ \\
\Omega e^{M\left(\zeta_{2}-\zeta_{1}\right)+m\left(H_{f}-\Delta\right)}-2 \Omega e^{M\left(\zeta_{1}-\zeta_{2}\right)}+\Omega e^{-M\left(\zeta_{1}+\zeta_{2}\right)+m\left(H_{f}-\Delta\right)}+\Omega e^{M\left(\zeta_{1}+\zeta_{2}\right)+m\left(H_{f}-\Delta\right)}- \\
2 e^{-M \zeta_{2}-m\left(H_{f}-\Delta\right)}+e^{M\left(\zeta_{1}-\zeta_{2}\right)-m\left(H_{f}-\Delta\right)}-2 \Omega e^{-M \zeta_{2}+m\left(H_{f}-\Delta\right)}-e^{M\left(\zeta_{1}+\zeta_{2}\right)-m\left(H_{f}-\Delta\right)}- \\
2 \Omega e^{-M \zeta_{2}-m\left(H_{f}-\Delta\right)}-e^{M\left(\zeta_{2}-\zeta_{1}\right)-m\left(H_{f}-\Delta\right)}+e^{M\left(\zeta_{1}+\zeta_{2}\right)+m\left(H_{f}-\Delta\right)}+2 e^{-M \zeta_{2}+m\left(H_{f}-\Delta\right)}+ \\
2 e^{M \zeta_{2}-m\left(H_{f}-\Delta\right)}-2 e^{M \zeta_{2}+m\left(H_{f}-\Delta\right)}+\Omega e^{M\left(\zeta_{1}-\zeta_{2}\right)-m\left(H_{f}-\Delta\right)}-e^{-M\left(\zeta_{1}+\zeta_{2}\right)+m\left(H_{f}-\Delta\right)}-2 \Omega e^{-M\left(\zeta_{1}-\zeta_{2}\right)} \\
-e^{M\left(\zeta_{1}-\zeta_{2}\right)+m\left(H_{f}-\Delta\right)}-2 \Omega e^{M\left(\zeta_{1}+\zeta_{2}\right)}-2 \Omega e^{M \zeta_{2}+m\left(H_{f}-\Delta\right)}- \\
2 \Omega e^{-M\left(\zeta_{1}+\zeta_{2}\right)}+4 \Omega e^{M \zeta_{1}}+\Omega e^{M\left(\zeta_{2}-\zeta_{1}\right)-m\left(H_{f}-\Delta\right)}+\Omega e^{M\left(\zeta_{1}+\zeta_{2}\right)-m\left(H_{f}-\Delta\right)}+\Omega e^{M\left(\zeta_{1}-\zeta_{2}\right)+m\left(H_{f}-\Delta\right)}
\end{array}\right\}\right) \\
& \mathrm{B}_{2,4}=\left\{+\Omega\left\{\begin{array}{l}
(\Omega+1) e^{-M\left(\zeta_{1}+\zeta_{2}\right)-m\left(H_{f}-\Delta\right)}+(\Omega-1) e^{M\left(\zeta_{2}-\zeta_{1}\right)-m\left(H_{f}-\Delta\right)}+(\Omega+1) e^{M\left(\zeta_{1}-\zeta_{2}\right)-m\left(H_{f}-\Delta\right)} \\
+(\Omega-1) e^{M\left(\zeta_{1}+\zeta_{2}\right)-m\left(H_{f}-\Delta\right)}+2 \Omega e^{-M \zeta_{1}}-2 \Omega e^{M \zeta_{2}-m\left(H_{f}-\Delta\right)}- \\
\Omega e^{-M\left(\zeta_{1}-\zeta_{2}\right)}-\Omega e^{-M\left(\zeta_{1}+\zeta_{2}\right)}-2 \Omega e^{-M \zeta_{2}-m\left(H_{f}-\Delta\right)}-2 e^{-M \zeta_{2}-m\left(H_{f}-\Delta\right)}- \\
\Omega e^{M\left(\zeta_{1}-\zeta_{2}\right)}+e^{-M\left(\zeta_{1}+\zeta_{2}\right)}-\Omega e^{M\left(\zeta_{1}+\zeta_{2}\right)}+e^{-M\left(\zeta_{1}-\zeta_{2}\right)}-e^{M\left(\zeta_{1}-\zeta_{2}\right)}-e^{M\left(\zeta_{1}+\zeta_{2}\right)}- \\
2 e^{-M \zeta_{1}}+2 e^{M \zeta_{1}}+2 \Omega e^{M \zeta_{1}}+2 e^{M \zeta_{2}-m\left(H_{f}-\Delta\right)}
\end{array}\right] e^{m\left(H_{f}-\Delta\right)}\right\} \\
& \left.\left.-\left[\Omega\left\{\begin{array}{l}
(\Omega-1) e^{-M\left(\zeta_{1}+\zeta_{2}\right)+m\left(H_{f}-\Delta\right)}+(\Omega+1) e^{M\left(\zeta_{2}-\zeta_{1}\right)+m\left(H_{f}-\Delta\right)}+(\Omega-1) e^{M\left(\zeta_{1}-\zeta_{2}\right)+m\left(H_{f}-\Delta\right)} \\
-e^{-M\left(\zeta_{1}-\zeta_{2}\right)}-e^{-M\left(\zeta_{1}+\zeta_{2}\right)}+e^{M\left(\zeta_{1}-\zeta_{2}\right)}+e^{M\left(\zeta_{1}+\zeta_{2}\right)}+2 e^{-M \zeta_{2}+m\left(H_{f}-\Delta\right)}- \\
2 \Omega e^{M \zeta_{2}+m\left(H_{f}-\Delta\right)}-\Omega e^{M\left(\zeta_{1}-\zeta_{2}\right)}-2 \Omega e^{-M \zeta_{2}+m\left(H_{f}-\Delta\right)}+2 \Omega e^{-M \zeta_{1}}- \\
2 e^{M \zeta_{2}+m\left(H_{f}-\Delta\right)}-2 e^{M \zeta_{1}}+2 \Omega e^{M \zeta_{1}}-\Omega e^{-M\left(\zeta_{1}-\zeta_{2}\right)}+\Omega e^{M\left(\zeta_{1}+\zeta_{2}\right)+m\left(H_{f}-\Delta\right)}+ \\
2 e^{-M \zeta_{1}}-\Omega e^{M\left(\zeta_{1}+\zeta_{2}\right)}-\Omega e^{-M\left(\zeta_{1}+\zeta_{2}\right)}+e^{M\left(\zeta_{1}+\zeta_{2}\right)+m\left(H_{f}-\Delta\right)}
\end{array}\right]\right] e^{-m\left(H_{f}-\Delta\right)}\right]\right] \\
& \text { (20) } \\
& \left\{m\left(H_{f}-\Delta\right)\left[\begin{array}{l}
(1+\Omega)^{2} e^{-M\left(\zeta_{1}+\zeta_{2}\right)-m\left(H_{f}-\Delta\right)}-(\Omega-1)^{2} e^{-M\left(\zeta_{1}+\zeta_{2}\right)+m\left(H_{f}-\Delta\right)}+\left(\Omega^{2}-1\right) e^{M\left(\zeta_{1}-\zeta_{2}\right)-m\left(H_{f}-\Delta\right)} \\
+\left(\Omega^{2}-1\right) e^{M\left(\zeta_{2}-\zeta_{1}\right)-m\left(H_{f}-\Delta\right)}+\left(1-\Omega^{2}\right) e^{M\left(\zeta_{2}-\zeta_{1}\right)+m\left(H_{f}-\Delta\right)}+\left(1-\Omega^{2}\right) e^{M\left(\zeta_{1}-\zeta_{2}\right)+m\left(H_{f}-\Delta\right)} \\
+(\Omega-1)^{2} e^{M\left(\zeta_{1}+\zeta_{2}\right)-m\left(H_{f}-\Delta\right)}-(1+\Omega)^{2} e^{M\left(\zeta_{1}+\zeta_{2}\right)+m\left(H_{f}-\Delta\right)}
\end{array}\right]\right\}
\end{aligned}
$$




\subsubsection{Components of $B_{3, j}$}

$$
\begin{aligned}
& \mathrm{B}_{3,1}=\left\{\begin{array}{l}
{\left[\begin{array}{l}
-(\Omega+1)^{2} e^{-M\left(\zeta_{1}+\zeta_{2}\right)-m\left(H_{f}-\Delta\right)}+(\Omega-1)^{2} e^{-M\left(\zeta_{1}+\zeta_{2}\right)+m\left(H_{f}-\Delta\right)}+\left(1-\Omega^{2}\right) e^{M\left(\zeta_{1}-\zeta_{2}\right)-m\left(H_{f}-\Delta\right)}+ \\
\left(\Omega^{2}-1\right) e^{M\left(\zeta_{2}-\zeta_{1}\right)-m\left(H_{f}-\Delta\right)}+\left(\Omega^{2}-1\right) e^{M\left(\zeta_{1}-\zeta_{2}\right)+m\left(H_{f}-\Delta\right)}+\left(1-\Omega^{2}\right) e^{M\left(\zeta_{2}-\zeta_{1}\right)+m\left(H_{f}-\Delta\right)}+ \\
(\Omega-1)^{2} e^{M\left(\zeta_{1}+\zeta_{2}\right)-m\left(H_{f}-\Delta\right)}-(\Omega+1)^{2} e^{M\left(\zeta_{1}+\zeta_{2}\right)+m\left(H_{f}-\Delta\right)}+8 \Omega
\end{array}\right]} \\
+\left[\begin{array}{l}
(\Omega+1)^{2} e^{-M\left(\zeta_{1}+\zeta_{2}\right)-m\left(H_{f}-\Delta\right)}-(\Omega-1)^{2} e^{-M\left(\zeta_{1}+\zeta_{2}\right)+m\left(H_{f}-\Delta\right)}-4 \Omega+\Omega^{2} e^{M\left(\zeta_{1}-\zeta_{2}\right)-m\left(H_{f}-\Delta\right)}+ \\
e^{M\left(\zeta_{1}-\zeta_{2}\right)+m\left(H_{f}-\Delta\right)}-\Omega^{2} e^{M\left(\zeta_{1}-\zeta_{2}\right)+m\left(H_{f}-\Delta\right)}-e^{M\left(\zeta_{1}-\zeta_{2}\right)-m\left(H_{f}-\Delta\right)}
\end{array}\right] e^{M \zeta_{2}} \\
{\left[\begin{array}{l}
\left(\Omega^{2}-1\right) e^{M\left(\zeta_{2}-\zeta_{1}\right)-m\left(H_{f}-\Delta\right)}+\left(1-\Omega^{2}\right) e^{M\left(\zeta_{2}-\zeta_{1}\right)+m\left(H_{f}-\Delta\right)}+(\Omega-1)^{2} e^{M\left(\zeta_{1}+\zeta_{2}\right)-m\left(H_{f}-\Delta\right)}- \\
(\Omega+1)^{2} e^{M\left(\zeta_{1}+\zeta_{2}\right)+m\left(H_{f}-\Delta\right)}+4 \Omega
\end{array} e^{-M \zeta_{2}}\right.}
\end{array}\right\} \\
& \left\{M \zeta_{2}\left[\begin{array}{l}
(1+\Omega)^{2} e^{-M\left(\zeta_{1}+\zeta_{2}\right)-m\left(H_{f}-\Delta\right)}-(\Omega-1)^{2} e^{-M\left(\zeta_{1}+\zeta_{2}\right)+m\left(H_{f}-\Delta\right)}+\left(\Omega^{2}-1\right) e^{M\left(\zeta_{1}-\zeta_{2}\right)-m\left(H_{f}-\Delta\right)} \\
+(\Omega-1)^{2} e^{M\left(\zeta_{2}-\zeta_{1}\right)-m\left(H_{f}-\Delta\right)}+\left(1-\Omega^{2}\right) e^{M\left(\zeta_{2}-\zeta_{1}\right)+m\left(H_{f}-\Delta\right)}+\left(1-\Omega^{2}\right) e^{M\left(\zeta_{1}-\zeta_{2}\right)+m\left(H_{f}-\Delta\right)}-(1+\Omega)^{2} e^{M\left(\zeta_{1}+\zeta_{2}\right)+m\left(H_{f}-\Delta\right)}
\end{array}\right]\right\} \\
& \mathrm{B}_{3,2}=\left\{\begin{array}{l}
{[-8 \Omega]} \\
+[4 \Omega] e^{M \zeta_{2}} \\
-[-4 \Omega] e^{-M \zeta_{2}}
\end{array}\right\} \\
& \left\{M \zeta_{2}\left[\begin{array}{l}
(1+\Omega)^{2} e^{-M\left(\zeta_{1}+\zeta_{2}\right)-m\left(H_{f}-\Delta\right)}-(\Omega-1)^{2} e^{-M\left(\zeta_{1}+\zeta_{2}\right)+m\left(H_{f}-\Delta\right)}+\left(\Omega^{2}-1\right) e^{M\left(\zeta_{1}-\zeta_{2}\right)-m\left(H_{f}-\Delta\right)} \\
+\left(\Omega^{2}-1\right) e^{M\left(\zeta_{2}-\zeta_{1}\right)-m\left(H_{f}-\Delta\right)}+\left(1-\Omega^{2}\right) e^{M\left(\zeta_{2}-\zeta_{1}\right)+m\left(H_{f}-\Delta\right)}+\left(1-\Omega^{2}\right) e^{M\left(\zeta_{1}-\zeta_{2}\right)+m\left(H_{f}-\Delta\right)} \\
+(\Omega-1)^{2} e^{M\left(\zeta_{1}+\zeta_{2}\right)-m\left(H_{f}-\Delta\right)}-(1+\Omega)^{2} e^{M\left(\zeta_{1}+\zeta_{2}\right)+m\left(H_{f}-\Delta\right)}
\end{array}\right]\right\}
\end{aligned}
$$




\section{Chapter 6.}

$$
\begin{aligned}
& \mathrm{B}_{3,3}=\left\{\begin{array}{l}
{\left[\begin{array}{l}
(\Omega+1)^{2} e^{-M\left(\zeta_{1}+\zeta_{2}\right)-m\left(H_{f}-\Delta\right)}-(\Omega-1)^{2} e^{-M\left(\zeta_{1}+\zeta_{2}\right)+m\left(H_{f}-\Delta\right)}+\left(\Omega^{2}-1\right) e^{M\left(\zeta_{1}-\zeta_{2}\right)-m\left(H_{f}-\Delta\right)}+ \\
\left(1-\Omega^{2}\right) e^{M\left(\zeta_{2}-\zeta_{1}\right)-m\left(H_{f}-\Delta\right)}+\left(1-\Omega^{2}\right) e^{M\left(\zeta_{1}-\zeta_{2}\right)+m\left(H_{f}-\Delta\right)}+\left(\Omega^{2}-1\right) e^{M\left(\zeta_{2}-\zeta_{1}\right)+m\left(H_{f}-\Delta\right)}- \\
(\Omega-1)^{2} e^{M\left(\zeta_{1}+\zeta_{2}\right)-m\left(H_{f}-\Delta\right)}+(\Omega+1)^{2} e^{M\left(\zeta_{1}+\zeta_{2}\right)+m\left(H_{f}-\Delta\right)}
\end{array}\right]} \\
{\left[\begin{array}{l}
-(\Omega+1)^{2} e^{-M\left(\zeta_{1}+\zeta_{2}\right)-m\left(H_{f}-\Delta\right)}- \\
(\Omega-1)\left\{(1-\Omega) e^{-M\left(\zeta_{1}+\zeta_{2}\right)+m\left(H_{f}-\Delta\right)}+(\Omega+1)\left[e^{M\left(\zeta_{1}-\zeta_{2}\right)-m\left(H_{f}-\Delta\right)}-e^{M\left(\zeta_{1}-\zeta_{2}\right)+m\left(H_{f}-\Delta\right)}\right]\right\}
\end{array}\right] e^{M \zeta_{2}}} \\
-\left[\begin{array}{l}
\left.\left(1-\Omega^{2}\right) e^{M\left(\zeta_{2}-\zeta_{1}\right)-m\left(H_{f}-\Delta\right)}+\left(\Omega^{2}-1\right) e^{M\left(\zeta_{2}-\zeta_{1}\right)+m\left(H_{f}-\Delta\right)}-(\Omega-1)^{2} e^{M\left(\zeta_{1}+\zeta_{2}\right)-m\left(H_{f}-\Delta\right)}+\right] \\
(\Omega+1)^{2} e^{M\left(\zeta_{1}+\zeta_{2}\right)+m\left(H_{f}-\Delta\right)}
\end{array}\right.
\end{array}\right\}
\end{aligned}
$$

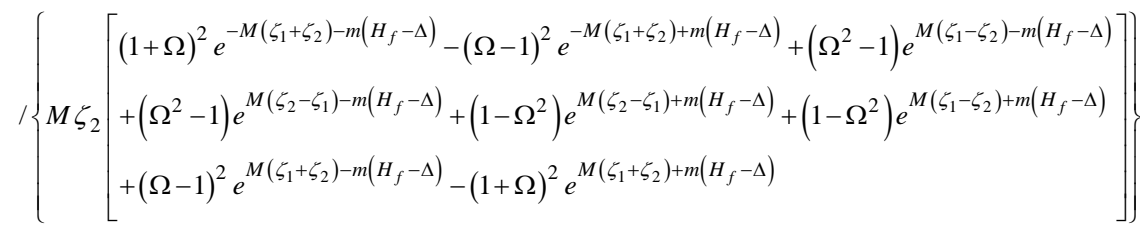




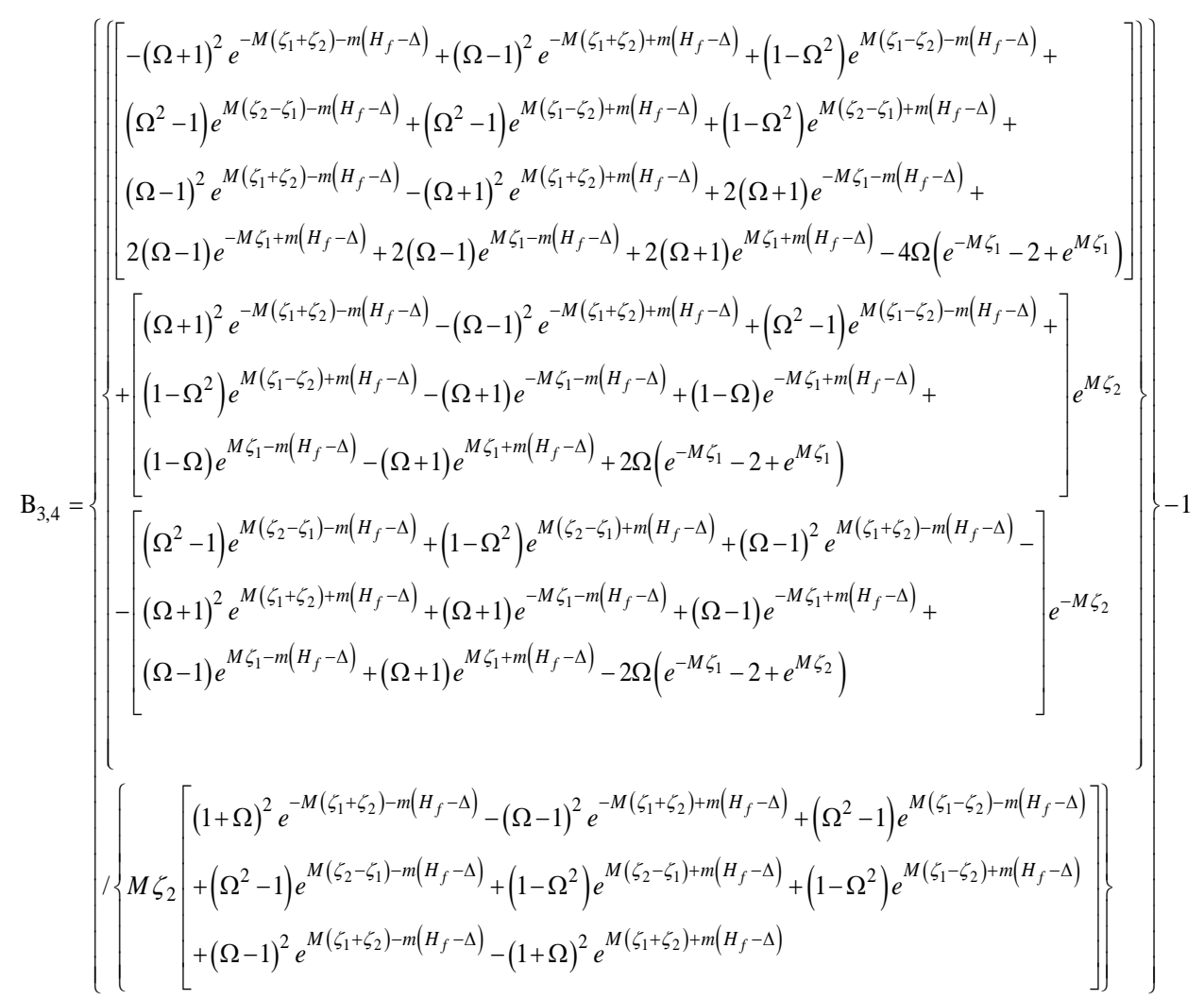

where

$M \quad$ is the wet fin parameter;

$m \quad$ is the dry fin parameter;

$\zeta_{1}$ is the length of first fin portion fp1, measured from the fin base;

$\zeta_{2}$ is the length of third fin portion fp3, measured from the fin tip;

$\Delta \quad=\zeta_{1}+\zeta_{2}$

$\Omega \quad=M / m ;$ and

$H_{f} \quad$ is the total fin height. 



\section{REFERENCES}

Agarwal, A., Bandhauer, T.M., Garimella, S. 2010. Measurement and modeling of condensation heat transfer in non-circular microchannels. International Journal of Refrigeration, 33(6): 1169-1179.

ARI Standard 410-87. 1987. Forced-circulation Air-cooling and Air-heating Coils. Air-Conditioning and Refrigeration Institute, Arlington, VA.

ASHRAE. 2009. ASHRAE Handbook—Fundamentals. ASHRAE Inc., Atlanta.

ASHRAE. 2011. ASHRAE Handbook—HVAC Applications. ASHRAE Inc., Atlanta.

Asinari, P., Cecchinato, L., Fornasieri, E. 2004. Effects of thermal conduction in microchannel gas coolers for carbon dioxide. International Journal of Refrigeration, 2: 577-586.

Ayub, Z. H. 2004. Industrial refrigeration and ammonia enhanced heat transfer.

Proc. of: ASME ZSIS International Thermal Science Seminar II, Slovenia, June, pp. 13-23.

Ayub, Z. H. 2005. Personal Communication.

Beaver, A. C., Yun, M. J., Bullard, C. W., Hrnjak, P. S. 1999. An experimental investigation of transcritical carbon dioxide systems for residential air conditioning. ACRC CR-18, Urbana, IL.

Bennett, D., Chen, J. 1980. Forced convective boiling in vertical tubes for saturated pure components and binary mixtures. AIChE Journal, 26(3): 454-461.

Bergman, T.L., Lavine, A.S., Incropera, F.P., DeWitt, D.P. 2011. Fundamentals of Heat and Mass Transfer. Seventh ed. John Wiley \& Sons, New York, NY.

Bertsch, S.S., Eckhard, E.A., Garimella, S.V. 2008. Refrigerant flow boiling heat transfer in parallel microchannels as a function of local vapor quality. International Journal of Heat and Mass Transfer, 51(19-20): 4775-4787.

Brix, W., Kærn, M. R., Elmegaard, B. 2009. Modelling refrigerant distribution in microchannel evaporators. International Journal of Refrigeration, 32(7): 17361743. 
Brix, W., Kærn, M.R., Elmegaard, B. 2010. Modelling distribution of evaporating $\mathrm{CO}_{2}$ in parallel minichannels. International Journal of Refrigeration, 33(6): 1086-1094.

Cavallini, A., Del Col, D., Doretti, L., Matkovic, M., Rossetto, L., Zilio, C. 2005. Condensation heat transfer and pressure gradient inside multiport minichannels. Heat Transfer Engineering, 26(3): 45-55.

Cavallini, A., Del Col, D., Matkovic, M., Rossetto, L. 2009. Frictional pressure drop during vapour-liquid flow in minichannels: Modelling and experimental evaluation. International Journal of Heat and Fluid Flow, 30(1): 131139.

Cengel, Y. 2002. Heat Transfer: A Practical Approach. Second ed. Mcgraw-Hill, New York, NY.

Chen, H., Wang, Y. 2008. Estimation of heat-transfer characteristics on a fin under wet conditions. International Journal of Heat and Mass Transfer, 51: 21232138 .

Chen, J. 1963. A correlation for boiling heat transfer to saturated fluids in convective flow. In: ASME preprint 63-HT-34, presented at: 6th National Heat Transfer Conference, Boston, USA.

Chen, L. 1991. Two-dimensional fin efficiency with combined heat and mass transfer between water-wetted fin surface and moving moist airstream. International Journal of Heat and Fluid Flow, 12: 71-76.

Chilton, T.H., Colburn, A.P. 1934. Mass transfer (absorption) coefficients prediction from data on heat transfer and fluid friction. Industrial and Engineering Chemistry, 26(11): 1183-1187.

Chisholm, D. 1972. An equation for velocity ratio in two-phase flow. NEL, report no: 535 .

CoilDesigner. 2010. Tool to Aid in the Design, Simulation and Optimization of AirCooled Heat Exchangers. Center for Environmental Energy Engineering, University of Maryland. Online: http://www.ceee.umd.edu/consortia/isoc/coil-designer

Coney, J., Kazeminejad, H., Sheppard, C. 1989a. Dehumidification of air on a vertical rectangular fin: a numerical study. Journal of Mechanical Engineering Science, 203: 165-175. 
Coney, J., Kazeminejad, H., Sheppard, C. 1989b. Dehumidification of turbulent air flow over a thick fin: an experimental study. Journal of Mechanical Engineering Science, 203: 177-188.

Coney, J., Sheppard, C., El-Shafei, E. 1989c. Fin performance with condensation from humid air: a numerical investigation. International Journal of Heat and Fluid Flow, 10: 224-231.

Cooper, M. 1984. Saturated nucleate pool boiling - A simple correlation. In: $I$. Chem. E. Symposium, series 86, vol. 2, pp. 785-793, presented at: 1st U.K. National Conference on Heat Transfer.

Corberán, J.M., De-Cordoba, P.F., Gonzálvez-Macia, J., Alias, F. 2001. Semiexplicit method for wall temperature linked equations (SEWTLE): A general finite-volume technique for the calculation of complex heat exchangers. Numerical Heat Transfer, Part B: Fundamentals, 40(1): 37-59.

Corberán, J.M., Gonzálvez, J., Montes, P., Blasco, R. 2002. 'ART' a computer code to assist the design of refrigeration and $\mathrm{A} / \mathrm{C}$ equipment . International Refrigeration and Air Conditioning Conference at Purdue, West Lafayette, IN, USA.

Domanski, P.A. 1991. Simulation of an evaporator with non-uniform one-dimensional air distribution. ASHRAE Transaction, 97(1): 793-802.

Domanski, P.A., Choi, J.M., Payne, W.V. 2007. Longitudinal heat conduction in finned-tube evaporator. 22nd IIR International Congress of Refrigeration, Beijing, China.

Elmahdy, A.H., Biggs, R.C. 1983. Efficiency of extended surfaces with simultaneous heat transfer and mass transfer. ASHRAE Journal, 89: 135-143.

EVAP-COND. 2010. Simulation Models for Finned Tube Heat Exchangers with Circuitry Optimization. National Institute of Standards and Technology, Building and Fire Research Laboratory, Gaithersburg, MD. Online: http://www.nist.gov/el/building_environment/evapcond_software.cfm

Fernando, P., Palm, B., Ameel, T., Lundqvist, P., Granryd, E. 2008. A minichannel aluminium tube heat exchanger - Part II: Evaporator performance with propane. International Journal of Refrigeration, 31: 681-695. 
García-Cascales, J.R., Vera-García, F., Gonzálvez-Macia, J., Corberán-Salvador, J.M., Johnson, M.W., Kohler, G.T. 2010. Compact heat exchangers modeling: Condensation. International Journal of Refrigeration, 33: 135-147.

Garimella, S., Agarwal, A., Killion, J. 2005. Condensation pressure drop in circular microchannels. Heat Transfer Engineering, 26(3): 28-35.

Gnielinski, V. 1976. New equations for heat and mass transfer in turbulent pipe and channel flow. International Chemical Engineering, 16(2): 359-368.

Goff, J.A. 1949. Standardization of thermodynamic properties of moist air. Heating, Piping, and Air Conditioning, 21(11): 118-128.

Goff, J.A., Gratch, S. 1945. Thermodynamic properties of moist air. ASHRAE Transactions, 51: 125.

Gossard, J.J., Han, X., Ramalingam, M., Sommers, A.D. 2013. Investigating the thermal-hydraulic performance of new refrigerant mixtures through numerical simulation of minichannel and microchannel evaporators. Applied Thermal Engineering, 50(1): 1291-1298.

Gungor, K., Winterton, R. 1986. A general correlation for flow boiling in tubes and annuli. International Journal of Heat and Mass Transfer, 29: 351-358.

Harrison, L.P. 1965. Fundamental Concepts and Definitions Relating to Humidity. In: Humidity and Moisture Measurement and Control in Science and Industry, Wexler, A., Wildhack, W.A., eds. Reinhold, NY.

Herrmann, S., Kretzschmar, H.J., Gatley, D. P. 2009. Thermodynamic properties of real moist air, dry air, steam, water, and ice (RP-1485). HVAC\&R Research, 15(5): 961-986.

Hesselgreaves, J.E. 2001. Compact Heat Exchangers Selection, Design and Operation. First ed. Pergamon, Oxford.

Hong, K., Webb, R. 1996. Calculation of fin efficiency for wet and dry fins. $H V A C \& R$ Research, 2(1): 27-41.

Hrnjak, P. 2005. Charge minimization in ammonia refrigeration systems. IIR Conference: Ammonia Refrigerating Systems, Renewal and Improvement, Ohrid, Macedonia. 
Huang, L., Aute, V., Radermacher, R. 2014. A model for air-to-refrigerant microchannel condensers with variable tube and fin geometries. International journal of refrigeration, 40: 269-281.

Huang, L., Bacellar, D., Aute, V., Radermacher, R. 2015. Variable geometry microchannel heat exchanger modeling under dry, wet and partially wet surface conditions accounting for tube-to-tube heat conduction. Science and Technology for the Built Environment, 21(5): 703-717.

Hwang, Y. 1997. Comprehensive Investigation of Carbon Dioxide Refrigeration Cycle. Ph.D. Thesis, University of Maryland, College Park, MD.

Hyland, R.W., Wexler, A. 1983a. Formulations for the thermodynamic properties of dry air from $173.15 \mathrm{~K}$ to $473.15 \mathrm{~K}$, and of saturated moist air from $173.15 \mathrm{~K}$ to $372.15 \mathrm{~K}$, at pressures to $5 \mathrm{MPa}$. ASHRAE Transactions, 89(2A): 520-535.

Hyland, R.W., Wexler, A. 1983b. Formulations for the thermodynamic properties of the saturated phases of $\mathrm{H}_{2} \mathrm{O}$ from $173.15 \mathrm{~K}$ to $473.15 \mathrm{~K}$. ASHRAE Transactions, 89(2A): 500-519.

IMST-ART. 2010. Simulation Tool to Assist the Selection, Design and Optimization of Refrigeration Equipment and Components. Instituto de Ingeniería Energética, Universitat Politècnica de València, Valencia. Online: http://www.imstart.com

Jiang, H. 2003. Development of a Simulation and Optimization Tool for Heat Exchanger Design, Ph.D. Thesis, University of Maryland, College Park, MD.

Jiang, H., Aute, V., Radermacher, R. 2006. Coil designer: a general-purpose simulation and design tool for air-to-refrigerant heat exchangers. International Journal of Refrigeration, 29(4): 601-610.

Jin, J., Chen, J., Chen, Z. 2011. Development and validation of a microchannel evaporator model for a $\mathrm{CO}_{2}$ air-conditioning system. Applied Thermal Engineering, 31: 137-146.

Kandlikar, S. 1990. Thermal Design Theory for Compact Evaporators. In: Compact Heat Exchanger, Shah, R., Kraus, Metzger, D., eds. Hemisphere, New York, NY, pp. 245-286.

Kandlikar, S., Balasubramanian, P. 2004. An extension of the flow boiling correlation to transition, laminar, and deep laminar flows in minichannels and microchannels. Heat Transfer Engineering, 25: 86-93. 
Kandlikar, S.G. 2002. Fundamental issues related to flow boiling in minichannels and microchannels. Experimental Thermal and Fluid Science, 26(2-4): 389407.

Kandlikar, S.G. 2007. A roadmap for implementing minichannels in refrigeration and air-conditioning systems-Current status and future directions. Heat Transfer Engineering, 28(12): 973-985.

Kandlikar, S.G., Grande, W.J. 2003. Evolution of microchannel flow passages thermohydraulic performance and fabrication technology. Heat Transfer Engineering, 24(1): 3-17.

Kandlikar, S.G., King, M.R. 2006. Chapter 1 - Introduction. In: Heat Transfer and Fluid Flow in Minichannels and Microchannels, Kandlikar, S.G., ed. Elsevier Ltd, Oxford, pp. 1-7.

Kays, W.M., London, A.L. 1984. Compact Heat Exchangers. Third ed. McGrawHill Book Co., New York, NY.

Kim, M.-H, Bullard, C.W. 2001. Development of a microchannel evaporator model for a $\mathrm{CO}_{2}$ air-conditioning system. Energy, 26: 931-948.

Kim, M.-H., Bullard, C.W. 2002a. Air-side thermal hydraulic performance of multi-louvered fin Aluminum heat exchangers. International Journal of Refrigeration, 25 : 390-400.

Kim, M.-H., Bullard, C.W. 2002b. Air-side performance of brazed aluminum heat exchangers under dehumidifying conditions. International Journal of Refrigeration, 25: 924-934.

Klein, S.A. 2004. Engineering Equation Solver (EES). F-Chart Software, Madison, WI. Online: http://www.fchart.com/ees/

Kuehn, T.H., Ramsey, J.W., Threlkeld, J.L. 1998. Thermal Environmental Engineering. Third ed. Prentice-Hall Inc., Upper Saddle River, NJ.

Kulkarni, T., Bullard, C.W., Cho, K. 2004. Header design tradeoffs in microchannel evaporators. Applied Thermal Engineering, 24(5-6): 759-776.

Kundu, B. 2009. Approximate analytic solution for performances of wet fins with a polynomial relationship between humidity ratio and temperature. International Journal of Thermal Sciences, 48: 2108-2118. 
Lee, J., Domanski, P.A. 1997. Impact of air and refrigerant maldistributions on the performance of finned-tube evaporators with R-22 and R-407c. Report no: DOE/CE/23810-23881, Gaithersburg, MD.

Lee, J., Mudawar, I. 2005. Two-phase flow in high-heat-flux micro-channel heat sink for refrigeration cooling applications: Part I-pressure drop characteristics. International Journal of Heat and Mass Transfer, 48: 928-940.

Lemmon, E.W., McLinden, M.O., Huber, M.L. 2002. REFPROP, version 7.0, U.S. Department of Commerce, Gaithersburg, MD.

Liang, S., Wong, T., Nathan, G. 2000. Comparison of one-dimensional and twodimensional models for wet-surface fin efficiency of a plate-fin-tube heat exchanger. Applied Thermal Engineering, 20: 941-962.

Lin, Y., Hsu, K., Chang, Y., Wang, C. 2001. Performance of rectangular fin in wet conditions: visualization and wet fin efficiency. ASME Journal of Heat Transfer, 123: 827-836.

Mahmoud, M.M., Karayiannis, T.G. 2013. Heat transfer correlation for flow boiling in small to micro tubes. International Journal of Heat and Mass Transfer, 66: 553-574.

Martínez-Ballester, S. 2012. Numerical Model for Microchannel Condensers and Gas Coolers with an Improved Air-Side Approach. Ph.D. Thesis, Universitat Politècnica de València, Valencia.

Martínez-Ballester, S., Corberán, J.M., Gonzálvez-Macia, J. 2013a. Numerical model for microchannel condensers and gas coolers: Part I - Model description and validation. International Journal of Refrigeration, 36: 173-190.

Martínez-Ballester, S., Corberán, J.M., Gonzálvez-Macia, J. 2013b. Numerical model for microchannel condensers and gas coolers: Part II - Simulation studies and model comparison. International journal of refrigeration, 36: 191-202.

Martínez-Ballester, S., Corberán, J.M., Gonzálvez-Maciá, J., Domanski, P.A. 2010. Analysis of segment-by-segment $\varepsilon$-NTU modelling of a minichannel $\mathrm{CO}_{2}$ gas cooler. International Refrigeration and Air Conditioning Conference at Purdue, West Lafayette, IN, USA.

Martínez-Ballester, S., Corberán, J.M., Gonzálvez-Maciá, J., Domanski, P.A. 2011. Impact of classical assumptions in modelling a microchannel gas cooler. International Journal of Refrigeration, 34(8): 1898-1910. 
McElgin, J., Wiley, D. 1940. Calculation of coil surface areas for air cooling and dehumidification. Heating, Piping and Air-Conditioning, March: 195-201.

McQuiston, F.C. 1975. Fin efficiency with combined heat and mass transfer. ASHRAE Transactions, 81(1): 350-355.

Mehendale, S.S., Jacobi, A.M., Shah, R.K. 2000. Fluid flow and heat transfer at micro- and meso-scales with applications to heat exchanger design. Applied Mechanics Reviews, 53: 175-193.

Mirth, D.R., Ramadhyani, S. 1993. Comparison of methods of modeling the airside heat and mass transfer in chilled-water cooling coils. ASHRAE Transactions, 99: 285-299.

Mishima, K., Hibiki, T. 1996. Some characteristics of air-water two-phase flow in small diameter vertical tubes. International Journal of Multiphase Flow, 22: 703-712.

Moallem, E., Cremaschi, L., Fisher, D.E., Padhmana, S. 2012. Experimental measurements of the surface coating and water retention effects on frosting performance of microchannel heat exchangers for heat pump systems. Experimental Thermal and Fluid Science, 39: 176-188.

Muller-Steinhagen, H., Heck, K. 1986. A simple friction pressure drop correlation for two-phase flow in pipes. Chemical Engineering Processing, 20: 297-308.

Nelson, H.F., Sauer Jr., H.J. 2002. Formulation of high-temperature properties for moist air. HVAC\&R Research, 8(3): 311-334.

Nielsen, K.K., Engelbrecht, K., Christensen, D.V., Jensen, J.B., Smith, A., Bahl, C.R.H. 2012. Degradation of the performance of microchannel heat exchangers due to flow maldistribution. Applied Thermal Engineering, 40: 236-247.

Park, C.Y., Hrnjak, P. 2007. Effect of heat conduction through the fins of a microchannel serpentine gas cooler of transcritical $\mathrm{CO}_{2}$ system. International Journal of Refrigeration, 30: 389-397.

Patankar, S.V. 1980. Numerical Heat Transfer and Fluid Flow. Hemisphere, New York, NY.

Pearson, A.B. 2003. Low charge ammonia plants: why bother? IIAR Ammonia Refrigeration Conference, Albuquerque, NM, USA, technical paper no. 5, pp. 1619. 
Pendyala V.R., Devotta, S., Patwardhan, V.S. 1986. The economics of heat pump assisted drying systems. Journal of Heat Recovery Systems, 6(6): 433-442.

Peppers, V.W. 1988. A new psychrometric relation for the dew point temperature. Unpublished, available from ASHRAE.

Pettersen, J., Hafner, A., Skaugen, G. 1998. Development of compact heat exchangers for $\mathrm{CO}_{2}$ air-conditioning system. International Journal of Refrigeration, 21(3): 180-193.

Qi, Z., Chen, J., Radermacher, R. 2009. Investigating performance of new minichannel evaporators. Applied Thermal Engineering, 29(17-18): 3561-3567.

Ragazzi, F., 1995. Thermodynamic Optimization of Evaporators with Zeotropic Refrigerant Mixtures. Ph.D. Thesis, University of Illinois, Urbana-Champaign, IL.

Ren, T., Ding, G., Wang, T., Hu, H. 2013. A general three-dimensional simulation approach for micro-channel heat exchanger based on graph theory. Applied Thermal Engineering, 59: 660-674.

Revellin, R., Mishima, K., Thome, J.R. 2009. Status of prediction methods for critical heat fluxes in mini and microchannels. International Journal of Heat and Fluid Flow, 30(5): 983-992.

Revellin, R., Thome, J.R. 2007. Adiabatic two-phase frictional pressure drops in microchannels. Experimental Thermal and Fluid Science, 31(7): 673-685.

Riad, B., Junhua, Y. 2011. Numerical Analysis of Heat and Mass Transfer in a Finand-Tube Air Heat Exchanger under Full and Partial Dehumidification Conditions. In: Heat and Mass Transfer-Modeling and Simulation, Monwar Hossain, ed. InTech.

Shah, M. 1982. Chart correlation for saturated boiling heat transfer: Equations and further study. ASHRAE Transactions, 88; 285-196.

Shah R.K. 1983. Classification of Heat Exchangers. In: Low Reynolds number Flow Heat Exchangers, Kakac et al., ed. Hemisphere, New York, NY.

Sharqawy, M., Zubair, S. 2007. Efficiency and optimization of an annular fin with combined heat and mass transfer - An analytical solution. International Journal of Refrigeration, 30: 751-757. 
Sharqawy, M., Zubair, S. 2008. Efficiency and optimization of straight fins with combined heat and mass transfer - An analytical solution. Applied Thermal Engineering, 28: 2279-2288.

Singh, V., Aute, V., Radermacher, R. 2008. Numerical approach for modeling airto-refrigerant fin-and-tube heat exchanger with tube-to-tube heat transfer. International Journal of Refrigeration, 31(8): 1414-1425.

Singh, V., Aute, V., Radermacher, R. 2010. Investigation of effect of cut fins on carbon dioxide gas cooler performance. HVAC\&R Research, 16(4): 513-527.

Steiner, D., Taborek, J. 1992. Flow boiling heat transfer in vertical tubes correlated by an asymptotic model. Heat Transfer Engineering, 13(2): 43-69.

Thome, J.R. 2004. Boiling in microchannels: A review of experiment and theory. International Journal of Heat and Fluid Flow, 25: 128-139.

Thome, J.R. 2010. Engineering Data Book III. Wolverine Tube Inc. Online: http://www.wlv.com/heat-transfer-databook/

Threlkeld, J.R. 1970. Thermal Environmental Engineering. Prentice-Hall Inc., New York, NY.

Tran, T., Chyu, M.-C., Wambsganss, M., France, D. 2000. Two-phase pressure drop of refrigerants during flow boiling in small channels: an experimental investigation and correlation development. International Journal of Multiphase Flow, 26: 1739-1754.

Ware, H., Hacha, T. 1960. Heat transfer from humid air to fin and tube extended surface cooling coils. ASME paper no. 60-HT-17, p. 7.

Whitman, W.C., Johnson, W.M., Tomczyk, J.A., Silberstein, E. 2012. Troubleshooting and Typical Operating Conditions for Commercial Refrigeration. In: Refrigeration \& Air Conditioning Technology, seventh ed. Delmar, Cengage Learning, New York, pp. 752-776.

Wojtan, L., Ursenbacher, T., Thome, J. 2005. Investigation of flow boiling in horizontal tubes: Part II-Development of a new heat transfer model for stratifiedwavy, dryout and mist flow regimes. International Journal of Heat and Mass Transfer, 48: 2970-2985.

Wu, G., Bong, T.Y. 1994. Overall efficiency of a straight fin with combined heat and mass transfer. ASHRAE Transaction, 100: 367-374. 
Wu, X.M., Webb, R.L. 2002. Thermal and hydraulic analysis of a brazed aluminum evaporator. Applied Thermal Engineering, 22: 1369-1390.

Yin, J.M., Bullard, C.W., Hrnjack, P.S. 2001. R-744 gas cooler model development and validation. International Journal of Refrigeration, 24: 692-701.

Yin, X.W., Wang, W., Patnaik, V., Zhou, J.S., Huang, X.C. 2015. Evaluation of microchannel condenser characteristics by numerical simulation. International Journal of Refrigeration, 54: 126-141.

Yun, R., Kim, Y., Park, C. 2007. Numerical analysis on a microchannel evaporator designed for $\mathrm{CO}_{2}$ air-conditioning systems. Applied Thermal Engineering, 27: 1320-1326.

Zhang, P., Hrnjak, P. 2010. Air-side performance of a parallel-flow parallel-fin $\left(\mathrm{PF}^{2}\right)$ heat exchanger in sequential frosting. International Journal of Refrigeration, 33(6): 1118-1128.

Zhao, Y., Liang, Y., Sun, Y., Chen, J. 2012. Development of a mini-channel evaporator model using R1234yf as working fluid. International journal of refrigeration, 35: 2166-2178.

Zhao, Y., Ohadi, M.M., Radermacher, R. 2001. Microchannel heat exchangers with carbon dioxide. Report no: ARTI-21CR/10020-01, College Park, MD. 


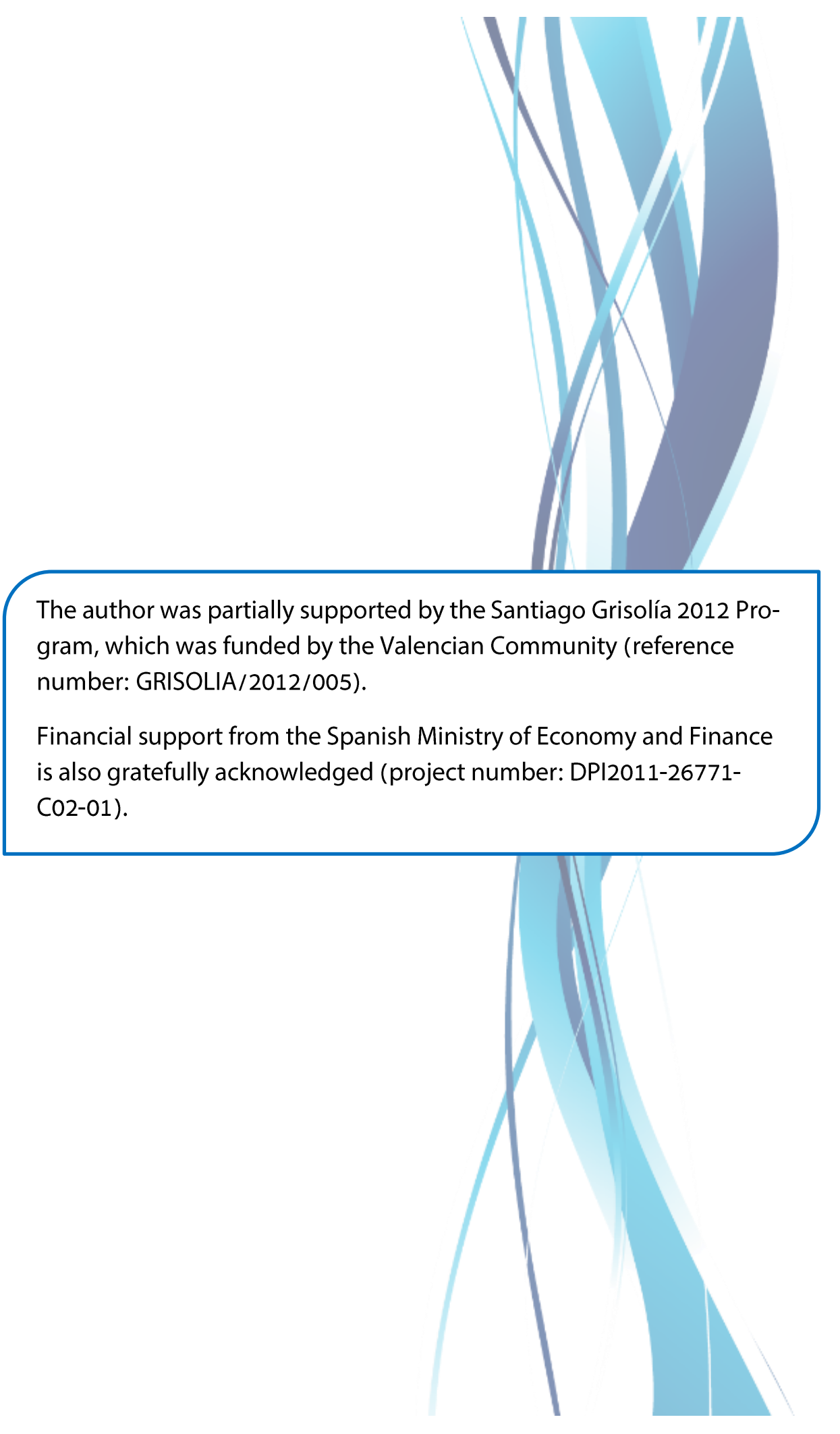

